\title{
Innovation management : how frontrunners stay ahead : an empirical study on key success factors in the ICT sector
}

Citation for published version (APA):

Huizenga, E. I. (2001). Innovation management : how frontrunners stay ahead : an empirical study on key success factors in the ICT sector. [Doctoral Thesis, Maastricht University]. UMP. https://doi.org/10.26481/dis.20010119eh

Document status and date:

Published: 01/01/2001

DOI:

10.26481/dis.20010119eh

Document Version:

Publisher's PDF, also known as Version of record

Please check the document version of this publication:

- A submitted manuscript is the version of the article upon submission and before peer-review. There can be important differences between the submitted version and the official published version of record.

People interested in the research are advised to contact the author for the final version of the publication, or visit the DOI to the publisher's website.

- The final author version and the galley proof are versions of the publication after peer review.

- The final published version features the final layout of the paper including the volume, issue and page numbers.

Link to publication

\footnotetext{
General rights rights.

- You may freely distribute the URL identifying the publication in the public portal. please follow below link for the End User Agreement:

www.umlib.nl/taverne-license

Take down policy

If you believe that this document breaches copyright please contact us at:

repository@maastrichtuniversity.nl

providing details and we will investigate your claim.
}

Copyright and moral rights for the publications made accessible in the public portal are retained by the authors and/or other copyright owners and it is a condition of accessing publications that users recognise and abide by the legal requirements associated with these

- Users may download and print one copy of any publication from the public portal for the purpose of private study or research.

- You may not further distribute the material or use it for any profit-making activity or commercial gain

If the publication is distributed under the terms of Article $25 \mathrm{fa}$ of the Dutch Copyright Act, indicated by the "Taverne" license above, 


\section{Innovation Management: \\ How Frontrunners Stay Ahead}





\title{
Innovation Management: How Frontrunners Stay Ahead.
}

An Empirical Study on Key Success Factors in the ICT Sector

\author{
PROEFSCHRIFT
}

ter verkrijging van de graad van doctor aan de Universiteit Maastricht,

op gezag van de Rector Magnificus,

Prof. dr. A.C. Nieuwenhuijzen Kruseman

volgens het besluit van het College van Decanen,

in het openbaar te verdedigen

op vrijdag 19 januari 2001 om 14.00 uur

door

Edward Istvàn Huizenga

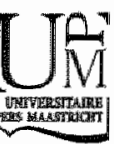




\title{
Promotor:
}

Prof. dr. J. F. den Hertog

\section{Beoordellingscommissie:}

Prof. dr. J.G.A.M. Lemmink (voorzitter)

Prof. dr. ir. K.L. Boon

Prof. dr. W. Buitelaar (Universiteit van Amsterdam)

This study is financed by the Dutch Science Foundation (Nederlandse Organisatie voor Wetenschappelijk Onderzoek)

\author{
(C) 2000 Edward Huizenga, Breda \\ ISBN $\quad 9052782946$ \\ Printer Datawyse/Universitaire Pers Maastricht
}


Voor Carine 


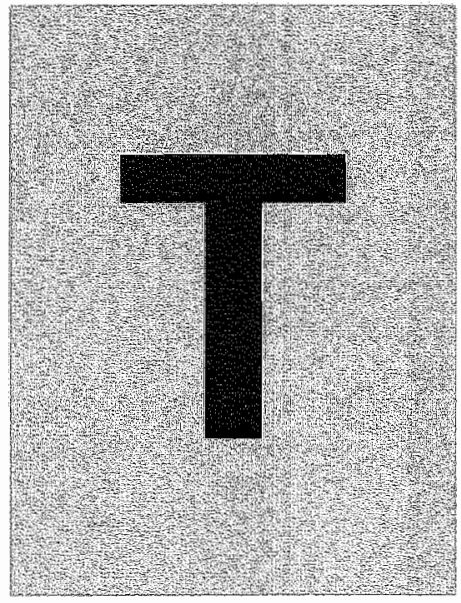

\section{Table of Contents}

Table of Contents

$\begin{array}{lll}\text { 1.1. Introduction } & 14\end{array}$

1.2 Research Goals \& Structure of the Study 16

1.3 The Context of the Research Study: The Information and 22 Communication Technology Sector

1.4 ICT Industry and ICT Service Sector: Figures \& Trends 24

2 Key Success Factors for Innovation Management: Recent Contributions

2.1 Introduction 30

2.2 Innovation: Concepts and Definitions 31

2.3 Key Success Factors: Studies \& Classifications 34

2.4 Key Success Factors in the Information \& 40

Communication Technology Sector

2.5 Innovation Research Streams: a Review 42 
3 The Nature of Strategy 49

3.1 Introduction 50

3.2 Strategy Safari: an Overview of Schools of Thought 51

3.3 Resource-Based View of Strategy $\quad 54$

3.4 The Dynamic Capabilities Perspective 59

3.5 Summary 61

4 Organisation of Innovation 63

4.1 Introduction 64

4.2 Onganisational Process Models of Innovation 65

4.3 Organisation Theory: Contingency perspective $\quad 70$

4.4 Organisation Theory: Configuration perspective 75

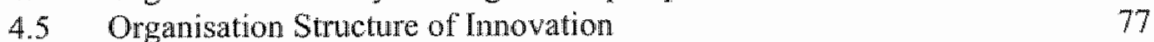

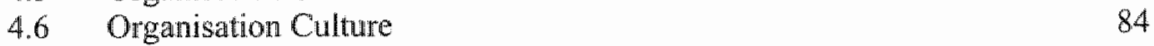

4.7 Organisation: The Human Capital Factor 85

Part II: Research Design \& Methodology 87

$5 \quad$ Research Methods $\quad 89$

5.1 Innovation Performance Measurement 90

$\begin{array}{ll}5.2 \text { Development of Performance Criteria } & 90\end{array}$

5.3 Innovation Success Criteria Selection 94

5.4 Research Design Differences: Some Remarks 102

$\begin{array}{lll}6 & \text { Research Design } & 107\end{array}$

6.1 Introduction 108

6.2 Dual Methodologies 110

6.3 (Dis)advantages of a Dual Methodology 113

6.4 Research Design of the ICT Research Study 115

$\begin{array}{lll}6.5 & \text { ICT Study Sample } & 117\end{array}$

Part III: The Empirical Findings

$7 \quad$ Strategy and Innovation Performance

$\begin{array}{lll}7.1 & \text { Introduction } & 124\end{array}$

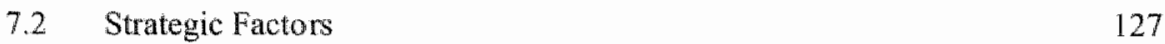

$\begin{array}{ll}\text { 7.3. Strategic Priorities on the Management Agenda } & 128\end{array}$

7.4 Key Success Factors in Strategic Priorities 131

$\begin{array}{ll}7.5 & \text { Discussion: Strategic Priorities } \\ 7.6 & 132\end{array}$

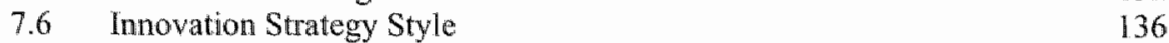

$\begin{array}{lll}7.7 & \text { Discussion: Innovation Strategy Style } & 138\end{array}$

$\begin{array}{ll}7.8 \text { Results: Resource Capacity } & 140\end{array}$

$\begin{array}{ll}7.9 & \text { Discussion: Resource Capacity } \\ & 144\end{array}$ 
8 Organisation, Process and Imnovation Performance

$\begin{array}{ll}\text { 8.1 Quality Management } & 150\end{array}$

8.2 Project Management 151

$\begin{array}{ll}8.3 & \text { Organisation Structure and Teams } \\ 8.455\end{array}$

$\begin{array}{ll}8.4 & \text { Organisation Culture } \\ & 158\end{array}$

8.5 Knowledge Development: Internal and External Co-operation 159

$\begin{array}{ll}\text { 8.6 Co-operation with Customers and Suppliers } & 162\end{array}$

$\begin{array}{ll}\text { 8.7 Co-operation during Stages of Innovation } & 165\end{array}$

$\begin{array}{ll}8.8 \text { Human Resource Management } & 168\end{array}$

9 Key Success Factors Differentiating the Frontrunners 173 from Pack Members: A Discussion

$\begin{array}{ll}\text { 9.1 Overview and Comparison } & 174\end{array}$

9.2 The Context behind the Research Findings 178

9.3 Findings Inconsistent with the Previous MERIT Study 180

$\begin{array}{ll}\text { 9.4. Future Research Agenda } & 185\end{array}$

$\begin{array}{ll}\text { References } & 189\end{array}$

$\begin{array}{ll}\text { Samenvatting } & 201\end{array}$

$\begin{array}{ll}\text { Nawoord } & 205\end{array}$

$\begin{array}{ll}\text { Curriculum Vitae } & 207\end{array}$ 



\section{Part l:}

\section{Introduction \&}

\section{Theory Overview}

Part I will clarify the concept and definition of iniovation and the tole and position of key success factor research. We will adopt a heoretical vewpoint towards inovation, strategy lleory and organisation theory litertature. A description of the development of the strategie Management domain is presented, startwg from stralege planing to the energing resource and competence bissed perspectives. When discussing the organisation literature we take up a nomative viewpoint, looking at the range of process approaches to innovation that have developed over the years. An organisation strueture-oilented view will present the tange of or ganisation structure options for innovation. We will point to the existence of or ganisation choice between organisation strtecure options, and will discuiss contributions fron the contingency and configutation approaches to innovation mainagement, incliding the debate on the link between strategy and strueture. 



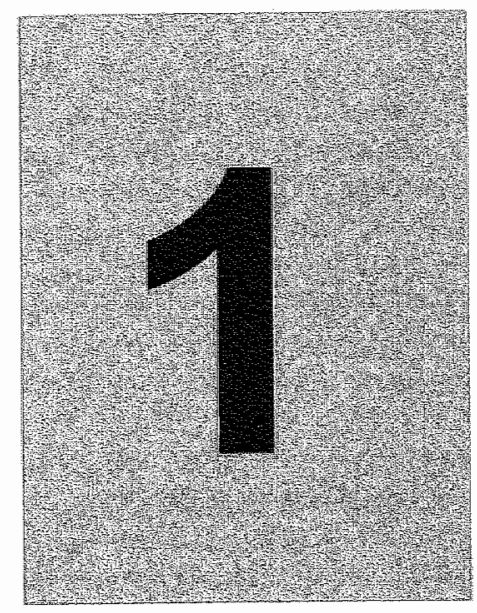

\section{Exploring Innovation in the ICT Sector}




\subsection{Introduction}

The twenty-first century has begun and represents a turning decade for managerial and academic thinking on innovation management in high-tech sectors. Innovation is important in today"s markets and can dramatically improve a company's competitive position, in particulant in the ICT sector. The Internet and electronjic commerce represent such significant innovations. New Intemet start-ups and established dotcom companies regularly appear in the news, Internet service providers and online retailers and financial service providers start initial public offerings in the United States and Europe, and the NASDAQ is the most volatile hightechnology index on the Stock. Exchange. Are these clear signs that the sector seems to thrive on innovation and entrepreneurship?

In the management literature it is observed that innovation drives corporate success and is a strategic endeavour contributing to a firm's differentiating capacity, growth, and sustainable competitive advantage. Some researchers even say that innovation has become the primary process (Jaikumar, 1986). Recently studies (e.g. Cooper \& Kleinschmidt, 1996; Brown \& Eisenhardt, 1995; Montoya-Weiss \& Calantone, 1994) have investigated the key success factors and sources of attaining competitive advantage through innovation. Such research has started to contribute to new insights into how a company turns good ideas into money and masters the art of designing and developing new products, services and processes. Meanwhile, companies need to ensure that resources are leveraged for the creation of new markets, products and services to serve customer needs (e.g. Hamel \& Prahalad, 1994).

On the other hand, it has been observed in the management literature that innovation can also be a high-risk adventure. Innovation projects may face a delay due to technical complexity, original ideas fail to make it to the market, or customers do not appreciate new products or services. These risks are well documented in the empirical and theoretical literature (e.g. Stacey, 1996; Rothwell, 1994; Roussel et al, 1991; Imai, Nonaka \& Takeuchi, 1985), as well as the opportunity risks associated with refraining from new product and process development. Firms that ignore renewal might reinforce the existing practices and hamper innovation (e.g. Dougherry, 1996). The consequence will eventually be a loss of revenue and market position. The danger of neglecting innovation can have a serious impact on the longterm survival of companies. Empirical findings have revealed that the inability to connect innovation with organisational resources, processes, and strategy thwarts innovation outcomes (e.g. Eisenhardt \& Tabrizi, 1996; Dougherty, 1990; Burgelman, 1983).

It is more and more recognised by the business and academic communities alike that the nature of innovation and the process of developing new products and services increasingly involve a mixture of managing potential good fortune, complexity and high risk. Furthermore it is recognised that service dimensions enter into all products and businesses. In fact, "service functions' seem to play a role in all business firms (e.g. Coombs et al., 1999). This raises new challenges for managers, as their competitive environment becomes more complex as a result of the rise of the 'service intensity'. More recently, a wiew has begun to emerge investigating imnovation in dynamic high-tech, high-risk and knowledge-intensive sectors, e.g. the information and commumication technology sector (ICT). Before discussing this subject let $\mathrm{u}_{\mathrm{s}}$ briefly address some of the typical characteristics associated with innovation. 


\section{Innovation characteristics:}

To be effective in their innovation efforts, companies have to take into account the nature of the strategy and organisational processes of innovation. Innovation is not similar to performing regular 'business as usual'. Innowation is to a large extent unpredictable, complex, dynamic, non-routine-based, and involves creativity and risk. Innovation is difficult to control and is essentially an entrepreneurial process. Among the basic characteristics of innovation we identify (based on Tushman \& Moore, 1992; Van der Ven, 1986) the following.

\section{Managing the risks, the change and chance}

These elements accompany the outcome of innovation, whether it be a new product, service or new business process. Immovation is a risky adventure involving a great deal of unforeseeable uncertainties. Innovation is based on a promising idea that is partially associated with luck and chance as to whether the product outcome will be accepted by customers. Development is associated with high-risk trajectories with potential pitfalls and uncertain, bigh cost and results.

\section{The complexity and unordered siructure}

Innovation processes are difficult to manage because of the range of complexities involved, such as functional interfaces, overlapping activities and customer interaction. They require multiple people, disciplines, and activities that need to be integrated. Innovation activities are a mixture of creativity, irrationality and invention. They are typically unstructured activities, which need to be aligned with a commercial rationality. Quinn (1985) pointed out that innovation management resembles the management of a creative chaos. Innovation balances between tight managerial co-ordination and commitment to free-foating experimentation to discover new technological or market opportunities. The multidisciplinary nature places strong demands on the cost and time of an organisation.

\section{New business development: the paradoxes and dynanics}

Van der Ven (1986) stated that innovation is conducted in an enterprise where operational business processes ("steady-state processes") appear to be in stability and formal control. Yet at the same time enterprises are facing a paradox because new alternatives beyond the steady state need to be developed (e.g. Abernathy \& Clark, 1985), which requires them to move away from formal control and stability. Innovation absorbs the resources that have to be distracted from streamlining steady-state processes that currently render value. These resources have to be devoted to unknown new business opportunities that might render value in the long run. This duality of imovation might put pressure on the willingness to innovate and introduces control problems.

\section{The cularal resistance to renewal}

Innovation is a 'people business'. If the people in the organisation are motivated to change, this can enhance the imovation success of the firm. Resistance to change, however, can hamper the performance of design and development activities. Innovation is not like doing business as usual. It drives out the existing practices, structures and routines in the organisation. Work routines have to be abolished and unleamed and new routines have to be learned. Innovation management is therefore also about developing new routines and meanwhile preventing core rigidities from occurring (e.g. Leonard Barton, 1992). 


\subsection{Research Goals \& Structure of the Study}

In this thesis we discuss the issues arising from the state of affairs on innovation in the Dutch ICT sector. It is our aim to contribute to the development of our understanding of imnovation in such a way that it accords with the recent insights into key success factors and the strategic management and organisation literature linked to change. In particular we will address the following issues.

\section{Research goals of the study}

Choices must be made in any research regarding its presentation, the objectives, the instruments, etc. These choices are never obvious. The researcher is always confronted with limitations. The degree of freedom is determined by the available research time, access to data and can be a severe limitation. In practice the researcher has to make a balance between what is desirable and attainable. The research strategy followed in this project also had to deal with these compromises in the sense that the development of knowledge in the course of a project is to be considered a significant step in the knowledge enterprise (Den Hertog \& Van Sluijs, 1995). On this basis, the research has been set up to serve both the management and scientific objectives, and is part of the MERIT (Maastricht Economic Research Institute on Innovation and Technology) innovation programme. Programmed research makes it possible to achieve objectives beyond the scope of the individual projects. This project has been set up and implemented on the basis of this point of view.

The ICT innovation study is founded on two pillars, a management viewpoint and a scientific viewpoint. The management viewpoint is intended to provide firms with clear insights, arguments and tools to improve or sustain their innovation success. This part of the study has led to various management-oriented publications (e.g. Cobbenhagen, Den Hertog \& Pennings, 1995; Cobbenhagen, 1999; Den Hertog \& Huizenga, 1997; Den Hertog \& Huizenga, 1997; Den Hertog \& Huizenga, 2000). The current thesis is the account of the scientific research stream within the study. This part of the study aims to contribute, in a modest way, to the development of a pragmatic framework. A framework, which provides insight into the key success factors for innovation management in the ICT sector.

\section{The cycling metaphor}

It is important to note that we used a cycling metaphor in this study to describe the differences in performance between firms. If we view innovation as a cycle race, the research questions of this study are formulated around the identification and explanation of the key success factors. In cycling terms we designate firms as frontrunners, members of the pack or laggards. In the management report (Den Hertog \& Huizenga, 1997) we already focused on explaining the differences between frontrunners, pack members and laggards. The scientific viewpoint focuses on the practices of frontrumers, how they perform, how they differ and how they sustain in their innovation success. These subjects are addressed by means of the key success factor framework.

It is important to note that the study is not focused on statistically measuring the difference between the best performing firms (the front rumners) and the worst performing firms (pack members and laggards), but on identifying and explaining KSF. We try to provide the followers with suggestions on how to escape from their position and join the frontrunners. The front rumers are provided with insights, which allow them to keep ahead of the pack. $d$ 
The key success factors tell us, to a certain extent, how frontrunners perform and might stay ahead of their competitors. These differences can arise from timing of strategic priorities, the path dependency of the firm or the differences in resource investments.

Key success factors contribute dramatically to the innovation success of a firm. They differentiate the successful ventures from the unsuccessful ones. Similar to bicycle racing we use the metaphors of frontrunners, members of the pack and laggards. The contributions of the ICT innovation study are particularly in investigating the broad spectrum of sectorspecific factors that explain innovation success. The research goals are as follows:

- To investigate whether the Key Success Factor (KSF) method is applicable and transferable to measuring imnovation performance in the ICT sector.

- To identify factors that discriminate between successfully performing companies and less effective companies. The research study explores a set of key factors conducive to innovation success but is also an attempt to identify the differentiating success factors. We are interested in the identification and explanation of the success factors.

- To investigate whether we can validate key success factors observed in other research studies (e.g. Cooper \& Kleinschmidt, 1993; 1995). Our goal is to validate the empirical findings from previous innovation studies. In particular, we replicate this study in order to be able to falsify the outcomes of the MERIT innovation study (Cobbenhagen, 1999).

- We also want to address the difference between sector-specific versus non-sector-specific factors. For example, we want to investigate whether some success items are sectorspecific and only appear in the ICT sector, or find out why no significant results have been found in the ICT. sector for key success factors that are supposed to be relevant according to the empirical KSF literature.

- In order to develop a deeper understanding of the process of innovation we not only address what matters to innovation but also why firms should innovate and how they shoulld do so. The methodological goal of this study is to find and try out a suitable research method. We use a dual research methodology, which combines quantitative (e.g. survey) and qualitative (e.g. case studies) methods: the case survey.

For this purpose, we chose a sector characterised by rapid technological developments and changing market demands. Moreover, the ICT sector is a knowledge-intensive sector where the service intensity might play an increasingly important pole. A company that operates under these circumstances is confronted with fierce competition, short product life cycles and the pressure to differentiate, creating a sense of urgency to innovate:

\section{Research questions}

These research goals resulted in the following main research questions in studying the innovation performance of companies in the ICT sector:

1. Which key success factors and differentiating factors contributing to a high innovation performance can be identified in the ICT sector?

2. Why and how do frontrumers differentiate from members of the pack?

3. To provide building stones for theory, what explanations from strategy and organisation theory can support our understanding of why new product and service development differ in terms of success?

It is expected that answers to these questions will increase our knowledge of the effectiveness of innovation management. It will provide insight into the company level driwers for successful innovation and contributes to the development of knowledge. Exploring the 
concept of strategy and organisation can contribute to further theory building on innovation management. The subsequent questions for the ICT sector that are being raised in this study? include the following:

1. How do ICT companies inmovate and what is the importance of innovation to software companies and ICT services prowiders?

2. Why are some software and/or service firms more successful than others in their innovation efforts?

3. Which factors differentiate between successful and less successful software firms and service providers, and which strategic and organisational conditions contribute to the innovative capacity of firms?

\section{Sirtcture of the research study}

In our quest for the determinants of innovation success at the company level we start with an overview of the innovation management literature. Figure 1 provides the reader with a route description.

In Chapter 2 we will clarify the concept and definition of innovation and the role and position of $\mathrm{KSF}$ research. We argue that the real world of business itself has been both the main source of inspiration and the main audience for KSF thinking. Many of the new concepts and approaches have been developed and tested in management practice. They were developed to find answers to the new problems in our knowledge-intensive economies. This has resulted, particularly in the last 15 years, in a rapidly growing multidisciplinary field of organisational science. We present a brief overview of what the search for key success factors (KSF) in the development of new products, services and processes has yjelded. We take up a practical standpoint by discussing some of the most valuable empirical studies, Later we will take a research perspective by presenting the typical research streams of 'variance-oriented" and 'process-oriented' research. These studies have revealed a core set of key success factors, e.g. on strategy, organisation, development process and human resource management. We have observed that little is known about ICT and services in the research field. Little empirical evidence has so far been gathered on the factors that contribute to the success of innovation in information technology. Finally, we will discuss the identification of methodological and theoretical shortcomings in the KSF research field.

In Chapters 3 and 4 we will adopt a theoretical standpoint. In Chapter 3 we will go into detail of the changing nature of strategy thinking. We describe the history of strategic managemem as far as it is linked to innovation, starting from strategic planning to the emerging resourceand competence-based perspectives. New perspectives have arisen that emphasise the importance of innovation and competence development. We argue that despite the research knowledge progress in the competence-based literature much research is of a theoretical (c.g. Teece ef al, 1997; Barney, 1991, 1995; Peteraf, 1993) or normative nature (e.g. Prahalad \& Hamel, 1990; Nonaka, 1991). The research field itself points to the need for more studies using more data and replicable, unambiguously defined constructs (e.g. Henderson \& Cockbum. 1994; McGrawth, 1995; McGrawth, MacMillan \& Venkatraman, 1995). In the innovation management literature little is known of the concepts of strategy and the effect on innowation success. In Chapter 3 we explore some of the new ideas for future theory building to be developed in innovation management. The empirical part of this study is exploratory in nature in that if experiments with strategy-related concepts and instruments that are replicable and can be validated in other settings (e.g. Cobbenhagen, 1999). 
From strategic management we move on to the organisation theory in Chapter 4. The importance of the organisation is referred to as a key attribute of successful innovating firms. In the theoretical discussion on the organisation process of innovation, scholars actually agree that the organisation form is an indispensable bulding block. Also, most empirical KSF studies pay attention to the organisation's impact on innovation success. Yet the organisation literature is known for its rich variety in perspectives and theories. In Chapter 4 we will take a look at organisation literature. From a normative viewpoint we will consider the range of process approaches that has developed over the years. This is followed by a structure-oriented view regarding the range of organisation structure options. We will point to the existence of organisational choice between organisation structure options. We will dwell on the relevance of the contingency and configuration approach for innovation management, including the literature debate on structure and strategy. The ideal-type configurations of organic and mechanistic organisations are addressed to show the early thinking on the organisation attributes for change and renewal. In the descriptive and empirical part we will discuss the different organisation structures, e.g. the functional organisation, matrix organisation and team-based organisation. The relative advantages and disadvantages of each form are considered. We will conclude with the role of culture and human resource management and the link to innovation success at the company level.

Elaborating on these findings we present our methodological goals of exploring new ideas and concepts and testing existing concepts for their theoretical soundness. In Chapter 5 and 6 we will describe the imovation performance methodology and the research design. Chapter 5 addresses the detailed explanation of the success measurement criteria for innovation performance. The landscape of the literature on innovation success and innovation effectiveness can roughly be described in terms of confusion, incomparability and disagreement around the concept of innovation success. We argue that no uniform set of success criteria has been used throughout recent years, and in some cases success measures have been used in studies that were inappropriate to the level of research analysis.

When setting out the drivers of innovation performance in the ICT sector, some beacons have to be developed in order to measure the company's performances. Wo point to the drawbacks of one-dimensional scores. This rating method does not unveil what drives success for innovation types such as improved products, radically new services and/or improvements of processes. We use multiple indicators that cover a widespreacl range of success rates, e.g. combining measures from objective attaimment and management satisfaction, financial measures, to overall ratings.

In Chapter 6 we will describe the dual research methodology and point to a research strategy of a case survey, which is regarded as the most appropriate method for the current research process. This dual methodology combines qualitative and quantitative research techniques, profiting from the combined strengths of case study research and survey research. Context and process information and statistical representativeness are among the criteria combined in the case survey. The advantages, disadvantages and requirements of designing a case survey are described. The actual development of the innovation survey for this study is based on the MERIT study (Cobbenhagen, 1999). We discuss the replication of the design of the quantitative and qualitative data-gathering techniques and the adaptations made for the $1 \mathrm{CT}$ sector. Furthermore, the sample selection criteria and sample characteristics are shown.

In the last part of the thesis we will expose the results of the empirical part of the study. The main aim is to present the key success factors and, more specifically, illustrarive case 
observations. The chapters show the qualitative material based on the extensive survey data with the qualitative data from interviews with CEO's, business and ICT managers. We use these combinations as supportive case data or as counter arguments, or to tell the story and the possible explanations behind the ligures. The results are compared with empirical results from the innovation literature review of Chapter 2. In Chapter 7 the elements of strategy are illustrated, followed by the organisation items in Chapter 8 . Finally, in the last chapter of the thesis, Chapter 9, we will discuss and summarise the findings consistent and those inconsistent with previous studies. We speculate on what is happening to the overall pattern of innovativeness in the ICT sector as a result of the study outcomes on, for example, client interaction, service innovation and innovation strategy style. We conclude with setting up a future research agenda for the next research phase and a vision for innovation management research.

Before addressing the research on innovation management we provide an outline of the industry and service sector context. 


\section{Figure 1: Route description of the ICT Innowation Research Study}

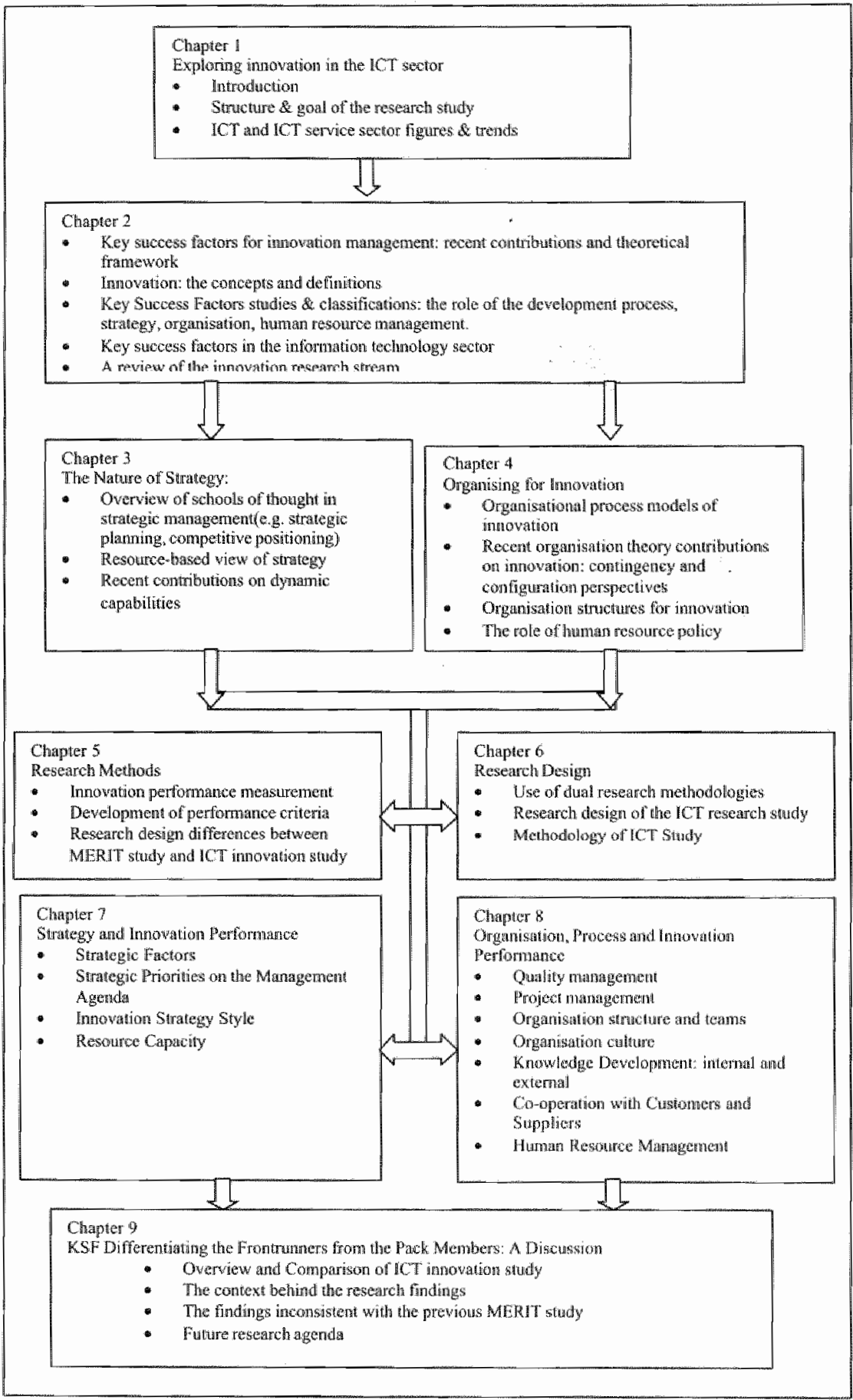




\title{
1.3 The Context of the Research Study: The Information and Communication Technology Sector
}

In 1996, the European Information Technology Observatory (EITO, 1996) reported the following on the importance of new product, service and process development (see box 1.1).

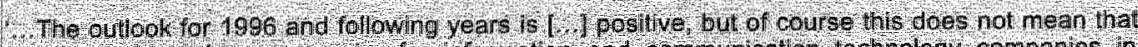
conditions have become easier for mormation and exemunication technology companes n

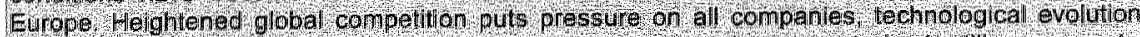

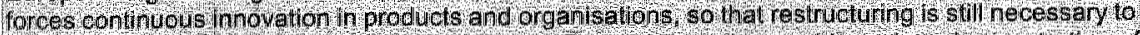
adjust the balaneo between rovenue and costs. 1 le 1965 rosulis provide a clear oenonstration of

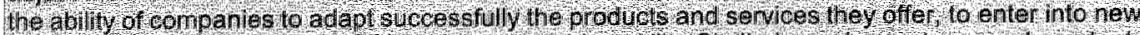

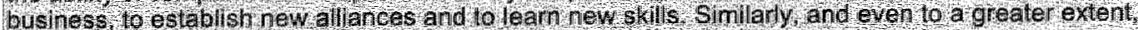

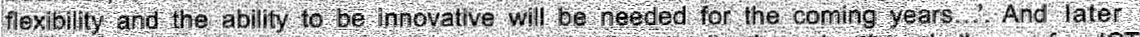

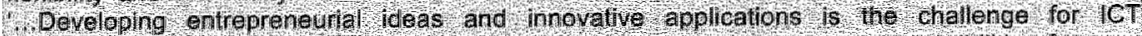
companes, As the maket growths and technological achevenents create possliblities for new

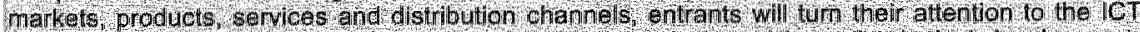
herket, Whereas the sector has tor many years been iominaled by techinolog cal develophent currenth tevelopment prosesses and the sugcess of products and serices ls market diven Customers, end users and suppil ers are of great mportance to the development of the sector This ilncicates that operating boundarles are shifing and new competive strugtires arise where new

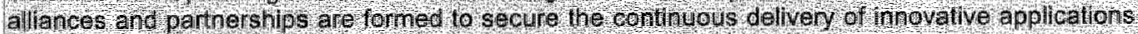
that are valued by he marrol.
\end{abstract}

\section{Box 1.1: Future perspectives in the ICT sector: A nash back (Source: EITO, 1996)}

In 2000 the EITO observed that the sector emerges in a new wave of European entrepreneurialism in the high-tech industry, particularly since 1998 with the emergence of players like Amazon.com, Priceline.com, Garden.com and the many start-ups in E-commerce and the massive demand for web-enabling capabilities. However, the majority of the European business and consumers seems to have adopted a "wait and see" attitude, which seems to be a barrier to innovation in e-commerce. Furthermore, a main breakthrough is expected from the development and revolution in the telecommunications driven by the diffusion internet-enabled devices, such as WAP mobile phones and palm-tops. We expect innowation to be of strategic importance to the information and communication technology (ICT) sector.

In this context it is important to learn more about the innovation efforts performed by ICT companies. However, there is a blank spot in the research field of innovation management with regard to the ICT sector. Only few studies (e.g. Eisenhardt \& Tabrizi, 1996; Cusumano \& Selby 1995; lansiti \& Clark, 1995; Bruce er al., 1995) have investigated the innovation performance of ICT companies. Little is recorded about what is conducive to the success of innovation at the firm level. Even ICT services, which have grown to constitute a large sector in terms of creating employment and generating output, have been ignored. With these observations in mind we have explored our research goals in the Dutch ICT sector. Before entering the research part, we provide a number of interesting features on the ICT sector and the role of ICT. 


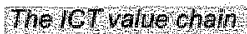

When looking at the IOT value chain we obsenve that ous hess is becoming nereasingly deponden!

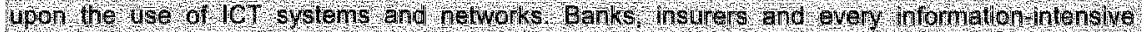
organistation rely on $1 \mathrm{CT}$ in their operations and control of he primany processes. The nhe enl

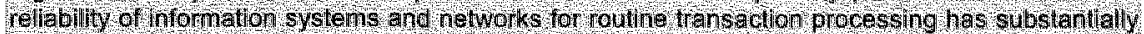
increased. Nowa days, control over transactions is moreasingl embed ded in sotware, mplying that the transaction noutives are replaed by soflware. furthermore, sofware is a basic ingredient for

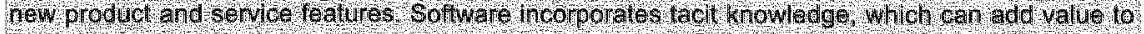

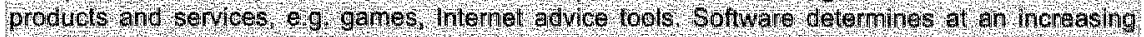
pace.

- the Uncilonality ol products services, processes;

6. the quallin, and

- the speed with which new products are the do bed en to tho hiarket and distributed

\section{Senve intensily}

Services are najor users of new Informalion (neludling cammuncalion) Tachnology (lCT) According to Coombs of al $(999)$ abou three quarters of all expenditure on (OT hardwane in the UK and 48 A stenis from services. Certan ypes of servaes (such as financlal services) are the loading users, both in terms of the volumes of hardware and sotware used, and in torme of

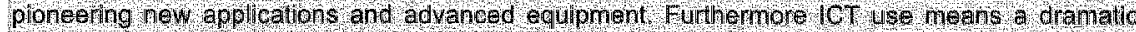
herease in the technology intensity of senices. Some commentators suggest that lot represents a Lechnological revolition for all kinds of hitermédian sencices sectors, e. gr brokers an banking Insurance travel and retall sectors. Ihese prelinibary observat ans are and ther reason to considen services as an interesting field for nonvalion research.
\end{abstract}

107 I new business develooment?

Al the same $t$ me companies can exp ot lCT as an enabler bl bus ness renewal Companies implement new informalion technoligies to inprove products and services and realise new

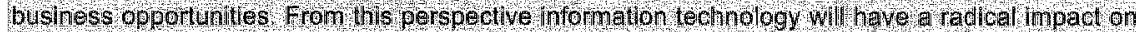
how business is organised and conducted duri g the ooming Yeats

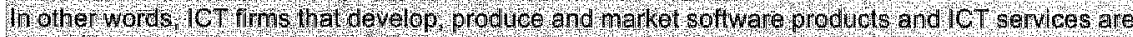
impentant to the economic progiess for indistry and senice.

het and the work enwironment

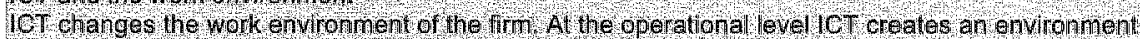
for the knowledge warker in which he can operate tar more effectvely it is an envioniment in Which

- routine opertitens are takenover by ystems.

- the supply of loformat on $1 \mathrm{~s}$ booming.

- explicl knowledge can be better storedand transierred

- and communcation across the organisalion is better and faster al all lavels of infomation exchange

\title{
Streaminha busthess processes
}

At the sane time, let has been the impetus for heremental and radical arganisational transiomation cnd business process reengineering (BPR) LCT enalbes the rearangement of exlsting intomation and distribution channels. industru structures can drastcally change due (o.

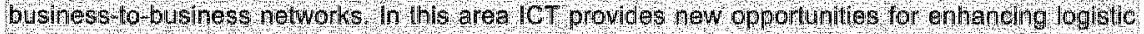

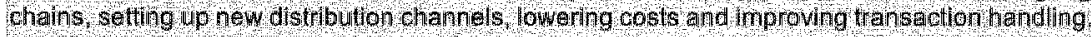

The atoption of $1 \mathrm{Cl}$

Nolan (1992) has deiscrbed he development of $10 \mathrm{f}$ in the olganisalion as a sequendal nodel of staiges:

Automation of data processing, In the siarting ohase, $10 \mathrm{t}$ ls $\mathrm{n}$ a slage of inithation wilt the Introduction of he first sotware and hardware appllcallons taking over transaction processes, $1 \mathrm{CT}$ improveinenis included shortened cycle lines and decreased failure rates.

Infomation supply h the nex t tage 1 CT was inplenented as a control and steeirng device, The goals of taking over data hansaction shifted towards the use of $1 \mathrm{C}$ t ab en enabler of beltet intormation supply for functional departments. Systems look over pents of the production processes and preduction control tasks were automated, Large budgets were spent on the implementation of Iiformation systems At the same fme management became aware that arger lot budgets caused new problems Despite the inves iments in office automation there was no direct nidication of a productwity incriase. But even more iremarkable was the enomous control 


\begin{abstract}
buiden that emerded resuling in the delay and excesswe costs of ch projects. Projects went wrong or were nol del vered on 1 me or without the pre defined specifications. Inithis stage, fings

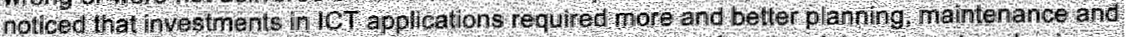
control Inforiation systems. Which had been butt h separate funct onal departhents or business

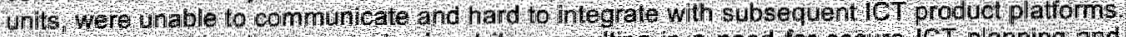

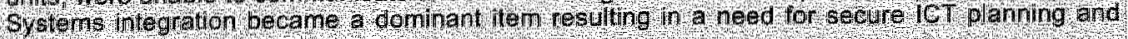
respuree allocation.

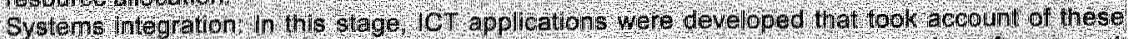

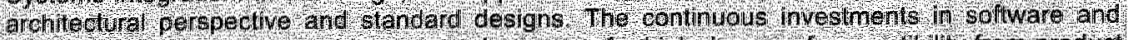

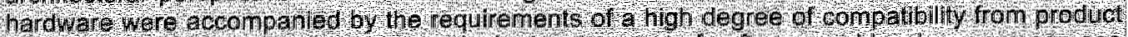

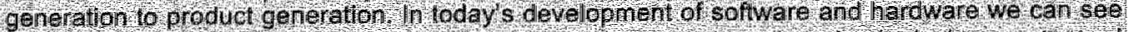
thet mprovements to sortware boll entail nore sophisticated leohnological aspects and incorpoiale new tunctionality, With the emergence of litemet, oxtranet and hiranet aspl cations an 1 st work area appears
\end{abstract}

\title{
Box 1.2: Recent developments in ICT
}

\subsection{ICT Industry and ICT Service Sector: Figures \& Trends}

To provide a clear picture of the size and structure of the ICT industry we present some financial figures of the sector. The market value of the total information and communications technology (ICT) market will reach 456 billion EURO in Western Europe in 2000 (see table 1.1), a growth of $7.5 \%$ compared to 1999 figures ( 424 billion EURO). Based on the most recent figures this represents approximately $5 \%$ of total European Gross Domestic Product (GDP) (EITO, 1999). Of the total ICT expenditure, the IT component will account for 231 billion EURO. Computer hardware accounts for 97 billion EURO (21\% of the total ICT value), services and software for 87 and 48 billion EURO respectively, representing $19 \%$ and $11 \%$ of the total ICT value in Westem Europe. The remaining part of total ICT spending can be assigned to telecommunications equipment and services with a market value of 224 billion Euro. Similar figures for the hardware, software and services share in total ICT value apply to the Netherlands.

\section{Table 1.. I: ICT market size}

\begin{tabular}{|c|c|c|c|c|}
\hline & $\begin{array}{l}\text { Walve } 2000 \\
\text { Europe }\end{array}$ & $\begin{array}{l}\text { As \% } \\
\text { oflCT }\end{array}$ & $\begin{array}{l}\text { Value } 2000 \\
\text { the Netherlands }\end{array}$ & $\begin{array}{l}\text { As \% } \\
\text { Of } \\
1 C T\end{array}$ \\
\hline Total & 231,967 & 51 & 11,860 & 52 \\
\hline 17 hardware & 96,809 & 21 & 5.287 & 23 \\
\hline 17 Services & 86,695 & 19 & 3,525 & 16 \\
\hline IT Sofware & 48,463 & 11 & 3,048 & 13 \\
\hline Total Telecom (日) & 224,151 & 49 & 10,858 & 48 \\
\hline TOTAL ICT & 456,118 & 100 & 22.718 & 100 \\
\hline
\end{tabular}

Note: Figures in millions of EURO. Figures for year 2000 are estimates.

(1) both telecom equipment (networks, terminals switching etc.) and telecom senices

(2) total UCT value is the sum of the total IT plus Telecommunications value.

Sourca: EITO, 1999

\section{Growth trends}

The growth figures for each marketproduct segment show that software is a driving force for IT growth. For the year $2000-1999$ a software growth rate is expected of $12.3 \%$, compared to a services growth of $1.2 .4 \%$ and hardware growth of $5.8 \%$. The figures for the Dutch economy show a somewhat different picture. The growth in software will be around $13.2 \%$ whereas the 
growth in IT services will increase by $9.7 \%$ (see table 1.2). In the Netherlands the growth in services falls behind the expected growth of software.

There are clear signs that growth rates in the hardware sector are influenced by the increased. demand for client-server solutions. Also, the increased quality, speed, reliability and performance of computers boosts hardware sales. Firms invest in systems and networks and are more confident in relying on ICT for their business processes. The services sector profits from the increased demand for consulting, facilities management, systems and network, implementation and operation services. Firms invest more in these areas of $1 \mathrm{CT}$ in their search for more effective business processes to beat competitors. The implementation of large complex Enterprise Resource Planning (ERP) software applications has positively influenced IT serwices spending as well.

Two other business topics relate to these services growth figures. First of all, the introduction of the EURO with its consequences for the payments and transactions traffic and services. The convergence of the Western European economies into one monetary union encompasses the introduction of one single currency, the EURO, as the accounting and paying device. This will require the adaptation of a large number of computer systems. Secondly, the historical ICT phenomenon of the year 2000 , which lead to a growth in the demand for millennium. repair services.

The high sofware growth figures result from many technological and market developments. Among the technological drives are the increased reliability of both software and systems and the introduction of innovative technologies such as Java and HTML. The implementation of client server architectures also positively influences software spending. Another technological trend is related to the fact that companies are entering the stage of integration and standardisation of systems and networks (Nolan, 1973). Firms can invest in tools and applications without having to deal with costly conversions and migrations between systems. One dominant market trend is the demand for relational database software and back-office and front office applications, e.g. Enterprise Resource Plaming (ERP) and Customer Relationship Management (CRM) sofware. Investment in this software are increasingly recognised as potential drivers for competitive advantage, e.g. better cost performance, customer information, improved information processing, and integrated business processes.

\section{The Dutch ICT sector: market size and structure}

The Dutch figures in table 1.2 reveal that the ICT market goes through a stage of rapid growth resulting from a strong increase in services and software spending. During the last three years software has grown by at least ten percent amnually. This figure has even increased since 1996 and the expectations for 2000 include a $13 \%$ growth. The same growth trend is being observed in the services sector. Services have risen over the last years because of the millennium and the introduction of the EURO. Strong growth has been observed in the consulting and implementation services, e.g. in the areas of e-commerce, enterprise resource planining and customer relationship management. Also outsourcing of internal maintenance and support functions by companies to IT service providers has contributed to the trend of increased demand for IT services. In contrast, the growth rates of hardware have declined since 1996 and have stagnated between 4 and $6 \%$, and are expected to stay low. In other words, the Netherlands is a software- and IT services-intensive country.

This supply side perspective can be complemented by data on the penetration of IT into the Dutch economy and the economic importance use of IT. Table 1.3 presents the degree of IT 
intensity of the Dutch economy. For 1997 we observe a concentration of industry of $45 \%$, which is high compared to the United Kingdom $(37 \%)$, France $(32 \%)$, and Germany (40\%) but low compared to Sweden $(50 \%)$ and Italy (54\%) The Dutch services sector shows a higher concentration index than the software sector. Interesting is the growth of this concentration index, which implies that over the years a few IT service providers have seized a higher market share. The reverse picture is obserwed for the Dutch hardware sector, where the concentration index has fallen from $20 \%$ to $15 \%$.

Table 1.2: Development of market value of IT products and services in the Netherlands

\begin{tabular}{|c|c|c|c|c|c|c|c|c|c|}
\hline & 2000 & 1999 & 1998 & 1997 & 1996 & $\begin{array}{l}\text { Growth } \\
2000199 \\
(\%)\end{array}$ & $\begin{array}{l}\text { Growth } \\
1999 / 98 \\
(\%)\end{array}$ & $\begin{array}{l}\text { Growh } \\
1998197 \\
(\%)\end{array}$ & $\begin{array}{l}\text { Growth } \\
1997196 \\
(\%)\end{array}$ \\
\hline $\begin{array}{l}\text { IT Services: } \\
\text { - consulting } \\
\text { - oplementation } \\
\text { management } \\
\text { - support services }\end{array}$ & $\begin{array}{l}3525 \\
403 \\
1636 \\
707 \\
778\end{array}$ & $\begin{array}{l}3213 \\
370 \\
1446 \\
661 \\
736\end{array}$ & $\begin{array}{l}2861 \\
331 \\
1222 \\
612 \\
696\end{array}$ & $\begin{array}{l}2513 \\
275 \\
1026 \\
552 \\
660\end{array}$ & $\begin{array}{l}2220 \\
233 \\
868 \\
473 \\
645\end{array}$ & 9.7 & 12.3 & 13.8 & 13.2 \\
\hline $\begin{array}{l}\text { Software: } \\
\text { systems } \\
\text { software } \\
\text { application } \\
\text { soffure }\end{array}$ & $\begin{array}{l}3048 \\
1629 \\
1429\end{array}$ & $\begin{array}{l}2692 \\
1427 \\
1265\end{array}$ & $\begin{array}{l}2351 \\
1246 \\
1105\end{array}$ & $\begin{array}{l}2092 \\
1109 \\
984\end{array}$ & $\begin{array}{l}1875 \\
975 \\
900\end{array}$ & 13.2 & 14.5 & 42.3 & 11.6 \\
\hline Handware & 5287 & 4977 & 4721 & 4508 & 4460 & 6.2 & 5.4 & 4.7 & 8.4 \\
\hline TOTAL IT market & 11860 & 10882 & 9933 & 9113 & 8255 & 7.1 & 8.4 & 9.2 & 10.5 \\
\hline
\end{tabular}

Note: Figures in millions of EURO. Figures for year 2000 are eslimates.

Source: EITO, 1999 .

Table 1.3 also reveals the IT investments by companies relative to Gross Domestic Product (GDP). This figure provides an indication of the economic importance of IT in the Netherlands. For 1998 we observe a penetration of $3.01 \%$. This figure has steadily grown since 1995, which means that the growth in IT expenditures has been higher than the growth in GDP over these years (nominal GDP growth was $3.9 \%$ in 1995 and $5.8 \%$ in 1998). This figure is high compared to the average IT percentage of GDP in Western Europe, which was $2,45 \%$. Compared to the United Kingdom $(3.51 \%)$ and Sweden $(3.66 \%)$ this Dutch figure is low, but it is high compared to Germany (2.24\%) and France $(2.65 \%)$. We can conclude that the Netherlands is an IT-intensive economy and that the Dutch IT sector is among the highgrowth sectors in Europe.

Table 1.3: IT market structures and penetration of IT in the Netherlands

\begin{tabular}{|c|c|c|c|c|}
\hline & 1998 & 1997 & 1996 & 1995 \\
\hline $\begin{array}{l}\text { Industry concentration } \\
\text { (overall top } 10 \text { vendors }\end{array}$ & - & 45.8 & 45.0 & 49.1 \\
\hline $\begin{array}{l}\text { Marketleaden's share } \\
\text { services } \\
\text { software } \\
\text { hardware }\end{array}$ & $\begin{array}{l}\text { m.a. } \\
\text { m.a. } \\
\text { m.a. }\end{array}$ & $\begin{array}{l}19.6 \\
4.2 \\
15.1\end{array}$ & $\begin{array}{c}16.3 \\
3.0 \\
17.3\end{array}$ & $\begin{array}{c}12.5 \\
3.1 \\
20.8\end{array}$ \\
\hline $\begin{array}{l}\text { IT market value as \% of Gross } \\
\text { Domestic Product }\end{array}$ & 3.01 & 2.92 & 2.78 & 2.65 \\
\hline
\end{tabular}

Source: EITO, 1999. More recent figures are not avallable. 


\title{
ICT market dynamics
}

What do these figures mean in terms of changes for the ICT companies? Several structural changes have taken place in the last few years, resulting in new competitive challenges (see box 1.3). New competitors have emerged at an accelerating pace, trying to capture some of the market growth. Many .com ventures have emerged that provided a new impetus for the concept of services. But new technological ventures are still scarce among the potential market entrants in the Netherlands. It has been argned that the financial infrastructure in the economy lacks the motivation to invest in promising new technological ideas (Den Hertog \& Huizenga, 1997). Nevertheless, in today's capital markets informal investors and venture capitalists have found their way to promising start-ups. At the same time established ICT companies have tried to expand their business by aggressively advertising and marketing their products and services. Recently also acquisitions and joint ventures have restructured the industry, e.g. the take-overs of small service providers by dominant market players and the take-over of internet start-ups by large financial and retail institutions, e.g. banks and insurance companies.

\begin{abstract}
In the context of the knowledgo based eisononto growth (Den Hertog 0 Hulzenga, 2000, 1907 )

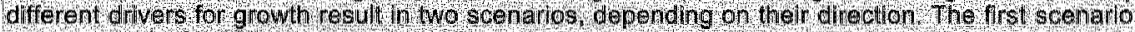

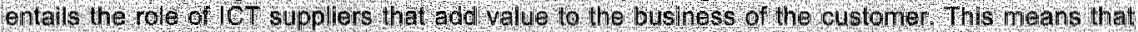

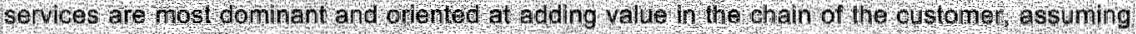
that margins on hardwaro and soinware will drop drasticall, senice will be bulding on he nost

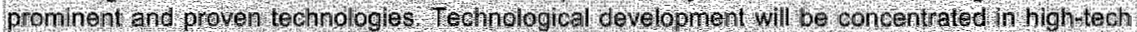

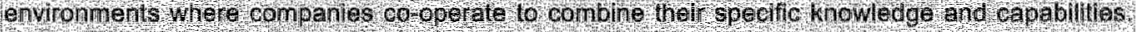

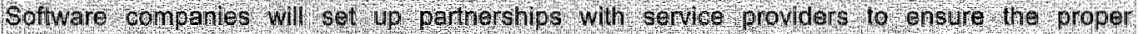

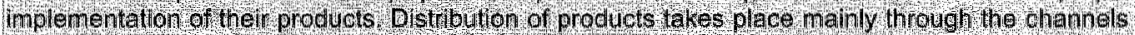
61 preferrods sipllers, valle added supplers

3.t.

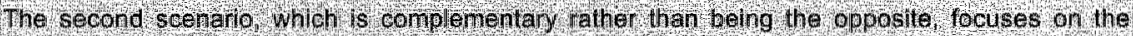

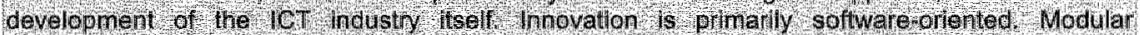

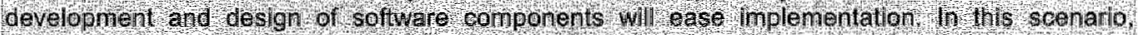

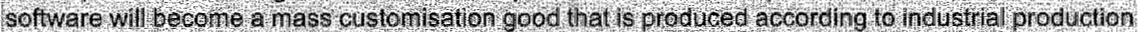

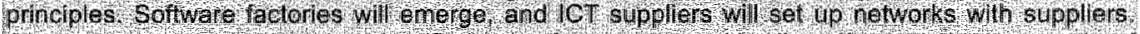

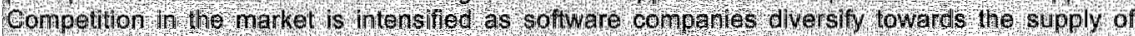
mplementailonservices.
\end{abstract}

\section{Box 1.3: Future scenarios of the innovation in the $\| \mathrm{CT}$ sector}

\section{The labour market}

The market situation has been influenced also by the state of the labour market in recent years. The Dutch economy has a structural shortage of skilled business and technical persomel. The demand for ICT personnel, due to high software and ICT services demand, is much bigger than the supply of graduates from universities and (poly)technic schools. This situation has led to the hiring and training of people without an ICT-specific educational background. These market changes have been structural since 1996 and have stimulated ICT suppliers to look for creative solutions such as training unemployed people, hiring people from other ICT-intensive countries such as India, or providing extra bonuses and fringe benefits for potential employees. High-quality skills are the basic resources for the further growth of the ICT sector. Investments in education and training represents one of the strategic areas of investment for the industry and government, especially because of the massive use of ICT, multimedia and the Internet. Skill shortage is one of the major barriers to competition. Recent surveys have indicated that Europe is suffering dramatically from this skill shortage. Accordingly, more than 500,000 potential ICT jobs are vacant in Europe and this number could grow to 1.5 million in a few years (Erro, 1999). Skill shortage is not a Dutch issue. It 
is a global phenomenon affecting not only Westem European countries but also the United Sates and Japan and is expected to persist for some more years.

\section{Future perspectives}

The most dominant development in the ICT industry is the emergence of the Internet. Integrated business-to-business and business-to-consumer networks provide a whole range of business opportunities. The Intemet and intranets are connecting people and business throughout the world. Nolan (1973) observed the emergence of a network area extending the reach of every individual to communicate and share information irrespective of time, geographic and organisational boundaries. New business is emerging as a result of these networks. Electronic commerce is the most prominent growth area. Retailers, tinancial service providers and information and content providers all focus on delivering new value propositions to the clients. In 1996 about 20 million business and home users were using the Internet and online services in Western Europe. In 2000 this amount will rise to 55 million users, of which 39 million people will be home users (EITO, 1999). Estimates for the Netherlands are that by February 2000 a total of 4.5 million people will have access to Internet either at home or at work. This figure has grown to 6 million for September 2000 (Nua.com, 2000; Proactive.com, 2000). On an average day, 20\% (2.5 million) of the Dutch population is online and 1.7 million Dutch people have bought a product online on one or more occasions.

These preliminary observations give us reason to believe that the rapid changes in products, services and process in the $\mathbb{C C T}$ sector are important to consider and represent an interesting research area with respect to innovation. Given the unarguable growth in the importance of ICT products and service sectors, increasing numbers of researchers and managers have to take a fresh look at innovation activities. This includes questioning the available wisdom regarding the innovation capacity of these firms. $\mathrm{ICT}$ companies have to make important choices about new products, services and markets, for example to start e-commerce initiatives, to sell products or service online, or to partner with others in new internet-based business models. New business development seems to be a core activity for the management of ICT companies. But the ICT market is unstable due to the rapid technological changes, the emergence of new entrants, and the scarcity of labour skills. However, a phase will emerge in which knowledge will determine the differentiating capacity of firms, followed by a possible shake-out in which not the pure technological capacity of the firm, but the unique knowledge and business offerings are the key to survival and growth for the ICT companies. Finally, in this study we speculate on what is happening to this overall pattern of innovativeness in the ICT sector as a result of the rapid technological progress, the rise of services and service innovation. 


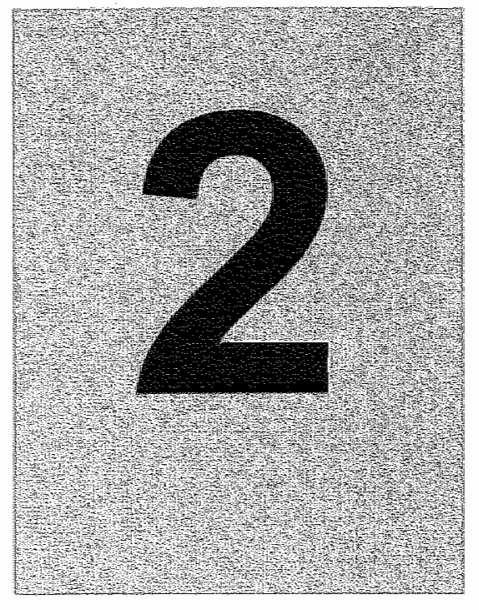

\section{Key Success Factors for Innovation Management: Recent Contributions}


Imnovation management has become one of the main fields of the management literature. The real world of business itself has been both the main source of inspiration and the main audience. A great number of the new concepts and approaches have been developed and tested in practice. They were developed to find answers to the new problems in our knowledge-intensive economies. Not surprisingly, in this search for new knowledge the focus has been to a large extent on the key factors that determine success in the complex and risky processes of innovation. The world of business expects simple answers to complex questions. Particularly in the last 15 years, this has resulted in a rapidlly growing multidisciplinary field of organisational science. In this chapter we present a brief overview of what this search for Key Success Factors (KSF) in the development of new products, services and processes has yielded. Before doing so, we need to clarify the concept and definition of innovation and the role and position of KSF research as a form of "variance-oriented" research. Below we present a brief literture overview of innovation management and the key success factors of new product and process development.

\subsection{Introduction}

Effective innovation management has gained a lot of research interest (Cooper \& Kleinschmidt, 1996, 1995; Griffin \& Page 1996; Souder, 1987; Rothwe11, 1972), in particular in studies exploring the factors that distinguish between success and failure. Previous findings argued that the size of R\&D expenditure might explain the performance differences between firms (see Freeman, 1988). However, more recent research has indicated that there might be other intervening factors that are of even greater importance to innovation performance. Such factors might reside in the way processes are designed, activities are organised and conducted, resources are allocated, and strategic objectives are pursued. Further research has investigated project failures and factors that inhibit innovation in order to understand what drives a good idea into a bad product outcome (Abernathy \& Clark, 1985).

The literature is known for its rich variety in approaches, perspectives, and outcomes of successful innovation management. In order to structure the discussions we take several viewpoints.

- We take a theoretical standpoint to take a tour of the concepts and definitions of imnovation and show the range of theoretical frameworks, which provided the foundation for our current thinking. We address some of the classification schemes and the fundamental issues of innovation, which will be discussed in Chapters 3 and 4 .

- We take a practical standpoint when discussing some empirical studies on key success factors that have contributed most. This part identifies and classifies key success factors at the product/service, project and company levels. Key success factor classifications include product advantages, new product development strategies, the development process, and the organisation factors. This will be discussed in Chapter 2 .

- We also take a research perspective. First we will present the typical research streams. It is argued that most research is conducted at the project level, is of an a-theoretical nature, and aims at identifying rather than explaining success factors. In the discussions on key success factor studies, we provide advice for the valuable future research directions. This will also be discussed in the current chapter. 
New concepts and approaches on innovation management have often arisen out of management practice. The management field has initiated the interest to find key success factors without a need for theoretical foundations. Managers were confronted with new problems requiring new solutions quickly. The key success factors were part of these solutions particularly when managers entered a new field of attention. The key success factors are a method to quickly grasp what matters to managing new product and process development.

Little is known about ICT and services in this field and in particularly in the combination of both areas: ICT services. So far, little empirical evidence has been gathered on the factors that contribute to the success of innovation in information technology, which constitutes the subject matter of this study. It is an important research area because of the rapid growth of the ICT industry and services sector and its important contribution to the economy. The lkey success factor method has been chosen to quickly map what happens in a new domain and where attention should be focused. This pragmatic attitude first starts with an overview of a rapidly moving field and will investigate the underlying insights at a later stage. This transition to knowledge development, which does not focus on the separate factors but on the process of innovation, is a necessary next step, which will be taken in the next chapter. But we will first turn to the key success factors as a first exploration and mapping of the field. We will look at the extent to which the knowledge on key success factors at hand is applicable to the world of ICT.

\subsection{Innovation: Concepts and Definitions}

The discipline of innovation management has rapidly developed into a separate research field throughout the past years. It can be regarded as one of the most rapidly growing fields in terms of the attention devoted by both economics, strategic management and organisational sciences to the role of innovation. This has generated a huge volume of theoretical and empirical work. The literature continues to grow, adding a multidisciplinary character to the imnovation management research. The source of this interest can be found in the increasing belief that firms can proactively adapt to changes in their environment by renewing their products, processes and organisation. This mulidisciplnary interest has the positive effect of generating a rich amount of knowledge on what product and process development is about and why some firms perform better than others. On the other hand, the research field faces the consequence of numerous variations in concepts and topics. Several authors have argued (Brown \& Eisenhardt, 1995; Montoya-Weiss \& Calantone, 1994; Cooper \& Kleinschmidt, 1994; Downs \& Mohr, 1976) that the innovation field is characterised by a multiformity of definitions, of designs and units of analysis. Few findings have been accumulated despite the many studies, which has resulted in instability in the research field. This thas led to the development of a large number of sub-theories rather than the integration of empirical findings (Damanpour, 1991). This multiformity and sub-theoretical focus is immediately reflected by the numerous innovation definitions. Daft (1983) distinguishes between administrative and technical innovation. Zmud (1982) separates initiation from implementation of imnovation to emphasise the adoption of a new product idea. Abernathy \& Utterback (1978) differentiate incremental innovation from radical imnovation to stress the degree of change. This multiformity is fuelled by the difference between the organisationoriented research and the economics-oriented tradition (Brown \& Eisenhardt, 1995; Adler, 1989). The former specifically looks at the micro-level of product development, whereas the 
economics tradition analyses macromdifferences in pattems of innovation across industrial sectors and countries and the sectoral evolution of technology (Freeman, 1988).

\section{Innovation research: process-and variance-oriented perspectives}

To structure the research domain of innovation, we can split it along two research streams. The difference between these streams is similar to what Mohr (1982) has identified as process-oriented and variance-oriented research. Process-oriented research primarily concentrates on the analysis of the structure of innovation processes. The goal of processoriented research is to develop a process theory that explains the effectiveness of innowation from the institutional context and the sequence of events in a development process (Den Hertog \& Van Sluijs, 1995). The research domain of innovation has generated standard classifications of innovation processes resulting from analysing and comparing the stream and coherence of development activities conducted. The studies belonging to the process-oriented stream have addressed the issue of how innovation is performed. To do so, a process perspective on innovation is needed to analyse "the temporal sequence of events" and describes the dynamics of change (Van de Ven \& Huber, 1990). A number of authors (Pettigrew, 1990; Mohr, 1982) refer to this as the 'process theory' as it explores the context, content and process of change in a time perspective. Variance-oriented research mainly concentrates on identifying the success factors in innovation and on analysing what causes the difference between successful and unsuccessful imnovations. Variance studies rather focus on the identification of key success factors to explain differences in innovation performance at the product, project and company levels (Van de Ven \& Poole, 1990).

The present study views the variance- and process-oriented approaches as being complementary rather than contradictory. For pragmatic reasons both strands of literature are discussed in separate chapters. Chapter 2 discusses the variance-oriented approach. Chapters 3 and 4 will focus on the process-oriented approaches. In Chapters 7,8 and 9 we will try to find ways to link both approaches.

\section{Classification schemes of innovation}

In the literature, mnovation is perceived as a broad concept and as a complex multidimensional phenomenon. Before we sketch the landscape of key success factor studies, we want to briefly discuss the fact that views of innovations. This tells us that the state of the innovation management field is in a growing phase of knowledge development. Different strands of literature have concentrated on one of the dimensions of innovation. Both the variety in dimensions and the many different interpretations of innovation have resulted in many overlapping concepts. Downs and Mohr (1976) argue that there is a lack of clarity on the subject of innovation studies as well as a lack of standard definitions. Gobeli and Brown (1988) attempted to structure the field, in which they basically identified four types of classification schemes of innovation.

First, what is the initial focus of an imnovation? Biemans (1992) refers to innovation as the process of developing a new item and the process of adopting the item and the new item itself. Gobeli and Brown (1988) and Abemathy and Utterback (1978, 1994) make a distinction between product, service and process innovation. A distinction, which is assumed to be relevant to the ICT sector. Another distinction is between organisational innovation and technological innovation. Organisational innovation involves the development and transformation of organisational structures and processes. Technollogical innovation, as defined by Freeman (1988), is the process of technical, design, manufacturing, management, and commercial activities irvolved in the marketing of a new or improved product or service. 
Whereas the former is expected to be relevant to IT service providers, the latter is expected to be relevant to software firms. Second, what is the state of the innovation system? Imovation can be a programmed range of activities or it can be non-programmed as a process of 'creative destruction' of existing structures and processes. Firms may want to conduct nonprogrammed innovation in the hope to find new breakthroughs that originate from creativity or slack resources. Third, what is the source of innovation? One can distinguish, for example, market pull wersus technology push innovations. Both are assumed to be of great importance to the ICT sector. Fourth, what impact does an innovation have? This refers to the impact on existing structures and processes. For a firm, an innovation can be incremental, implying small improvements, or radical, which means it has a radical impact on existing structures. The degree of change and the benefit of the innovation determine the intensity of change (Gobeli \& Brown, 1988). Table 2.1 presents a matrix that distinguishes four levels of effects, i.e. application, radical incremental and technological change.

Table 2.1: The effect of an innovation (Source: Gobeli \& Brown, 1988)

\begin{tabular}{lll}
\hline & low benefits & high benefits \\
high level of change & application & radical \\
low level of chenge & incremental & technological
\end{tabular}

This matrix is useful in clarifying the complexity associated with innovation. Schumpeter (1942, p. 84) states that radical innovations "command a decisive cost or quality advantage that strikes wot at the margin of the profits and the outputs of existing firms, but at their foundations and their very lives'. Tushman and Anderson (1986) refer to radical as '...the technological discontinuties that dismupt existing structures and processes. New products that differ in every aspect from the existing technological base...'. Both statements clarify the radical impact attributed to innovation and the consequences for "doing business as usual'. New insights into the role of competencies and the impact of innovation on competencies have emerged. Researchers argue that innovations destroy competencies and favour newly developed technological competencies at the expense of market incumbents who exploit established competencies (Leonard Barton, 1995; Tushman \& Anderson, 1986). This addresses the competitive implications of technological innovations (Abemathy \& Utterback, 1978). Box 2.1 provides a useful competency framework for assessing the impact of an innovation on the existing production and marketing system. This framework can help us in a later stage to distinguish the several types of innovations in the $\mathrm{ICT}$ sector:

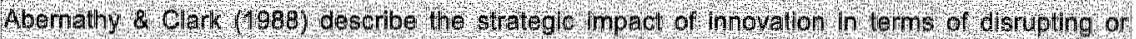

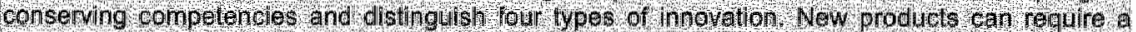

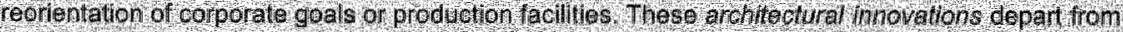

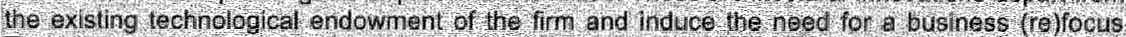
They are radical in nature because of their durable and dominan dosigns. They have an owerall

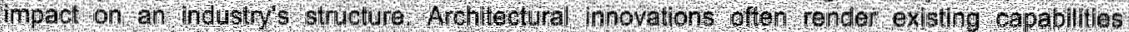

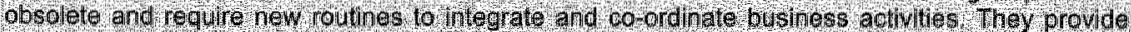

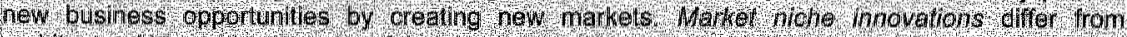

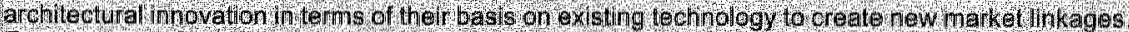

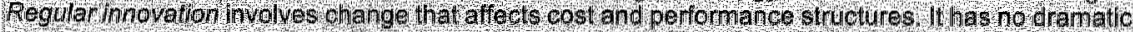

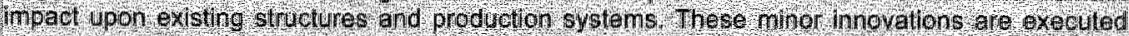

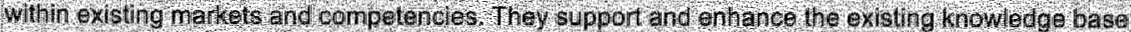

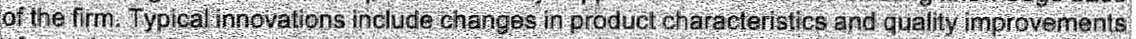

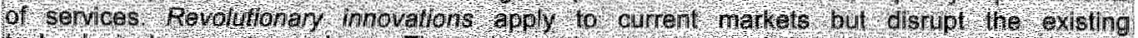

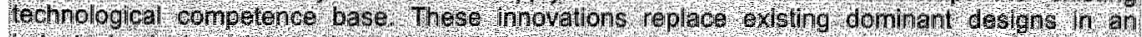
ndustry by designet thare based on rovel technologies
} 


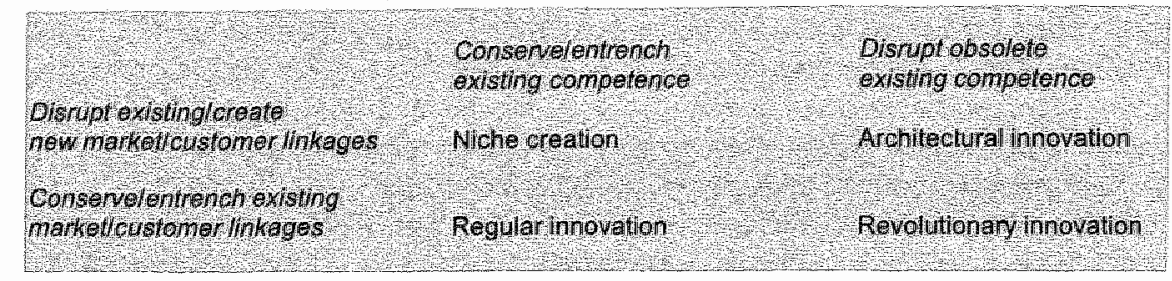

\section{Box 2.1: Strategic impact of inmovations}

In order to ensure a consistent meaning of innovation throughout the research study we have defined innovation as follows (OECD, 1994; Tushman \& Moore, 1992):

- Product and service innovation: important improvements of existing products and services and the development and commercialisation of new products and services.

- Process innovation: important changes and improvements of existing processes and the development and implementation of new processes.

- Basically, we will address in this study all of the above-mentioned aspects, e.g. the focus, the source and the impact of imnovation. All things that are new to the company are considered to be relevant to innovation in the ICT sector because the sector is knowledgeintensive and facing continuous and rapid technological progress. However, we expect the managers in the study to particularly address such subjects as the creation of competencies, the radical role of technological change versus the presence of incremental innovations and the benefits of new or improved products, services and internal processes to their customers.

The definitions have been used in the survey and in the interviews with managers. With this theoretical tour in mind we have arrived at a more practical point: a discussion of some of the most contributing and useful empirical studies and mapping their contributions to the field.

\subsection{Key Success Factors: Studies \& Classifications}

This section aims at providing a broader understanding of KSFS are and their role in innovation management. In three parts we elaborate on the wature of KSFs, the main KSF innovation studies and studies in the ICT sector.

Key success factors are the relatively small number of truly important matters that managers should focus attention on. For this reason, the term key success factor has been chosen in accordance with preceding innovation studies. They represent the few "factors" that are the "keys" to the "success" of innovation. There are, in every manager"s life, an incredible number of things to which attention can be diverted at the company level. The key to success for most managers is to focus their limited resources on the things that really make the difference between success and failure. KSFs are about the few areas of activity that are "close to the bone".

Typical areas of KSFS in variance-oriented research include:

- The industry or service sector. Each sector has a set of critical success factors that are determined by the characteristics of the sector itself, e.g. chemicall, ICT, banking or retail. Each company in the industry must pay attention to these factors. 
- Competitive strategy and industry position. Each company"s situation within an industry or service sector is determined by its history (also called: path dependency, see chapter 3) and current competitive strategy. The company's position in the industry dictates some KSFs.

- Envirommental factors. Environmental factors are those areas over which an organisation has little control. The organisation must accomplish its mission while riding the tides of environmental change and selection.

- Temporal factors. A number of areas of activity become critical for a particular period of time for a company or a sector. Either because something out of the ordinary has taken place, or because there is a temporary unique resource (such as knowledge, insight, routine, etc.) or a resource that is hard to imitate. Over time these factors disappear as they have become common practice in a sector.

- Functional managementfactors. Each management area has a set of KSFs assoctated with functional disciplines, e.g. marketing.

KSF imnovation studies, programmes and classification schemes

Although the above classifications are widely used, the innovation management discipline still disputes on which factors matter and influence success. Going back to the beginning of variance-oriented research we identify the roots of key success factor studies in three major empirical studies: the SAPPHO studies, The Stanford Innovation Project (SINPRO), and the New Product Program (NEWPROD). The MERIT progtamme (Cobbenhagen, 1999; Den Hertog ef al., 1997; Den Hertog \& Huizenga, 1999, 2000) shows similarities with the range of NewProd studies (see chapter 5).

The SAPPHO project (Rothwell, 1972; Rothwell et al., 1974) analysed the characteristics of successful innovators in technologically advanced companies. The study compared 43 success-failure product pairs in the chemical and instruments sector. Among the key results of this study are:

- understanding of user needs,

- efficient development,

- market attention,

- senior leadership.

The SINPRO studies (Maidique \& Zirger, 1985) analysed 70 success-failure procluct pairs, from 21 case studies, in a longitudinal study in the US electronics. This study also addressed the importance of product advantage, market altractiveness and organisation. The product advantage factor referred to the low cost, high quality or uniqueness of the product. Market attractiveness referred to the presence of a large volume and high-growth markets. The organisation factors referred to high internal communication in cross-functional teams and supportive senior management.

The NewProd programme (Cooper, 1979) sharpened the emerging research emphasis on product advantage, market attractiveness and internal organisation. NewProd studies started with comparing new product success and failure. The programme produced research results on success factors through replicating the study in many sectors and countries (Cooper \& Kleinschmidt, 1995). These studies are often regarded as the first projects that showed consistency in results, quality of the methodological framework and a consistent chain of reasoning (Barclay, 1992). The key contribution of these studies is its identification of success factors at the project level and process-related factors (Cooper \& Kleinschmidt, 1995). The 
success factor investigations have delivered insights from success stories and provided lessons on what should be stimulated to improve output. The research is valuable as it offers ideas for improving the practices of innovation and can guide management in making development efforts successful.

A more recent NewProd study of particular importance was the study by Cooper \& Kleinschmidt (1987). The study analysed 203 products, of which 123 were a success. A total of 125 firms were involved in this study. The findings revealed that the most important success factor was product advantage. Product advantage offered the firm a superior position relative to competitors. Product advantage involved a unique superior attribute in the eyes of the customer. These benefits were not found in competitive products. The advantage stemmed also from the high performance-to-cost ratio and the economic advantages to the users. The use of advanced technology in the design and the low purchasing costs for the customer explain the advantage. This product advantage rendered value to customers through high quality and innovative product features that helped customers solve problems and contribute to a higher margin for the furm. In addition, the organisation of the internal development process was critical to success.

The organisation involved marketing factors, management factors and synergy factors. Essential was the pre-development planning. This up-front homework would include a basic understanding of the user needs, market knowledge and marketing proficiency. This market focus would improve the essential market information gathering. Along the innovation chain this would result in a clear target market, innovative product features. It would also support the vision and consensus on the product concept and the achievement of a strong market launch.

The management factors involved top management commitment to the project, especially from senior management. Also an efficient and well-planned R\&D process and good internal communication between groups are key factors. The synergy between the marketing and technology discipline was conducive to success. This involved a good fit between production, research, sales and marketing requirements and the available resources and skills. Although less important, the market conditions were relevant success factors. Markets characterised by growth and relatively weak competition were conducive to new product success. The authors also indicated that markets characterised by dynamic needs, for example a high degree of change in customer needs and wants for a product category, might increase product success through raising opportunities.

Based on the NewProd experiences, Cooper \& Kleinschmidt (1995; 1995) developed a conceptual framework to identify the major drivers of new product performance. Based on studies by Shrivastava \& Souder (1987), Griffin \& Hauser (1996), Johne \& Snelson (1988), Song \& Parry $(1996,1999)$ this framework incorporates five classes of critical success factors:

1. Process: the firm's new product development process and the specific activities within this process,

2. Sirategy: the new product strategy as part of the business strategy,

3. Organisation: the way projects are organised,

4. Culture: the firm's internal culture and climate for innovation,

5. Commitnent: management involvement and corporate commitment to new product development. 
Complementary to the work by Cooper and others, Montoya-Weiss \& Calantone (1994) performed a review study and meta-analysis of 47 studies on new product performance. This study, which is the most complete study in the sense that it integrates the major empirical research findings), identifies four major sets of key success factors that drive new product success (table 2.2).

\section{Table 2.2: Key Success factors (Source: Cooper \& Kleinschmidt, 1995)}

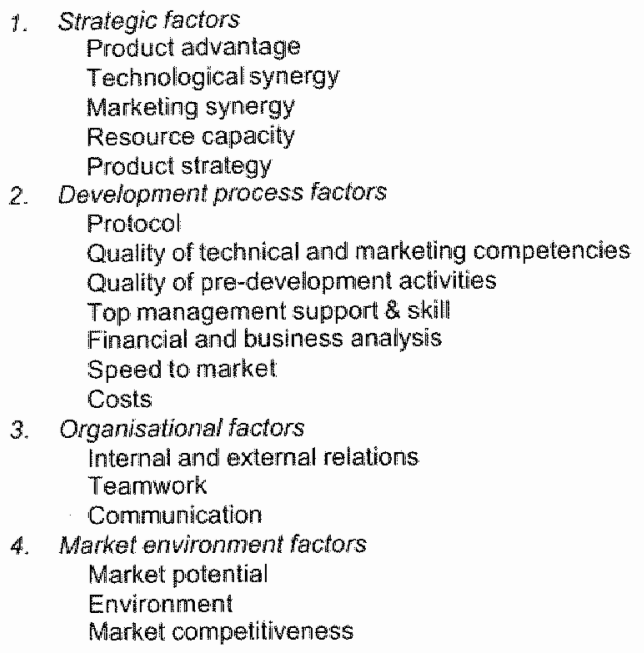

We go more into detail of other key success factors to address the major subjects of innovation that are especially relevant to the ICT innovation study.

Critical aspect in the new product development process

Researchers have stated that innovation calls for sophisticated management and organisation in a company in order to manage the complexity. Clark \& Wheelwright (1993) and others (e.g. Stacey 1996; Gobeli \& Brown, 1988) have argued that firms operating with project teams are more successful, but firms have to recognise that this structure places high demands on the decision-making and control processes of innovation.

\section{Pre-development work}

Pre-development work has been mentioned as one critical success factor in innovation (Cooper \& Kleinschmidt, 1993; 1994, 1996; Rothwell 1992; Montoya-Weiss \& Calantone, 1994). A strong attention for up-front activities involving a strong market orientation, a thorough understanding of the marketing tasks ensures the quality of pre-development. Project management should start with high-quality pre-development work. The proficient execution of these tasks prior to the start of a development stage can result in a better and faster development process. In line with this finding Johne and Snelson (1988) argued that the existence of a formal procedure for a new product development process is related to success. Such procedural items would set clear target market and product requirements prior to development stage. 


\section{Concrete planning and go/no go decision points}

One might expect proper planming and explicit project plans to reduce the total development time. Roussel et al. (1991) argued that planning and scheduling could reduce the risks between the hand-over of the design and development stage. Cooper"s (1994) stage gate development process introduces the presence of go/no go decision points in order to monitor the process. Eisenhardt \& Tabrizi (1995) found support that the frequent use of milestones accelerates product development and obserwed that milestones between stages ensure that the project members keep track of their pre-defined budget and time objectives. In line with Eisenhardt \& Tabrizi, Gersick (1994) argues that in conditions of rapid technological change milestones are an effective tool for advancement. Additionally, Ancona \& Caldwell (1992) found concrete project plans to be related to the motivation of team members (also Gersick, 1988). Their study indicated that deadlines and milestones create a sense of urgency and commitment with the team to achieve pre-set goals. The presence of dedicated project leaders and team members can drive the profitability of the business development efforts.

\section{Project management and project tools}

Cooper \& Kleinschmidt $(1995,1995)$ showed that successful firms are characterised by strong project management. The quality of project management included an emphasis on upfront honework, a sharply defined early product definition before development, tough milestones and flexibility to combine stages and decision points when needed. The role of pre-development work includes a detailed market and technical assessment. By assessing the market potential, the customer needs, capital requirement, manufacturability, skills and technical requirements along the process, fims can prevent the failure of starting product development due to inadequate understanding of the innovation chain.

Strong project management is reflected in formal procedures that are made explicit in project management techniques such as project evaluation and review technique (PERT) or critical path method (CPM). These formal planning and control methods are used to ensure alignment of the complicated streams of activities. Clearly defined tasks, responsibilities, skills, and formal authority characterise project management procedures.

\section{Innowation strategy}

According to some studies (Dwyer; 1990) strategy is the essential cornerstone of innovation success. A business strategy is actually the outlet of a strategic vision about future markets and techmologies. An explicit resource commitment to innovation and the presence of a shared vision about new product-market combinations are critical components in a business strategy (Dwyer, 1990). This implies that the innovation strategy seems like a formal arrangement for the resources, which might raise several questions. But what about the strategic priority setting? Do company objectives on sales, profits and market shares conflict with innovation? And what about timing as a strategy wersus product differentiation? Should companies develop areas of product advantage that support a differentiation strategy?

Shrivastava \& Souder's key success factor study (1987) argues that that the new product strategy should be part of the business strategy. Cooper \& Kleinschmidt (1995) strongly argue for the strategic need for product advantage and a separate product strategy. Other studies (Roussel er al., 1991; Rothwell, 1.992) provide arguments for the selection and composition of project portfolios, and the screening of new product ideas and technologies to assess the market attractiveness. There clearly seems to be a dispute in this part of the empirical literature.

On this dliscussion issue, Barczak (1995) conducted a study with 128 firms in the telecommunications industry. Three new product development strategies (NPD) were 
compared: a first-to-market, a fast follower, and a delayed entrant strategy. Remarkably, this study found no support that a single NPD strategy stands out as being better that any other. The results indicated that a company's focus should be on ensuring the best possible fit between the chosen NPD strategy, the corporate goals and the capabilities. Besides this specific outcome, the conclusions include the following:

- Performance is related to the use of cross-functional teams (e.g. project and R\&D teams), a finding consistent with the Cooper \& Kleinschmidt and Clark \& Wheelwright studies. Barczak's study suggests that first-to-market firms rely more on R\&D teams than fast followers or delayed entrants.

- Product champions, managers that personally commit to, guard and invest in an innovation project, are valuable contributors and influence the success of new product programs. This finding accurred in other studies (e.g. Allen (1978) on R\&D professionals as technology gatekeepers) and confirms prior research on champions and new product success factors (Stacey, 1996, Gobeli \& Brown, 1988).

- Remarkable is the emphasis on the importance of idea generation and idea screening for success. Prior research already identified the importance of pre-development activities. In this study both tasks have been identified as critical activities, for all three NPD strategies. In addition, the results indicated that a fast follower should offer distinctive products. This implies that fast followers should emphasise on such activities as concept definition and (consumer prototype) testing.

We will discuss these subjects further in the next chapter the upheaval on both in the academic literature and business profession on resources and competencies, which has shed new light on the role of strategic management (Hamel \& Prahalad, 1994; Teece et al., 1997).

\section{Organisation of innovation}

Elements like the multidisciplinary teams (e.g. Gobelli \& Brown, 1988), the process of problem solwing (e.g. Nonaka \& Takeuchi, 1994) and the cross-functional interfaces between (e.g. Galbraith, 1994) are considered beneficial to innovation. In a meta-analytic study on organisational innovation, Damanpour (1991) listed several organisational dimensions that moderate innovation performance (see box 2.2). There is little debate in the literature that these elements should occur in the presence of a parallel rather than a sequential development process. All these factors are considered to improve the innovation performance and shorten the time-to-market of the process.

- Specialisation teflects a greater variety of spectalists provides a larger knowledge base and Thureases choss fertilisat on of ldeas.

- Profassionalism: increases boundary spanning activity, and commitrient to adjust the slatus guo.

- Fomalisation cen hamper the fllexibility requited to fachitate nnovation. The lower the degree of formalisalion the more open and recieptive an organisation ls to change.

- Decentralisation points to the concentration of authority and control to the lowest possible: operational level encounaging atwareness, commitment and involvement to hrovation

- Slach resources allow inims 10 discover and explore new opportunities end detect emerging market needs.

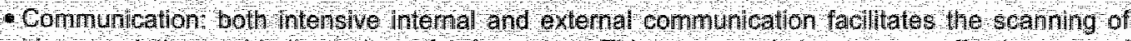
deas and the rapid dispersion of niormation. This gan result in a more efective 150 of infomation and acceleration of process steps. 
In particular, some studies (e.g. Cooper, \& Kleinschmidt, 1995; Song \& Parry, 1996, 1999; Eisenhardt \& Tabrizi, 1995; Cobbenhagen, 1999) argue that whenever more responsibilities are delegated towards the project team, the more autonomous a team works. This is in line with Clark \& Wheelwright's (1993) argument of a heavyweight project leader. They propose that when more responsibilities are decentrallised towards the project teams, teams are more empowered to execute successive innovation steps. The project responsibilities range from initiating the kick-off of a project to managing the team through the concept, design and development stages. Based on a clear set of project responsibilities project leaders would use their anthority and control over resource allocations.

\section{Culture}

The cultural factor addresses the atmosphere that resides with an organisation. A lot of studies (Scott-Morgan, 1994; Senge, 1990; Souder, 1987) on culture pointed to success factors, e.g. practices that stimulate brainstorm work, idea generation, or R\&D scouting time to discover new opportunities. Culture elements that stimulate informal communication and co-operation and reward learning behaviour allow for entrepreneurship. Moss Kanter (1983) and Pfeffer (1994) argue that innovation is stimulated in an environment that has an external open view and tolerates learning from mistakes and comprises little hierarchical levels.

\section{Management commitment}

The key success factor literature (e.g. Cooper \& Kleinschmidt, 1987; Johne \& Snelson, 1988; Griffin \& Hauser, 1996) has expressed that management involvement is an essential key attribute for product success. The presence of managerial elements like motivation, dedication and support are associated with high innovation performance. Among the typical elements are management styles that express risk-taking behaviour, a clear dedication to innovation and the reflection of both in the allocation of resources for product development (e.g. Barney, 1991). This argument implies that management commitment is also reflected in the dedication to the role of human resources (Huselid et al., 1997). Nonaka \& Takeuchi (1994) and Brown \& Eisenhardt (1995) argued for close involvement of senior management in project decisions and in the case of project difficulties, eventually contributing to higher performance.

The above-discussed studies have been summarised in table 2.3 (see table 2.3 at the end of chapter two), which shows a clear variation in industries. Some studies have incorporated multiple industries as research focus. Some of them have been replicated in other industry settings to uncover and validate industry similarities and differences.

\subsection{Key Success Factors in the Information \& Communication Technology Sector}

Although multiple-industry studies are valuable in generalising knowledge, they cancel out these nuances of a particular industry. Single-industry studies accentuate the effect of industry characteristics of how firms cope with new product development. Although we may not generalise single-industry studies, they can enhance the knowledge about a given industry and may offer valuable insights both to academics and managers. In this section we will discuss selected studies that are characterised by one particular sector focus: the information technology sector. Little evidence has so far been gathered on the factors that contribute to the success of innovation in information technology. A number of studies focused on the innovations in either hardware and/or software. None of the has taken an integrated perspective of the ICT sector, taking aspect into account both services and products. 
Furthermore the focus has been on identifying factors. The aim of the ICT innovation study was to contribute to this small research field by focusing at ICT services and ICT products. By using a combination of qualitative and quantitative methods we will not only identify but also try to explain key success factors.

Eisenhardt \& Tabrizi (1995) examined the computer industry in Japan, Europe and the United States by looking at 72 products in 36 computer firms. The focus was on PC, workstation, mainframe, and peripheral segments in the hardware sector. Performance was measured in tems of speed of development. They contrasted a "compression model" of innovation (compressing sequential development stages) with an "experiential model" (characterised by flexubility of design and improvisation). They concluded that product teams developed ICT products more quickly when acting in an experiential and improvisational design stage. Multiple design iterations, forceful project leadership, and multifunctional teams accelerate the innovation process. In contrast with expectations about tools to improve rapid application development, the use of computer-aided design (CAD) systems, schedule attainment planning and rewarding, supplier involvement and parallel development stages and pre-development planning failed to accelerate the development. Even more remarkably, this mechanism could even slow down the innovation process. A study by Van Reeken (1991) supports these findings. In summary, the key outcomes of Eisenhardt \& Tabrizi are the following:

- cross-functional teams,

- iterative prototype and test process,

- limited planning and limited use of $C A D$,

- no rewards for employees when reaching schedule deadlines.

Ilansiti \& Clark (1994) performed a variance study in the mainframe sector investigating the capability building process and the effect on dynamic performance. They found evidence that the capacity to integrate the knowledge (bases) in an organisation through effective problem solving is conducive to performance. In addition, lansiti \& Khanna (1995) presented a longitudinal study on the technological evolution in the mainframe computer industry. They presented a critical path model to investigate the influence on product development of complexity, rapid technological change and substantial discontinuities in IT components. The study showed that the ICT sector is characterised by obsolescence of technological capabilities. Iansiti et al. (1994, 1995) argues that firms need to develop dynamic capabilities to constantly renew the knowledge in the organisation.

Voss (1988) investigated the key success factors in new product development at the company level of 16 application sofware packages. The study resulted in seven key deteminants of success and failure in software innovation processes. Success was determined at three levels: installation success, commercial success, and a composite measure of overall success. Table 2.4 reports the set of critical success factors. External communication is important to obtain a clear wiew of the industry context relevant to the sofware-operating enviromment and better identification of potential markets. Efficient development work is reflected in lower costs and less lead time. This is associated with proper planning and pre-development work. Project championing as well as sufficient resource commitment to innovation represented the top management priority. Priority was measured in terms of resource availability. Product advantage in terms of software functionality revealed to be important in the diffusion of a software innovation. Reference sites, demonstrations, in-house or with independent users, provided the credibility for the product and the confidence for potential customers. A culture 
stimulating risk taking and accepting uncertainty were beneficial to the success of the software development.

Table 2.4: Key success factors in software development (Source: Voss, 1988)

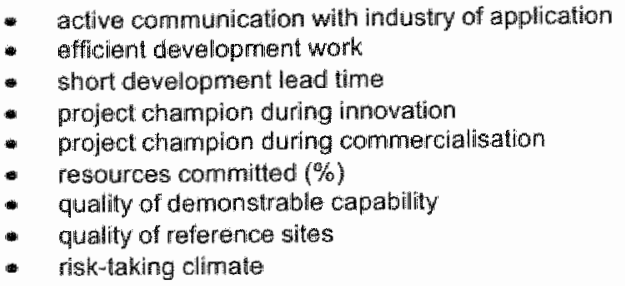

An additional study on the success of collaborative product development (Bruce et al., 1995) investigated the collaborative ventures of $100 \mathrm{ICT}$ companies in the United Kingdom. The driving forces behind collaboration are the reduction of time-to-market and the sharing of costs and risks in product development. Remarkably, the study revealed that the expected benefits may not be accrued and collaboration even has a negative impact, e.g. longer lead times, higher costs and an inefficient control. The study reported that difficulties in managing extemal collaboration relate to the paradoxical or "extraordinary management" requirements (Stacey, 1996; Den Hertog \& Huizenga, 2000). Such paradoxes appeared between:

- starting co-operation with potential competitors and continuing to be competitive,

- retaining flexibility while establishing goals and project plans, and

- balancing the management focus on the internal and external factors that influence the commercial outcome.

We now turn to a discussion on the use of the KSF concept from a more theoretical standpoint.

\subsection{Innovation Research Streams: A Review}

The multidisciplinary nature of innovation research has enriched the understanding of what distinguishes the better pertiorming innovators. Let us briefly address the KSF approaches and methodology. The range of key success factors point to a small set of strategy, process, organisational and environmental factors. However, as Brown \& Eisenhardt (1995) argue, there is a lack of theoretical understanding on success factors. Despite its multidisciplinary character, this research field has not provided a theoretical base and deeper understanding on each of the key success factors. Furthermore, little is known about the explanation behind and the relations between the factors. Brown \& Eisenhardt (1995) structured the research field and identified the work by Cooper and similar scholars as a research stream, which they tefer to as the 'rational plan'. This stream characterises a large part of the research on innovation. Their classification (table 2.5), which complements our earlier distinction between process and variance research, includes the following:

- product development as a rational plan. containing research on factors determining financial performance of product success. Project planning, cross-functional teams and managenent commitment are often regarded as key success factors; 
- innovation as a communication nerwork: research looking at the internal and external communication by project teams in product development process;

- innovation as disciplined problem solving: research concentrating on the problem-solving capacity of the project team and the heavyweight project leader and the importance of top management commitment.

Table 2.5: Inmovation research streams (adapted from Brown \& Eisenhardt, 1995, p. 347)

\begin{tabular}{|c|c|c|c|}
\hline Concepts & rational plan & communication web & $\begin{array}{l}\text { disciplined problem } \\
\text { solwing }\end{array}$ \\
\hline key idea & $\begin{array}{l}\text { prodict advantages, } \\
\text { market attractiveness } \\
\text { and rational organisation } \\
\text { are conducive to success }\end{array}$ & $\begin{array}{l}\text { success wia internal and } \\
\text { external communication }\end{array}$ & $\begin{array}{l}\text { success via problem } \\
\text { solving }\end{array}$ \\
\hline theory & a-theoretical & $\begin{array}{l}\text { infolmation and resource } \\
\text { dependence }\end{array}$ & information processing \\
\hline methods & $\begin{array}{l}\text { Surveys, } \\
\text { bivariate analysis, } \\
\text { one information source } \\
\text { dependent and } \\
\text { independent variables }\end{array}$ & $\begin{array}{l}\text { deductive and indurive } \\
\text { reasoning } \\
\text { multiple sources } \\
\text { multivariate analysis }\end{array}$ & $\begin{array}{l}\text { multiple sources } \\
\text { case-based research } \\
\text { from inductive to } \\
\text { deductive }\end{array}$ \\
\hline $\begin{array}{l}\text { performance } \\
\text { (dependent variable) }\end{array}$ & $\begin{array}{l}\text { finalncial success in } \\
\text { terms of profits, sales, } \\
\text { and market share }\end{array}$ & $\begin{array}{l}\text { perceptual success by team } \\
\text { and management ratings }\end{array}$ & $\begin{array}{l}\text { operationall success } \\
\text { in terms of productivity } \\
\text { increase and time-to- } \\
\text { market }\end{array}$ \\
\hline Examplestudy & Cooper (1986) & Ancona \& Caldwell (1992) & $\begin{array}{l}\text { Nonake \& Takeuchi } \\
\text { (1986) }\end{array}$ \\
\hline
\end{tabular}

Studies belonging to the rational plan (Cooper, 1986; Maidique \& Zirger, 1984; Rothwell, 1972) analyse the characteristics of successfully innovating firms and compare new product success and faillure. The communication web research stream is in contrast with success factor studies for its linkages to information processing-based theories. The research stream of disciplined problem solving is more concerned with the organisation of teams and the role of team leadership.

\section{Major contributions and critiquen}

Rational plan research is a domain characterised by its empirical nature, variety of methodologies, focus on financial success measures and lack of integration of earlier findings. There exist studies that rely on qualitative data gathering techniques Nonaka \& Takeuchi, 1986), comparative case studies analysis to develop theory (Bourgeois \& Eisenhard, 1988), or large scale surveys (Cooper \& Kleinschmidt, 1995; Calantone \& Di Benedetto, 1988). "The field is dominated by empirical studies and is primarily based on assessing the correlation between the dependent variable success and the independent variables. What is typical of KSF sindies? The empirical research is bighly exploratory in nature and lacks synthesis (Montoyam Weiss \& Calantone, 1994). Due to variation in concepts, variable definitions, research contexts and operationalisations, there is a pluriform collection of studies. Despite these critical notes, these studies have made the following major contributions. Montoya-Weiss \& Calantone, 1995).

- The identification of a core set of key factors that contributes to innovation success. There is remarkable consistency of some of the results, despite the high variance in data sets, methodologies and operationalisations. This is due to numerous differences in sample size, 
the scope of the study (product, project, programme or firm level), the level of data collection, the performance definition, and the sector focus of the study. This makes generalisation and integration of conclusions difficult.

- The studies concentrate on identifying rather than explaining success factors and are primarily concerned with applied research. But this helped managers to better understand the management of innovation.

- The retrospective and replication character of studies has strengthened the external validity, but many studies incorporate methodological threats on the internal validity due to non-randomisation of project cases and a lack of explicit selection criteria.

\section{Valuable research directions}

There is a blank spot on the empirical research map of studies incorporating both the strategy and organisation factors. There seems a clear need for a broad assessment and replication of the core set of success factors. A great deal of success factors has been studied at the project or R\&D programme level or analysed from one functional angle. However, success at the company level is different. Success/failure studies have used numerous metrics to assess the product success or project success. But innovation performance at the firm level involves more and complex factors. At this point the research domain faces intriguing challenges. Cooper \& Kleinsclmidt $(1996,1995)$ argue for a more macro view of innovation by conducting firm level innovation research, because of:

1. the unit of analysis: success at the firm level is different from project level success;

2. the mis-specification of factors: company practices can prevail that are not observed nor measured at the project level but are important to success, and

3. the limits inherent to the research design: when analysing project success and failure, firm characteristics do not differentiate when both project success and failure are subject of analysis. Firm characteristics will be common to both projects.

An innovation strategy that is not explicitly stated might, for example, play a role as an underlying factor explaining success. This notion of underlying factors may be of little

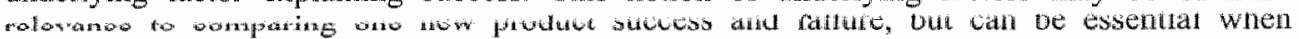
regarding a whole range of innovation projects, e.g. in successive time periods. More firm level features can be of vital importance to innovation performance. In particular strategy, organisation and human resource management are structural characteristics that can influence the performance in the longer run. Similarly, Brown \& Eisenhardt (1995) encourage researcl into "the primary rellations of innovation". In other words, analyse the causal relations between performance, organisation and strategy. They support more firm level research to account for the role of company-wide competencies that operate at the project level of innovation. These are not identified nor measured when the project is the unit of analysis. Furthermore, they encourage research that develops insight into the managerial role in development processes. Managentent concepts such as strategic vision and management control are still vague in this research field. According to Rothwell (1994) more insight is needed into the qualities and competencies that control and steer innovation processes.

At the same time, numerous studies have reported the effects of strategic factors upon innovation performance. Especially product advantage, technological synergy and marketing synergy are among the frequently mentioned factors that are tested and found to be critical (Montoya-Weiss \& Calantone, 1994). Yet when focusing on the question of "why strategy is relevant" the innovation research field misses solid findings. Therefore more research can bridge the gap between the innovation literature and the competitive strategy literature. This 
could result in a more profound role for strategy in new product development. This is in line with Mintzberg (1994), who remarked the recent theoretical debates in the field of strategy and the remarkable rise of 'strategic thinking in competencies and resources' and fall of 'strategy as planning and positioning'. Conducting more strategy-oriented research implies something different than merely testing another list of strategic elements. It involves both the incorporation of the theoretical and empirical findings in the strategy field and the understanding of new developments regarding resource-based and competence-based approaches to strategy (Teece et al., 1997; Barney, 1991). Or as Montoya-Weiss \& Calantone argue (1994, p. 413): "...continued replication of the dominant strategy factors will not answer any new substantial questions, nor will it contribute to progress in this field of research unless importan modenator variables, study characteristics or methodological iswes are being addressed...'.

The key success factors represent one phase in the knowledge development of the innovation management discipline. The challenge is to link this to process-related information on the management of new product and process development. In the management practice, the average manager knows seven out of ten of the key success factors. But what is actually lacking is insight into the relations between these factors. We conclude that key success factors are an important field, which we will continue to develop. The ICT study, as part of the MERIT innovation programme, aims to contribute to this area. The MERIT tradition also aims to link more process information and context information to the KSF field, similar to Montoya-Weiss \& Calantone and Brown \& Eisenhardt. With a challenging ICT research focus and a subsequent challenging research methodology (chapter 5), combining survey and case data, we try to appeal to some of these calls for new contributions. The study tries to explore both the strategy and organisation aspect to innovation performance and aims to contribute to new theoretical and practical insights. 
Table 2.3: Overview of selected studies of innowation key success factors.

\begin{tabular}{|c|c|c|}
\hline Sources & Listed key success factors & Research context \\
\hline $\begin{array}{l}\text { Madlique \& Zirger } \\
(1985)\end{array}$ & $\begin{array}{l}\text { - Product advantage, market attractiveness and } \\
\text { organisalion }\end{array}$ & $\begin{array}{l}70 \text { success-failure } \\
\text { product pairs in } 21 \\
\text { case studies at the } \\
\text { company level: a } \\
\text { longitudinal study in } \\
\text { the US electronics } \\
\text { industry }\end{array}$ \\
\hline $\begin{array}{l}\text { Cooper \& } \\
\text { Kleinschmidt (1987) }\end{array}$ & $\begin{array}{l}\text { - Product advantage } \\
\text { - Trganisation of the internal development process } \\
\text { - Top management commitment to the project } \\
\text { - Efficiency and planning execution R\&D process } \\
\text { - Strong internal communication between groups } \\
\text { - Fil between production, research, sales and marketing } \\
\text { requirements of the new product and the available } \\
\text { resotirces and skills (synergy) } \\
\text { Market conditions: } \\
\text { - markets characterisect by growth and relative weak } \\
\text { - markets characterised by a high degree of change } \\
\text { in customer needs for a praduct category }\end{array}$ & $\begin{array}{l}203 \text { products, of which } \\
123 \text { were a success } \\
\text { and } 80 \text { were fallures in } \\
125 \text { manufacturing } \\
\text { companies }\end{array}$ \\
\hline $\begin{array}{l}\text { Shrivastava \& } \\
\text { Souder (1987): } \\
\text { Griffin \& Hallser } \\
\text { (1996): Johne \& } \\
\text { Snelson (1988): } \\
\text { Song \& Parry (1996, } \\
\text { 1999) }\end{array}$ & $\begin{array}{l}\text { The firm s new product development process and the } \\
\text { specific activities within this process, } \\
\text { The new product strategy as part of the business } \\
\text { strategy, } \\
\text { The way projects are organised, } \\
\text { - The firm sinternal culture and climate for innowation, } \\
\text { Management commitment to new product development. }\end{array}$ & $\begin{array}{l}\text { Various performance } \\
\text { measures, various } \\
\text { industries }\end{array}$ \\
\hline $\begin{array}{l}\text { Cooper \& } \\
\text { Keinschmidt } \\
\text { (NewProd studies } \\
1979 ; 1993 ; 1995)\end{array}$ & $\begin{array}{l}\text { Strategic factors } \\
\text { Product adwantage, technological synergy, marketing } \\
\text { synergy, resource capacity, product strategy } \\
\text { Development process factors } \\
\text { Protacol, quality of technical and marketing competencies, } \\
\text { quality of pre development activities, top management } \\
\text { support \& skill, inancial and business analysis, time-to- } \\
\text { market, cosis } \\
\text { Organisational factors } \\
\text { Intermall and external relations, teamwork, communication } \\
\text { Market enviroment factors } \\
\text { Market potential, environment, market competitiveness }\end{array}$ & $\begin{array}{l}\text { Financial performance } \\
\text { and management } \\
\text { ratings }\end{array}$ \\
\hline $\begin{array}{l}\text { Stacey(1996)i Clark } \\
\text { \& Wheelwright } \\
\text { (1993): Gobali \& } \\
\text { Brown (1988) }\end{array}$ & $\begin{array}{l}\text { Multidisciplinary project teams and heavyweight project } \\
\text { leaders }\end{array}$ & Multiple sectors \\
\hline $\begin{array}{l}\text { Cooper } \& \\
\text { Kleinschmidt (1993) }\end{array}$ & $\begin{array}{l}\text { Producl adwantage and pre-development work, } \\
\text { Market attractiveness not found to be a key success } \\
\text { factor }\end{array}$ & Chemical industry \\
\hline Barczak ( 1995$)$ & $\begin{array}{l}\text { Fit between strategy, corporate goals and capabilities. } \\
\text { instead of new product development timing strategy } \\
\text { Cross fumctional teams } \\
\text { - Froduct champions } \\
\text { - Idea generalion and idea screening }\end{array}$ & $\begin{array}{l}\text { High or low } \\
\text { performance of } 128 \\
\text { companies in } \\
\text { telecommunications } \\
\text { industry classified as: } \\
\text { first to market. fast } \\
\text { follower, delayed } \\
\text { entrant }\end{array}$ \\
\hline Gersick (1994) & $\begin{array}{l}\text { Milestones are an effective tool for advancement in } \\
\text { conditions of rapid technological change }\end{array}$ & \\
\hline
\end{tabular}




\begin{tabular}{|c|c|c|}
\hline Saurces & Listed key success factors & Research context \\
\hline $\begin{array}{l}\text { Cooper } 8 \\
\text { Kleinschmid }(1995 \\
1995)\end{array}$ & $\begin{array}{l}\text { Strong project management. } \\
\text { Qually of project management included an emphasis } \\
\text { on up-front homework, a sharply defined early prodisct } \\
\text { definition before development, tough milestones and } \\
\text { flexibility to combine stages and decision points withen } \\
\text { needed. } \\
\text { - The role of pre-development work includes a detailed } \\
\text { market and technical assessment }\end{array}$ & $\begin{array}{l}\text { Success at company } \\
\text { level }\end{array}$ \\
\hline $\begin{array}{l}\text { Ancona \& Caldwell } \\
(1992) ; \text { Gersick } \\
(1988)\end{array}$ & $\begin{array}{l}\text { External communication: ambassadorial and task co- } \\
\text { ordination } \\
\text { Internal communication: concrete project plans with } \\
\text { deadlines and milestones are associated whtth } \\
\text { motivation of team members }\end{array}$ & $\begin{array}{l}45 \text { product } \\
\text { development teams, } 5 \\
\text { high tech company? } \\
\text { case studies }\end{array}$ \\
\hline Damanpour (1991) & $\begin{array}{l}\text { List of organisational dimensions that moderate innovation } \\
\text { performance: } \\
\text { Specialisation: a greater variety of specialists provides } \\
\text { a larger knowledge base and increases cross- } \\
\text { fertilisation of ideas. } \\
\text { Professionalism: increases boundary spanning activity, } \\
\text { and commitment to adjust the status quo. } \\
\text { Formalisation: can hamper the flexibility required to } \\
\text { facilitate innovation. The lower the degree of } \\
\text { formalisation, the more open and receptive an } \\
\text { organisation is to change. } \\
\text { Decentralisation: points to the conoentration of authority } \\
\text { and control to the lowest possible operational level } \\
\text { encouraging awareness, commitment and involvement } \\
\text { to innovation. } \\
\text { Slack resources: allow firms to discover and explore } \\
\text { new opportunities and detect emerging market needs. } \\
\text { Communication: both intensive internal and external } \\
\text { cornmuinication facilitates the scanning of idleas and the } \\
\text { rapid dispersion of information. }\end{array}$ & $\begin{array}{l}\text { Meta-analysis of } \\
\text { innovation studies } \\
\text { Orientated at effective } \\
\text { use of inforimation and } \\
\text { accelleration of } \\
\text { process steps. }\end{array}$ \\
\hline $\begin{array}{l}\text { Montoya-Weiss \& } \\
\text { Calantone (1994) }\end{array}$ & $\begin{array}{l}\text { The nature of problem solving and the interfiaces } \\
\text { between orgarisational members. } \\
\text { Use of cross-functional teams, } \\
\text { - Cross-functional interfaces between departments. } \\
\text { - Parallel rather than sequential development } \\
\text { - Shared responsibilities }\end{array}$ & $\begin{array}{l}\text { Inmovation } \\
\text { performance and } \\
\text { shorten the tirne-to- } \\
\text { maket }\end{array}$ \\
\hline $\begin{array}{l}\text { Brown \& Eisemhard } \\
\text { (1995) }\end{array}$ & $\begin{array}{l}\text { research stream: rational plan: } \\
\text { Project planning, cross functional teams and management } \\
\text { commitment }\end{array}$ & $\begin{array}{l}\text { Meta-analysis. } \\
\text { Finencial success in } \\
\text { lerms of profit, seles } \\
\text { and market share }\end{array}$ \\
\hline
\end{tabular}




\begin{tabular}{|c|c|c|}
\hline Sources & Listod key success factors & Research context \\
\hline $\begin{array}{l}\text { Brown \& Eisenhardt } \\
(1995)\end{array}$ & $\begin{array}{l}\text { research stream: communicafion network } \\
\text { Internal and external communication by project teams in } \\
\text { product development }\end{array}$ & $\begin{array}{l}\text { Meta anialysis. } \\
\text { Perceptual success by } \\
\text { leam and } \\
\text { management ratings }\end{array}$ \\
\hline $\begin{array}{l}\text { Brown \& Eisenhard } \\
\text { (1995) }\end{array}$ & $\begin{array}{l}\text { research stream: disciplined problem solwing } \\
\text { Problem-solving capacity of the project team, the } \\
\text { heawyweight project leader and the importance of top } \\
\text { management. commitment }\end{array}$ & $\begin{array}{l}\text { Meta-analysis. } \\
\text { Operational success in } \\
\text { tems of productivity } \\
\text { increase and time to- } \\
\text { market }\end{array}$ \\
\hline Voss (1988) & $\begin{array}{l}\text { - Actwe communication with industry of application } \\
\text { - Eficient development work } \\
\text { - Project champion during innovation } \\
\text { - Project champion during commercialisation } \\
\text { Resources committed (\%) } \\
\text { Quality of demonstrable capability } \\
\text { Quality of reference sites } \\
\text { Risk-taking clmate }\end{array}$ & $\begin{array}{l}16 \text { product } \\
\text { development projects } \\
\text { in software sector }\end{array}$ \\
\hline $\begin{array}{l}\text { Elsenhard } 8 \text { Tabrizi } \\
\text { (1995) }\end{array}$ & $\begin{array}{l}\text { Product teams acting in an experiential and } \\
\text { improvisational design stage } \\
\text { Multiple design iterations, } \\
\text { Forceful project leadership, and } \\
\text { Multifunctional teams accelerate the innovation } \\
\text { process. } \\
\text { In contirast with expectations, the following factors showed } \\
\text { to be ineffective in accelerating the development: } \\
\text { - The use of computer-aided design (CAD) systems, } \\
\text { - Schedule altainment planning and rewarding } \\
\text { - Pupplier involvement and } \\
\text { - Parallel development stages } \\
\text { - Pre-development planning }\end{array}$ & $\begin{array}{l}72 \text { development } \\
\text { projects in } 36 \\
\text { computer firms, speed } \\
\text { of innovation process } \\
\text { Used as success } \\
\text { variable }\end{array}$ \\
\hline
\end{tabular}




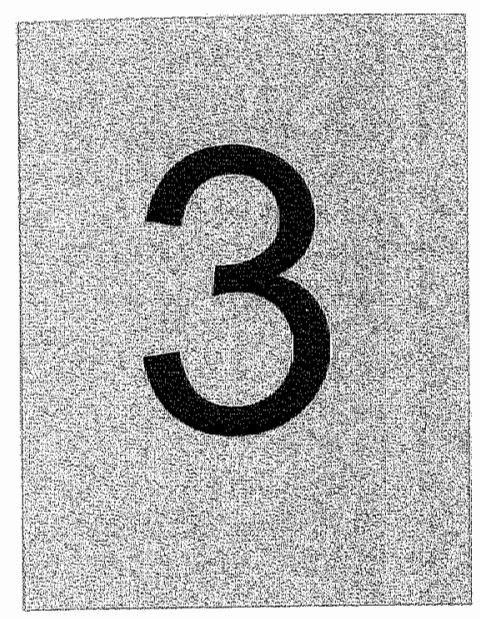

The Nature of Strategy 


\subsection{Introduction}

Innovation research used to be predominantly concerned with the key success factors in the design and development of novel products (e.g. Dwyer, 1990). An important key success factor is strategy, in particular new product strategy. However, the KSF literature does not go into detail about the content of strategy. By focusing on the question "why strategy is relevant" the innovation research field lacks solid findings. Empirical research (e.g. Barczak, 1995; Cooper \& Kleinschmidt, 1995; Roussel et al., 1991; Rothwell, 1992) on new product development strategies (NPD) has shown that a company should focus on the best possible fit between the chosen NPD strategy, the corporate goals and the capabilities. Others argue that each company's situation is determined by its history (e.g. Teece's et al. "path dependency') and the current competitive strategy. This part of the empirical literature seems to be subject to debate.

This chapter goes into more in detail of the subject of strategy to demonstrate the possibility of synthesis between the strategy and innovation research field. The first reason is a practical one: to contribute to the progress in the KSF field (see table 3.1). The second reason is more theoretical: to contribute to knowledge development in the field of innovation management. This transition to knowledge development, which focuses on the process of innovation rather than on the separate factors, is a challenging but necessary next step. Conducting more strategy-oriented innovation research implies something different than merely testing a list of strategic elements. It involves both the incorporation of theoretical and empirical findings into the strategy field and the grasp of new approaches to strategy. This includes the recent theoretical debates and the remarkable rise of "strategic thinking in competencies and resources" and the fall of "strategy as planning and positioning' (Mintzberg, 1994). It is relevant to comparing one new product success and fallure, and can be essential when regarding a whole range of innowation projects, e.g. in successive time periods.

Table 3.1: Perspectives on strategy of innovation

\begin{tabular}{|c|c|c|}
\hline Innovation Management & Research & \multirow{2}{*}{$\begin{array}{l}\text { Descriptive and empirical theory } \\
\text { on strategic management }\end{array}$} \\
\hline Empirical KSF research & Monmative viewpoint & \\
\hline 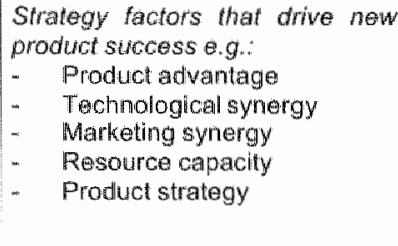 & $\begin{array}{l}\text { Fit between new product } \\
\text { dewelopment strategy, the } \\
\text { corporate goais and the } \\
\text { capabilities }\end{array}$ & $\begin{array}{l}\text { The fall of 'strategy as } \\
\text { planning and positioning' } \\
\text { New perspectives: the rise of } \\
\text { strategic thinking in } \\
\text { competencies and resolurces } \\
\text { (e.g. dynamic capabilities } \\
\text { concept: process, paths, } \\
\text { positions) }\end{array}$ \\
\hline
\end{tabular}

But why do we have to look at the role of strategy for innovation management in the ICT sector? We assume that innovation is the source of business value, growth and competitive edge for ICT companies. The ICT sector is a young, dynamic high-tech sector, which drives on developing new business. We are interested in observing how fims differ in their strategy. The contrast between empirical insights into strategy of ICT firms and recent descriptive theory will contribute to our understanding of the future directions of the ICT sector. According to Hamel \& Prahalad (1994) and other scholars (e.g. Den Herlog \& Huizenga, 
2000; Teece et al., 1997; Quinn, 1997; Sanchez \& Heene, 1997) strategy deals with answering both the two following questions:

- 'Are we doing the right things?', resulting in an answer that must be provided for the firm to continue to exist, and

- 'Are we doing the right things right?", resulting in an answer, if positive, that adds to the firm's differentiation and competitive edge.

There is a strong element of corporate strategy in this, with different firms taking different decisions - and with perspectives changing over time as experience on the potential clients for new services and products accumulates. A large number of the firms in the $1 \mathrm{CT}$ sector might have problems in developing such an innovation strategy.

Furthermore, in many sectors, and especially the ICT sector, competition is shifting away from producing towards serving customers. Businesses increasingly recognise that the nature of their offering involves a mixture of tangible and intangible properties. These service dimensions enter into all products and businesses, which raises new challenges for strategy. The competitive enviromment becomes more complex due to the rise of the 'service intensity' of all markets. Consequently, ICT firms need to consider this development in their strategy. In the contemporary strategy research literature, new perspectives appear that describe the role of such "complementary assets", e.g. the dynamic capabilities of Teece et al. (1994).

This might raise numerous questions. What is a successfiul new business strategy? What about the strategic priority setting? Do company objectives regarding sales, profits and market shares conflict with innovation? What about timing as a strategy versus product differentiation? Should companies develop competencies? In this chapter, we will try to address these issues on the basis of the strategic management literature, in order to contribute to the knowledge development of innovation. The valuable strategy concepts and their relation to innovation are illustrative and will be taken up in the empirical part (chapters 7,8 and 9). With this perspective we draw directly on a considerable volume of work by strategy scholars.

\subsection{Strategy Safari: an Overview of Schools of Thought}

In this section we briefly discuss the main characteristics, the contributions and the critiques on the strategy schools. Mintzberg (1994) argued that a first glance of the literature shows that the strategy field is characterised by fragmented uncomected theoretical perspectives. Basically, two opposite perspectives have emerged: the behavioural and organisational perspective on the one hand, and the economic perspective on the other. The former research stream concentrates on the internal components of the firm while the latter analyses the firms with an external focus on competition. This has led to a theoretical polarisation and fragmentation of strategic concepts. The research field has been dominated by view of strategy formation that is referred to by Whittington (1993) as the "classical approach", by Nonaka \& Takeuchi (1995) as the "structural approach", and by Chaffee (1985) as the "linear model of strategic management'. These early approaches are characterised by a formulation of strategy as a rational process, prescribed by techniques to identify current strategy, analyse the environments, the resources and revealing strategic alternatives (Pettigrew, 1985, p. 276). Sanchez and Heene (1997) argue that the traditional strategy lost much of its power to guide 
the management of organisations in today"s business, due to the dynamic competition in many industries.

\section{The design, planning and positioning school}

Mintzberg (1990) identifies nine different perspectives of strategic management (for a detalled description of all the characteristics of the schools we refer to the article). The most interesting perspectives include the design school, planning school, the positioning school and configuration school. The configuration school will be discussed in chapter 4 . Chandler (1962) has initiated the strategy structure debate, suggesting selective strategic configurations.

The design and planning perspectives provide an overview of the state of the field from the 1970 s until the late 1980s. Both the design school and planning school regarded strategy formation as a controlled, conscious process of thought. Characteristic of this strategy perspective is that responsibility rests with the chief executive officer, who was viexed as "the strategist'. Strategies should be explicit, thus requiring a simple model of strategy formulation. Implementation was seen as a sequential, separate task, executed after the formulation stage. Both perspectives built upon the work by Andrews (1971) and Ansoff (1965). This strategy thinking was popularised by SWOT analyses examining the strengths and weaknesses of the firm and the opportunities and threats from the environment.

The ideas and concepts of strategy formation as a conceptual and formal process were challenged and questioned. The planning tools were intuatively sound, but no further insights existed into how to assess strengths and opportunities. The research field was dissatisfied with the prescriptive attitude of the strategy schools (Collis \& Montgomery, 1995; Mintzberg, 1994). The main criticism was related to the relevance of the strategy design \& planning model, which was inappropriate or even counterproductive for organisations. In addition, the disconnection between formulation and execution implied that strategic thinking was performed in the first part only. Adaptation of a strategy and learning from previous strategic formation activities was neglected in both perspectives. Also, the idea of one single individual as a strategist was far from business reality. Overall, the assumptions from the design and planning school were likely to lead to an oversimplification of strategy, with its inherent risk of a mismatch with the market.

The contributions of the planning school next to the design school were the development of a highly formal planning and execution process. The informal design perspective was replaced by a formal explicit sequence of steps with the CEO as 'strategic architect' accompanied by strategic planners. Strategy implementation became a matter of developing objectives, budgets, programmes, and operating plans. Although resulting in valuable contributions in terms of techniques, the perspective was criticised. Planning did not encourage change but was essentially an inflexible process favourable to a stable environment. While decomposing and formalising process steps, the strategic planning lost synthesis. Strategy became a collection of separate components without an integrative element (Donaldson, 1995).

\section{The positioning school}

With the emergence of concepts of "competitive positioning" Porter $(1980,1985)$ gave new stimulus to the strategy field. Porter's work extended the structure-conduct-performance framework by analysing the position of the firm with respect to the competitive environment. In his view the firm is part of an environment that is dominated by five competitive forces: the customers, competitors, potential market entrants, suppliers, and substitute products. These forces influence the strategic position of the firm, which is defined in terms of product market 
combinations and the fit between strengths, weakness and market opportunities. Based on this competitive forces framework a firm can pursue three different generic strategies for achieving high performance:

1. Cost leadership strategy: a firm designs its intemal processes more effectively than its competitors, resulting in producing at lower costs.

2. Product differentiation strategy: a firm develops the ability to differentiate from its competitors by positioning its products and services differently on price, image, support, quality or design.

3. Focus strategy: a firm serves a niche market segment with a focused customer base. The focus strategy can be pursued on the basis of low costs or differentiation.

Essential in Porter's analysis is the idea of the firm as a bundle of activities to deliver products and services. This idea has been developed using the concept of the value chain. The value chain describes a sequence of strategically important value activities (the "primary process') and the secondary supportive processes. By means of defining the value chain a company can define its activities that add most value and which distinguish the firm from its rivals. Furthermore, the value chain provides understanding of the cost behaviour of activities and reveals the relation within the chain of activities, but also that between value chains of suppliers and customers.

The positioning school has also suffered from criticism. It is a strategy perspective biased by conventional well-established big firms in large industries. The role of entrepreneurship is hardly conceptualised (e.g. Stopford \& Baden Fuller, 1994). Although the perspective discusses the role of market entry and exit bartiers, the emphasis is positioning in current markets and less on creating future generic positions (e.g. Hamel \& Prahalad, 1994).

\section{Strategy and performance: external versus internal focws}

Over the past years criticism has been concerned with the applicability, universality and validity of strategic concepts. The strategic research theld was facing the challenge of understanding more deeply the complex nature of strategy, which required improvement of the practical relevance. Rumelt, Schendel and Teece $(1991,1994)$ argued that despite the criticism the theoretical strategy research streams have contributed to a deeper understanding of the elementary strategic questions:

1. How do firms behave?

2. Why are firms different?

3. To what extent should structures be decentralised?

4. What is the function of corporate headquarters in a multi-business firm?, and

5. What determines the success or fallure of a firm?

Especially the second question has recently led to a strong debate among strategy scholars. The industrial organisation paradigm focuses on industry effects to explain superior rents that firms can collect (Hansen \& Wernerfelt, 1989; Vasconcellos \& Hambrick, 1989; Rumelt, 1991; Schmalensee, 1985; Bain, 1959). A study on the variance of rates of retum on assets anong busimess units Schmalensee (1985) concluded that industry effects are an important variable explaining performance variance. This argues in favour of the focus on the industrylevel analysis. However, Rumelt (1991) performed a similar study with longitudinal data, which revealed that the dispersion of returns is explained by business unit effects more than by inclustry effects. He concludes that industry analysis neglects the fact that industries are too 
heterogeneous to support one general industrial organisation theory. Furthermore, empirical studies have revealed that differences in profitability within an industry are more important than differences between industries. This suggests that innovation success is driven by strategic and resource differences between firms rather than by the industrial characteristics. We will explore this topic in chapter 7.

These perspectives should be complemented by an approach taking into account the internal resources and competencies that matter. Sanchez and Heene (1997, p. 303) speak of "... a movement to make strategy theory more relevant to contemporary forms of competition by rethinking the content and process of strategic management theary and practice..." In a special issue of the Strategic Management Journal, Prahalad and Hamel (1994, p. 6) refer to: ?... a weed for a basic re-evaluation in order fo pave the way for new ideas ... [and] ... many of the assumptions that were embedded in traditional strategy models may be incomplete or outdated as we approach the new competitive milieu...'. What caused the theoretical debate on strategic models of competitive advantage? Much of the discussion concentrates on the rapid change of the external environment (e.g. Mahoney \& Pandian, 1992; Collis, 1995; D*Aveni, 1996). A change that has evolved slowly, almost indiscemibly, but had a tremendous impact on business and competition. Prahalad \& Hamel (1994, 1991) point to some major drivers for a revitalisation of approaches to strategic thinking and development, such as the need for 'competing for inchustry foresight' and 'strategic intent and expeditionary marketing".

\subsection{Resource-Based View of Strategy}

Contemporary strategy research has shifted to perspectives that emphasise the resources of the firm as a productive factor and competitive weapon. The internal firm resources are regarded as a key variable for competitive advantage (Teece et al., 1997; Amit \& Schoemaker, 1993). Basically, two opinions of resource-based perspectives can be distinguished:

- One perspectives underlines the idea that intemal resources are valuable and investigates why firms need to concentrate on resource accumulation. This view is rooted in the seminal work of Penrose (1959), which stressed the importance of resources for firm growth.

- The second perspective, which is complementary to the first, underlines the idea of resource exploration and exploitation, in particular with respect to innovation.

What are the essential arguments of this particular view? The resource-based perspective regards the firm as a bundle of durable, intangible assets. Firms are assumed to be heterogeneous and differ in their collection of physical and intangible resources. This resource endowment of the firm can account for a sustained competitive advantage by capturing entrepreneurial rents (Peterat, 1993; Barney, 1991; Dierckx \& Cool, 1989; Wemerfelt, 1984). Collis (1991) points out that these resources are the input for conducting functional activities and make a firm strategically different. The literature on the resource-based view (RBV) of the firm uses a variety of definitions for resources (see box 3.1). The RBV of the firm rejects the Darwinian selection assumption of the external enviromment that characterises the positioning perspective. A theoretical research stream that further elaborates on this principle is the population ecology (Hannah \& Freeman, 1977). In this perspective, strategy formation is a passive process. The environment is viewed as a set of strategy-dictating forces. The 
principle of selection and retention ensures that organisations find ecological niches and must ensure to adapt over time. If they don"t, they will disappear from the market.

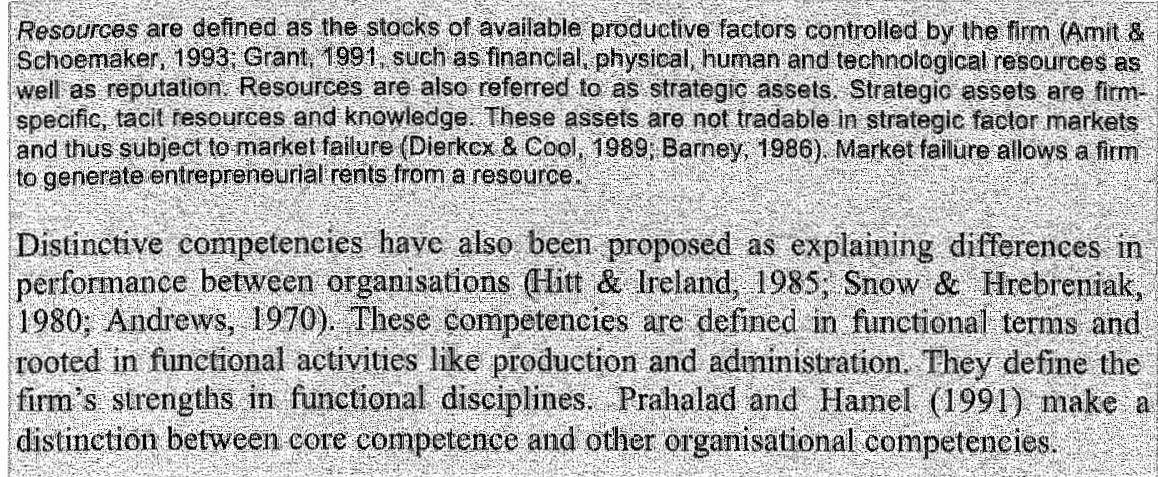

\section{Box 3.1: Resources: some definitions}

\section{The value of resources}

Teece et al. (1994) observe from a theoretical standpoint that resources derive their valtue from qualifying on three criteria. The first criterion refers to the 'stickiness' of resources in the short term. Stickiness is derived from:

a) the complexity of business development;

b) the difficulty in asset tradability;

c) the lack of superior information on the value of a resource.

The interaction between these criteria determines the value of a resource (Collis \& Montgomery, 1995). In order to be valuable in the long term, a resource has to pass a range of tests. Long-term value only holds for those resources that are hard to imitate. The difficulty of imitation may rest in geographical immobility, imperfect information or firm dependence. The accumulation over time also generates barriers to imitation. Resources that are collected over a longer period of time become path-dependent. Competitors have to invest in resources accumulation to acquire this valuable resource. R\&D investments, for example, are closely related to the idea of path dependency and inimitability (e.g. Iansiti \& Clark, 1994; Pisano \& Wheelwright 1995). The second criterion for the value of a resource is concened with the durability of the resources. A durable resource is a resource that does not become obsolete or is not substituted in the short term.

The third market test for resource value is the appropriability, or rent-eaming potential, of resources. It refers to the owner that actually receives the rents from a resource. For example, the control over human and technological resources depends on the relationships between the organisation and its employees, technology alliance partners and its customers. If this relationship is strongly embedded in the organisation, the management might be better able to appropriate the rent. The appropriability is strong if the resounce is difficult to replicate, and if there are barriers to imitation, such as a patent system.

A number of other concepts related to the walue of a resource include the stock and flow of resources. On the one hand, the stock of resources can account for rent earning and be conducive to competitive advantage or firm success. The efficient deployment of an existing 
stock of resources, e.g. a market share, a brand name, or the number of employees or the customer portfolio, can create such entrepreneurial rents. Dierckx and Cool (1989) refer in this respect to "asset mass efficiency". On the other hand, the accumulative flow of resources over time can be a deterninant of superior performance. Examples are marketing investments for higher brand recognition or a training programme. Dierckx and Cool (1989) speak of "time compression diseconomies', which are acquired by accumulating resources at an accelerated pace resulting in a higher firm performance.

\section{Key contributions of $R B V$ to strategy research}

The main contribution from the resource-based view is the ability to explain long-lived differences in firm performance that cannot be attributed to industry differences Peteraf, 1993). An overview of these concepts that have strengthened foundations of the RBV is presented in box 3.2. This is an interesting element for our sector-specific study because it suggests that frontrunners and pack members differ in their stock or How of resources. This. subjeet will be discussed in chapter 7 .

The resource based perspective has offered a competing view to the planning and positioning view of strategy by drawing attention to entrepreneurship. Preoccupation writh market positioning has been supplemented by internal phenomena such as resources, endowments, investment and management systems. These factors have not attracted much attention in the positioning literature. With the arrival of the RBV there is an explicit recognition for the importance of unique managerial resources and the resource investments.

The idea of resource superiority has prowoked new approaches to analysing diversification and vertical integration like mergers and acquisitions (Teece et al., 1994). The decision to enter a market or to develop a new product or service rests the availability and uniqueness of the resources. The resources argument has shed new light on the make-buy decision of the firm (Stopford \& Baden-Fuller, 1994). Firms invest in assets that ensure a competitive advantage. An interesting research question is whether firms should develop these assets intemally or (partially) source them from the market. This subject will be discussed in chapter 7. According to Cohen \& Levinthal (1990) such investment decisions can be based on the flexibility of the firm and its absorptive capacity to create and transfer resources faster than the market can imitate them. Related to this research the RBV has inspired empirical studies on the relationship between strategic groups and firm performance (Duysters \& Hagedoorn, 1995; Cool \& Schendel, 1988). Resource similarities and strategic capabilities are proposed in explaining the existence of strategic groups or patterns of network linkages. The symmetry of resource endowments between firms is one factor that could explain the structure of strategic linkages in a network within an industry sector.

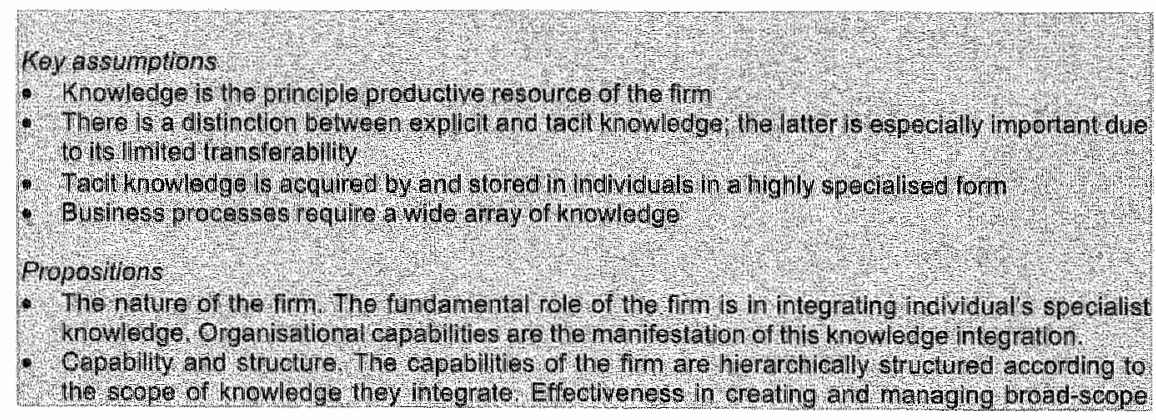




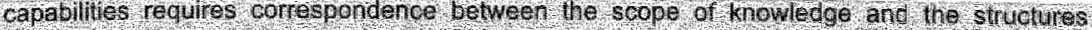
needed for inanaging surd inegration

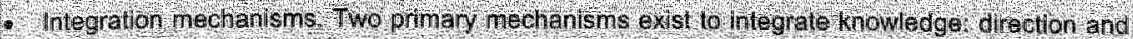

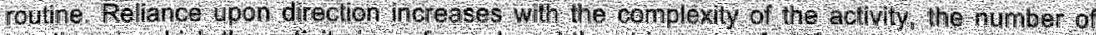

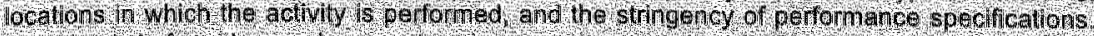

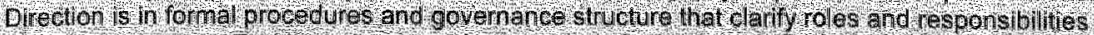

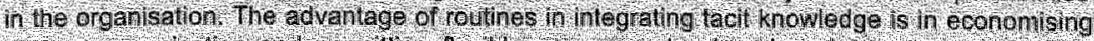

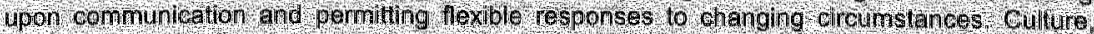

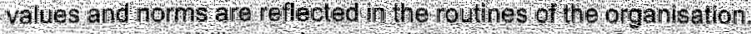

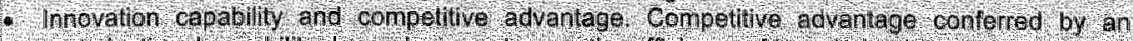

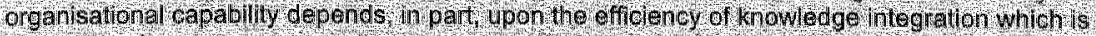
a functionot

A) the level or compen knowladoe among ongan's tional nembers

b) treguency and varabilty of he actily

c. structure which edonorises on genmumetion

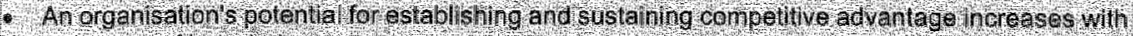
the scope of howledge.

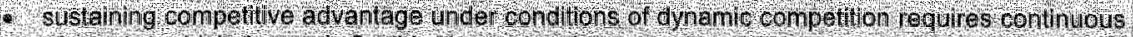

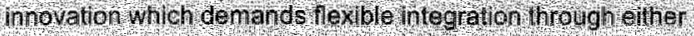

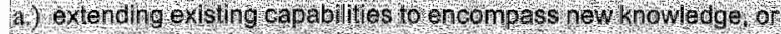

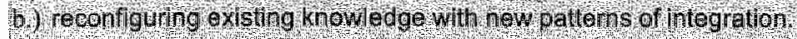

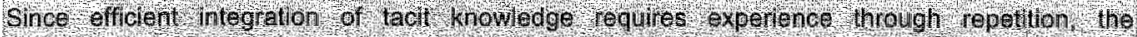

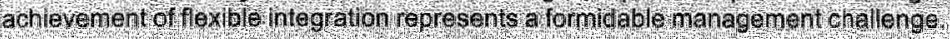

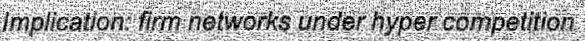

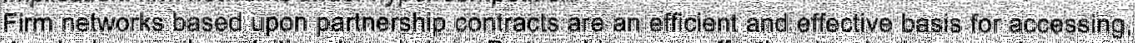

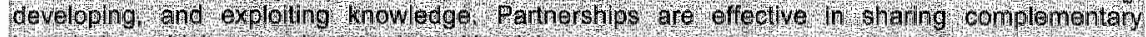

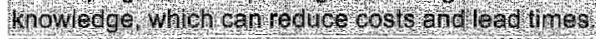

\section{Box 3.2: Summary of the resource-based view and dynamic capabilities view (Source: Grant, 1996)}

\section{Criticism on the resource-based perspective}

The main criticism of the resource-based perspective is its lack of attempt to explain the nature of the isolating mechanism that provide entrepreneurial rents and competitive advantage. Teece et al. (1994) argue that the dynamics of competition are ignored, the resource development and exploitation is undefined, and the selection environment is not taken into account. The theoretical question is whether there is a relationship between resources and competitive advantage. This is in contrast with the idea of Wright \& McMahan (1998), who argue that the stock of human resources is directly related to competitive advantage.

RBV investigates the relationship between asset specificity and firm specificity (Barney, 1986). Although the RBV addresses the essence of resource accumulation, the view has not elaborated on/detailed how the combination and co-ordination of resources occurs (Quélin, 1997 , p. 142). The dynamic capability perspective addresses the organisational mechanisms to integrate resource flows. Wernerfelt (1.984) concludes that the resource-based perspective invites the consideration of managerial strategies for developing new capabilities.

The resource-based perspective concentrates on organisational collections of resources and the relation with performance. Although the RBV implicitly acknowledges the role of exploring and exploiting resources (MoGrawth, 1997) it does not formally integrate these 
concepts in its perspective. Resources are accumulated without expressing how this process actually takes places. Resources have to be renewed, as they do not render valuable services eternally. Resources become obsolete and have to be replaced. The resource-based view fails to account for these dynamics and does not conceptualise how resources devellop. The collection of resources is a rather static concept when environmental changes are not addressed. Or as McGrawth (1997, p. 33) states: '... if exploration, search and the creation of new routines are processes left to the disappearance of slack and increasingly poor performance spark, the firm may be poorly equipped to then engage in the dissipative. discovery oriented learning which its new situation may require...?

Table 3.2 provides an overview of the major distinction between the preceding strategy frameworks and the emerging resource-based frameworks. The major contribution of the RBV perspective is its emphasis on the entrepreneurial role of the firm in the competitive environment and the focus on the internal strengths as a source of competitive advantage. The main contribution of the RBV is its ability to explain long-lived differences in firm performance that camnot be attributed to differences in indusiry conditions Peteraf, 1993). The dymamic capability framework concentrates on change and the creation of new market and technological opporinities. The perspective focuses on "...the how and why question about firms building competitive advantage in regimes of rapid change... (Peteraf, 1993). The strategic planning and positioning schools have not addressed these questions.

Table 3.2: A comparison of the strategy schools

\begin{tabular}{|c|c|c|}
\hline Strategy dimensions & Competitive positioning & $\begin{array}{l}\text { Dynamic capabilities and } \\
\text { Resource-based strategy }\end{array}$ \\
\hline Message & Strategy as fit & $\begin{array}{l}\text { Strategy as competence builcling } \\
\text { Strategy as strelch }\end{array}$ \\
\hline Competifive environment & Match with external requirements & $\begin{array}{l}\text { Ambitious strategic vision and } \\
\text { leverage of scarce resources }\end{array}$ \\
\hline Whew of the firm & $\begin{array}{l}\text { Portfolio of product market combination. } \\
\text { sau reflects portiolio of products and } \\
\text { markets and is the unit of analysis. Firm } \\
\text { is part of complew competitive system }\end{array}$ & $\begin{array}{l}\text { Fim as a porfolio of pesources and } \\
\text { dynamic capabilities. Firm acts as } \\
\text { entrepreneurial unit in a } \\
\text { manosuvable context }\end{array}$ \\
\hline Major business strategy & $\begin{array}{l}\text { Generic strategy: } \\
\text { Cost leadership } \\
\text { Differentiation } \\
\text { Focus }\end{array}$ & $\begin{array}{l}\text { Create mew markets and buld new } \\
\text { compelenches }\end{array}$ \\
\hline View of innowation & $\begin{array}{l}\text { Technology development as support } \\
\text { activity to primery process }\end{array}$ & $\begin{array}{l}\text { Innowation primary process and } \\
\text { source of sustainable competitive } \\
\text { advantage }\end{array}$ \\
\hline Strategy process & $\begin{array}{l}\text { Fomalised strategic analysis and } \\
\text { strategic planning \& control }\end{array}$ & Strategic alignment \\
\hline Content of strategy formulation & $\begin{array}{l}\text { Focus upon current core business } \\
\text { activities in the value chain }\end{array}$ & $\begin{array}{l}\text { Focus on three Ps: processes, } \\
\text { positions and paths }\end{array}$ \\
\hline Main contributors & Porter, Ansoff, Scherer, Andrews & $\begin{array}{l}\text { Penrose, Teece, Barney, Hamel \& } \\
\text { Prahalad }\end{array}$ \\
\hline
\end{tabular}




\subsection{The Dynamic Capabilities Perspective}

Sanchez \& Heene (1997, p. 306) point out that the resource-based view of the firm failed to build a coherent theoretical model and left the research field with conceptual gaps and fragmented theory between the behavioural and economic perspectives. A new breed of literature, inspired by management practice and strategy theory (e.g. Hamel \& Prahalad, Teece at al. and Barney), initiated the development of an integrative strategic management approach. The dynamic capability view has the following characteristics:

The internal perspective supplements the external analysis by emphasising current markets;

- It refers to competencies and future markets as the source of conmpetitive advantage (Teece et al., 1997; Hamel \& Prahalad, 1994); and

- A tirm becomes successful by developing an advantage based upon the internal competencies and knowledge (Leonard Barton, 1995; Nonaka \& Takenchi, 1994).

Sanchez \& Heene (1997, p. 307) formulated this as: ".. The centrat objective in competence theory and management practice is anderstanding the co-evolutionary dynamics of environmental and organisational change and their roles in shaping orgamisational competencies...'.

\section{Capability and competencies versus resource}

Many discussions in strategy related journals described the essential differences between capabilities, competencies and resources (see box 3.3). Grant (1991) argued that competencies refer to the ability of a firm to attain a durable strategic advantage through sustaining the coordinated deployment of resources and capabilities. There is a key distinction between resources and capabilities. Resources are inputs into a transformation process. When combined, resources become productive and generate value. A capability is the capacity for a bundle of resources to conduct an activity (Grant, 1991). They are 'repeatable patterns of action in the use of assets to produce goods and services" (Sanchez, Heene \& Thomas, 1996). Capabilities involve complex patterns of co-ordination and co-operation between individuals, teams and organisations. Such integration can take many forms, such as project team organisations, models of communication, intra-business relations and inter-business relations.

\section{Key contributions}

The interest for the internal strengths of the firm as a source of competitive advantage has gained a lot of attention in the literature. Whereas economic perspectives view the firm as rational agents pursuing maximising behaviour, compelence theory regards the firm as an open system of knowledge asset stocks and flows (Den Hertog \& Huizenga, 2000; Dierckx \& Cool, 1989). The latter explicitly relates internal organisational processes with the extemal interfaces of the firm. This research field explicitly attempts to integrate the fragnented strategic perspectives that prevailed until the $1980 \mathrm{~s}$. Recent publications have proposed the theory of competence-based competition (Sanchez \& Heene, 1997; Heene \& Sanchez, 1997; Sanchez, Heene \& Thomas, 1996; Hamel \& Heene, 1994; Hamel \& Prahalad, 1994). The propositions of this theory supplement and enrich the resource-based perspective. Lowendahl \& Haanes (1997) point to the strengths of the perspective:

- its emphasis on an open holistic and systemic view of the organisation,

- its focus on the dynamics of competence building and leveraging, and

- its extension of definitions of competencies and capabilities. 
Although the conceptual integration is a valuable objective for this research stream, there is the risk that the creative ideas of this paradigm are weakening. The explosion of theoretical and empirical studies has fragmented the competencies research field with respect to definitions (see box 3.3).

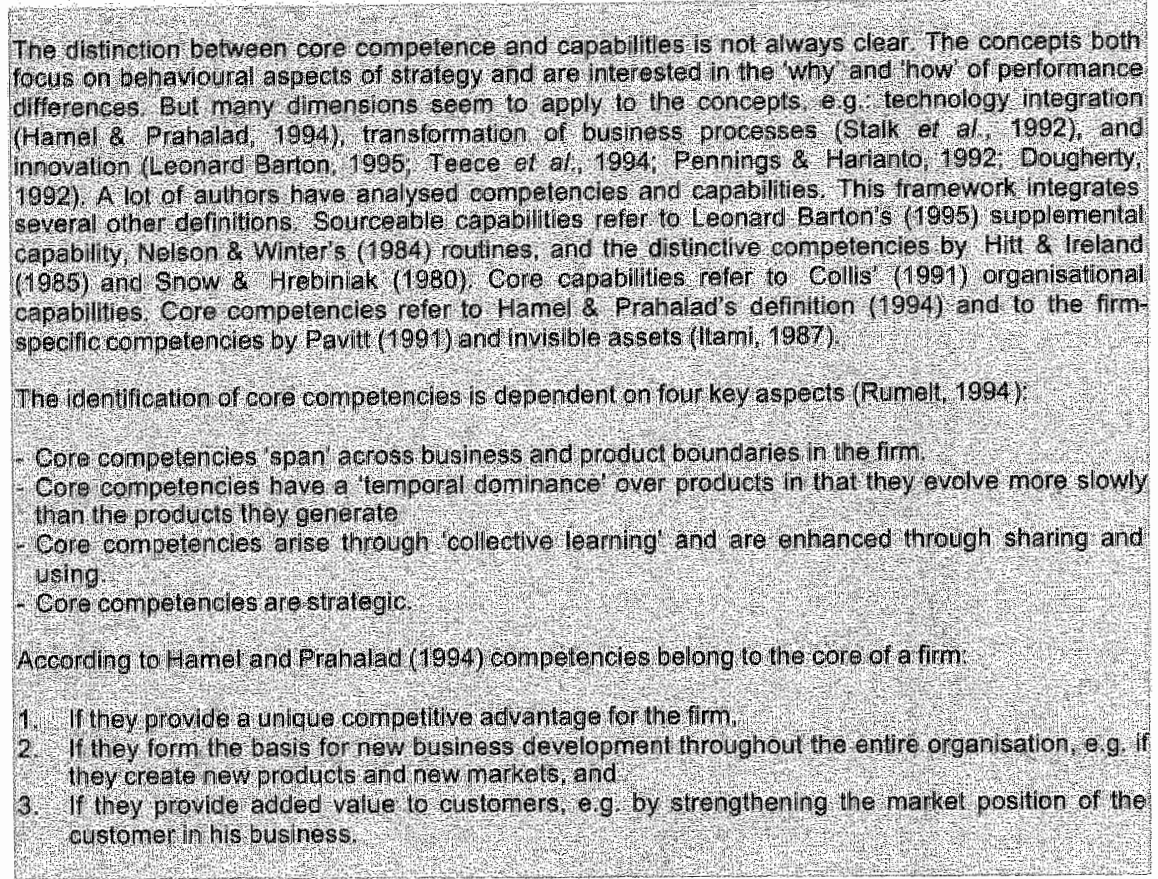

\section{Box 3.3: Definitions in the dynamic capability perspective}

\section{The concepts of paths, processes and positions}

The key elements of capabilities are their embeddedness in the organisational processes and the integration of technology and knowledge flows to develop new products, services and process. Teece et al. (1997) identifies three dimensions of dynamic capabilities: the three Ps of Processes, Positions, and Paths. Teece ef al. (1997, p. 518) state: '...The confent of these processes and the opportunities that capabilities afford for developing competinive advantage at any point in time, are shaped significantly by the assets (= positions) the firm possesses (both internal and market) and by the evolwionary poth it has adopted/inherited... '. The dynamic capabilities concentrate on change and the creation of new products, markets and technological opportunities. Dynamic capabilities focus on: "... [the] innovative successful companies [that] distinguish by timely responsiveness, rapid and flexible product innovation integrated with the management capability to co-ordinate and redeploy competencies effectively...' (Teece, Pisano \& Shuen, 1997, p. 515). If a firm wants to develop and exploit its capabilities it must have a system to manage the business activities and knowledge flows (Leonard Barton, 1995).

The path dependency of the firm is am important element as it restricts the resources available for new opportunities. Past strategic and organisational choices have determined the building and leveraging of the fim's durable competencies. This implies that the firm develops an 
organisational inertia, which limits the firm in picking up technological or market opportunities. Paths refer to the strategic alternatives available to the firm. In the learning organisation routines for imovation, knowledge development and customer services render the firm path-dependent. The resulting danger is that the firm ends up in a competition trap and is unable to catch up with new emerging technologies and dominant designs (Pennings, 1997).

\subsection{Summary}

This chapter has shed light on the strategy and the link to innovation from a normative and descriptive theoretical perspective. The schools of thought presented can help us in understanding the innovation issues in the ICT sector. By outlining the types of strategy theories we have observed that the design, planning and positioning schools debate the strategy-conduct and performance. The resource-based and dynamic capabilities views do so from a combined internal and external perspective. Especially the contributions from the dynamic capability perspective are promising to the innovation research field. The dynamic capability view concentrates on change and the creation of new products, markets and technological opportunities. Three dimensions of dynamic capabilities were considered to be of importance: the process, position and path dependency dimension. We will pay special attention to these interesting phenomena in the qualitative discussions with managers in the ICT companies, which will be addressed in the empirical part in chapters 7,8 and 9 .

We have suggested that the strategy view and innovation literature include related conceptual frameworks that can benefit from closer linkage. Research on resource accumulation can help innovation literature to overcome the empirical drawbacks common to key success factor studies. The dynamic capability framework might be suitable for questions on why firms are able to change in time and outperform their competitors. In the empirical part of this study we will investigate the usefulness of the concepts to the actual management practises of ICT companies. We will evaluate our research results and use the strategy concepts of the literature to put them into perspective. 



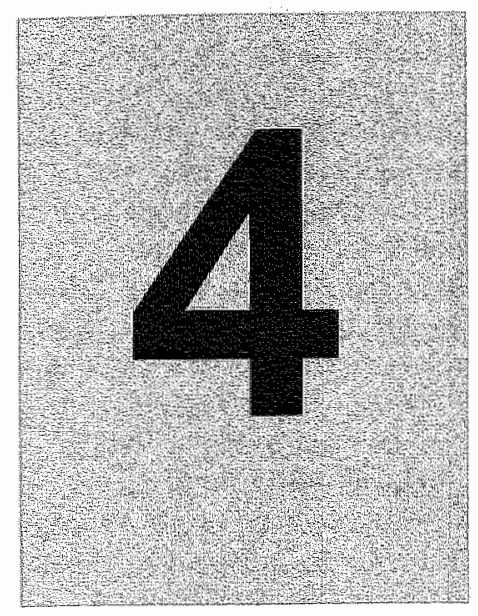

Organisation of Innovation 


\subsection{Introduction}

In the literature on key success factors there is a prominent place for organisational factors. The importance of the organisation is a key attribute of successful innovating firms. In fact, in the theoretical discussion on the organisation process behind innovation, scholars agree that the type of organisation is an indispensable building block. Also, most empirical studies on new product and process development draw attention to the organisation's impact on innovation success. There seems to be little controversy in the literature as to these viewpoints. On the other hand, the organisation literature is known for its rich variety in approaches, perspectives, and theories. Our goal for this part of the book is to look at this organisation literature insofar as it is linked to innovation. In order to structure the discussion we take up several wiewpoints (see table 4.1):

1. A nomative wiewpoint. Within this viewpoint we distinguish between:

- A process-oriented view regarding a range of normative process approaches that have developed over the years. This has resulted in richer and more detailed descriptions of the design of an innovation process.

- A structure-oriented view regarding a range of structure options. This implicates the existence of an organisational choice between various organisation structures. We will discuss the contingency and configuration approaches, including the literature debate on structure and strategy and ideal-type configurations of organic and mechanistic organisations.

2. A descriptive and empirical theoretical viewpoint. We will look at different organisation structures, e.g. the functional organisation, matrix organisation and team-based organisation. Ideas on functional specialisation and integration, as well as the relative advantages and disadvantages of each organisation type will be considered. These ideas relate to the importance of cross-functional relations (Clark \& Wheelwright, 1993) and communication interfaces (e.g. Montoya-Weiss \& Calantone, 1994) for innovation.

\section{Table 4.1: Perspectives on organisation of innovation}

\begin{tabular}{|c|c|c|}
\hline \multicolumn{2}{|l|}{ Normiative view } & \multirow[t]{2}{*}{ Descriptive and empirical theory } \\
\hline Design viowpoint & Design options & \\
\hline $\begin{array}{l}\text { - organisational history } \\
\text { - } \quad \text { generations of process models } \\
\text { - } \quad \text { best-pracilice' process models }\end{array}$ & $\begin{array}{l}\text { arganisiational choice } \\
\text { options } \\
\text { contingency and } \\
\text { configuration school } \\
\text { - ideal-type configurations }\end{array}$ & $\begin{array}{l}\text { organisation theory } \\
\text { organisation structures, e.g. } \\
\text { functional, matrix and team- } \\
\text { based organisation } \\
\text { empirical studies on cross- } \\
\text { functional relations and } \\
\text { communication interfaces }\end{array}$ \\
\hline
\end{tabular}

In later parts of the book we will return to these viewpoints to see if the ICT sector is different in the way it is organised for innovation, which will allow us to identify whether there is a gap beiween what is "theory" and 'practice' in the ICT sector.

New perspectives will be brought forward that view innovation mainly as a knowledge development activity. Part of the knowledge is explicit in an organisation, and part is tacit, embodied in the people working in the organisation. Such ideas place the organisation in another perspective. The last part of this chapter dwells on these ideas and their implications for the culture and the management of the human capital factor. The literature journey of this chapter is not intended to address all similarities and differences between different 
organisational theories. It merely shows the variety of views of organisation structure imovation. Additionally, it provides expectations of topics that are supposed to be of great importance to a knowledge-intensive business as the ICT sector.

\subsection{Organisational Process Models of Innovation}

The importance of the organisation of imnovation process has been given considerable attention in the literature (e.g. Carter \& Williams, 1957; Allen \& Cohen, 1969; Rothwell et al., 1974, Cooper, 1979; Henderson \& Clark, 1990; Takeuchi \& Nonaka, 1996). A great number of normative models of new product development processes have been proposed to address the 'how' and 'what' questions of innovation. Also, models have been adopted by companies, which generally had a strong positive impact on a firm's innovation efforts (Cooper, 1994). Typically, each nomative model in the literature represented an effort to describe the 'one best process model' for innovation. This attempt to describe innowation process models can be characterised as a search for the "one size fits all" model, irrespective of the type of product or organisation. From an organisation design perspective, three generations of process models are identified (Cooper, 1983; Rothwell, 1994; Sarren, 1984). Although the ICT sector is still a relatively young industry, innovation is a key to competition and survival. We expect the later generations of process models to be relevant to the complex. innovation processes taking place in ICT companies.

\section{First-generation models: linear and sequential process}

The early insights into innovation models were rooted in ideas of systems thinking in the 1950 s (Lewis, 1994). Systems analysis is a methodology for systematically organising large, complex processes and its constituent successive stages of activities. In the systems perspective, innovation was regarded as a co-ordinated set of procedures for making rational choices in a complex situation. The guiding principles underlying systems thinking are:

- rationality,

- linearity and predictability of activities,

- structuring of alternatives, and

- a scientific-based selection approach.

Systems thinking and early work by Carter \& Williams (1957) and Myers \& Marquis (1969) contributed to the first generation of linear models of innovation (Cooper, 1996, 1983). These models suggest that innovation proceeds along an orderly, predictable sequential way in an attempt to minimise the risks. The linear nodel assumes a step-by-step sequence of independent phases including the concept, feasibility, definition, design, and implementation. An activity was completed and the outcome was 'handed over' to the next department or activity. Booz, Allen \& Hamilton (1968) popularised this idea with an empirically based model (figure 4.2) that begins with an exploration of the marketplace for customer needs. The simplistic linear models were refined when the element of control was integrated. Control was explicitly introduced through the incorporation of a "review phase" upon completion of an activity. In the 'phased review process models' each activity was followed by a formal go-no go decision To give an idea of the broad spectrum of linear innovation process models, Sarren (1984) identified six distinct classes of innovation models (figure 4.1). 
Figure 4.1: Example of a departmental stage model (Sarren, 1984)

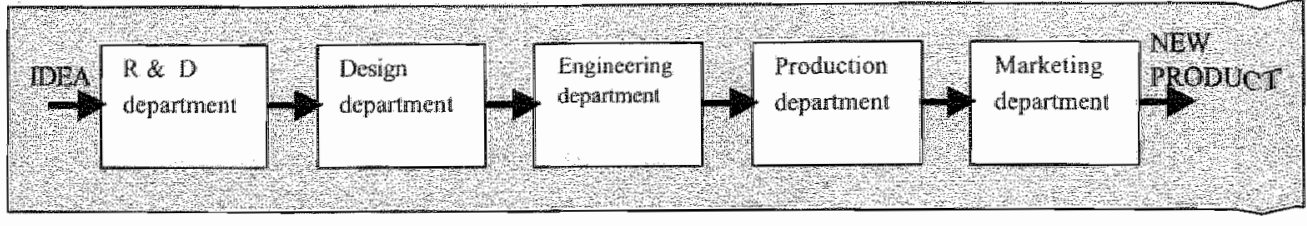

Figure 4.2: Example of an activity stage model (Based on original classification by BonzAllen \& Hamilton, in: Cooper, 1983)

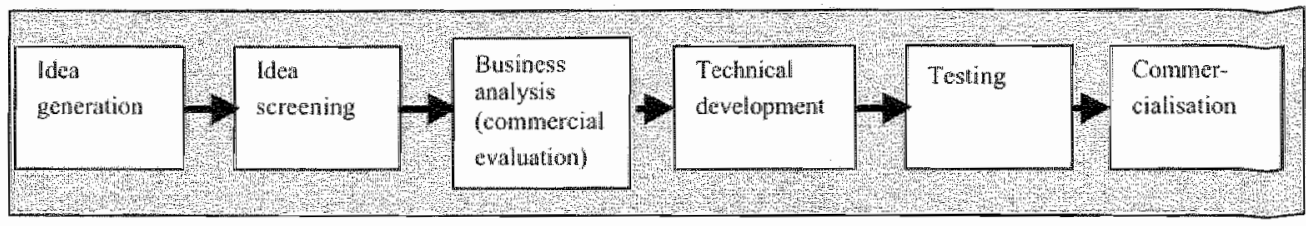

Figure 4.3: Example of a decision stage model (adlapted from: Cooper \& Moore, 1979)

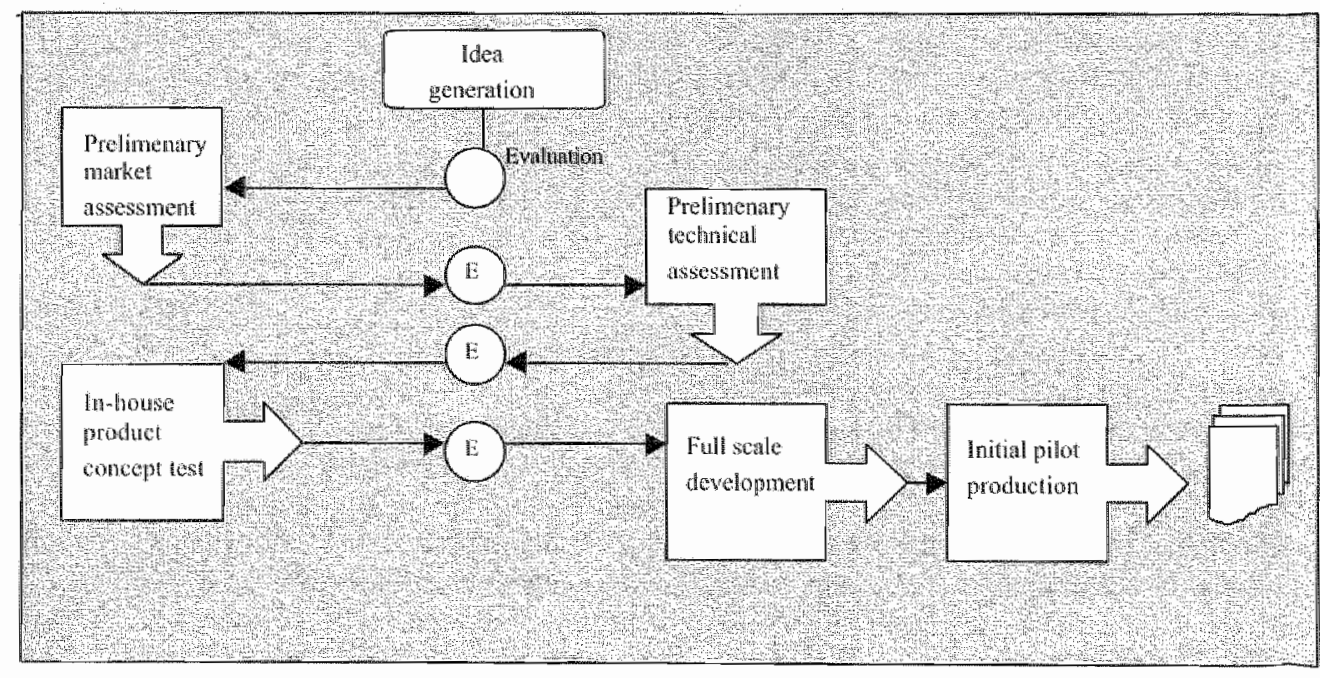


Figure 4.4: Example of a conversion model (adapted from: Twiss, 1980)

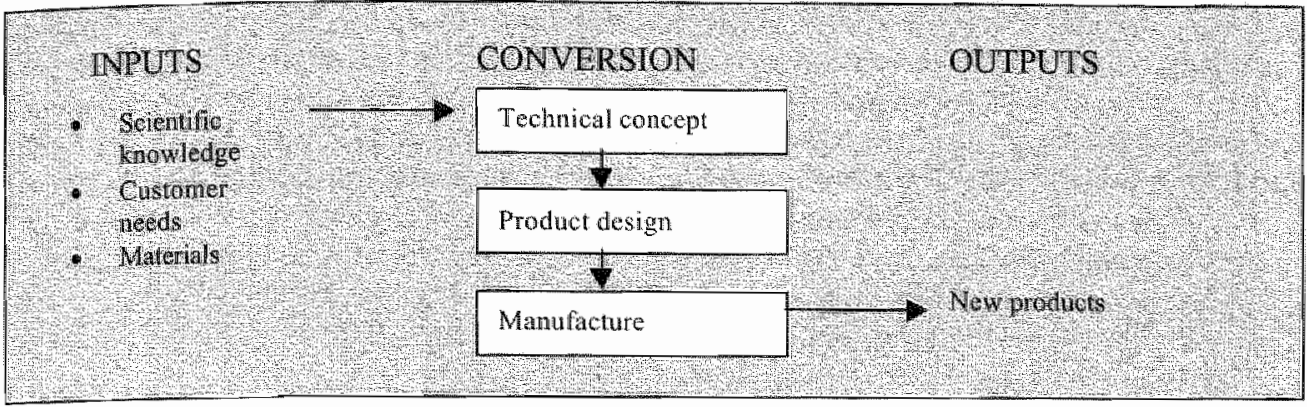

1. the departmental stage models, describing the sequence of functional departments that are active in an innovation process;

2. the activity stage models, showing the sequence of activities conducted in an innovation process;

3. the linked department/activity models, illustrating the sequence of fumctional departments and their activities involved in an imnovation process;

4. the decision stage models, addressing the key decision moments between successive stages in an imnovation process;

5. the conversion process models, addressing the input and output generated in an innovation process which is regarded as a conversion process; and

6. the response models, describing how the organisation reacts to stimuli and the firm"s response to change (e.g. a series of four stages: perception - search - evaluation response).

\section{Hedging innovation}

Each of the simplistic models (Rothwell, 1992) emphasises a distinct feature of the innovation process. The first three models concentrate primarily on hedging the functional departments or functional activities involved in innovation. The latter three models focus on hedging the sequence of decisions and transformations.

An advantage of representing a linear process is the potentially better control by hedging activities in the complex process of changes. Among the disadvantages are the implied rigidity of steps, and the unclearness about responsibilities between successive steps. Also characteristic of these models is the absence of feedback or feed-forward linkages, e.g. when corrective actions need to be taken at a later stage in the process. But the assumption about linearity and predictability does not require a repetition of repeat activities or the involvement of successive departments at an early stage. However, the basic problem of innovation is the paradox between freedom of choices and the knowledge available. This can be attributed to the fact that in the upstream initiation phase design choices need to be made without an adequate level of product knowledge. Whereas in the downstream phase the degree of freedom to manoeuvre is limited, project decisions are irreversible, but learning along the trajectory has resulted in in-depth knowledge. This is known as one of the central "problems" of investigation in the management of imnovation (Van der Ven, 1988, p. 111): .../the] prolferation of ideas, people, and iransactions over time is a pervasive but lible understood characteristic of the innovation process, and with it come complexity and interdependence. and the basic structural problem of managing part-whole relations...". 


\section{The need for streamlining}

New practical evidence (e.g. Imai, Nonaka \& Takeuchi, 1985; Womack, Ilones \& Roos, 1990;

Clark \& Fujimoto, 1991) has emerged showing other shortcomings and problems of managing innovation as a linear process. The main difficulty arose in managing the interface moments, especially the linkage between $\mathbb{R} \& D$ and marketing. At each interface, and at each decision point every idea, concept or product feature was specified in detail before being handed over. But this assumption did not seem to be valid in real life. Such a transition from one stage to another can be compared to a relay race. At critical moments, handing over the stick ("throughput") to the next stage failed. In the relay race a lot of time was wasted on such hand-over moments. The interfaces could thus become the bottleneck in each innovation stage with the ultimate consequence of delay. There appeared to be a need for streamlining activities to better organise the part-whole relation of activities.

\section{Second-generation models: towards parallel, overlapping phases}

The chain-linked integration model (Kline, 1990) is one of the popular models that emerged This model distinguishes from first-generation models as to:

- the initiator for innovation,

- the role and presence of R\&D and knowledge, and

- the definition of several feedback loops and information links.

The chain-linked model consists of five phases (see figure 4.5): market finding, invent andior analytic design, detailed design and test, redesign and produce, distribute and market. In contrast to linear models, this process is not initiated by research (technology push), but by market findings and invention. Research is a separate activity that is not directly coupled to the invention and innovation phases. Between these phases and the research layer exists a 'body of knowledge'. This body of knowledge accumulates over time through new research and experience. During the different phases in the process, the knowledge layer is used to conduct such activities as invention, design, development and production. If this layer of knowledge falls short in providing solutions to problems encountered in designing or testing, additional research is started.

\section{Figure 4.5: The chain-linked model (arrows refer to feedback loops) (Kline, 1985)}

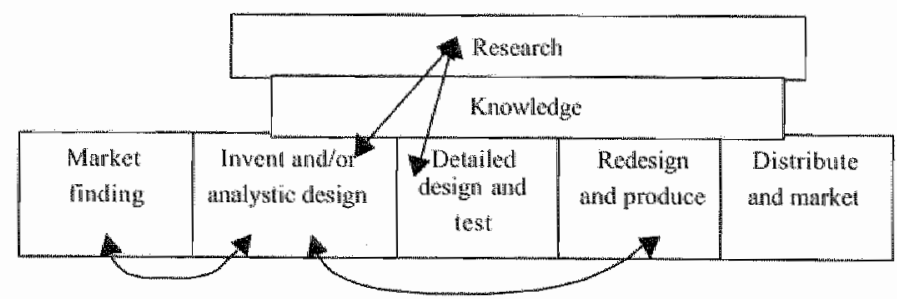

The chain-linked model represents a one-way flow from new market ideas to the distribution of a product. Essential for the working of a research and knowledge layer are the feedback loops at three levels:

1. the iterative feedback between each successive phase,

2. the feedback links between research, knowledge and design, and

3. the feedback links between upstream and downstream activities (e.g. design and produce). The chain-linked model still bears elements of a linear sequence of process phases. The next innovation models appeared in the early 1980s. These models perceived innovation as a "stage gate process' with a multidisciplinary team (Cooper, 1996). The team jointly completes each 
predetermined innovation stage and proceeds to the next gate. Particularly important is the presence of overlapping activities. Working in teams proved to be a remedy for the drawbacks of sequential development. Innovation was no longer the sole task of one functional department, followed by the next department. Innovation came to involve more functional disciplines at the same time. In this perspective, innovation much resembles a rugby approach, where team players jointly proceed forward to the end. The main differences between a relay race and rugby approach in tems of innovation is the presence of overlapping development stages, the early co-operation of various functional disciplines even at the predevelopment stage. Table 4.2 summarises and contrasts the generation models.

\section{Table 4.2: Differences between innovation process models}

\begin{tabular}{|c|c|c|}
\hline First-generation madels & Second-generation models & $\begin{array}{l}\text { Third-generation } \\
\text { Models }\end{array}$ \\
\hline $\begin{array}{l}\text { Linear sequence of stages: } \\
\text { activilies, departments, } \\
\text { decisions } \\
\text { (phased review model") }\end{array}$ & $\begin{array}{l}\text { Process includes feedback loops } \\
\text { (chain-linked model') or } \\
\text { overlapping phases 'stage gate } \\
\text { process') }\end{array}$ & $\begin{array}{l}\text { Process includes overlapping phases, } \\
\text { most departments invalved from beginning } \\
\text { until end }\end{array}$ \\
\hline Innovation initiated by $\mathrm{R} \& \mathrm{D}$ & $\begin{array}{l}\text { innowation initiated by market } \\
\text { findings }\end{array}$ & $\begin{array}{l}\text { Emphasis on multidisciplinary input at idere } \\
\text { generation stage }\end{array}$ \\
\hline Technology push & Market pull and technology push & $\begin{array}{l}\text { Market pull and technology push and early } \\
\text { involvement of llead users and suppliers }\end{array}$ \\
\hline No feedback fleed-forward & Feedback and feed-forwand & $\begin{array}{l}\text { Especially feedback and feed-forward in } \\
\text { pre-development stage }\end{array}$ \\
\hline Sequential activities & $\begin{array}{l}\text { Parallel activities (similar to } \\
\text { "concurrent engineering') }\end{array}$ & $\begin{array}{l}\text { Parallel activities directed at shortening } \\
\text { ime-to-market sharper product definition }\end{array}$ \\
\hline Mono-discipline & $\begin{array}{l}\text { Cross-disciplinary between } \\
\text { deparments at silccessive } \\
\text { stages (marketing and } \\
\text { manufacturing integral part of } \\
\text { process) }\end{array}$ & $\begin{array}{l}\text { Multidisciplinary teams in pre-development } \\
\text { stage, followed by functional groups that } \\
\text { operate in parallel. Decisions are also } \\
\text { cross-functional }\end{array}$ \\
\hline Relay race & Rugby approach & American foolball \\
\hline
\end{tabular}

Third-generation models: shorter time-to-market

Authors like D'Aveni (1996), Stalk (1988), Hamel \& Prahalad (1994) and Teece et al. (1997) have emphasised a changing competitive environment. To compete, firms must continuously improve their performance by reducing costs, innovating products and processes, and improving speed to market. Shorter time-to-market becomes a way for firms to achieve a competitive advantage (Karlsson \& Ahlstrom, 1996). A straightforward result will be a shortening of product life cycles. This would require firms to speed up their innovation process. Cooper (1994) refers to this movement as follows: 8 is particular emphasis is on efficiency: on speeding up an already effective second generation stage gate process and a more efficient allocation of development resources.". What are the implications for the organisation of the innovation process? Some of the problems in second-generation process models could weaken the rapid completion of an innowation process, such as:

- the delay for innovation projects that must wait to pass a decision gate,

- the lack of prioritisation in activities in the whole process, 
- the delay resulting from having to pass many (or even all) gates and stages, and

- a tendency of processes becoming too bureaucratic.

A third generation of nomative models appeared to be driven by the quest for speed and overlapping stages. Central elements in the models are the strong upstream and downstream relations in the innovation process, cross-functional teams, and the integration of functional tasks. Case studies of such companies as NEC. Fuji-Xerox, Honda and studies in the automobile sector, which typified mass-market industry, contributed to this development of process models (Imai, Nonaka \& Takeuchi, 1985; Womack, Jones \& Roos, 1990; Clark \& Fujimoto, 1991). These studies revealed new insights including:

- the relevance of extemal sources for new ideas and the early involvement of "lead users" (Von Hippel, 1986) and specialised suppliers in the innovation process;

- the importance of internal information flows, especially the functional interface between R\&D and marketing (Griffin \& Hauser, 1996; Song \& Parry, 1996, 1999; Souder, 1987); and

- the role of tacit knowledge, team learning and subtle team control in product development (Nonaka \& Takeuchi, 1995; Senker, 1995).

These elements are supposed to be present in the ICT sector as well. More recently (Takeuchi \& Nonaka, 1996), the use of multidisciplinary teams was refined on the basis of case studies at Nissan in Japan. There, multidisciplinary teams were predominantly used in the predevelopment stage. Once the design of the product was clear the tean split up and the activities continued to be performed by functional groups working in parallel on parts of the work. The groups ensured sufficient functional knowledge input from the various functional disciplines in the predevelopment stage. This method resembles the American football game. In American football, teamwork and individual actions go hand in hand within a predefined set of rules.

In summary, the belief in the importance of the design of the innovation processes has spurred managerial thinking about process models, as long as over 30 years ago and continuing up to the present. Essentially one could distinguish between three generations of innovation process models. The early studies typically involve product development processes of a linear sequential nature. New insights have shown that organisational integration of different disciplines drives superior innovation processes. The models emphasise the importance of feedback and overlapping process stages. Recently, new ideas have emerged on the involvement of external parties (e.g. Von Hippel, 1986) and multidisciplinary teams to compress the innovation process and shorten the time-to-market. The question is whether these items also appear in innovation in the ICT sector.

\subsection{Organisation Theory: Contingency Perspective}

In this section we take a step away from process design and turn to the organisation theory. There seems to be a lot of argument and dispute among different schools of thought. A quick look shows a rich academic body of knowledge on organisational designs ranging from highly structured bureaucracy forms (Mintzberg, 1990) to flexible, organic organisation designs (e.g. Burns \& Stalker 1961). The organisation discipline mainly focused on the primary process of production. Innovation processes are now being regarded as important, and even referred to by some as the primary process. This requires us to look at the accumulated organisational 
knowledge from a different view. Organisation scholars now call for flexibility in the organisation design (e.g. Volberda, 1990). Daft \& Lewin (Special Issue Organisation Science, 1993) expressed their concern about new contributions when asking: where are the new theories of organisation...???'. In this chapter we will pick up two interesting schools of thought that address innovation. Both schools can help us at a later stage to explain some of the typical innovation issues in the ICT sector.

In order to use words in a consistent manner we refer to structure as: the set of formal and informal relationships between people and resources in an organisation, inctuding the authority relationships and control systems (Donaldson, 1995).

Contingency theory: fit

The dominant and leading thoughts on organisational structure were dominated by classical management theory (c.g. Taylor, 1919; Fayol, 1949 in: Shadritz \& Ott, 1987). This management theory was driven by principles arguing for one universal best way to structure an organisation. In this traditional perspective the organisation structure resembled "...a herachical, highly formalised arrangement in which behaviour was governed by detailed plans and systems that were determined centrally...' (Donaldson, 1995, p. 11). The development of contingency theory is a reaction to the ideas of 'one best way' to organise and manage a firm. (Stacey, 1996; Lawrence \& Lorsch, 1967; Child, 1984). Chandler (1962) opposed to this universality of 'one best structure', by stating that organisations adapt their structure to reach a fit between changing factors, as the world seems more complex due to different tasks and technologies in an organisation. The theory further proposes that organisations actively change to correct a structure misfit to improve performance. Empirical research (Burns \& Stalker, 1961; Woodward, 1965; Lawrence \& Lorsch, 1967) tried to show that success was not correllated with a simple single set of factors. Instead, it was argued that the effectiveness of a particular organisation is dependent upon a number of factors. Thus, the belief that performance differences can be attributed to the organisational state-of-affairs is grounded in what is called "the structural contingency theory" (Ketchen et al., 1997; Meyer et al., 1993). Donaldson (1995, p. 12) summarises this approach to organising as follows: :...contingency theory regards the design of an effective organisation as necessarily having to be adapted to cope with the "contingencies" which derive from the circumstances of the environment, in which the firm is operating...'

\section{Contingency factors}

Research in the contingency school concentrated on explaining the degree of centralisation, which depends on contingent factors such as:

- the strategy (Chandler, 1962),

- the operational technology (Woodward, 1965),

- the rate of environmental change (Bums \& Stalker, 1961; Lawrence \& Lorsch, 1967), or

- the firm"s size (Pugh et al., 1969).

Later research studies have added other contingency factors. Scholars have argued that, in order to be effective, an organisation's policies must be consistent with other aspects of the organisation. For example, studies have indicated how a number of human resource management practices can be consistent with different strategic positions, and how these practices relate to firm performance (e.g. Gomez-Mejia \& Balkin, 1989). 


\section{Critiques on contingency perspective}

The empirical evidence on the structural contingency has shown that the assumptions of structural adaptation are somewhat controversial. But there are validated empirical findings that performance can be partially explained by organisational contingencies (Ketchen el al.s 1997; Thomas \& Venkatraman, 1988). Despite the contingency theory contributions, a variety of views on organisation structure have rejected the contingency theory. Over the years, structural contingency theory came under attack with respect to the rationality, organisational power and environment concept (Mintzberg, 1990). Astley (1985) argued that environments are quite open and receptive whatever variations are imposed on them. Van der Ven (1979) suggests that variations might be attributed to the many and different individual choices made by entrepreneurs and inventors.

The impact of the "environment" on the structure-strategy fit is complex. According to the classic strategic management literature (Chandler, 1962), strategy is defined in relation to the nature of the threats and opportunities in the environment. A number of organisation theorists (e.g. Freeman \& Boeker, 1984; Aldrich, 1979; Hannan and Freeman, 1977), under the label of population ecology postulated that environmental conditions forced organisations into strategies, namely market niches. The organisation obeyed to the enwironment, or else it was selected out. Organisational theorists such as Hannan and Freeman (1977) argued that the power to change rests with the environment rather than the organisation. In their opinion, the environment is complex, dynamic and hostile, dictating strategy. This population-ecology theory agrees with the contingency idea of constant environmental pressure to change, but rejects the cause and impact of change. Ecologists assume that change is induced by the environment and is not a purposeful and rational adaptation process towards strategic fit. In other words, the firm is not explicitly able to make choices (see box 4.1). The contingency school assumes that firms have power to adapt to changes and survive.

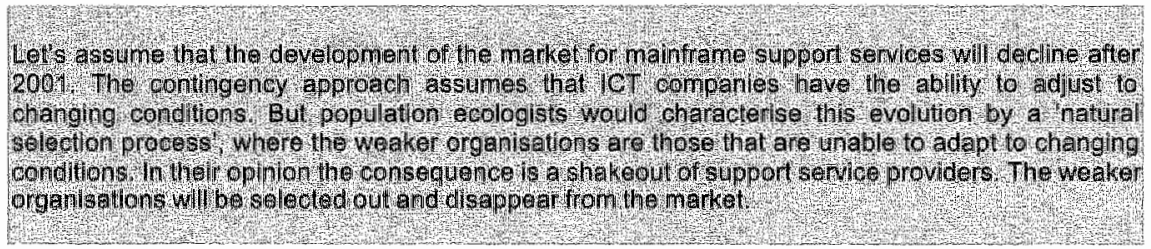

\section{Box 4.1: Example of ecology view on organisation}

The economics discipline has also contributed to the thinking on the organisation principle of fit. Transaction cost theory and agency theory (c.g. Williamson, 1985; Jensen \& Meckling, 1976) are two influential contributions to organisation theory. Both approaches to organisation deal with the issue of reaching a certain fit between conflicting interest. Dealing with this kind of fit will influence the organisation performance. These approaches view organisations as a collective of individuals that show opportunistic behaviour. In particular, in the agency theory the organisation is represented by a situation of conflict of interest between two roles known as the 'principals', e.g. company' shareholders, and the 'agents', e.g. managers, On the question of how to organise, certain control structures have to be implemented to monitor the interest of both agents and principals. If not, one party will be opportunistic and strive for maximum personal benefit. Transaction cost theory holds the assumption that market failure typically occurs and hierarchical control must be introduced both to ensure effective operations and prevent managers from favouring personal goals over corporate goals. 
Size as a contingency factor

Returning to the contingency idea, it was Weber's $(1949,1968)$ type of "bureaucracy" that exemplified the contingency element of size to the organisational structure. Bureaucracy can be seen as a work system in which work and administrative roles are specialised, individual tasks are explicitly defined, formal roles have been determined and standard operating procedures assure the execution of administrative tasks (Donaldson, 1993). In this perception an organisation consists of functional departments (e.g. marketing, production, R\&D) which are supervised by higher levels. Essentially, bureaucracy is an organisational structure characterised by three elements (Donaldson, 1993, p. 39):

- functional specialisation,

- standardisation, and

- formalisation.

Empirical studies (e.g. Child, 1975; Khandwalla, 1973) have shown that a larger organisation is often accompanied by higher degrees of bureaucracy. These studies support the contingency view that size is positively associated with both functional specialisation, standardisation of tasks and formalisation.

\section{Strategy as a contingency factor: the strategy-structure debate}

The idea of strategy as a contingent factor appeared when Chandler (1962) proposed that the choice of organisational structure depends upon the firm strategy being pursued. Chandler"s (1962) argument was based on a study of US firms in the period 1919-1959. Cases of General Motors, DuPont, Sears and Roebuck, Standard Oill of New Jersey showed that structural adjustments in the organisation were implemented after strategic initiatives had been taken. These initiatives occurred in areas unrelated to the traditional lines of business (e.g. new business development). This study and later ones (Galbraith \& Nathanson, 1979) found empirical evidence that firms first start diversification, which then leads to divisionalisation and the appearance of the multidivisional organisation. The essence of their proposition is that the organisational structure is secondary to strategy (Christensen et al, 1978). Moreover, and in line with contingency thinking, the '...strategy-structure fit positively affects performance and strategic changes cause a misfit and subsequenty a struchual change... (Donaldson., 1995).

This idea, however, provoked a debate known as the strategy structure paradigm: does structure follow strategy (as Chandler asserted), or is it the other way around: does strategy follow structure as argued by Burgelman (1983) and others (e.g. Hall \& Saias, 1980)? There have been many debates in the strategy literature regarding the causal relationship between strategy and structure (most recently, Amburgey \& Dacin 1994).

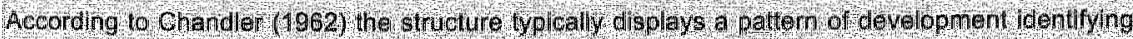
foutstages:

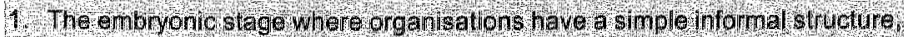

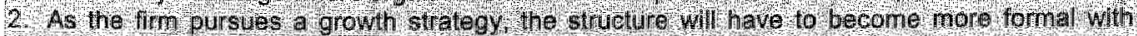

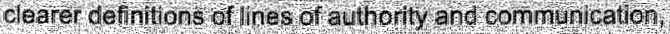

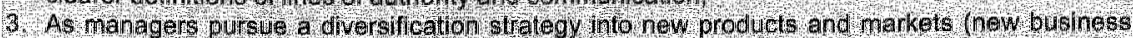
opportunites) addilonal structuros are needed and

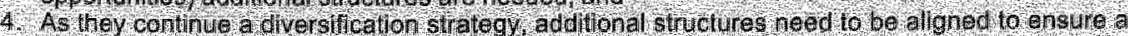

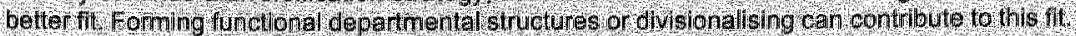

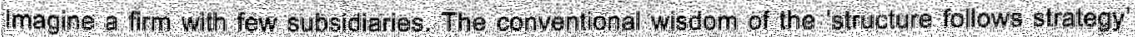
school would hidicate that corporate top nansge ment defines a strusture (a structural context) tor 


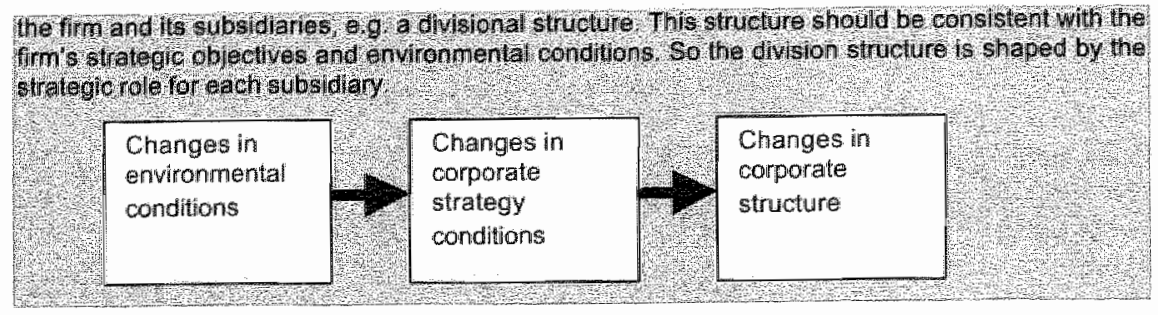

\section{Box 4.2: Strategy and structure in four stages (Chandler)}

Burgelman (1983) disputed Chandler's argument and commented on the point of structure following strategy. He refined this idea by arguing that the relationship strategy-structure depends on the part of the strategic process that is analysed. He asserted that "structure follows strategy" generally holds true for strategic activities initiated by the current corporate strategy. However, as a firm matures (stages 3 and 4 in Chandler's growth stages), the argument of fit between structure and strategy might not be valid. Burgelman's $(1983$, p. 61) review of studies in the light of intenal corporate venturing suggested: "a model of the strategic process in large complex firms, where current corporate strategy induces some strategic behaviour but changes in corporate strategy follow other awtonomous strategic behaviour'. The critical insight is that two kinds of strategic activities are suggested. Most strategic activities are induced by the firm's strategy, but also a number of autonomous activities emerge that fall outside the scope of the current strategy. This research suggests (see figure 4.6) that the autonomous actions of a subsidiary, for example, can also be induced by the existing structural context. To return to the previous example, the subsidiaries of a firm, given their divisional structure, would take autonomous initiatives to expand internationally, e.g. by initiating imternal corporate ventures resulting from their division structure.

Figure 4.6: Model of 'strategy follows structure'

\begin{tabular}{|c|c|c|}
\hline $\begin{array}{l}\text { Changes in } \\
\text { corporate } \\
\text { strategy } \\
\text { conditions }\end{array}$ & $\begin{array}{l}\text { Changes ith } \\
\text { conponate } \\
\text { ghruture }\end{array}$ & $\begin{array}{l}\text { Changes in } \\
\text { comporate } \\
\text { strategy }\end{array}$ \\
\hline
\end{tabular}

While there is no shortage of literature on issues of strategy and structure, the body of empirical evidence is less impressive. Bower (1970) found support for Burgelman's argument, based on a study on the management of strategic capital investment projects. Contingency scholars generally agtee that initially structure follows strategy. But it is a woway process as argued by Hedlund and Rolander (1987). A new idea contributing to this discussion would be the role of the customer. What is the actual influence of a customer focus, especially in a service sector, on the strategy and the structure of a knowledge-intensive firm? What happens if firms design their structure around their customers and discover the need to adjust their strategy? These questions related to strategy and organisation are relevant to ICT companies. 


\subsection{Organisation Theory: Configuration Perspective}

\section{Configuration approach: 'getting it all together"}

In contrast, the configuration approach does not take the viewpoint that circumstances have to be defined before making the combination of strategy and structure that fits. Configuration arguments are more complex that contingency arguments (see table 4.3). It is not about fit between each individual contingency factor and the structure, but about aligning the collective set of factors with the structure. Configurational theories differ from contingency theories because the former (Doty, Glick, \& Huber, 1993; Delery \& Doty, 1996)."

- are guided by the holistic principle of inquiry (which means trying to identify configurations that are maximally effective),

- are usually based on typologies of ideal types (which means they are theoretical constructs rather than empirically observable phenomena), and

- explicitly adopt the systems assumption of "equifinality" (which means that multiple unique configurations can result in maximum performance).

Configurational notions are currently incorporated in both theoretical and empirical studies. Numerous authors (Miles \& Snow, 1978; Khandwalla, 1970) have attempted to develop a priori typologies of effective organisation systems and link the performance of these systems to firm strategy. Mintzberg's (1990) argued in Strategy Safari, a historical overview of strategic management, that strategy and structure should be treated as integrated phenomena. Accordingly, in the configuration school one assumes synergy, as stated by Stacey (1996), as: "... some rypical constellation of structural, cultural, strategy pattern, control system features and other organisational factors appropriate to a particular enwironment. In other words, a particular configuration is one of a limited number of categories, based on many interrelated and muitually supportive features..."

In other words, organisations perform well as a result of combining strategic and structural attributes in a synergistic way. The configuration school received a lot of research attention (e.g. Frederickson, 1986; Miller, 1986; Ettlie et al., 1984; Rumelt, 1974). Khandwalla's (1970) study on effectiveness was among the first to justify configuration research. "The effectiveness in the organisations studied by Khandwalla did not relate to the use of one particular characteristic, but to a configuration set of characteristics. In the remainder of this section we will present influential work of configuration research linked to innovation.

Table 4.3: Differences in contingency and configuration perspectives (Sources: Mintzberg, 1990; Donaldson, 1995)

\begin{tabular}{|c|c|c|}
\hline & Contingency theory & Configuration theory \\
\hline Message & $\begin{array}{l}\text { Fit, } \\
\text { "il all depends on contingen factors' }\end{array}$ & $\begin{array}{l}\text { Synergistic combination, 'getting it all } \\
\text { together' }\end{array}$ \\
\hline Organisation dynamics & React & Integrate \\
\hline Key elements & $\begin{array}{l}\text { Environmental dynamism, complexity, } \\
\text { selection, external fit }\end{array}$ & $\begin{array}{l}\text { Configuration, ideal lype, external } \\
\text { and internal fil }\end{array}$ \\
\hline Enviromment & $\begin{array}{l}\text { Broad dimensions, contingent factors } \\
\text { like size, strategy, lechnology }\end{array}$ & Any \\
\hline Situation & Any best fit & $\begin{array}{l}\text { Any as long as it belongs to a } \\
\text { category }\end{array}$ \\
\hline Structure & $\begin{array}{l}\text { Any likely bureaucratic form based om } \\
\text { degree of functional specialisation. } \\
\text { standardisation, and formalisation }\end{array}$ & $\begin{array}{l}\text { Any as long as it is a configuration } \\
\text { ideal type }\end{array}$ \\
\hline
\end{tabular}




\section{Configurations: Burns \& Staker organisation structure typology}

Burns \& Stalker's (1961) study presented configurations of organisations long before configuration research emerged. They elaborated on the creative and innovative aspects of the organisation. Burns \& Sialker described the opposite ends of a continuum of organisational forms as (p. 119): "...two polar extremities of the forms which systems can take when they are adapted to a specific rate of technological and commercial change..." The first ideal type is the mechanistic organisation, supposed to be suitable for companies operating in a stable environment. At the other end is the ideal type of the organic organisation structure, supposed to be rellewant to firms in dynamic and complex environments. It is seen as a more flexible structure appropriate for changing conditions.

Table 4.4 summarises some configuration aspects of the organisations. With respect to innowation the organic structure is typically characterised by loosely coupled informall networks, making sure that routine bureaucratic aspects of an organisation do not impede the innowation process. The mechanistic organisation is characterised by such bureaucratic elements as strong formal lines of authority and hierarchical procedures. The mechanistic organisation is regarded as ineffective to innovation due its rigidity, regulated co-ordination, and hierarchy of control. Empirical studies (see: Rothwell, 1972; 1994; Cobbenhagen, 1999) have adwocated the idea that innovation will seldom flourish in an organisation environment typified by mechanistic principles of organising.

\section{Table 4.4: Organic and mechanistic organisations (Source: Burns \& Stalker, 1961)}

\begin{tabular}{|c|c|}
\hline Organic orgamisation & Mechanistic organisation \\
\hline individual iresponsibility abowe rules and procedures & rigal functional departments \\
\hline cross-functional participation and dialogue & functional specialisation \\
\hline informall intemal environment & bureaucracy \\
\hline informal channels of communication & operational rules and procedures \\
\hline cross-functional teams operating across boundaries & farmal lines of control \\
\hline emphasis on creative interaction & long decision lines and slow decision making \\
\hline external focus & relatively little experimentation freedom \\
\hline non-thirarchical & formal channels of communication \\
\hline lop-down and bottom-up flows of information & internaly oriented \\
\hline & top-down strategy \\
\hline
\end{tabular}

Configurations: Miles d Snow strategy typology

Another straightforward contribution to the strategy-structure relation is the well-known study by Miles \& Snow (1978) on the identification of four strategy typologies. They stated that (1978, p. 7): '...one can conceptually associate strategy with intent and structure with action... They identified four ideal types: 'analysers", 'prospectors', "defenders' and "reactors". Each type is associated with a different organisational structure, processes and competencies. The configurations were derived from defining a set of distinctive functional competencies, e.g. financial management, marketing and sales, R\&D, and engineering.

The study results indicated that firms labelled as defenders, analysers or prospectors were all competent in general and financial management. Typical of the ideal types were:

- Defenders, which were strong in production and applied engineering, indicating strengths in production cost efficiency.

- Prospectors, which excelled in product research and development and basic engineering, indicating their search for new market opportunities. 
- Analysers' pattern of competencies, which differed strongly with the industry sector, resulting in no clear standard configuration. These firms had a consistent configuration of strategy, structure and competencies that reflected the defender and prospector type.

- Reactors that did not have a logic competence pattern showed no consistency in strategy and structure and were outperformed by the other configuration types, with the exception that reactors perform well only in highly regulated industries.

One can observe from this study that firms pursuing different strategies do so with a different organisational configuration. The strategic differences among the ideal types suggest that organisations can pursue alternative strategies, which are accompanied by different practices and which can be equally effective in increasing performance. Many studies have found support for this typology and validated the Miles \& Snow typology in various sectors (e.g. Nijssen, 1992; Shortell \& Zajac, 1990; Miller, 1986; Snow \& Hrebiniak, 1980; Miller \& Friesen, 1980).

\section{Human resounce management configurations}

The basic idea is that structure or instruments are not enough. It is the whole texture of structure and actions that counts. Mohrman ef al. (1992) argued that human resource management is a configuration of elements, as the set of human resource instruments is greater than the sum of its parts. That's why the literature on human resource contributes valuable insights that are of interest to the organisation of innovation (Becker \& Gerhard, 1996; Pfeffer, 1994; Mohrman et al., 1992) (see also section 4.5).

\section{Summary}

The purpose of these two sections has been to articulate two types of organisation theories which can be useful in discussions of imnovation in the ICT sector to see whether the strategy and structure of ICT firms incorporate configurational and contingent elements. According to the contingency theory, the effectiveness of a firm is contingent upon factors like strategy, size, and environment. An organisation will be more effective if it adopts a structure and strategy that fits with the environmental conditions. The configuration viewpoint assumes both external and internal fit and emphasises the need for synergistic effects to enhance performance.

\subsection{Organisation Structure of Innovation}

Cameron (1980) and others (e.g. Pascale, 1990; Stacey, 1996; Hamel \& Prahalad, 1994) argued for creating creative tension in an organisation. Such a tension will keep organisation allert to new external developments, new technologies, or newly emerging competitors. In this section we will elaborate upon a number of the organisation design options relevant to innovation. The alternatives, functions and dysfunctions are discussed. Three influential organisation design options are presented:

- the functional organisation, representing functional departmentalisation and centralised authority,

- the matrix organisation, combining functional and product departmentalisation, and

- the team-based organisation, using teams as the central co-ordinating device.

These options are not about adopting a best practice or a blueprint for a newly emerging organisation. Rather, they represent theoretical contributions, which stem from Galbraith 
(1973, 1994) and others (Nonaka, 1994; Grant, 1996). Galbraith's work inspired other contributions (Larson \& Gobeli, 1988; KJimstra \& Pots, 1988; Montoya-Weiss \& Calantone, 1994; Cobbenhagen, 1999) that have appeared on the effectiveness of these organisation designs. Each form has its advantages and its disadvantages, which can partially explain the variations in effectiveness for innovation. They will be discussed in the following paragraphs.

\section{Innovation in a functional organisation}

A functional organisational structure represents a hierarchical and functional form of organising (Williamson, 1991; Chandler, 1991). This structure is close to Burns \& Stalker's (1961) mechanistic organisation structure, which is based on functional concentration and functional order of activities. When we look at the constellations of the functional structure, Mintzberg (1979) refers to "building an administrative hierarchy of authority". Mintzberg (1979) conceptualised the functional organisation as a configuration of:

- an operational part performing the basic productive tasks, and

- an administrative part with co-ordinating tasks.

\section{Figure 4.7: Functional design option}

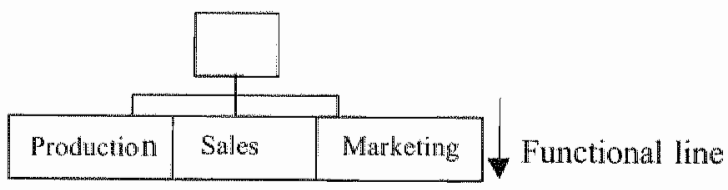

\section{Balancing specialisation and differentiation}

Classical organisational theorists (e.g. Taylor, 1919 and Fayol, 1949) regarded functional specialisation as the main organising mechanism. The grouping of similar activities, tasks and skills would allow for the creation of functional specialists, add to saving labour cost, and enable co-ordination by central control. In parallel with a move to specialisation, differences in behaviour and thought pattems occur among different functional specialists, which is called differentiation (Walker \& Lorsch, 1968). Differentiation contributes to functional specialisation. A prerequisite for such circumstances is a separation of activities in work parts to be allocated to functional departments. At a later stage the separate parts can be reinfegrated as planned in advance. The question arises as to what balance is needed between specialisation and differentiation, in particular in a functional organisation where activities become nore complex. Then a functional organisation could become ineffective. The tradeoffs are summarised in box 4.3 .

\section{Asstes on functional specialisation: sub-optimisation}

The first drawback of specialisation deals with the unpredictability and difficulty to break down and integrate the separate functional activities. Among the origins of this drawback is the appearance of functional barriers. Specialisation into functional units has the potential disadvantage of creating functional barriers between departments, for example between R\&D, production and marketing. These barriers can result because of (Griffin \& Hauser, 1996):

- different task priorities,

- unclear responsibilities between functions,

- control systems that evaluate activities differently,

- dual rewarding and career development schedules, or

- lack of top management support. 


\title{
Table 4.5: Functional organisation: advantages and disadvantages
}

\author{
Advantages \\ Promotes functional sikill specialisation \\ Reduces duplication of scarce resources \\ Enhances career development for specialists within departments (hurnan resource management) \\ Facilitates communication and sharing of expertise within function \\ is consistent with high centralisation and formalisation \\ Functional speciabisation leading to labour cost savings, and better use of equipment \\ Single line-reporting relationships

\section{Disadvantages} \\ Unclear responsibilities between functions \\ Appearance of Not-Imvented-Here syndrome in R\&D department \\ Is too rigid for turbulent envirommenis \\ Emphasises a functional routine task, encouraging short time horizons \\ Reduces communicaujion and co-operation between departments \\ Mulliple interclependencies, which can make co-ordination and scheduling difficult \\ obscures accountability for overall outcomes and can lead to interclepartmental conflict and competition
}

\section{Mechanism for integration}

Several authors (e.g. Clark \& Wheelwright, 1993; Nonaka, 1994) have argued for the need for cross-functional co-operation as a means for closer integration between functions. Research since Lawrence \& Lorsch (1967) has continued to be concerned with the ability of the organisation to use integration mechanisms. It is argued (Mintzberg, 1979; Starbuck, 1965) that increasing integration (or 'interdependence') needs result from increasing complexity of the environment. In our earlier discussions on first-generation innovation models we pointed out that integration is a must in circumstances where departments work sequentially and depend directly on each other's work.

Two organisational mechanisms for integration are (Grant, 1996b) direction, and routine. Direction telates to the presence of formal procedures (programming), and the distribution of authority, control of tasks and responsibilities (Grant, 1996b). It can take many forms and is often embedded in the management systems of the organisation. Procedures are explicit and refer to structure (Giddens, 1979). Such formal procedures include project planning techniques, investment decision and budget control methods.

Routines are implicit and refer to action (Giddens, 1979; Nonaka, 1994). They might be compared with the 'builtain patterns of action' and the way people operate in an organisation. Routines are embedded in the people working in the organisation (Nelson \& Winter, 1982). Often the company culture is associated with routines (Schein, 1989). The relevant question here is whether routines can contribute to better integration. If the integration of separate functional tasks can become a built-in routine, people will share their knowledge automatically. As an example, if market researchers share their first findings on consumer trends and share them at an early stage with R\&D people, this will contribute to integration of such tasks as concept development. Routines are "path-dependent", similar to the ideas developed in the resource-based wiew of the firm (Teece et al., 1997). Or as Nonaka and Takenchi (1996) state: routines, just as capabilities, are socialised in the organisation. 


\section{Innowation in a matrix organisation}

The matrix design has received considerable attention in the literature since the major contributions by Galbraith $(1971,1973)$. Because the matrix organisation is a complex and recent response to both the needs for specialisation and co-ordination, its effectiveness is difficult to assess. The matrix form fundamentally breaks with the basic principle (Fayol, 1949) of organising: unity of control. Research findings (Cobbenhagen, 1999; Larson \& Gobeli, 1988) have shown that a matrix-like organisation can be more effective in enhancing project integration and speed (Larson \& Gobeli, 1985) and meeting client needs (Bertsch \& Stam, 1990). In this study we expect ICT firms to be progressive in the use of matrix-like structures. But let us look at a theoretical explanation first.

Galbraith (1973) described the matrix organisation as a structure model with dual lines of authority. The functional line organisation continues to exist, but in addition an overlay of a project line is introduced, which would comordinate the activities of the departments. This structure is characterised by functional lines of authority that are deliberately combined with the existence of formal project teams. This construction would ensure proper communication and co-operation across functions in an innovation project. Studies (Cobbenhagen, 1999; Barczak, 1995; Yap \& Souder, 1994; Larson \& Gobelli, 1985, 1988, 1987; Klimstra \& Potts, 1988) have shown that matrix approaches can work well as a temporary or permanent design. Some of the trade offs of the matrix organisation are summarised in table 4.6 .

\section{Table 4.6: Matrix organisation: advantages and disadvantages (adapted from $J$. McCann \& J. Galbraith, in: Nystrom \& Starbuck, 1981)}

\footnotetext{
Advantages

May be permanent or temporary

Makes specialised functional knowledge available to all projects. Uses people flexibly since departments maintain reservoirs of specialists

Maintains consistency between different departments and projects by forcing communications between managers Can adapt to environmental changes by shifting emphasis between projects and functional aspects

Broadens experience bases and career potentials for key people (human resource management)

Results in higher cross-department consensus decistong
}

\section{Disadvaritages}

Can be very difficult to improduce without a pre-existing supportive management climate

Dual reporting relationships leading to decision-making conflici

Increases role ambiguity, stress, and anxiety by assigning people to more than one department

Without power balancing between functional managers and project managers can affect overall performance

Makes an inconsistent demand, which may result in unproductive contitcts and short-tem crisis management Rewards political skills

Disadvantages mainly result form the inherent conflict of interest of the functional line and the project line. This leads to the appearance of dual reporting lines causing decision-making problems. Duality in communication, co-operation, and reporting might be considered as the potential organisational constraint. It may result in a lack of clarity on work expectations and work performance between departments and with the project line. Also, conflicts with regard to resource availability and allocation can crop up due to different organisational demands. These conflicting situations can induce the emergence of politics by project and functional managers to reach certain goals. Furthermore inefficiency may arise as a result of "non-coordinated' duplication of activities. 


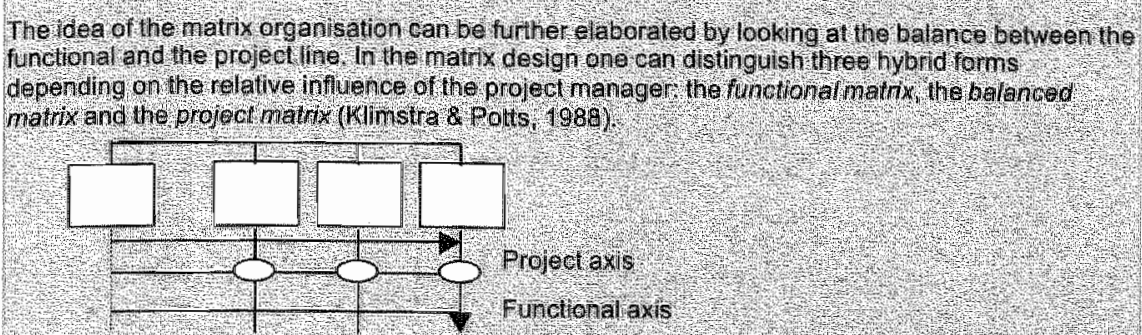

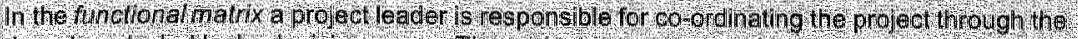

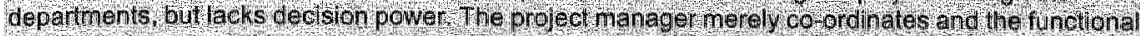

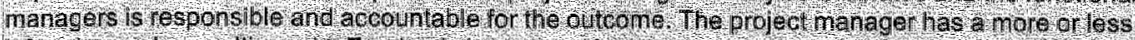

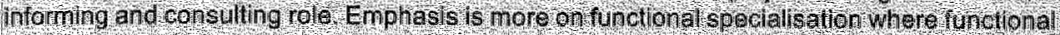
hanagers make decislons on resource alecat on

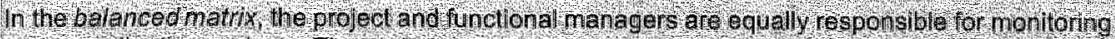

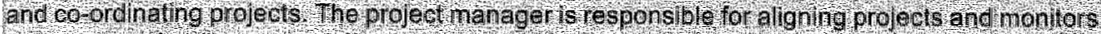

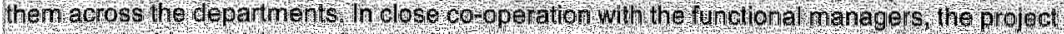

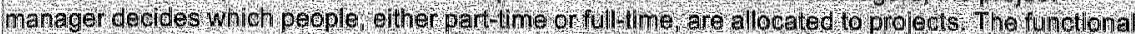

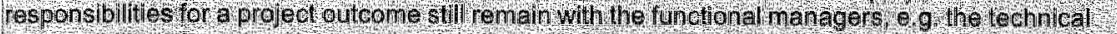

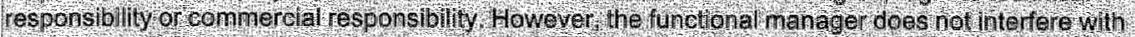

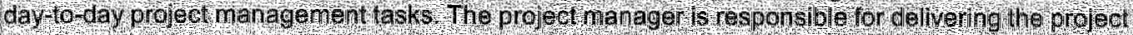
results on the

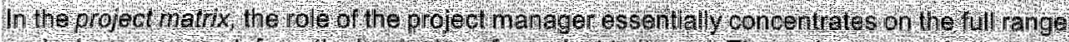

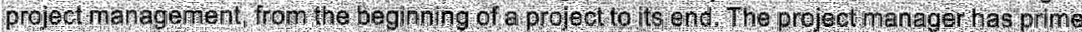

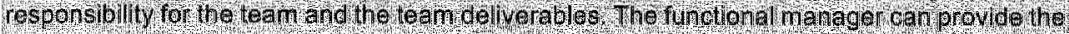

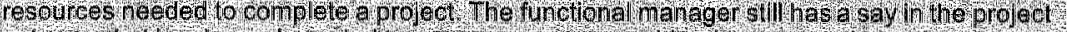

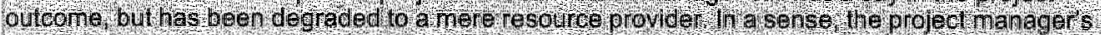

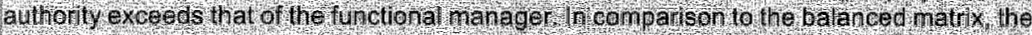

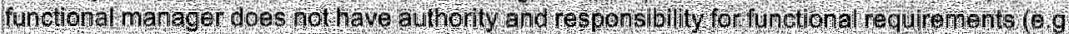

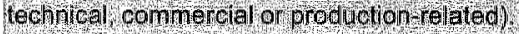

\section{Box 4.3: Matrix design options}

In essence, the difference between matrix designs is the relative dominance of the project flow aver the functional flow. This creates space for flexibility because the demand of control resides with the project manager. Donaldson (1995) points out that the choice for a more entral or participatory matrix form is a contingency choice $(1995, \mathrm{p} .12)$ : "...the extent to which lateral co-ordinating devices or, in extreme, fully fledged matrix structures were required.... to be determined by contingency factors such as the rate of environmental change and product diversity...'

\section{Innowation in a project team organisation}

The role duality and interdependence in the matrix form (Stacey, 1996) is reduced when the influence of the functional manager is decreased. In such a situation one can speak of a project team structure. Compared to the matrix organisation the project team structure is extended along the project axis (Larson \& Gobeli, 1988). Characteristic of this form is a project leader who is put in charge of a project team composed of a core group of people from all relevant functional disciplines. They are allocated to the project on a full-time basis. Functional managers do not have any formal involvement. Cross-functional teams are assumed to be critical to innovation performance (e.g. Clark \& Fujimoto, 1991; Dougherty, 1992; Zirger \& Maidique, 1990). Table 4.7 briefly summarises the differences in design 
options. We expect the ICT firms to be progressive and keen on matrix and project team designs due to the knowledge-intensive type of business requiring strong cross-functional working.

Table 4.7: Summary of organisation design options (Various sources: Cobbenhagen, 1999; McCann \& Galbraith, 1981; Roussel et al., 1991)

\begin{tabular}{|c|c|c|c|}
\hline & Functional organisation & Matrix organisation & Project team \\
\hline Focus & Functional specialisation & $\begin{array}{l}\text { Functional lines combined } \\
\text { with formal project lines }\end{array}$ & Multidisciplinary teams \\
\hline Organisation flexibility & Weak & Medium & High \\
\hline Resource efficiency & $\begin{array}{l}\text { Medium, reduces } \\
\text { duplication of scarce } \\
\text { resources: }\end{array}$ & $\begin{array}{l}\text { Thigh } \text { peservoirs of } \\
\text { specialists }\end{array}$ & Medium "project-driven \\
\hline $\begin{array}{l}\text { Inferdepartmental } \\
\text { relationships }\end{array}$ & Multiple, simple & Multiple, complex & Mulltiple, within team \\
\hline Line of raporting & Single line, functional & Dual line & Single line, project \\
\hline Manager & Functional manager & $\begin{array}{l}\text { Lightweight project } \\
\text { manager and functional } \\
\text { manager }\end{array}$ & $\begin{array}{l}\text { Heawyweight project } \\
\text { manager }\end{array}$ \\
\hline $\begin{array}{l}\text { Cross-functional } \\
\text { integration }\end{array}$ & Weak & Maderate & Strong \\
\hline Customer focus & Weak & Maderate & Strong \\
\hline $\begin{array}{l}\text { Hiuman resource } \\
\text { management emphasis }\end{array}$ & Functional & Cross-functional & Cross-functional \\
\hline
\end{tabular}

The design of lateral linkages (Den Hertog \& Huizenga, 2000) in an organisation can help to surpass organisational boundaries. Project team structures are suggested (e.g. Pierce \& Delbecq, 1977; Larson \& Gobeli, 1988) to be effective in designing such cross-functional linkages. The suggestion of lateral links, without burdening the hierarchy, is a rich concept further developed by Galbraith $(1973,1994)$. Galbraith refers the organisation designed with cross-functional linkages as the 'lateral organisation'. Lateral relations cut across functional lines of authority. They allow for decentralisation of decision making to the lowest possible level of action. The result of such structures is an increase in the capacity of the organisation to absorb and process information and make decisions rapidly. Next, we will describe the ideas on project teams and multidisciplinary teams. This team concept is supported by research on the organisation of innovation (Leonard Barton, 1995; Dougherty \& Hardy, 1996; Cooper, 1994; Pisano \& Wheelwright, 1995; Clark \& Fujumoto, 1991; Souder, 1987). In table 4.8 we see the (dis)advantages of project team structures, which typically mirror a functional organisation.

\section{Meanyeight project teams}

Several authors (e.g. Clark \& Wheelwright, 1992; Clark \& Fujimoto, 1991) conducted empirical research in the automobile industry, which is supportive of the use of nultidisciplinary teams. Clark \& Wheelwright (1992) introduced the concept of heavyweight project teams, which is typical of large-scale innovation projects. Heavyweight project teams are multidisciplinary teams with a heavyweight project leader who acts as a powerful linking pin and co-ordinates the activities of the product development tearm, but also works with senior management to create an overarching product concept. In this concept the senior management can exercise subtle control through such project leaders, who manage the multidisciplinary team in the context of a product vision. This type of team structure offers improved communication, stronger identification with and commitment to a project target, and a focus on cross-functional problem solving. 
Table 4.8: Project team organisation: advantages and disadvantages

\author{
Adwantages \\ Makes specialised functional knowledge input availlable to all projects. \\ Sutable for integrating technical, engineering, production and marketing tasks \\ Supportive lo parallel conducting activities the innowation process \\ Absorption of functional knowledge and technology \\ integrates critical actiwities upstream and downstream the innovation process at early stage \\ Avoids problems of transfer and miscommunication \\ Broadens experience bases and career potentials for key people when transferred between projects (human \\ resource mamagement)

\section{Disadwantages} \\ Can be very difficult to introduce without a pre-existing supportive managenent climate \\ Does not promote functional skill speclalisation \\ Does not enhance career development for specialists within departments (human resource management) \\ Decentralised working and decistion making might lead to duplication of efforts
}

\title{
Multidisciplinary team design oprions
}

Multidisciplinary team concepts appear in various forms, such as 'mgby' teams' (Takeuchi \& Nonaka, 1986), skunkworks (Quinn, 1985), or venture teams (Bart, 1992). Tom Peters (1988) defined skunkwork as highly innovative, fast-moving, and slightly eccentric activities operating at the edges of the corporate work. The origins of skunkworks go back to a development team at Lockhead's Design and Development Centre. These cross-functional teams operate for a centain period on a new product concept and are fully detached from the regular organisation and daily practice. They often have a separate location and work under tight deadlines. In contrast, venture teams operate in an enwironment with high-risk endeavours. It is uncertain if this specific team approach is favourable above other team structures, as they are infrequently used for new product development (Bart, 1992). Each of these multidisciplinary team concepts resembles what Bums \& Stalker (1961) refer to as the organic structure of organisations. When we regard the advantages of team designs and record the variations in team concepts it is likely that similar design options will appear in the ICT sector.

\section{Multidisciplinary team approach: some empirical findings}

Ancona \& Caldwell (1990, 1992) examined 45 product development teams in 5 companies on their success pattems and the ways of external communication. Success was measured by subjective team and management ratings of performance. The study observed that team members communicate more with outsiders who had similar functional backgrounds. Thus, when multiple functions were represented on the team, there was more external communication by the team as a whole. The issue of internal communication has been explored extensively (e.g. Dougherty, 1990,1992 ; Dougherty \& Corse, 19; Imai, Nonaka \& Takeuchi, 1985). Keller (1986) found that internal group cohesion helped improve performance. Ancona \& Caldwell (1992) found similar evidence on the role of internal communication among team members. They observed a contributing role to performance by strong internal communication on goal definitions, development of work plans and prioritisation. As suggested by Dougherty $(1990,1992)$ multidisciplinary teams can overcome cross-functional communication barriers. Especially when team members participate in concrete tasks together and violate routines such as division of tasks. Multidisciplinary teams are known to break away from built-in rigidity and daily routine practice, which can hamper change (Leonard-Barton, 1995$)$. 


\subsection{Organisation Culture}

Successful innovation involves more than designing structures and systems. Investments in the quality of innovation are also affected by the organisational culture of a company. A dominant view in studies on organisation culture is that the development of a culture is based on the shared experiences of organisational members (Schein, 1985). Culture then creates a shared belief between organisational members (Pfeffer, 1981). Influential work by Schein (1985) argues that culture contributes to enhancing (but at some stage inhibiting) the internal integration and the adaptation of the organisation to change. Organisation culture is like a 'glue' for aligning internal processes and adaptation to changing market conditions.

Different descriptions and definitions of culture have been developed. Schein $(1984,1985)$ asserts that the analysis of culture can take place at three subsequent levels.

- The first culture level of an organisation is maintained through artefacts and creations. These are more explicit like managerial policies, educational programs, and investment principles (Leonard Barton, 1995). They result from experience accumulation but are not well documented. They identify the "gut feelings" and 'rules of thumb" that direct actions and decisions.

- The second level incorporates the values of a company, which are espoused, overt and often subject to debate. They are more deeply rooted in the organisation's systems, behaviour and processes.

- The third level involves basic characteristics of human nature, communication and relationships. The values that are generic are often cited as the corporate values of a company (Leonard Barton, 1995). They form a set of strongly related assumptions that are shared by all company employees. A strong culture might indicate that values are anchored in the organisation and difficult to change as they are widely shared by employees. Studies (e.g. Scott Morgan, 1994) have documented that the cultural barriers ("unwritten rules of the game") can be strong and can impede renewal and innovation.

\section{Culture \& innovation}

There are many research studies on the cultural dimensions of an organisation and their effect on behaviour and performance (Xenikou \& Furrham, 1996; Chatman \& Jehn, 1994; O'Reilly et al. 1991; Schein, 1985). In the innovation literature, culture is often regarded as the final organisational ingredient essential to make imnovation happen (Cooper, 1993). Some specific studies describe "the way an organisation operates" (e.g. Cobbenhagen, 1999; Moss Kanter; 1983) and have recorded the importance of culture for innovation success. They have identified that the values and noms have a profound effect on innovation and building up knowledge and capabilities (Leonard Barton, 1995). Organisational characteristics such as openness, respect, teamwork, external openness, and commitment to learning are assumed to be supportive for innovation success (Leonard Barton, 1995). Bolwijn \& Kumpe (1992) also assert that technological innovation is strongly related to culture. They state that innovation is a dominant competition criterion, requiring a company where $(1992$, p. 75): "behaviour is minorly formalised.. There is an amosphere of openness. Thinking in alternatives is strongly developed. Across the organisation there is much information exchange. ... much communication is informal". "This leads us to say that it is likely that firms that are successful in innovation have an organisation culture that differentiates on such dimensions as informal, openness, extrovert and low formalised rules. We will investigate whether ICT firms have a similar profile. 


\subsection{Organisation: The Human Capital Factor}

Recently scholars have argued that knowledge is an important production factor in innovation (e.g. Den Hertog \& Huizenga, 1997; 2000; Nonaka \& Takeuchi, 1994; Drucker, 1993). Part of the knowledge is tacit knowledge (Polanyi, 1966), which resides in the human resources in an organisation. An innovation process is driven by the development and sharing of both this explicit and tacit knowledge. Explicit attention for the human resources in an innovation process can contribute to improving the development and sharing of tacit knowledge (e.g. Leonard-Barton, 1995; Nonaka \& Takewchi, 1994). This notion suggests a policy role for human resources management in strengthening the ability to learn and to innovate in a company. We expect these topics to be of great importance to the ICT sector as instruments to intervene in knowledge development processes.

\section{Human resource management: recent contributions}

In the literature contributions (Huselid et al., 1997; Schuler \& Jackson, 1995; Den Hertog of al. 1991) there is a call for a strategic orientation to human resources, which entails the design and implementation of a consistent set of instruments and policies. Becker \& Gerhart (1996) and Pfeffer (1994) suggest that human resource policies should be sufficiently rare and inimitable to create a sustainable competitive advantage. This extends the 'traditional' idea of a technical, cost-oriented personnel policy (Huselid \& Becker, 1996; MacDuffie, 1995; Van Sluijs \& Den Hertog, 1993). In general, the HRM philosophy proposes that human resources are a valuable knowledge source that is difficult to imitate (e.g Den Hertog \& Huizenga, 1997; 2000; Becker \& Gerhardt, 1996; Pfeffer, 1994; Bamey, 1991), and that HRM involves the methods, policies and practices that allocate knowledge to the most productive use (Drucker, 1994). The instrument panel of the HRM field (Den Hertog \& Huizenga, 1997; 2000 ) can be used to steer the development of knowledge in the organisation and imptove innovation performance (Huselid et al., 1997). What main practices are relevant to ensure a cross-functional focus?

\section{Cross-functional mobility}

There exists strong evidence (Griffin \& Hauser, 1996; Song \& Perry, 1996, 1999; Souder, 1987) that shared commitment and co-operation between marketing and R\&D enhances success, for example, in setting new product goals, identifying opportunities for product improvement, resolving engineering problems and customer needs. Stimulating the crossfunctional mobility might be achieved by putting people in various jobs in various functions or projects. In the R\&D philosophy this has been documented as a dral career ladder (Allen \& Katz, 1986). The idea of the clual career ladder is that R\&D people have the opportunity to develop thenselves along a management trajectory or a research trajectory. This dual ladder can be mono-disciplinary in nature, if one specialises within the R\&D context. From the viewpoint of cross-functional mobility, this ladder might need a third career stream: a 'pyramid ladder'. A pyramid career would allow for a career development along three dimensions: the management level, deeper functional skills and broader cross-functional jobs.

\section{Career development \& planming}

Case studies record (e.g. Den. Hertog \& Van Slijs, 1995) that people become personally responsible for their career growth. In the past, firms provided lifetime employment and a career pattem. Individuals recognise that their employability increases if they acquire skills that make them more flexible for job switching and rotation (Gaspersz \& Ott, 1996). Career development plans can make explicit which path an individual has to follow to achiewe future job positions and become multidisciplinary. 


\section{Recruiment \& selection}

Typical of a "people business' is the recruitment, selection and coaching element. We expect ICT companies to be keen on these subjects as well. One way to acquire knowledge is the recruitment of people who have the necessary skills to perform a job. Recruitment and selection can take many forms, like formal selection and interview procedures, internal job pools or external networking. The selection policies are based on the principle of "matching job requirements with the employee"s knowledge and skills'. Aligning these practices with the imnovation could mean that the recruitment practice focuses on people who are apt to learning.

\section{Coaching \& rewarding}

Coaching of human resources is often oriented at supporting current job fulfilment and less on knowledge development. Coaching as a steering instrument can be supportive to innovation. It is used to identify differences between current and future requirements of knowledge and the skills within a person's individual profile. Steering on individual development plans aims to upgrade the knowledge level. Complementary to that are reward systems, known as one of the most powerful motivators in the organisation. Rewarding can be a direct instrument for evaluating an individual's contributions and progress.

\section{Edwcation de training}

This topic is a well-understood and obvious HRM instrument in the knowledge-intensive business sectors. We expect it to be a self-evident subject in the ICT sector. If education focuses on deepening of functional skills ("more of the same') and not on broadening skills this might risk the development of new knowledge (Mohman, 1992). To prevent this from happening education and training policies can be used as a steering instrument for crossfunctional knowledge sharing and development. This can take many forms like formal training and development programs. Furthemore, there is a risk that knowledge becomes obsolete over time. People forget, unlearn, are suck in routines, which hampers innovation. Even more, due to the intensified market competition and the ongoing urge for value and productivity increases, knowledge becomes obsolete quickly.

\section{Summary}

This chapter has shed light on the organisation and the link to innovation from a nomative and descriptive empirical perspective. The presented schools of thought can help us in understanding the innovation issues in the $1 \mathrm{CT}$ sector. Three generations of innovation process models have been discussed showing the progress in the empirical and theoretical insights of innovation processes. Innovation is viewed today as an interactive, multidisciplinary process with feedback activities. In outlining two types of organisation theories we observed that the contingency view debates the role of size, strategy and environmental conditions. The configuration view argues that much of the organisation's performance rests on finding a unique fit between the organisations components. Next to this, the organisation structure options have been discussed, e.g. the functional, matrix and project team structure. The basic message is that team approaches enhance cross-functional communication and co-operation, and increase the speed of development. In the remainder of this chapter we discussed the organisation culture and the human resounce factor. In the empirical part of this study we will show the similarities and difference with the actual management practises of ICT companies. We will evaluate our research results and the above findings of the empirical literature to put them into perspective. 


\section{Part II:}

\section{Research Design \& Methodology}

Part II provides the research methodology. The research process, the research strategy and design is presented: This contains the process of collecting, analysing, and interpreting observations. The use of nuttiple data collection and analysis approaclies is described as a dual methodology. $A$ dual methodology is explained by describing tow the combination of the following elements has been achieved: case studies based on in-company interviews with four persons, and an in-cempany large seale survey, consisting of over 500 variables. This combination can be referred to as a case survey. 



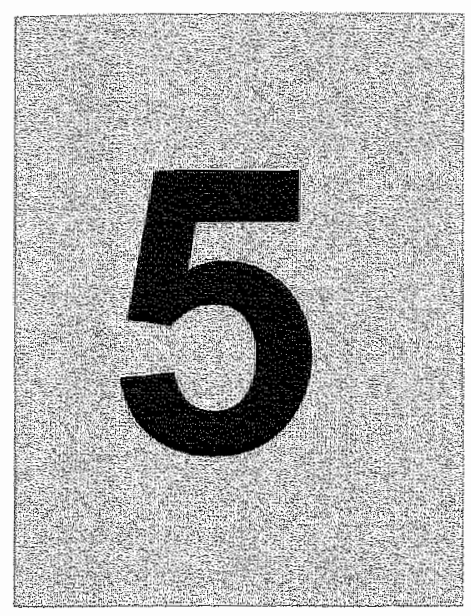

Research Methods 


\subsection{Innovation Performance Measurement}

In his article on organizational effectiveness Cameron (1986) stated that: '...despite the prominent place of organizational effectiveness in madern organizational America, confusion and ambiguity still characterize scholarly writing on the subject. Problems of definition, circumscription, and criteria identification plague most work... The landscape of the literature on success and innovation effectiveness can roughly be described in similar terms, where confusions, incomparability and disagreement surround the concept of innovation success. No uniform set of success criteria has been used throughout recent years, and in some instances success measures have been used in studies that were inappropriate to the level of research analysis. Cooper $(1993, \mathrm{p} .16)$ suggested that much of the confusion is inherent to the new product and process development literature, because innovation success is a multidimensional phenomenon. Alternative performance criteria like market share, meeting turnover objectives, and opening new opportunity cover different aspects of innovation. The drawback with such one-dimensional scores is that they include different types of new products, services and/or processes. This rating method does not unveil what drives success for innowation types like improved products, radically new services and/or improvements of processes. Other, more methodological sound studies (see Chapter 2), use multiple indicators, which cover a wide range of success rates, like objective financial measures, management satisfaction and overall ratings and expert opinions. Because there is no one standard concept of innovation success, this study had to balance on previously validated success criteria and theoretically sound new concepts.

When setting out the drivers of innovation performance, a number of beacons have to be developed in order to measure the company's performance. The success factors identified in this study particularly address success at the company level. Compared to measuring success at the project level this measure considers practices and characteristics - such as strategy, structure and culture - that are an important issue and not identifiable at the project level. Thes subjects cut across the boundaries of one project and apply at the business unit, division or enterprise level (Cooper, 1995). In other words, in this study we have taken a broader perspective of innovation.

\subsection{Development of Performance Criteria}

In the next paragraphs the development of the innowation success criteria will be explained. In previous chapters we have seen that innovation is a multidimensional phenomenon. In order to categorise the innovation performance criteria we need comparable success measures in this study. The procedure to develop these measures included the following steps:

1. performing a literature search on success criteria;

2. analysing empirical findings of the original sudy with respect to success measures,

3. determining the relevance of that criteria for this $\mathbb{I C T}$ study,

4. selecting commonly used criteria from empirical studies and comparing these with the original set of criteria,

5. inchuding a complete set of variables in the benchmark survey,

6. limiting 25 variables to a valid, workable set of 22 success variables,

7. correlating success variables, with company variables to derive both key success factors and discriminating success factors. 


\section{Literature search on success criteria}

The literature on new product development contimues to grow, leading to a variety of studies on measuring success of product development. Brown and Eisenhardt (1995) indicated three imnovation research streams (see also chapter 2 ). They pointed out that each stream centred on a particular form of performance. The rational plan research especially concentrates on financial performance measurement (profits, turnover, market share). The communication web research especially addresses the effects of communication on project performance, using perceptual success measures (team and management ratings). The disciplined problemsolving stream focuses on the product effects on the development process, by using operational success measures (e.g. speed and productivity).

In their report on measuring product development success and failure, Griffin arid Page (1993) observed that success is a multidimensional concept, i.e. that new product success can be considered in different ways. Companies can innovate for different goals. Some companies innovate to achieve a better efficiency, or a larger market share, while others want to enter new business areas or improve turnover and profitability. Clearly, innovation has a multidimensional flavour, just as innovation success.

Early innovation studies usually focused on a single type of new product success. Different innovative efforts were looked upon from this single point of view. This one-dimensionality might limit the usefulness of the findings. It might overlook factors because the focus is on one dimension, and factors relate to one goal. Other factors might not be included because they relate to other forms of success, which were not part of the study. The logic behind this multifaceted picture of success is that different factors, for example technological success, may actually be derived from other types of success. In statistical terms: inter-correllation. One should be careful in using one saccess measure because factors are goal-specific.

The same arguments apply to studies using one overall success criteria. Many, also recent, studies use one overall success rating to identify key success factors. Sometimes one overall rating is used as a measure, while in other studies the overall rating is derived from statical analysis. In both cases, reducing different sets of success criteria to one single overall success dimension may endanger the research findings. Many of the ingredients of success might remain uncovered (for statistical reasons). Generalisation of performance to one overall success measure may limit the interpretation of the many innovation factors. Factors may be overlooked for statistical reasons: those that do not correlate significantly with an overall success measure are rejected from further analysis. Relationships maly exist beiween single performance criteria and one individual variable, but disappear in the statistical generalisation to one overall success.

The current research builds on the empirical findings of the MERIT study and the viterature search on performance criteria, and takes a broader perspective of innovation success. We are interested in success not only in terms of growih, profit and market share, but also in terms of innovation aspects. We are interested in the key success factors that drive high overall suecess, but also in the discriminating factors and key factors that drive innovation success. We did not focus on one single success criterion, but took a range of success criteria to explore the relationships between practices and performance. By allowing the companies to use multiple measures of success we obtained more detailed information. We did not specify or defined innovation success in advance. Instead we used a sensitising concept for successful innovation. A sensitising concept is a workable definition that is open to improvement based. on empirical findings. We applied the following broad definition of innovation the renewal, 
including improvement, of products, processes and services. Cooper (1996) suggested two definitions of newness:

1. New to the company, in the sense that the firm has never made or sold this type of product, service or process before, but other firms might have.

2. New to the market or "innovative": the product is the first of its kind on the market.

The MERTT study used the first definition. In order to ensure a valid replication of the study we also addressed the first definition. The success rate of innovation has been covered in the innovation literature along with a number of other terms such as "innovation performance", "innovation effectiveness', "innovation success" or "new product performance". We also used the success definition used in the MERIT study. Successful innovation was defined as the economic exploitation of imnovation. "Turning good ideas into good currency", as Van de Ven (1986) suggested. This enabled us to measure success in terms of achieving cost, profit or turnover objectives, meeting customer needs or technological success. We recognised that performance depends to a large extent on the types of new products, services and processes. The impact of innovation efforts is not measured at one moment in time. A broader concept would have to take the life cycle of innovations into account. Furthermore, by including multiple measures both the development and management of new products, services and processes are taken into account (Barclay, 1992). To summarise, the idea is to address the success factors based a a multidimensional framework. Although there are no ready-made procedures for this method several innovation studies provide examples on the use of this method of success measurement.

\section{Imnovation success measurement}

Cooper and Kleinschmidt (1995) conducted a multi-firm benchmarking study to identify the company-level drivers of success in new product development. Given the multidimensional nature of NPD performance they used 10 performance measures of a company's new product programme: a success rate, percentage of turnover, profitability relative to spending, technical success rating, turnover impact, profit impact, success in meeting turnover objectives, success in meeting profit objectives, profitability relative to competitors, and overall success. Based on factor analysis of the metrics they constructed two overall dimensions: programme profiability and programme impaci. Programme profitability comprised the company"s innovation programme profitability rating and the overall success rating, both relative to competitors; whether the programme met profit objectives; the programme's profitability relative to spending; the impact of the programme on firm's profits; and whether the programme met turnover objectives. Programme impact comprised the percentage of tumover by new products; the impact of the innovation programme on company turnover and profits; an overall success rate, and a technical success rating. A similar procedure was performed in Cooper"s study (1986 \& 1996) of 161 firms on the drivers of new product performance in business units within corporations. By using this procedure, insight was gained into the factors and practices that discriminate between top and poorer performers. Ten key performance metrics were used identical to the 1995 study. Based on the factor analysis two success dimensions were constructed: profitability and impact. Profitability captures how profitable the business's total new product efforts were. This dimensions consisted of profitability versus competitors and overall success rating of the business's total new product effort; whether the total initiative mer profit objectives; its profitability relative to spending; and the impact of the total effort on the business's profits. Impact was concerned with the impact of total new product efforts on the business. This performance dimension consisted of percentage turnover by new products achieved by a firm (in their study a business unit); the 
impact of new products on both turnover and profits of the unit; the success rate achieved; and the technical success rating.

Cooper \& Kleinschmidt (1987) conducted research on different dimensions of new product success based on a sample of 125 companies, with 123 new product successes and 80 failures. They found three independent dimensions of success: financial performance, opportumity windows, and morket share. These dimensions are a reduced subset of ten measures of new product performance: profitability level, the product's payback period, donestic market share, foreign market share, relative turnover, relative profits, turnover versus objectives, profits versus objectives, opportunity window on new categories and opportunity window on new markets. The financial performance dimension captured the overall financial success of the product. This comprised of relative profits, meeting profit objectives, meeting furnover objectives, relative turnover, profitability level, and payback period (negative). The opportunity window item shows the degree to which the product/service opened new opportunities for the furm (in terms of category of products and a new market for the its products). The third dimension, market share, describes the impact of the product on both domestic and foreign markets. This dimension thas been constructed by using market share measures and relative tumover and meeting turnover and profit objectives.

In a large sample benchmark study including 135 firms (Cooper \& Kleinschmiat, 1995) new product performance was captured using seven measures of company's new product programme performance. New product programme referred to the totality of new product efforts of the company or division of analysis. Firms from the USA, Canada, Germany and Denmark participated. This study explored the relationship between practices and performance by considering the impact that each practice or firm claracteristic had on performance. In the research design seven metrics were defined: meeting company sales objectives, profit objectives, success rate of new products, sales impact of entire programme on company, profit impact on the company, profitability relative to competitors and overall success, as a global measure relative to competitors.

Overall, these studies have provided useful insights into how new product success can be measured and which independent and unique dimensions of success can be used. Given the fact that many different concept of success were used in the past, the financial return on investment is one of the most easily quantifiable parameters (Maidique \&. Zirger:1984). At the same time it is not the only important one. Success is clearly more than the financial benefits accruing from innovation. More extensive studies, such as NewProd II (Cooper \& Kleinschmidt, 1987), incorporated more measures, with more explanatory power. Absolute figures, like profitability levels, were no longer measured in absolute terms but related to competifor profit figures. Profitability as a level of success was constructed relative to meeting project objectives, and management-rating measures were used in addition to more quantifiable financial measures. In this way success was measured in different directions. Next, we will present the development of the performance criteria for this study step by step. 


\subsection{Innovation Success Criteria Selection}

For the data collection a benchmark instrument was developed. Among the variables in this survey were 25 success variables. The variables were constructed and derived on the basis of an extensive literature search on organisational effectiveness and effective innovation management (Page \& Griffin, 1993). The criteria for the selection of the variables related to the validity, rigour, and relevance of the success variables in earlier empirical studies. When constructing the set of success variables, emphasis was placed on measuring existing structure, process and action outcomes. In other words, the study tried to assess performance from realistic, observable sources. In addition, we based performance on common practice in the product development literature (Page \& Griffin, 1993; Brown \& Eisenhardt, 1995). A part of the success variables we selected belong to the category of managerial perceptions of innovation aspects. These variables (see chapter 7) were gauged using a $1-5$ Likert-type scale. These variables were combined with a second category of financial data, which were directly measured as percentages or absolute values. All measures were developed to address firm level innovation, i.e. performance measurement was not restricted to a single product, project or programme level, but included the total scope of a firm's product and process innovation efforts

The original set of success ratings included 25 variables. This set was narrowed down to 22 performance variables. Several reasons were underlying this success measure reduction. The initial set of 25 variables included all success criteria of the preceding MERIT study. Furthermore this study used some new success variables which originated from the innovation literature. These measures related to market success, such as market share per product/service range, and management ratings of market leadership. The reasons for eliminating success variables were:

1. Data availability: The main reason for reducing the set of success ratings was that we had insufficient data for some variables. A number of companies did not or was not able to provide the data needed. In particular, data related to market shares, profit and sales contributions from the company's range of products and services were not provided, not known, unavailable or confidential. For some data, e.g. profit-related figures, the success variables were recorded as missing data because of confidentiality. A number of participating firms that were part of a larger corporation were not allowed to publish detailed company figures, either because of restrictions for stock market quoted firms, or as part of the corporation's communications policy,

2. Misinterpretation and non-comparability: Two success-related questions, concerning the degree of technological success and meeting project objectives, were skipped during the data collection phase of the survey, due to the possibility of misinterpretations of the questions, which would affect data analysis.

First, data results revealed that most firms performed well. The positive growth figures, on many success measures, reflect the growth development of the sector. When we relate turnover and profit growth to innovation the following results appear (table 5.1). On average, new products and services introduced throughout the past 3 years accounted for $38 \%$ of annual turnover and $39 \%$ of annual profit. 
Table 5.1: Contribution to turnover and profit resulting from innovation

\begin{tabular}{lcc}
\hline & $\begin{array}{c}\text { Contribution to tumover } \\
\%\end{array}$ & $\begin{array}{l}\text { Contribution to profit } \\
\%\end{array}$ \\
\hline Products \& services newly introduced in the market & $38 \%$ & $39 \%$ \\
$\begin{array}{l}\text { Products \& services drastically improved } \\
\text { during the past } 3 \text { years }\end{array}$ & $30 \%$ & $30 \%$ \\
$\begin{array}{l}\text { Products \& services hardy improved } \\
\text { during the last } 3 \text { years }\end{array}$ & $32 \%$ & $31 \%$ \\
\hline
\end{tabular}

With respect to performance in the development process, an average of $39 \%$ of new product and service ideas were selected to become an innovation project. $56 \%$ of the projects succeeded in reaching the commercialisation phase. This implies that on the basis of this study sample of 32 firms, on average 1 out of 5 ideas, resulted in a commercial product or service in the ICT sector.

\section{Factor analysis}

The next step in the performance evaluation was to construct a performance map to reduce the individual performance variables (Cooper \& Kleinschmidt, 1995). This was done through a factor analysis. The purpose of factor analysis was to deduct a set of underlying, unobservable patterns (factors) from covariance relations among individual variables. The variables within one factor show a high correlation, whereas they are hardly correlated with variables in another factor. Several criteria have been used for the final choice of the number of factors (Cobbenhagen, 1999):

- the proportion of variance explained;

- knowledge of the subject matter, and

- the 'reasonableness' of the results.

- the goal to obtain a simple structure of factor solutions

Factor analysis technique was used to derive a comprehensive set of success variables. As discussed in chapter 2 , innowation success is multidimensional phenomenon. Therefore we used a factor analysis to obtain a range of success criteria. The statistical procedure included the following steps:

1. Based on the extensive literature survey (see chapter 2) and the validated MERITbenchmark questionnaire (see: Cobbenhagen, 1999) 25 individual success variables were selected. Before applying the survey we limited the set of 25 success variables to a range of 22 success variables. This was based on the applicability findings of an ICT expert panel. Due to data availability a workable set of 20 success variables was used (table 5.3 provides the details). The research also aimed to find a simple structure of the factor solutions.

2. A principal component analysis was conducted, with a sample of 32 companies $(n=$ 32): based on the results we extracted 6 factors on the basis of an Eigenvalue Varger than 1. This set of factors explained $78 \%$ of the variance. The correlation matrix indicated that the variables were suitable for factor analysis. The KMO statistic was 0.61 , which is 'middling appropriate' for factor analysis (Kaiser, 1974). 
3. A Varimax rotation was conducted: we used this rotation technique to converge to better success variables, which are better interpretable. The results of this Varimax rotation are presented in table 5.2 . The advantage of performing Varimax rotation is a higher correlation of the individual variables with the factors. We observed that 5 out of 20 variables were correlated to more than one factor, indicating that some factors are somewhat correlated to each other. This is especially the case with the following variables: rapid product \& service introduction, continuous innovation, capturing new market opportunities and cost reductions. Although a small violation against simple structure analysis (not all variables perfectly correlated with one and only one factor), the results produced an interpretable set of factors.

4. Based on the statistical results and grouping of variables we labelled the factors as process success, portfolio success, growth success, opportunity success, project success and quality.

5. To rate the overall success of a firm the top management and technical managers were asked to rate their firm"s overall performance. Intercorrelation of the overall success measure and the factors reveals no significant intercorrelation. This overall success measure was used together with the six other extracted success measures. 
Table 5.2: Factor loading on success variables

\begin{tabular}{|c|c|c|c|c|c|c|}
\hline Variable & $\begin{array}{l}\text { Process } \\
\text { Success }\end{array}$ & $\begin{array}{l}\text { Portfolio } \\
\text { Success }\end{array}$ & $\begin{array}{l}\text { Growth } \\
\text { success }\end{array}$ & $\begin{array}{l}\text { Opportunity } \\
\text { success }\end{array}$ & $\begin{array}{l}\text { Projed } \\
\text { success }\end{array}$ & Quality \\
\hline $\begin{array}{l}\text { Tumover growth } \\
\text { from new products }\end{array}$ & 0.45 & & & & & \\
\hline $\begin{array}{l}\text { Introduction new } \\
\text { process } \\
\text { technologies }\end{array}$ & 0.67 & & & & & \\
\hline $\begin{array}{l}\text { Degree of technical } \\
\text { creativity }\end{array}$ & 075 & & & & & \\
\hline $\begin{array}{l}\text { Technological } \\
\text { competence }\end{array}$ & 0.85 & & & & & \\
\hline $\begin{array}{l}\text { Technological } \\
\text { knowledge transfer }\end{array}$ & P.985 & & & & & \\
\hline Cost reductions & 0.60 & & 0.45 & & & \\
\hline $\begin{array}{l}\text { Capturing new } \\
\text { market } \\
\text { opportunities }\end{array}$ & 0.63 & & 0.57 & & & \\
\hline $\begin{array}{l}\text { Rapid product \& } \\
\text { service introduction }\end{array}$ & 0.40 & $\sqrt{049}$ & 0.42 & & & \\
\hline $\begin{array}{l}\text { Continuous } \\
\text { innovation }\end{array}$ & 0.43 & 0059 & & & & \\
\hline $\begin{array}{l}\text { Turnover from new } \\
\text { products and } \\
\text { services }\end{array}$ & & 0.94 & & & & \\
\hline $\begin{array}{l}\text { Profit from new } \\
\text { products and } \\
\text { services }\end{array}$ & & 02 & & & & \\
\hline Turnower growth & & & P076 & & & \\
\hline Profit growth & & & 80.62 & & & \\
\hline $\begin{array}{l}\text { Growth of } \\
\text { eimployees }\end{array}$ & & & 086 & & & \\
\hline $\begin{array}{l}\text { Turnower growth by } \\
\text { entering new } \\
\text { markets }\end{array}$ & & & & 0.67 & & \\
\hline $\begin{array}{l}\text { Profit growth by } \\
\text { introducing new } \\
\text { products and } \\
\text { services }\end{array}$ & 0.42 & & & 6.5.5. & & \\
\hline $\begin{array}{l}\text { Profit growth by } \\
\text { entering new } \\
\text { markets }\end{array}$ & & & & (1) & & \\
\hline $\begin{array}{l}\text { \% of new ideas } \\
\text { turning into projects }\end{array}$ & & & & & 0.80 & \\
\hline $\begin{array}{l}\% \text { of projects that } \\
\text { reach market } \\
\text { introduction }\end{array}$ & & & & & 0.81 & \\
\hline $\begin{array}{l}\text { Degree of product \& } \\
\text { service quality }\end{array}$ & & & & & & 0.65 \\
\hline
\end{tabular}

Note: Factor loadings less than 0.4 have been omitted. 
Table 5.3: Short description of success variables

\begin{tabular}{|c|c|c|}
\hline Variable & Short description & Rating \\
\hline $\begin{array}{l}\text { Thinower growath from } \\
\text { new products }\end{array}$ & $\begin{array}{l}\text { The degree to which a company, compared to it's } \\
\text { competitors, perfoms in the realisation of lumower } \\
\text { growth by introducing new products into the market }\end{array}$ & $\begin{array}{l}\text { Managerial rating; Likert-typie } \\
\text { scale, score } 1\left(-5^{*}\right)\end{array}$ \\
\hline $\begin{array}{l}\text { Introduction new } \\
\text { process technologies }\end{array}$ & $\begin{array}{l}\text { The degree to which a conpany, compared to it's } \\
\text { competitors, performs in the introduction of new } \\
\text { process technologies }\end{array}$ & 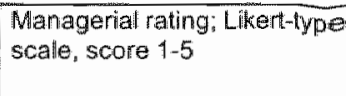 \\
\hline $\begin{array}{l}\text { Degrae of technical } \\
\text { creativify }\end{array}$ & $\begin{array}{l}\text { The degree to which a company, compared to it's } \\
\text { competitors, performs on technical creativity }\end{array}$ & $\begin{array}{l}\text { Managerial rating; Likerthpe } \\
\text { scale, score 1-5 }\end{array}$ \\
\hline $\begin{array}{l}\text { Technobogical } \\
\text { competence }\end{array}$ & $\begin{array}{l}\text { The degree to which a company, compared to it"s } \\
\text { coumpeliturs, performs in technological competence }\end{array}$ & $\begin{array}{l}\text { Managerial rating; Likert-type } \\
\text { sciale, score } 1-5\end{array}$ \\
\hline $\begin{array}{l}\text { Technological } \\
\text { knowledge transfer }\end{array}$ & $\begin{array}{l}\text { The degree to which a company, compared to it's } \\
\text { competitors, performs on technological knowledge } \\
\text { transfer through co-operation agreements }\end{array}$ & $\begin{array}{l}\text { Managerial rating: Likert-lype } \\
\text { scale, score } 1.5\end{array}$ \\
\hline Cost reductions & $\begin{array}{l}\text { The degree to which a company, compared to it's } \\
\text { competitors, performs in cost reductions because of } \\
\text { new technologies or materials and tools }\end{array}$ & $\begin{array}{l}\text { Managerial rating: Likert-type } \\
\text { scale, scone } 1.5\end{array}$ \\
\hline $\begin{array}{l}\text { Capturing new market } \\
\text { opportunities }\end{array}$ & $\begin{array}{l}\text { The degree to which a company, compared to itt's } \\
\text { compelitars, succeeds in capiuring market } \\
\text { opportunities }\end{array}$ & $\begin{array}{l}\text { Managerial rating; Likert-type } \\
\text { scale, score } 1-5\end{array}$ \\
\hline $\begin{array}{l}\text { Rapid product \& } \\
\text { service introduction }\end{array}$ & $\begin{array}{l}\text { The degree to which a company, compered to it's } \\
\text { competitors, performs in rapidly introducing product } \\
\text { and services into the market }\end{array}$ & $\begin{array}{l}\text { Managerial rating; Likert-type } \\
\text { scale, score } 1.5\end{array}$ \\
\hline $\begin{array}{l}\text { Continulious } \\
\text { innovation }\end{array}$ & $\begin{array}{l}\text { The degree to which a company, compared to it's } \\
\text { competitors, performs in continuous product and } \\
\text { services innovation }\end{array}$ & $\begin{array}{l}\text { Managerial rating; Likert-type } \\
\text { scale, score 1-5 }\end{array}$ \\
\hline $\begin{array}{l}\text { Turnover from new } \\
\text { products and services }\end{array}$ & $\begin{array}{l}\text { The contribution to hurnover from new products and } \\
\text { services }\end{array}$ & $\begin{array}{l}\text { Financial rating, \% of total } \\
\text { tumover }\end{array}$ \\
\hline $\begin{array}{l}\text { Profit from new } \\
\text { products and services }\end{array}$ & $\begin{array}{l}\text { The contribution to profits from new products and } \\
\text { services }\end{array}$ & $\begin{array}{l}\text { Financial rating. \% of lotal } \\
\text { profit }\end{array}$ \\
\hline Tumover growh & The realised lurnowar growth $1996-1995$ & Financial rating , growth rate \\
\hline Profit grawth & The realised profits in 1995 & Financial rating growth rate \\
\hline Growth of employees & $\begin{array}{l}\text { The nalised growth in number of employees } 1996- \\
1995\end{array}$ & Financial rating, growth rate \\
\hline $\begin{array}{l}\text { Turnower growth by } \\
\text { entering now markets }\end{array}$ & $\begin{array}{l}\text { The degree to which a company, compared to if's } \\
\text { competitors, performs in the realisation of lurnower } \\
\text { growth by creating new markets }\end{array}$ & $\begin{array}{l}\text { Managerial rating; Likert-type } \\
\text { scale, score } 1.5\end{array}$ \\
\hline $\begin{array}{l}\text { Profil growth by } \\
\text { introducing new } \\
\text { products and services }\end{array}$ & $\begin{array}{l}\text { The degree to which a company, compared to it's } \\
\text { competitors, pertorms in the realisation of proft } \\
\text { growth by introducing new products into the market }\end{array}$ & $\begin{array}{l}\text { Managerial rating; Likert-type } \\
\text { scale, score } 4-5\end{array}$ \\
\hline $\begin{array}{l}\text { Profit growth by } \\
\text { entering new markets }\end{array}$ & $\begin{array}{l}\text { The degree to which a company, compared to it's } \\
\text { competitors, performs in the realisation of profit } \\
\text { growth by creating new markets }\end{array}$ & $\begin{array}{l}\text { Managenal rating, Likert-type } \\
\text { scale, score } 1-5\end{array}$ \\
\hline
\end{tabular}




\begin{tabular}{|c|c|c|}
\hline $\begin{array}{l}\text { Do of new ideas } \\
\text { huming into projects }\end{array}$ & $\begin{array}{l}\text { The actual percentage of new product ideas that } \\
\text { resulted in a project. }\end{array}$ & Percentage rating \\
\hline $\begin{array}{l}\text { W of propects that } \\
\text { reach market } \\
\text { introduction }\end{array}$ & $\begin{array}{l}\text { The actual percentage of imnovation projects that } \\
\text { reached the market and were successful }\end{array}$ & Percentage rating \\
\hline $\begin{array}{l}\text { Degree of product \& } \\
\text { service quality }\end{array}$ & The level of quality of products and services & $\begin{array}{l}\text { Managerial rating; Likert-type } \\
\text { scale, score } 1.5\end{array}$ \\
\hline
\end{tabular}

For more detailed information: the full questionnaire is available upon request. See Cobbentagen el al. (1995) for a short published version.

$$
\begin{aligned}
& \text { *) Scale: } \\
& 1=\text { company lags behind the pack } \\
& 2=\text { company drives in the end of the pack } \\
& 3=\text { company drives in the midde of the pack } \\
& 4=\text { company leadis the pack } \\
& 5=\text { company leads the fiontrunners group }
\end{aligned}
$$

\section{Argumentation for factors}

Next to this statistical interpretation of success criteria, the grouping of the variables can be argued from a content point of view.

1. Process success: This performance dimension consists of seven success variables. All of them were management ratings. The ratings were closely correlated with each other. This dimension puts emphasis on: (a) an innovation's contribution to turnover growth, and (b) the incorporation and translation of new technologies into new processes. These measures have a strong correlation. This might be an indication that companies, who have been successful at absorbing advanced technologies and turning these into new products and services, are also high growth companies, in terms of turnover. This performance dimension includes the following success variables:

- realisation of tumover growth by introducing new products on the market;

- successful introduction of new process technologies;

- the degree of unique technical creativity;

- the degree of technical competence relative to competitors;

- achievemeni of cost reductions resulting from new technologies, resources, and tools;

- successful transfer of techological knowledge through co-operation;

- capturing new market opportunities.

Brown \& Eisenhardt's research (1995) of the empirical innovation literature supports the underlying rationale for these dimensions. The combination of the two factors, process performance and turnover-related success, might be the following. Process performance entails the introduction of new technologies (e.g. Java, HTML), resources (e.g. new technical know-how) and tools (e.g. software development tools). A productive process means lower costs and hence lower prices for products and services, which in turn might lead to increased product success. Furthermore, the introduction of new technology creates a faster process and might lead to more flexibility and less time for development and production. This may result in greater financial success, in terms of turnover growth. The process success dimension belongs to the communication web stream of innovation research as discussed by Brown \& Eisenhardt (see chapter 2). It consists of perceptual success measures provided by multiple informants, e.g. management ratings of overall technical performance and success in terms of achieving turnover growth and cost reduction.

2. Portfolio success: This performance dimension consists of four success variables. Two of them are a management rating, the other variables are percentage ratios. Such ratios should 
be a better measure than an absolute number due to the warying sizes of the business units and firms in our sample. This factor portrays the success of continuous innovation. Successful firms that, relative to their competitors, pick up innovative ideas before their competitors do so and transform them quickly into new products and services. These firms. are the first to seize profit and "turning good ideas into money quickly". The factor includes:

- continuous innowation in products and services,

- the speed of innowation, e.g. rapid product and service introduction,

- the percentage of turnover generated by products and services introduced throughout the past three years (see also table 5.1),

- the percentage of profit that generated by products and services introduced throughout the past three years (see also table 5.1 ).

This performance dimension relates to the rational plan research stream in terms of Brown \& Eisenhardt (1995). Such measures have been used in other studies to measure performance where the latter two variables are considered core success measures and a standard success measure used by the Product Development Management Association (PDMA) (Griffin \& Page, 1993; Barczak, 1995). It characterises new product effectiveness, whereas the former dimension emphasises process performance. Portfolio success is primarily oriented towards the financial performance of new products and services relative to the existing range of products and services. This dimension is similar to Cooper's $(1987,1995)$ success dimension of impact. The portfolio success measure takes the impact of innovation efforts on the business into account.

3. Growth success: This performance dimension consists of turnover, growth \& profit success variables, both measured as percentage ratios. It includes:

- the turnover growth, of each company for the years 1996 and 1995;

- employee growth, of each company for the years 1996 and 1995;

- profits (as a percentage of annual turnover) of each company for the years 1996 and 1995.

This perfomance dimension is a financial measure that closely relates to the ration plan research stream. It characterises how profitable the business of the total new product and service efforts and process innovations are. This dimension mirrors success ratings at the company level, used in the SAPPHO study $(1972,1974)$ and many of Cooper et al.'s NewProd studies (1979, 1987). In a replication study of NewProd (Cooper, 1992), using data from 123 industrial product firms, success and failure were defined from a financial viewpoint. The study used the degree to which the new product's profits exceeded (or fell short of) the firm's acceptable profitability level for this type of investment. The constructed performance dimension is identified (Griffin \& Page, 1993) as an appropriate measure.

4. Oppormmity success: This perfomance dimension consists of three success variables, measured by management ratings. It is a factor that describes the success of new business development efforts. It consists of:

- The degree to which a company, compared to it's competitors, performs in the realisation of turnover growth by creating new markets;

- The degree to which a company, compared to it's competitors, performs in the realisation of profit growth by introducing new products into the market; 
- The degree to which a company, compared to it's conpetitors, performs in the realisation of profit growth by creating new markets

This dimension is similar to what Cooper \& Kleinschnidt (1987) identified as an "opportunity window". Business opportunity is the degree to which the product or service opened new opportunities to the firm resulting in a new productcategory and a new market for the firm. The dimensions adhere closely to Hamel \& Prahalad's (1994) idea of stretching a firm's competence endowment to pursue attractive opportunities. The dimension of business opportunity belongs to the communication web research stream (Brown \& Eisenhardt's, 1995 ).

5. Project success: This performance dimension consists of two success variables, both measured as percentages. The "project success" measure describes the success of the project efforts of the firm. The degree of success refers to (a) the generating of new product/service ideas, and (b) the project selection mechanisn of the firm to select ideas and turn them into projects. Furthermore it portrays the success of managing innovation projects in commercially launching a new product or service idea. This factor consists of:

- the percentage of new ideas that have become a project, and

- the percentage of projects that have resulted in a product on service that is launched in the market.

Cooper \& Kleinschmidt (1995) used a similar measure, which they called success rate, which measures the percentage of projects that entered the development stage and were ultimately considered a commercial success. Both Iansiti's (1993, 1994) studies of 27 development projects in the mainframe industry and Eisenhardt and Tabrizi's (1995) study of 72 development projects in 36 computer firms used similar project-related success measures. These studies used speed (of the development process) as a pertormance measure. This measure portrays the success of the development efforts. Both studies related this performance dimension to such factors as pre-development work and early project planning. The project success criteria fit with the disciplined problem-solving research stream (Brown and Eisenhardt, 1995). This stream is concerned with problem solving in projects (e.g. by cross-functional teams) and high communication flows, to successfully execute the project step in the development process.

6. Quality: This perfonmance dimension consists of one success variable, which was rated by the director. Single-item measures are not generally considered 'good measures' of any construct. However, the measure was strongly independent of the other success measures. This variable describes the quality of the business offerings of a company, as observed by the director. It consists of the variable: quality of products and services, relative to competitors.

This dimension characterises the successful adaptation of products and services to customer needs, thereby realising high-quality product/service offerings. This is often regarded as a pre-requisite for the firm"s continuily. Striving for quality improvement is an important factor in realising competitive advantage. Keller (1986) used a quality measure in a study of 32 R\&D project groups. In this study, quality was related to the quality of the project outcome. Clark \& Fujimoto (1991) and Womack et al. (1990) used, among speed and productivity variables, quality as a performance variable in their in-depth case studies in the automobile sector. The quality performance dimensions mostly fits with the disciplined problem-solving research stream, which is characterised by single-industry 
studies (Brown \& Eisenhardt, 1995). In this stream, quality is often viewed as a highquality productservice concept resulting from a fast development process.

In sum, using performance dimensions that can be described along the three streams of innovation research proposed by Brown \& Eisenhardt (1995, p. 365), we focused on somewhat different aspects of innovation success. Complementary success variables have been combined with independent factors in order to cover the many dimensions of innovation success.

\section{Owerall innovation success}

The constructed performance dimensions are independent. A tinal step in the performance evaluation was the use of an overall success measure. Next to these success dimensions, top management and technical managers were asked to rate the overall success of their firm's imnovative efforts. Intercorrelation of the overall success measure and the factors reveals no significant intercorrelation. This provides strong support for the relevance and validity of the overall success criteria. With these categories of success measures we continued further statistical analysis to identify the key success factors in innovation. What then are the key success factors in innovation, the factors that drive performance in IT companies? The empirical results are shown in chapter 7.

\subsection{Research Design Differences: Some Remarks}

Basically, the ICT study is a replication of the MERIT study conducted previously to explore the factors that differentiate frontrunners from pack members (Cobbenhagen, 1999), which is part of the innovation programme of the MERIT research institute. Both the survey methods and questionnaire design have been re-used.

The present study is part of a formal research programme (Cobbenhagen, 1999). The possible advantage of a research project in a programme is the opportunity to contribute to multiple objectives that go beyond the scope of an individual project (Hoesel, 1985). The projects might am at verification and cross-validation of insights and/or the development of a theoretical model. In chapter 2 we referred to a number of important innovation research programmes, such as NewProd (Cooper et al., 1987) and SAPPHO (Rothwell, et al., 1974). Another well-known innovation programme is the Minnesota Innovation Research Program (MIRP) (Van de Ven \& Poole, 1989). The current project is the third in at series of five projects in the MERIT Innovation Programme (see table 5.4).

The first project in the range was a qualitative study of imnovation management in a number of companies in the chemical industry. The outcomes of this study, and the literature study performed in parallel, resulted in a working model (temporary construct) and provided insight for the methodological steps to be taken, in particular (Cobbenhagen, 1999, p. 62):

- Test current insights (or rather, 'conjectures") on the basis of hypotheses, and

- Develop a general (non-sector-specific) theoretical model.

The second project was sef up on the basis of policy and scientific reasons. It also enabled the development and iefinement of novel ideas and the set-up of a qualitative and quantitative data set and instruments. The objective of the complete set of projects is to come up with and elaborate on a theoretical framework, eg. with the verification of hypotheses, by performing 
replication sndies in different business populations. This approach to deduction and replication can provide a deeper understanding of innovation management.

\section{Table 5.4: Innovation research programme and projects at MERIT}

\begin{tabular}{|c|c|}
\hline Innowation nesearch project & Research aim \\
\hline $\begin{array}{l}\text { Mamagement of Innovation in the Processing lindustry } \\
\text { (research period 1988-1994) }\end{array}$ & $\begin{array}{l}\text { Explorative siludy almed at understanding the } \\
\text { complex phenomenon of innowation and how it can } \\
\text { be managed }\end{array}$ \\
\hline $\begin{array}{l}\text { Successful innovating firms: Front rumers versus } \\
\text { pack members (research period } 991-1996 \text { ) }\end{array}$ & $\begin{array}{l}\text { ldentifying the factors that differentiate frontrumers } \\
\text { from pack members in a wide range of industries and } \\
\text { service sectors }\end{array}$ \\
\hline $\begin{array}{l}\text { Innovation success in the laformation \& } \\
\text { Communication Technology sector (reseanch period } \\
1996-2000 \text { ) }\end{array}$ & $\begin{array}{l}\text { identification and explanetion of key success factors. } \\
\text { Developing process insights into innovation } \\
\text { management. Validation of sector-specific and non- } \\
\text { sector-specific key success lactors in the ICT sector } \\
\text { within a random sample. Contribute to use and } \\
\text { development of knowledge of dual methodologies of } \\
\text { case survey. }\end{array}$ \\
\hline $\begin{array}{l}\text { Achieving irnowation success: Breaking away from } \\
\text { the pack (research period 1998-2000) }\end{array}$ & $\begin{array}{l}\text { Longitudinal follow-up study: prescriptive study } \\
\text { aiming at identification of how firms can become } \\
\text { frontrunners }\end{array}$ \\
\hline $\begin{array}{l}\text { Successfully innovating firms in Spain (research } \\
\text { period } 1998-2002 \text { ) }\end{array}$ & $\begin{array}{l}\text { Valication of the second project within a random } \\
\text { sample in a different country }\end{array}$ \\
\hline
\end{tabular}

The current study in the ICT sector builds on these insights and the work conducted in the preceding projects. Moreover, the research programme builds on the wide range of literature available in the area of innovation management. In the preceding chapters as well as the preceding research projects, an attempt las been made to incorporate the literature related to imnovation. The extensive literature study has been the source for the developinent of a temporary theoretical framework. Notwithstanding the methodological objectives to triangulate (i.e., combining methodologies in the study of the same phenomenon (Hammerstey \& Atkinson, 1983), verify and cross-validate, there are differences between research projects. The aim has been to achieve uniformity in research approach, research questions, objectives and instruments in an innovation programme approach. Given the research objectives of the current study (ICT sector-specific key success factors) it is difficult to completely cross-validate earlier research using the same approach due to its sector-specific nature.

Furthermore, given the nature of the research projects, with large samples, interview and data sets and intensive company involvement, each research project must devote a certain degree of methodological flexibility to the research goal. The verification of the survey, data sets and operational research procedures require testing and updating in order to contribute to the development of a general non-sector-specific model. Below is a list of choices that have been made, either resulting from the different research context or in the process of the research due to practical considerations (e.g. company commitment, resource capacity for research. confidentiality restrictions during data gathering). Where does the current research study match and where does it differ from the preceding research project by Cobbenhagen (1909)? 


\section{Similarities in research setting}

1. Both studies are at the company level, not the project level.

2. Both studies try to provide a comprehensive picture of explanatory factors, by exploring the correlation between groups of variables in order to provide a more integrated overview of the drivers for innovation success.

3. Both studies are concerned with linking to the existing theory and contribute to theory development by generating redundancy of data (Glaser \& Strauss, 1967).

4. Both studies have a strong commitment from the companies involved and had been commissioned by policy sponsors (e.g. Ministry of Economic Affairs and sector representative organisations), resulting in management-relevant concepts and outcomes.

5. Both studies used extensive data-gathering techniques, including a survey, interviews, and documentation analysis by means of instruments developed in the research programme.

6. Both studies recognise the important role of having both qualitative and quantitative data. The quantitative data give an indication of the 'what' question, whereas the qualitative data provide insight into the "how" question (Yin, 1989). Mixing the different types of data contributes to: a) an in-depth understanding of the phenomenon under investigation, b) understanding the driving forces for innowation success, c) identifying findings consistent with and inconsistent with earlier studies, and d) triangulating the company picture.

7. Both studies build upon good practices to combine managerial ratings with more objective ratings for success. This issue of inter-subjectivity was explicitly addressed in the studies by conducting a) a pre-coded questionnaire and survey, b) exact financial measurements, and c) the gathering, use and mixture of diverse sources of information.

\section{Differences in research seting}

1. The current study is sector-specific, the MERJT study is cross-sector.

2. The current study investigates key success factors without verifying hypotheses, whereas the preceding study, to an limited extent, does verify hypotheses.

3. The preceding study assumes that differences in innovation success between companies can be explained by differences in managerial competencies (routines, skills and leaming experiences). It investigated the question of how to identify such competencies, given a range of sectors. The current study focused on the identification and verification of key success factors for imnovation

4. In the preceding study success was measured by indicating firms as a frontrumner or member of the pack. Such measures have been extensively used in the literature (Barczak, 1995; Robinson, Fornell \& Sullivan, 1992; Haines et al, 1989; Schnaars, 1986). Moreover, in the MERIT study, the differences between frontrunners and pack members were measured among the better performing companies. In contrast, the current study incorporates both fiontrunners, members of the pack and laggards. Thus, there is a subtle 
difference with the less success full innovators between the two studies. In the MERIT study this is an average representative of the sector, whereas a less successful innovator in the ICT study performs similar to a laggard.

5. The sample of the MERIT study can be represented as a kind of a dichotomous distribution with frontrunners and pack members, whereas the current study has a normal distribution. The result of this sample distribution difference is that the correlation results in the current study are, on average, not very high.

6. The MERIT study uses a matched pair comparison, whereas the current study compares at the company level using a contimuous scale for innovation success.

7. The MERIT study uses outside informants (Snow \& Hambrick, 1980) for sample selection. In the ICT study, however, independent external informants were wsed as a reference to check the appropriateness of the instruments, and provide knowledge of the ICT environment, the competitive context and the role of imovation Harrigan, 1983). External informants are regarded as a reliable and accurate source of strategic information (Chen et al., 1993).

8. The MERIT study makes use of a pair-wise performance comparison. This method consists of a) the selection of success heuristics for each sector (which was done by using sector experts), b) the selection of relevant heuristics, c) the identification of accompanying success criteria, and d) the identification of a pair of companies with one frontrunner and one pack member. In principle, two firms with different performance levels within one sector are compared with other pairs from different sectors. One firm is rated as a frontrumer, e.g. a successful innovator, and the other is rated as a member of the pack, e.g. a less successful innovator. By means of the experts rating procedure industry experts selected two companies, one successful and one less successful, on the basis of a list of success criteria. The MERIT study was not interested in the "poorly" innovating companies. The MERIT study resembles more or less what we have described in chapter 2 as the success vs. failure studies. Cooper (1992) used a similar technique, the Newlrod model, to predict the success or failure of an innovation project. The use of dichotomous success measurement (success versus failure) has been used in other studies as well, both at the company level and the project level. Dougherty $(1990,1992)$ and Dougherty \& Corse (1997) used the distinction between failure and success at the project level as the dependent performance variables. Their study used a sample of 40 productdevelopment projects in 15 high tech firms, where management rated the project as a success or failure.

9. The ICT study does not use a dichotomous success scale, but opted for a continuous success scale. Basically, in order to:

- allow for triangulation of data sources,

- ensure better directional relation of cause and effect and finding of alternative explanations,

- ensure variation within the group of companies, and

- account for the diversity in practices and performances of the firms, the current study used a randomly selected sample. 
10. We assumed in the current study a random variation in the degree of innovation success. The use of contimuous success scales would provide information with mone explanatory power on the non-sector- and sector-specific differences between firms.

11. The MERIT study incorporated two criteria for innovation success. First, the dependent variable is the frontrunner/pack nember dichotomy, rated by an external expert, with the corresponding values of 1 . (frontrunner) or 0 (pack member); Secondly, incorporating two additional success measures, next to the expert rating, namely the researchers" judgement and the CEO/General Manager score. In the current study these success measures were refined on basis of appropriateness, relevance and validity.

12. Finally, a reservation should be made in advance as to the significance of the correlation coefficients in this study. On average, this study reveals no highly significant findings. Amongst the possible explanations are the sample size, the method of performance indicators, and the sector context and absence of a selection enviromment (see next chapters). High scores of correlation coefficients on variables are found to be rare in this survey, possibly accruing firom a data set that can be considered small in terms of number of firms. However, the data set is large in terms of number of variables, data points and interview respondents. This might suggest that the data set is normally distributed, which might explain the lack of exceptionally high scores for the variables. Furthermore, the factor scores for each of the success factors include both financial and perceptual values. The use of a mixture of financial and perceptual measurements indicates that the overall results will not be high and are uncommon using the broad range of statistics used. Hence, due to the small sample size, the results of the correlation analysis must be interpreted tentatively. Nevertheless, the study results and correlation coefficients provide an idea of the most interesting relationships between innovation performance and firm characteristics. 


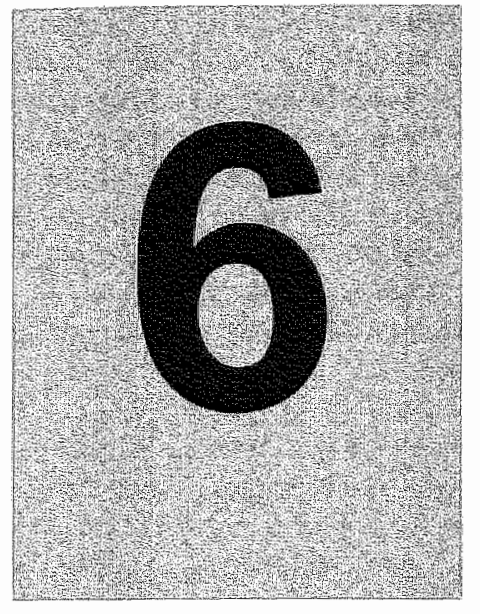

Research Design 
The uste of multiple data collection and analysis approaches facilitates exploratory research. Given our research interest in studying change, we constructed a hybrid methodology. The questions raised in this study require a broad perspective of the management, strategy and organization of ICT companies and their respective business environment. Analysis of innovation and change in the ICT sector implies that both software and service innovation are induded in the study, primarily because software products and ICT services are closely related. A major change in a software or hardware product influences other producers and serwice providers along the ICT value chain, because of the close interdependence of products, processes and services. Technological changes affect many interrellated products and services. Insight into the variety of business of ICT companies is thus necessary to understand innovation in the IT context (Abemathy \& Utterback, 1988). These circumstances require a research design that takes account of these issues.

\subsection{Introduction}

A research strategy, or design, is a process of collecting, analysing, and interpreting observations ( $\mathrm{Yin}, 1984$ ). It is regarded as a "logical model of proof". Within social sciences different research strategies prevaill to analyse complex situations. The most dominant strategies are the experiment, the survey, and the case study. The experiment is a specific form of research as it involves reseamcher intervention. For this study it was not an appropriate strategy. The attraction of the research strategy largely depends upon the research questions asked and the purpose of the research, e.g. being explanatory, descriptive or exploratory. The choice of strategy is determined by the initial questions asked. Research is essentially a process consisting of a range of process phases. For each phase one can pursue different research strategies that have their own specific value. These vallue-driven strategies are based on answering 'who', "where', 'when', "what', "why", or 'how' questions.

The dual methodology used in our research strategy combined the following elements:

1. case studies based on in -company interwiews with four persons, and

2. an in-company large scale survey, consisting of over 500 variables

This combination can be refered to as a case survey.

\section{The Case Study}

Case studies are a preferred research type if the three following conditions apply (Yin, 1989):

- if how and why questions are being asked,

- if the investigator has little or no control over events,

- if the focus is on contemporary phenomenon within a real life context.

Most case studies are of a retrospective nature because they describe past events. Reports, documents and business plans provide insight into past actions and strategic and organisational choices that have been made. Case comparison and analysis reveals a number of underlying factors and patterns. This kind of analysis can be called 'detective work" and is designed to reveal patterns and consistencies between cases (Mintzberg, 1979). A traditional comment on case study research is concemed with its lack of comparison, making generalisations difficult. However, there is an essential difference between qualitative and quantitative research in this respect. The basic premise of quantitative research is that statistical inferences can be drawn that provide generalisations going beyond the sample. Qualitative research does not ain at statistical generalisation but at theoretical generalisation (Yin, 1984). Yin argues that the case is an experiment to falsify some theoretical proposition. 
Yet this implies that the case selection is not a random but a carefully selected process for theoretical generalisation. One case study, bowever, cannot provide the entire setting of a phenomenon (Yin, 1984). Multiple case design is a method to increase the generalisability, or external validity, of the outcomes. Contrary to generalising from increasing the number of cases and degrees of freedom (statistical generalisation) in quantitative research, qualitative research contains a 'replication logic' (Yin, 1989). Yin (1989, p. 53) proposes two different logics of replication:

1. theoretical replication: being i.e. the careful selection of cases to provide results for rejecting previous reasoning, and

2. literal replication, aimed at: predicting similar results.

\section{Use of Case Study Material}

Pettigrew (1990) recommended that when research is characterised as exploratory or theorybuilding, it is particularly important to begin with an 'extreme case', i.e., a setting where the phenomena of interest are frequently occurring and readily transparent. Because this study of innovation attempts to explore the validity of key success factors and explore new constructs to contribute to resource-based theory, the ICT industry provides an ideal context for this research. A large number of companies visited in the ICT sector have argued in their external commumication and during the interviews that the "unique' or 'idiosyncratic' nature of their firm distinguishes them from their competitors. They implied that their business strategy, organisational design and human resource policy differed from others. This would indicate a heterogeneity of firms in the ICT industry. The resource-based approach (Bamey, 1991) assumes that this idiosyncrasy of tangible and intangible factors upon which strategy is based, can explain performance differences. The research field can be strengthened by empirical investigations of the resource-based view that incorporate the constructs accompanying this approach.

The cases were primarily used for three purposes:

1. Cases have been used for illustrative purposes. Case descriptions have been entered to confirm the statistical findings. This can both support the statistical results and clarify its context. This reduces the risk of drawing wrong conclusions from quantitative data and supports the generalisation of findings. We are not interested in the statistical generalisation to a population. We use a meaningfull sample to understand the relations and the process and context behind innovation.

2. Case descriptions have been admitted for providing altemative explanations. Whenever statistical outcomes could not be explained, the case material could explain the unique character of an outcome or give an alternative reasoning. Whenever possible we listed case material to support alternatives.

3. Cases were carefully used to test specific assumptions that could not be explored with quantitative technique and collection methods. Although this does not result in statistical generalisations it can support sensitising concepts and add to analytical generalisation.

In this way we have tried to triangulate the data. There exists a fourth purpose for using cases, namely the possibility of a comparative case study research. This entails comparison of the case data along the guidelines of Grounded Theory (Strauss \& Corbin, 1990), However, this process of structuring, coding and comparing case data fell outside the main goals and framework of this study. 


\section{The Survey}

A survey is a collection of research methods that are used to develop statistics within a population or a representative sample (Fowler, 1988). A survey is a research method specially designed to answer "what", "where", and "when' questions. Its advantage over case studies is the ability to calculate whereby systematic measurement yields a data matrix that can be analysed to reveal patterns. In the data matrix relations can be found between the variables. There are three preconditions for the existence of causal relations (Den Hertog \& Van Sluijs, 1995):

1. covariance,

2. exclusion of altemative explanations, and

3. ane-directional relation between cause and effect.

The most important drawback of the survey is that it is incapable of providing a meaningful. interpretation of why things happen. Although surveys are not suitable for these research questions, it does happen that studies try to understand complex processes by designing a survey. The second drawback is the lack of excluding alternative explanations. A check on the non-response is one way to decrease the set of explanations. Another problem with surveys is its time dependency. Leonard Barton (1990) argued that measures are sensitive to the point in time at which they are administered. Survey studies often leave the researcher with more questions about the 'how" and "why' of a phenomenon. In that case, qualitative data can enrich the understanding of the innovation process.

If the goal of a research study is to grasp the context of a phenomenon or if its objective is theory development, case study research is the appropriate strategy. With this study we analyse the context and process of innovation in the ICT sector. An appropriate methodology would be the case study, which has the drawback of dependency on one specific situation. One can generalise to a theoretical Level only. What we are interested in at the same time is a statistical generalisation, which calls for a survey.

In this study we proposed and conducted a combination of case study and survey. This research stategy is called a duat methodology. The analysis of many aspects of innovation requires dual methodologies to cover all topics of interest. The sample of the study will be large enough to draw statistical conclusions and meanwhile interpret the results within the context of the study. This calls for a dual methodology. It is a methodology that combines the theoretical generalisation with the statistical generalisation and analyses covariance structures from the context perspective. It is a methodology that supports quantitative findings and qualitative data, where structured data analysis is complemented by the availability of altemative explanations.

\subsection{Dual Methodologies}

What is the status of case study research in innovation research? Empirical research related to dymamic capabilities and competencies perspectives is grounded on descriptive case studies from successful firms Collis \& Montgomery, 1995; Hamel \& Prahalad, 1994; Nonaka, 1991). These case studies have provided significant insights into the nature of competencebased competition. Recent contributions by Miyazaki (1995), McGrawth (1996), Iansiti \& Clark (1994) and Henderson \& Cockburn (1994) have enriched the field with survey data. 
These studies provide us with the opportunity to test the rigoumess and sensitivity of the concepts and measures over time (Leonard Barton, 1990).

Research approaches to new topic areas often rest upon novel combinative research methodologies like 'blended' and 'dual" methodologies (Den Hertog et al., 2000). Theory building research typically combines multiple data collection methods (Eisenhardt, 1989). Eisenhardt and Bourgeois (1988) combine surveys with qualitative evidence from interviews and observation to describe strategic decision making in high-velocity markets such as the computer industry. Womack et al. (1990) consolidated data from different sources in their MIT study. Work by Jick (in: Den Hertog et al., 2000) promotes the use of multiple sources of evidence by advocating triangulation of data types, providing reliable constructs and better hypotheses. Mintzberg (1979, p. 587) described the importance of triangulation by stating: '... for while systematic dara create the foundation for ou theories, it is the anecdotal data that enable us to do the building. Theory bulding seems to require rich description, the richness that comes from anecdote. We uncover all kinds of relationships in our hard data, but it is only through the use of this soft data that we are able to explain them..."

In this study we wanted to combine a large enough number of firms to quantify results with the principle of collecting a large amount of quantitative and qualitative data. The strength of this combination is with finding interpretations of the results. This dual methodology is called the case survey.

\section{The case survey}

This strategy has appeared in several forms (Den Hertog \& Van Sluijs, 1995). The case is regarded as the unit of analysis and attention is paid to the context of the change processes that are analysed. Four categories of case surveys can be identified (figure 6.1):

1. a survey within one case: Leonard Barton (1990) performed a survey administered to several employees within one company (case study).

2. case sampling and a survey from codified data: Larsson (1993) proposed a design by drawing a sample of cases from a larger number. For each case qualitative information was coded into quantitative data allowing for statistical analysis. This procedure uses a strict coding scheme and independent interpreters to transform data.

3. a large survey with one individual case: the unit of analysis is an exemplary case that can be a project, programme or firm. For this case some contextual data is acquired (Van de Ven \& Poole, 1989).

4. a smaller survey with more cases: each case is subject to a complete survey. Cases consist of a complete set of interviews, documents and case descriptions. A large survey data set is available for each case (Den Hertog \& Huizenga, 1997). 
Figure 6.1: Case survey methodologies

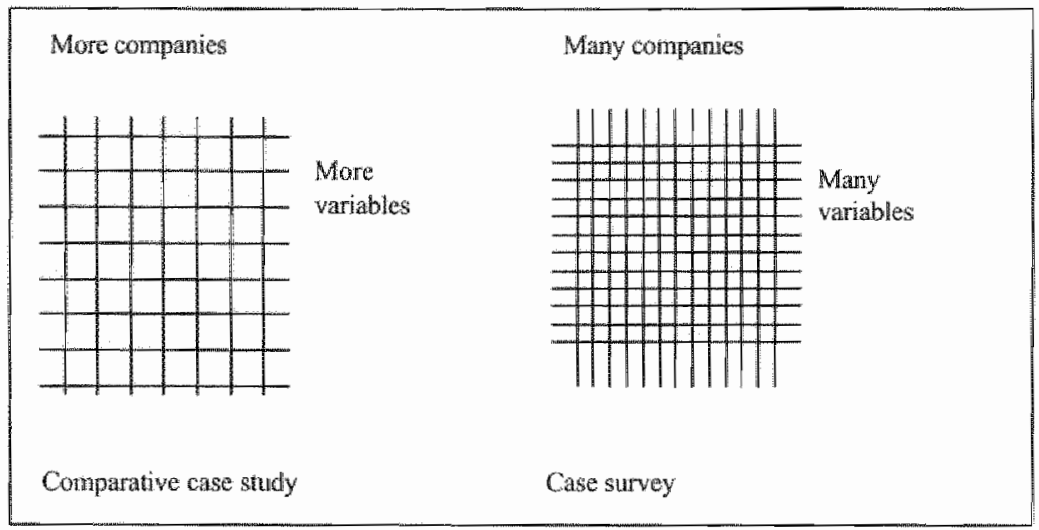

Eisenhardt (1989) and Leonard Barton (1990) argue strongly in favour of the use of dual methods. Combining methods creates synergistic advantages and can indicate salient relationships that would not have been detected if one method had been used. At the same tirne it can support findings or prevent false interpretations. Qualitative data contribute to the understanding of the quantitative relationships and strengthening them. Combining research methods has advantages and disadvantages, which will be discussed below. Table 1 provides a summary of comparison between the methodologies used.

When analysing innovation, manifest structures are observable by using quantitative techniques. However, the concept of competencies and capabilities assumes the existence of latent structures (Kets de Vries, 1991). These are powerful unconscious determinants that need to be identified and incorporated, since they influence and underlie much of the tacit and explicit strategic actions. In this context, Scott Morgan (1994) refers to the "unwritten rules of the game" in an organisation. The tacit knowledge in the organisation is based upon routines that are performed. These routines incorporate an implicit logic that is built on the cultural values in the organisation (Den Hertog \& Huizenga, 2000). In organisations many processes are not clearly observable at first instance. Qualitative techniques are the most appropriate method to detect them. The operationalisation of the competencies construct might be achieved by means of the observation and measurement of a firm's pattern of competitive actions. Our interest is in the dymamics of innovation. This requires a process orientation exploring the context, content and process of change in an organisation over time (Pettigrew, 1985). Teece ef al. (1997) refer to this as the path dependency and process criteria of dynamic capabilities development of a firm. A process-centred paradigm is the most promising for understanding competence development (McGrawth ef al., 1995)

Leonard-Barton (1990) provided two sets of advantages for combining different methodologies in a multiple cases and longitudinal case study on technology transfer: 1. specilic strengths in the data-gathering process for each method compensate for particular lacks or weaknesses in the other, and 2. complementary approaches in each method enhance validity because of synergy obtained by combining methods (p. 255). 
In order to pursue this combined value-driven research strategy, several methodological choices were made at the beginning of the research study:

1. A focus on the process and performance of innovation,

2. Gathering enough relevant data to increase the potential generalisability of theoretical propositions that go beyond single case study interpretations (Yin, 1989), and

3. Triangulation: complementing different research methods to obtain the advantages of complementary and synergistic data gathering and analysis (Leonard-Barton, 1990 ).

4. The study involved a range of on-site interviews about recent events, past actions and plans that provided the benefit of proximity in time to current events. The case descriptions increased the likelihood that the sequence and nature of the events could be accurately described and determined (Leonard-Barton, 1990).

\section{3 (Dis)advantages of a Dual Methodology}

The strength of a case survey is that one can generate covariance to analyse the possibility of causal relations. Because of the context of the case data one is able to generate altemative explanations for statistical relations identified.

\section{Biases}

The advantages of a case study are its direct observation, systematic interviewing and full variety of sources of evidence. One disadvantage of case study research is the danger of biased views influencing the direction of the findings. However, this bias can also enter in the design of a survey (Yin, 1989). The critique of the low generalisability of cases is safeguarded through designing and administering a large-scale survey.

\section{Context}

Case studies are also typical instruments for placing a phenomenon in a historical context (Den Hertog \& Van Sluijs, 1995), allowing for the description of changes, processes, organisational choices. The advantage of multiple cases is that concepts can be better defined and general patterns can be recognised in different environments (Eisenhardt, 1989).

Dyer \& Wilkins (1991) point out that multi-case research remains too general and fails to go into the deeper meaning of events. The collection of detalled data at multiple sources and multiple organisational levels can compensate for this drawback.

The coherence between successive events, e.g. strategic and organisational choices with respect to innovation, is better addressed by using cases rather than by proving correlation relationships ( $\mathrm{Mohr}, 1982$ ). The advantage of case research is that one takes into account the type of firms and the markets they serve. In the study we tracked down the strategic development and path dependency of the firms. In the interviews and the survey, we have used time -dimensions to track the origins of the firms and the strategic directions that have been chosen.

\section{Alternative explanations}

One important element of case study in relation to a survey research is concerned with explanation building. Case study research can consider plausible alternative explanations. Surveys cannot; if they did they would endanger the internal validity and hence one of the preconditions for causal relations. The combination of both methods prowides the opportunity of (re)viewing alternative explanations when no clear relationship between variables is detected in the first instance. 
Advantages of dual research methods are based upon the combinative strengths of both methods. However, there are some disadvantages as well, which are concemed with with the design and the data collection. Leonard Barton (1990) observed co-ordination problems and information overload as being disadvantages inherent in the design. Operational problems encountered in their study were based on difficulties in data structuring, in defining the unit of analysis and in finding the rational choice for the selection of cases. Much time and effort are required to co-ordinate the collection of data.

Table 6.1: Overview of the methodologies (adapted and adjusted from Leonard-Barton, 1990).

\begin{tabular}{|c|c|c|}
\hline Research phase & multiple cases & surwey \\
\hline \multicolumn{3}{|l|}{ 1. dala collection } \\
\hline efficiency & $\begin{array}{l}\text { relatively high, danger of irrelevant dala } \\
\text { galhering }\end{array}$ & $\begin{array}{l}\text { focused data collection by means } \\
\text { of precoded questionnaire }\end{array}$ \\
\hline objectivity & $\begin{array}{l}\text { danger that information is subject to } \\
\text { bilases from respondent and researcher } \\
\text { biases }\end{array}$ & $\begin{array}{l}\text { - no interference by researcher } \\
\text { - no control over correct } \\
\text { interpretation of precoded } \\
\text { questions heading to halo- } \\
\text { effect } \\
\text { - multiple sources }\end{array}$ \\
\hline pattern recognition & pattern matching across cases & stalistical generalisation \\
\hline
\end{tabular}

\begin{tabular}{|l|l|l|}
\hline 2. qually af design & \\
\hline internal validity & $\begin{array}{l}\text { cause and effect relations difficult to } \\
\text { recognise }\end{array}$ & $\begin{array}{l}\text { covariance and correlation } \\
\text { analysis }\end{array}$ \\
\hline external validity & theoretical generalisation & statisticai generalisability \\
\hline consinuct validity & validate constructs across events & $\begin{array}{l}\text { operationalisation of constructs } \\
\text { through pre-testing questionnaire }\end{array}$ \\
\hline
\end{tabular}

\section{Unit of amalysis}

To fully understand the complex interactions underlying innovation the research methodology incorporated an embedded design (Yin, 1989). An embedded design denotes several levels of analysis. This provides the researchers with multiple perspectives to explain factors underlying the process of innovation. In this study the firm level and project level is examined. We used multiple sources of information and (functional) perspectives to establish a chain of logical reasoning (Den Hertog \& Van Sluijs, 1995).

\section{Disadvantages of case survey}

The danger of conducting only a survey or case study is that is might lead to irrelevant or unreliable results. The advantage of a case survey is that different research strategies support the outcomes of s study. However, there are also a number of practical disadvantages. First of all, the interpretation and continuous interaction between qualitative and quantitative data calls for a carefully structured method, requiring strong research skills with regard to analysing and combining data. Second, case descriptions are not as extensive as in the case of a single or multiple case study. The in-depth knowledge gained in a case study is more than that in a case survey. The case description of a case survey tries to construct the 'Gestalt'. Third, a case survey does not always yield statistically significant results. This is mainly due 
to the small sample size. The size of the sample is a choice between "knowing a lot from a select sample' or 'knowing little from a large number of units in a sarmple'.

In sum, dual methodologies are combined research strategies with the intention of grasping both "what", "why", and "how" questions within one study. Both survey data and contextual information are collected to generate a complete picture of a phenomenon. In the next paragraph we will go into detail on the design of the case survey.

\subsection{Research Design of the ICT Research Study}

This study is a replication of a research study on key success factors of innovation within 60 companies. The research design used in the preceding study was re-used and adapted to the methodological requirements of a one-sector study for a specific industry. Below we will discuss the constitutive design components.

\section{The Survey Questionnaire}

For the survey a questionnaire was used. A questionmaire is a highly structured data collection technique where respondents are asked a same set of questions (De Vaus, 1993). This study uses an existing and validated survey instrument on imovation (Cobbenhagen, 1999). The questionnaire was evaluated and customised to make it appropriate for the study of innovation in the ICT sector. and administering the survey entailed the following steps. The process of designing and administering the survey entailled the following steps.

\section{Redesigning the questionnaire}

Based on an extensive review of the strategic, organisational and innowation literature new concepts and variables have been added to the questionnaire. Appendix 1 provides an indication of the variables and its descriptions. The research experience and the statistical outcomes of the earlier study (Cobbenhagen et al. 1995) called for the reconstruction of several variables. Missing data for several variables indicated that the question did not provide the answers that had been expected. Also some questions were insufficiently (and inadequately?) specified, yielding imelevant answers. Largely because of the wording, this resulted in non-waluable data, harming construct validity. These questions have been redesigned. Some variables have been deleted from the questionnaire because they were not relevant to this study. Also, a number of new variables have been added representing new theoretical developments in the strategic management literature, such as learning styles and knowledge management.

\section{Scaling}

Revisions for some questions were made as they originally yielded irrelevant data as a result of the use of scaling types. The organisational culture variables used a semantic differential scale in the original questionnaire. The use of adjective pairs, e.g. open to change versus closed to change, did not differentiate between cases. Also, some variables were overlapping in wording, leading to confusion about interpretation. We modified the scale by using a Staple scale where the adjective pairs are tested separately (Hawkins et al., 1974 in: Cobbenhagen, 1999). For some variables the differential scale was replaced by a Likert-type scalling, which can be used to measure attitudes (Likert, 1932). These variables were excluded from the comparison between the current study and the original study. 
The questionnaire includes over 500 vartables. Respondents were asked to score on each questionnaire item using a 1 tot 5 Likert scale, where 5 indicates a larger value of the variable. Financial data were gathered and for some variables percentages were used for the scale. Some questionnaire items were presented to one respondent and others were presented to all the respondents in one company. We interviewed four persons in each company. A changing team of two researchers conducted intervicws with the marketing manager, R\&D manager, and managing director in all companies. A fourth person, either a financial manager, senior project leader or personnel officer, was consulted for company background information and financial data. Sometimes initial in company interviews were held to ensure that the proper unit of analysis and correct sources of information were used.

We expected to find differences in the responses from the people interviewed, e.g. the cultural variables, the degree of cross-functional co-operation and the external co-operation with customers and suppliers. To include a path dependency element in the questionnaire, a time frame was used for some variables. Similarly, the variables on strategic priorities were measured for two periods, 1988-1992 and 1992-1996.

\section{Pre-testing phase: test survey with experts and small set of firms}

To prevent bias, miscommunication and irrelevance in the questions and in order to reduce missing data a test phase was introduced. The full questionnaire was administered in five companies and evaluated by five industry experts, enabling us to customise the questions to the prevailing business practice in the JCT firms.

\section{Non-response survey}

The use of a check on non-response (De Vaus, 1993) increases the relliability of a study. One must assume that the non-responding firms present a different set of characters. To check if the non-responders were different, we conducted a check on the non-responding firms. From the initial results we selected the most statistical significant variables. A two-page faxsurvey containing these variables was designed and sent to the non-participating firms. The results showed no differences between the firms that belong to the sample and the non-responders. This increases the reliability and generalisability of the conclusions.

\section{Data collection}

During the pre-collection phase several steps were taken to acquire an overview of the industry. Open interviews were conducted with 15 experts in the sector, representing both the business perspective and the academic discipline: software clients, researchers, industry analysts, ICT consultants and the management board of the sector organisation. This research phase aimed at testing the questionnaire that had been developed and gaining information on the industry structure. The information, consisting of market figures and growth perspectives, was stored in a database. and consulted throughout the research period.

We conducted the study between 1995 and 1997 . In-depth semi-structured interviews were held with 125 managers in 32 software companies, following a pre-developed interview protocol. Managers were asked to tell their story with respect to innovation in their organisation and the success of their innovative efforts. This way the researchers deliberately tried to create an interview atmosphere where the managers would not feel any constraints because of predefined questions that were unsuitable or irrelevant. During the interview the researchers posed more detailed and specific questions on such issues as business strategy, organisational design, markets, teclunology and innowation processes. All predefined questions were presented in the format of a benchmark questionnaire. Initial questions asked. were concerned with the company development (paths), the current position, and the future 
direction. These interview topics are very similar to Teece et al.'s (1997) three dimensions of dynamic capabilities, e.g. position, paths, and processes. The intention of these interviews was to hear the company story from objective sources. The managers that were interviewed had been selected by means of a profile that had been sent to the firms in advance.

Additionally, we selected relevant company documents, e.g. business plans, project management procedures, annual reports and company reports. Secondary data sources were consulted to obtain information from the companies, e.g. IDC, Gartner, EITO. Also a database was developed containing a collection of web sites, professional journals, newspaper articles, and research reports.

\section{Use of self-rating scales}

One might argue that the use of self-rating scales affects the reliability of information. The use of self-rating scales for innovative success has been used extensively (Cooper \& Kleinsclamidi, 1995). However, concern has been expressed that these scale types are reliable and unbiased. The use of self-reporting scales as performance measures has been criticised for its subjectivity and danger of overestimation by respondents (Chenhall \& Brown, 198.8). To prevent the collection of unreliable data, multiple sources have been used. Furthermore, items have been developed that describe the organisational routines in a firm. Using the questionnaire we collected data on facts that were not subject to subjective interpretations my managers.

Brownell \& Dunk (1991) argue that the nature of any bias by self-reporting measures has never been described or shown to impair the inferences drawn from the data. Venkatraman \& Ramanujam (1987, p. 10) support this observation by concluding that: '... neither type of measure is intrinsically superior to the other in terms of consistently providing valid and reliable" measures of performance...'. There is no convincing evidence that objective measures, e.g. financial data, are either more reliable or valid in studies (Brownell \& Dunk, 1991.).

Several studies on competencies use self-reporting scales to grasp the tacit concept of competencies. We asked the respondents to report on objective organisational and strategic itens. Spector argued that the distortion of information under this condition is nore limited than when subjective characteristics are being rated (McGrawth ef al., 1995, 0. 266). Crampton \& Wagner (1994), on the basis of a meta-analysis of 42934 correlations published in 581 articles, also argue that self-report measures are not less reliable than objective measures. In their study on team performance in new product development, Ancona \& Caldwell (1992) use subjective ratings for measuring competencies. They argue that: "... subjective performance ratings are most often used to make budget and promotion decisions; they are related to final performance evaluation, and objective results are often the resultant of subjective ratings..."

\subsection{ICT Study Sample}

The aim of this study was to present a broad picture of innovation in the ICT industry. Therefore we opted for a meaningful sample, rather than a random sample for statistical generalisations. The research concentrated on all activities across this industry. The emphasis was to be more on the complete range of $\mathrm{ICT}$ activities than on the statistical representativeness. Another argument for adopting a cross-industry perspective is the existence of "mixed companies". These firms perform the complete range of the ICT chain, 
e.g. software development, implementation and system maintenance. This strengthened our belief that the sample should include the whole range of ICT activities, instead of focusing on one ICT activity alone. In order to obtain a complete mage of innovation in the ICT sector we intended to analyse innovation in such activities as software-package development, software tool development, system maintenance and control, and posting ICT personnel.

At the same time we also wanted to include small and medim-sized firms as well as large firms in the sample, once again with the purpose of obtaining, a broad picture. Furthermore we selected firms that conduct all business functions that are relevant to innovation. This implied that firms with large R\&D centres located outside The Netherlands (e.g. Silicon Valley) were excluded from the sample. These firms performed their own technology development. All firms should perform their own marketing, production and R\&D activities. We excluded firms with less than 20 employees from the sample, in order to ensure the presence of all business functions. As a consequence hardware companies fell out of the range of the study because there is only one hardware firm in the Netherlands that performs its own R\&D. These initial requirements have been composed in order to control for the autonomy of the firm (Child, 1984).

\section{Sample sielection procedure}

A database from the sector organisation FENIT (Federatie Nederlandse IT) has been the starting point for the sample selection. This organisation represents $180 \mathrm{ICT}$ firms in The Netherlands, which represents $90 \%$ of the Dutch ICT market in terms of turnover. Before selecting the firms we defined three classes of ICT companies:

- Software developers, whose main activities are basic research, applied research, development and distribution of standard application and system software packages and development software (case tools).

- System integrators, whose main activities are services for system and network integration, and the development of customised software, including consultancy and softwaremaintenance and training.

- System and network control and maintenance, being services firms that provide outsourcing and outsourcing services for systems and networks.

Sample selection took place in two parallel steps. First, all of the 180 FENIT members were invited to participate. On the basis of this invitation, 15 firms agreed to participate right away. At the same time we took a random sample of 70 firms from the population of 180 FENIT companies. These companies were contacted both by snailmail and telephone. A great many follow-up telephone calls resulted in another 14 firms that agreed to participate In parallel, we selected 80 firms from a database of 2,749 companies, of which 2,500 appeared to be appropriate. This database contained a lot of very small companies (less than 10 employees), many "mixed companies", as well as companies that perform irrelevant activities. These 80 firms selected from this second database were not a member of the sector organisation. This resulted in another 6 firms that wanted to participate in the study,

What are the results of the sample selection and what are the characteristics of the sample of 32 companies? The sample of firms represents a total revenue of 3.970 million guilders in $1995,4,200$ in 1996 and an estimated revenue of 4,500 in 1997 . The sample covers $25 \%$ of the total ICT market in terms of revenue. The firms employ $24 \%$ of the total ICT personnel in the sample. Remarkably, the number of companies in the sample represents $5 \%$ of the total number of companies on average. $5 \%$ of the ICT firms produce $25 \%$ of the total ICT market 
rewenue. The reason for this percentage is the huge amount of very small ICT firms, with less than 10 employees. Table 6.2 provides some other sample characteristics of interest.

In this way we tried to compose a group of firms that characterise the entire ICT sector. The adoption of a case survey enabled us to obtain a large amount of contextual data. The most important market players were included in the sample. At the same time the sample represented a large part of total ICT sales in The Netherlands. This gave us the opportunity to generalise some of the findings to the entire ICT population.

\section{Table 6.2: Sample characteristics}

- ICT rewenue of the 32 firms: $60 \%$ services, $24 \%$ software and $16 \%$ hardware activities.

- $25 \%$ of the firms are specialised in sofware development and implementation.

- With the exception of three large firms, the top 10 of largest Dutch ICT firms is included in sample.

- Two ICT firms belong to the top 50 of langest Eurapean $1 \mathrm{CT}$ firms.

- Firms ranked according to revenue, employees, profit and scater in time.

- $25 \%$ of the system integrators and sofware firms conduch international business.

- $15 \%$ of the firms are subsidiaries of European or US firms.

- At the time af the research, $20 \%$ of the firms was activelly involved im an acquisition.

- At the time of the research, three firms were lacing serious organisational problems

- The sample includes high-growth firms and firms with below market average growth rates.

- The sample does not include small firms with tess than 20 employees and technological startups.

\section{Sample limitations}

The nature of the study implies that it is limited by the traditional pitfalls that exploratory research entails. Work remains to be done to generalise the conclusions beyond this sample, as they need to be tested in a larger sample. Because of the small sample size and the nonrandomness of the sample units one needs to be careful with respect to the interpretations that have been made. A more comprehensive and larger research analysis can provide important insights for the development of competence-based perspectives of innovation. However, the richness of the data set and the representativeness of the firms in the sector seem to offer solid and reliable findings.

\section{Use of performance benchmarking}

Benchmarking is a performance measure and evaluation technique. Benchmarking is used to gain knowledge about a firm's relative performance. It can serve several goals. Firsi, benchmarking serves to compare core activities with best practices. Second, it is an instrument that can be applied as a steering device for process improvement. And third, it can be a motivation tool for better performances of employees (Zaini, 1996). One can identify four types of benchmarking, e.g. internal, functional, competition and generic. Benchmarking provides a strategic reference point for an organisation to make decisions (Bamberger \& Fiegenbaum, 1996). Decisions are made in a context of uncertainty and complexity. Decisionmakers are keen to obtain as much information as possible to reduce the risk of taking a wrong decision. Benchmarking is a powerful tool to obtain relevant information.

According to these researchers, different theoretical perspectives of the organisation use altemative mechanisms of comparison and evaluation. They distinguish between internal, external and time-dependent reference points. Internal organisational goals and capabilities are critical reference points for resource-based perspectives (Barney, 1991). Perspectives like competitive position and resource dependence use external comparisons. Bamberger \& Fiegenbaum (1996) combine these internal, external and time-based points proposing a strategic reference point theory, i.e. a configuration of the three dimensions. In their opinion 
management evaluates the current position on the environment, the internal processes and routines and the past actions and future opportunities.

In this study we used a metaphor to describe the differences in performance between firms. In cycling terms we designated firms as frontrunners, members of the pack and laggards. Foster (1986) called the first category the attackers. The firms that participated in the study received a benchmark report containing detailed information on relative performances and activities. 


\section{Part III:}

\section{The empirical findings}

The next chapters will expose the results of the empirical part of the stidy. The nain ain is to present the key success: factors and, nore specilically, observations derived from the qualitative and quantitative research. The chapters combine qualitative material based on the extensive survey. data with the qualitative data from over 100 interviews with business and ICT managers. The results are compared with empirical results from other MIERIT stidies and the innovation. Literatire review. The elements of strategy: organisation ard innovation perfornance will be described. in three different chapters, each beginning with a presentation of the empirical results. In the last chapter we will discuss and summarise the findings consistent and those inconsistent with previous stadies. 



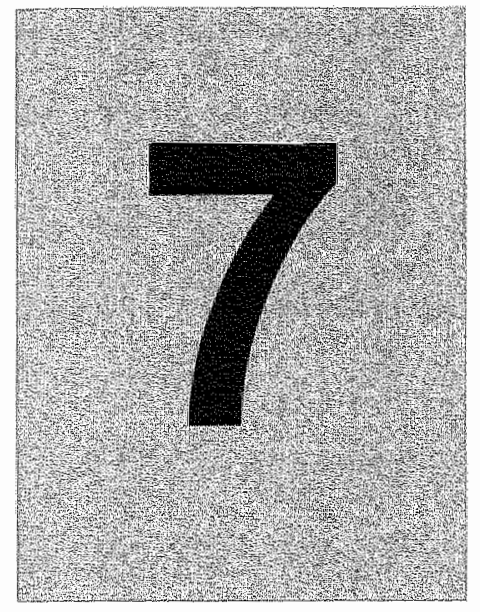

\section{Strategy and Innovation Performance}




\subsection{Introduction}

The outcomes of the ICT study may differ from research studies conducted at MERIT, using samples of companies in different sectors. Therefore, we will also discuss whether success factors are typically non-sector-specific, or have appeared solely in the present ICT sector study. In particular, this study has been compared with a study by Cobbenhagen (1999) on success factors in 30 different industry and service sectors. The following chapters will reveal that a large number of the success factors identified here also appeared to be critical in the above-mentioned study on effective innovation by Cobbenhagen. An additional set of success factors that we found is probably contingent upon the ICT sector. This has provided us with new insights into an interesting and booming sector, which has undergone a lot of developments.

In the early 1990s, the ICT sector was facing an image problem due to the lack of growth, unreliable hardware suppliers, the effect of an economic slowdown, clients freezing their $1 \mathrm{CT}$ expenditures and a questionable quality and service level of many suppliers. All of these developments had a damaging impact on the sector and resulted in companies slimming. Companies disappeared altogether and there were a lot of take-overs between hardware, software and service providers. Later in the 1990s, the economic tide changed. Suppliers became more known as reliable business partners, ICT expenditures were on the rise, and the higher quality of personnel contributed to an improved sector image. New business lines emerged, such as ERP implementation (enterprise resource planning), CRM (customer relationship management) consulting and e-commerce.

One of the factors causing these growth rates in the late 1990 s was the higher demand for client-server solutions in the hardware sector. Increased quality, speed, reliability and performance of computers also boosted hardware sales. Firms were investing in systems and networks and became more confident about relying on ICT for their business processes. The services sector profited from the increased demand for consulting, facilities management, system and network implementation, and operation services. Firms invested more in these areas of ICT in their search for more effective business processes to get ahead of competitors.

The more recent Millennium and Euro conversion projects led to steeply rising turnover figures of ICT companies. Before the twentieth century came to an end, computers had to be adjusted to deal with the change in date. Inventory systems, distribution centres, reservation systems, process monitoring systems, etc., had to be adjusted in order to prevent systems downtime.

The most dominant development in the ICT industry was the emergence of the Internet. Integrated business networks in the business-to-consumer and business-to-business markets provided new roles for ICT. ICT was connecting persons, consumers and business enterprises throughout the world, irrespective of time, geographic or organisational boundaries to form a "network area" as it extended the reach of every individual to communicate and share information. New business was arising from the emergence of networks, including electronic commerce in retailing and finance, the most prominent today. But also transport reservations in the hotel and flight industry were booming. About 68 million people were using the Internet and online service in 1996 (EITO, 1997, p. 144). Estimates pointed at that time to at $100 \%$ growth annually. 
In this hectic business context, the research study identifies a number of interesting insights in the ICT sector that are not explicitly addressed in the innovation literature. In addition, the analysis might reveal success factors, e.g. multidisciplinary teams, that ane often taken for granted in the innovation literature, but that do not appear to be relevant in the ICT sector. We also expect several interesting outcomes on the strategy of ICT firms (see box 7.1).

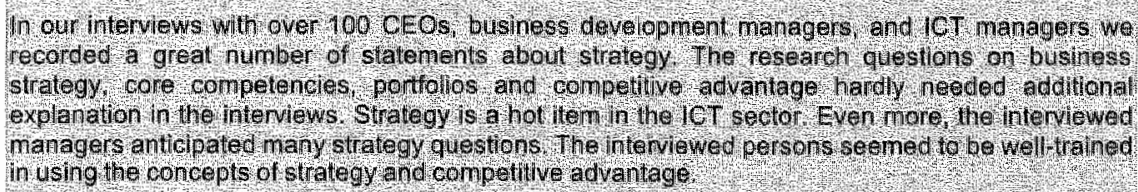

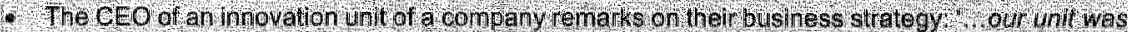

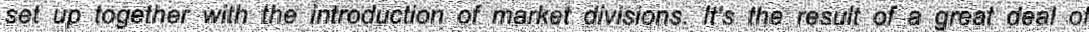

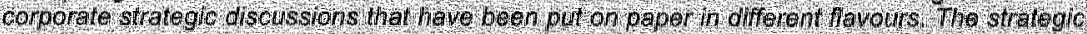

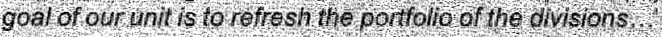

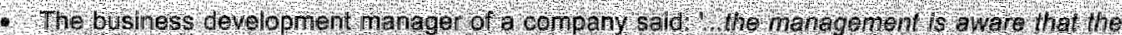

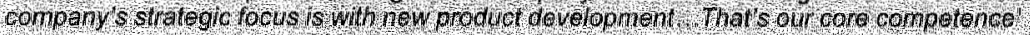

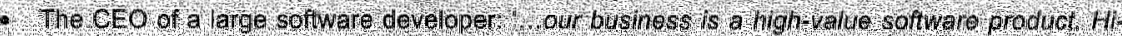

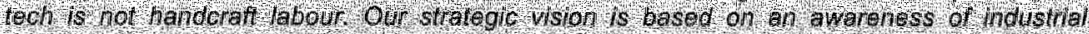
thinkng.t.

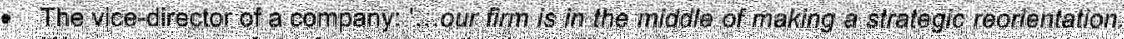

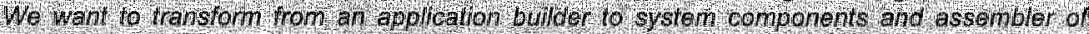

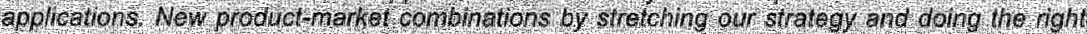
hings inghw

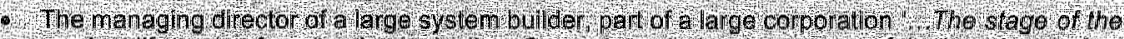

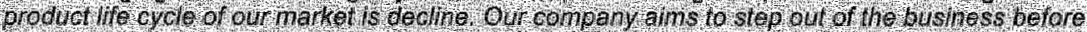

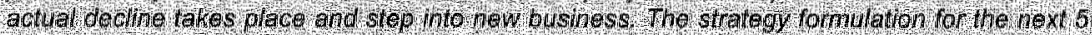

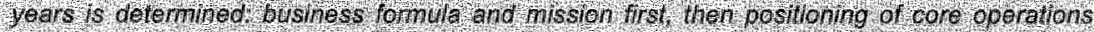
Whith the corocrate enterontse.

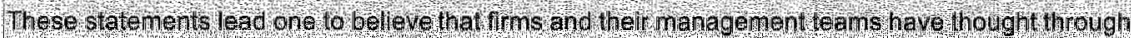

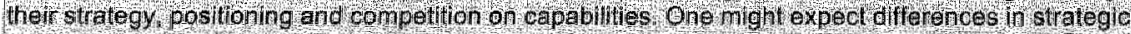

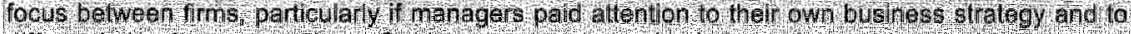

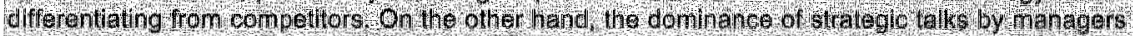

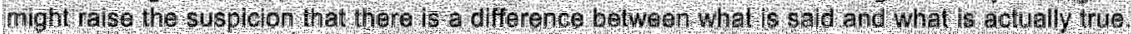

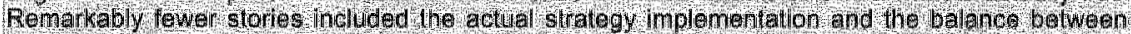

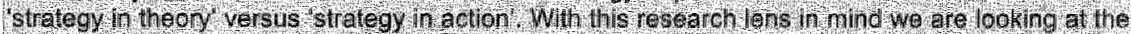
dateprosented here

\section{Box 7.1. Strategy in theory and in practice}

The reader therefore needs to bear in mind that we have taken a snapshot picture of the landscape of innovating ICT firms. This means that key success factors are perishable and subject to depreciation both in terms of time and business. A last note for the reader is concerned with the purposeful use of a multiple success criterion. Because we were interested in more than one overall dimension other than newness of a product, it was our intention to cover different facets of imovation. Multiple indicators were used, which cover a widespread range of success rates, e.g. combining measures from objective data measurement, management ratings, financial figures, etc. Also, similar to other innovation studies, we tried to make use of both qualitative and quantitative data accessibility. 
In the lasi part we explained our research viewpoint. The companies were examined from different research angles (both inside information and external information of the company) and with different research lenses (e.g. strategy, organisation and technology). Over 100 interviews, lasting more than one hour each, were conducted in combination with a largescale survey incorporating more than 500 variables per company. The aim was not to acquire a vast amount of quantitative and qualitative data, but a rich set of data to find success factors that differentiate the frontrunners from the members of the pack.

The basic assumption is that there exist strategy ellements that discriminate between successful innovation and less successful innovation. To do so we distinguish between two kinds of success factors:

- Key success factors. A variable is designated as a key success factor when the correlation between variables and the overall success measure is statistically significant.

- Discriminating factors. In the study we refer to high and significant correlation coefficients on the individual success criteria.

The aim of this chapter is to provide insight into both the key success factors and the discriminating success factors in the areas of:

- business strategy,

- innovation strategy,

- strategic priorities over different time periods.

Success criteria have been checked for their contingency, applicability, relevance and validity in the ICT sector. In particular, we are interested in identifying sector-specific vs. non-sectorspecific success factors. We compare the ex-post outcomes with what is known from the literature and other MERIT studies. In is not our intention to present the outcomes of this chapter as a possible supporti, rejection or as being inconclusive to a well-formulated hypothesis. The expectations on organisation and strategy, which were laid down in Chapters 2 to 5 , will be discussed. We want to observe and explain the presence of these important subjects in the ICT sector.

The main focus of the study is the use of a multiple success criterion as explained in Chapter 5. The aim of this study is to both identify and explain the key success factors. In order to present the outcomes in a readable manner we will first present an overview of factors that might be relevant to innovation in the ICT sector, based on the findings in Chapters 2,3 and 4. At the end of part III we will return to this overview to see whether:

- strong and significant support was found;

- some support was found;

- the outcomes were inconclusive;

- the outcomes indicated a reverse relation of the one assumed; or whether

- it was impossible to test the variable's effect on innovation success, or the variable's effect was not tested.

Chapter 9 lists the range of success factors incorporated in the survey in the ICT sector. This list has been compiled using an extensive key success factor overview (Chapter 2) and the replication of the survey of the preceding MERIT innovation study (Cobbenhagen, 1999). 


\subsection{Strategic Factors}

Innovation can be a matter of strategic importance for companies. It is a competitive weapon to expand and/or strengthen the core business of an enterprise. This strategic importance is reflected in attaining market share, outclassing competitors and attracting new customers. In this context, the company's strategic vision of innovation tells us something about the firm's aspirations. In particular, we looked at innovation awareness and strategic commitment of companies.

The first survey question was to identify the awareness in (top) managers of the relevance of innovation. Given the intensive strategy discussions that were recorded (see box 7.2), a clear vision of innovation could be expected. The respondents, a CEO or managing director, had to define innovation. To give some anecdotal case examples, box 7.1 presents a number of managerial quotes. We observed that firms have different wisions of what innovation actually is.

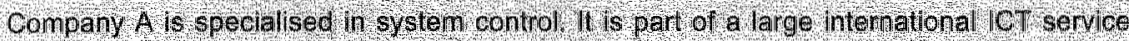

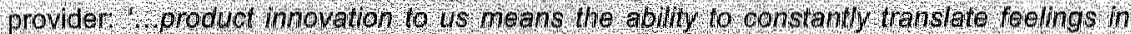
Whe markel Wto semies wat are targeted to wat market.

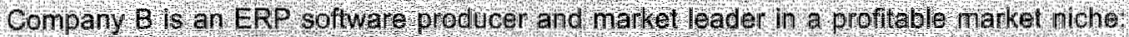

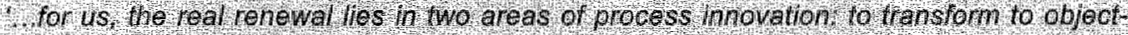

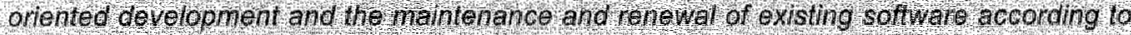
rapid applation dovelopment (RAD) method:

A business unil of a large lot: serveo conpany company C is a softwaro producor and

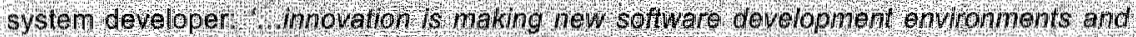
Wrolling new products...

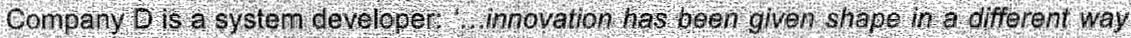
in owr compary wan in ather conpanies Others do hot pay attention to process

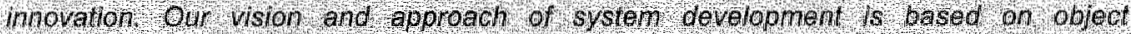
orentawont?

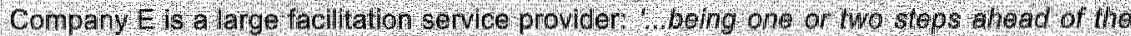
customers devetopinents, Gnderstanding the thsmess processes of the antomer evon better than they do. That is how we th to innoware.t.

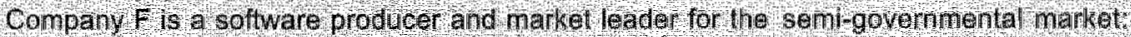
1. the core of howation is to ofrer semices lo cistoness hat bing hom arvantage hi torms of the, money and wight The technology is a side aspeut.
}

\section{Box 7.2: Management quotes of ICT firms on innovation}

\section{Management priorities:}

Managers have to make choices. These choices are reflected by the policy priorities of the firm. Measuring the policy agenda at two time periods might identify the path dependency of the firms. Priority setting for successive time periods was used as a way of acquiring a clear indication of the companies" awareness and choices regarding innowation. In the survey these strategic priorities were measured for two time periods: 1988-1992 and 1992-1996. In today's competitive ICT markets it is more difficult for managers to set priorities. More complex technology issues have to be addressed at the same time. We assumed that tanking a set of business issues might suggest how much attention is actually devoted by the management of 
an ICT firm. The survey presented more than 20 strategy items, which had to be ranked according to the company"s priorities by the respondents. Innowation issues were presented in addition to issues such as cost efficiency, market share increase and organisational redesign.

Imnovation strategy style:

Secondly, we tried to find out if innovation was also expressed in the company"s business strategy. The survey presented a set of questions aimed at labelling the strategy of the firm. In this way, the study looked for a more detailed characterisation of the innovation dimension in the business strategy. Based on the MERIT suryey we provided CEOs and managers with a set of strategy descriptions. Labels such as creative inventor, first mover and technology imitator have been used to indicate the firm's strategic focus on new markets, technologies or competencies.

Resource capacity conmitments:

Thirdly, we raised the question as to whether this commitment to imnowation was actually implemented. The realisation of innovation efforts requires the allocation of such resources as time and money. The survey included resource criteria to indicate the actual commitments to innovation. In other words, it indicated how much money and time was (structurally) spent and to which activities.

\subsection{Strategic Priorities on the Management Agenda}

Results

To provide insight into the management agenda, the respondents were asked to mark their policy priorities. A total of 25 topics were presented with a 1 to 5 Likert-type scale ranging from low attention to top priority. Figure 7.1 provides the descriptive data for the most important topics. As we observed previously, strategy is a core discussion topic in the ICT sector. What then is its impact on the management agenda? The retrospective data reveal that the management agenda has drastically changed over time. The subjects that were high on the agenda years ago have been replaced by new topics such as a focus on core business and quality. The topics that attracted little attention in the period 1988-1992, such as training, new internal information systems and market co-operation, have been given reasonable to high priority more recently (1992-1996). The most urgent topics attracting management attention are cuality assurance, profit improvement, recruitment of personnel and concentration on core activities. We will discuss these into more detail below. 
Figure 7.1: Strategic prionities for ICT companies

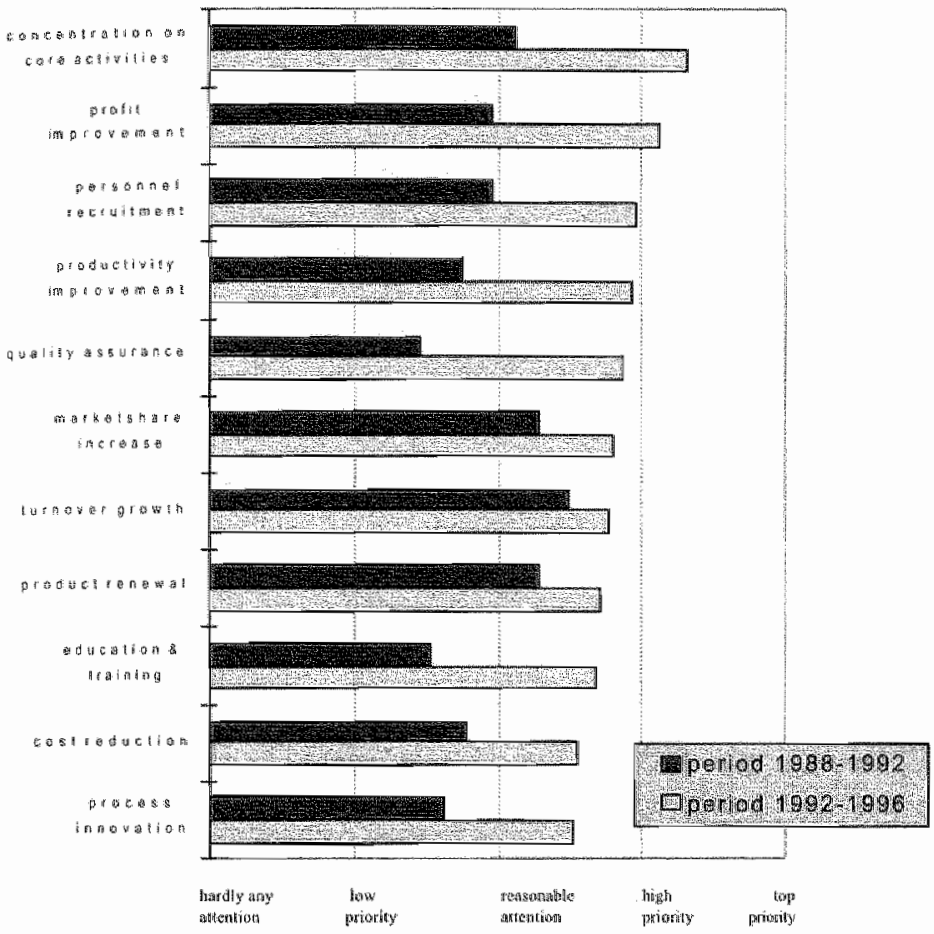

\section{Concentration on core activities}

This topic has been given the highest priority by the majority of ICT companies in the sample, which suggests that software producers and service providers have fundamentally (re) discussed their own business. Interview data reveal that companies have investigated their value chain to identify those activities that generate most added values. Also activities outside the core portfolio have been assessed in terms of their synergistic advantages. This movenent of making organisations 'lean and mean' has resulted in throwing away 'excess weight". Business activities that do not directly contribute to strengthening the core business are abandoned.

\section{Enterprise growth}

Expanding current business has been a high priority for both software developers and service providers. The management of ICT companies has put growth-related matters high on the policy agenda. Throughout the last ten years, growth of turnower has been given reasonable to high priority. It was the most important policy matter during the $1988-1992$ period. Turnover growth is regarded as a key management objective that aftracts constant attention. The increase in market share continues to be a dominant item for expanding a company's business. Directly related to enterprise growth is personnel. The shortages of ICT labour supply are a dominant restrictive factor for further growth of companies, resulting in a relatively high priority for personnel recruitment. Another key priority at the top management level is an increase in employee productivity. Due to the rapid growth, the organisation of the company was often neglected, leading to high costs. Competitive pressure and the need for fast and 
high-quality product and service delivery might explain the increased need for more efficient working methods and productivity increase.

\section{Innovation}

Imnovation is not among the top three priorites of the management of ICT companies. Product renewal is the first innovation-related aspect and one of the important topics mentioned. In the 1992-1996 period, process innovation attracted more attention. The item shifted from the range of reasonably important to high-priority matters. The same "pathdependent" movement can be found for product renewal, although the increase in priority was less spectacular. Product renewal was among the highest priorities five years ago. The attention for growth and profit improvement was of most concern for top managers. Product renewal as such was not one of the hot topics on the agenda.

\section{Quality assurance}

This topic gained several places on the management agenda as compared to a number of years ago. In a study of more than 60 firms Cobbenhagen, 1999) this issue was given only moderate importance. The attention attached to quality by the top management of ICT firms indicates that it is a dominant subject in today"s ICT markets. Quality assurance had a low priority in the period 1988-1992, but is among the high priority matters for management today.

\section{Business-specific priorities}

We were interested to see whether the data suggest a distinction between the policy agendas of software producers and service providers. It appeared that software producers specifically focused management attention, for the period 1988-1992, on:

- product renewal, e.g., new server platforms based on new technologies;

- turnover growth, e.g., partnering with service providers;

- increase in market share, e.g., take-over of smaller competitors.

Remarkably, top priority was given to the following subjects in the period 1992-1996:

- product and process innovation. e.g.s a decision by a large company to set up an independent imnovation unit;

- productivity improvement, e.g., a training programme for Java software developers;

- concentration on coie activities, e.g., a developer of transaction sofiware decides to withdraw from billing services.

The strategic subjects for ICT service providers are similar to those of sofware producers for the period 1988-1992. In particular, the focus on tumover growth and market share increased. However, the policy agenda of service providers in the 1992-1996 period changed and focused on three subjects, listed in order of priority:

- recruiment of personnel, e.g., a hardware maintenance company started recruiting higher vocational education ("HBO") students);

- core activities, e.g., a software maintenance company withdrew from PLI programming;

- profit improvement, e.g, a software developer made low return on investments.

These variables might explain a clear distinction in strategic focus. Software producers tend to focus more on innovation, whereas service providers concentrate on growth and result improvement. As the strategic discussions in the ICT sector are thriving (see box 7.3), these findings do not differ from our expectations that companies differ in strategic focus. The next question to be raised, of course, is which management choices and actions really matter for 
excellent innovation performance. To investigate the impact of policy prionities, a compartson of correlation coefficients reveals more than a mere comparison of the averages of variables, as done previously.

\subsection{Key Success Factors in Strategic Priorities}

Table 7.1 shows the correlation coefficients of the malysis of the strategic priorities and the innovation success criteria. The table reveals the correlation between variables, but reservations need to be made because no high correlation levels were found.

\section{Table 7.1: Correlation coefficients between strategic priorities (period 1992-1996) and performance}

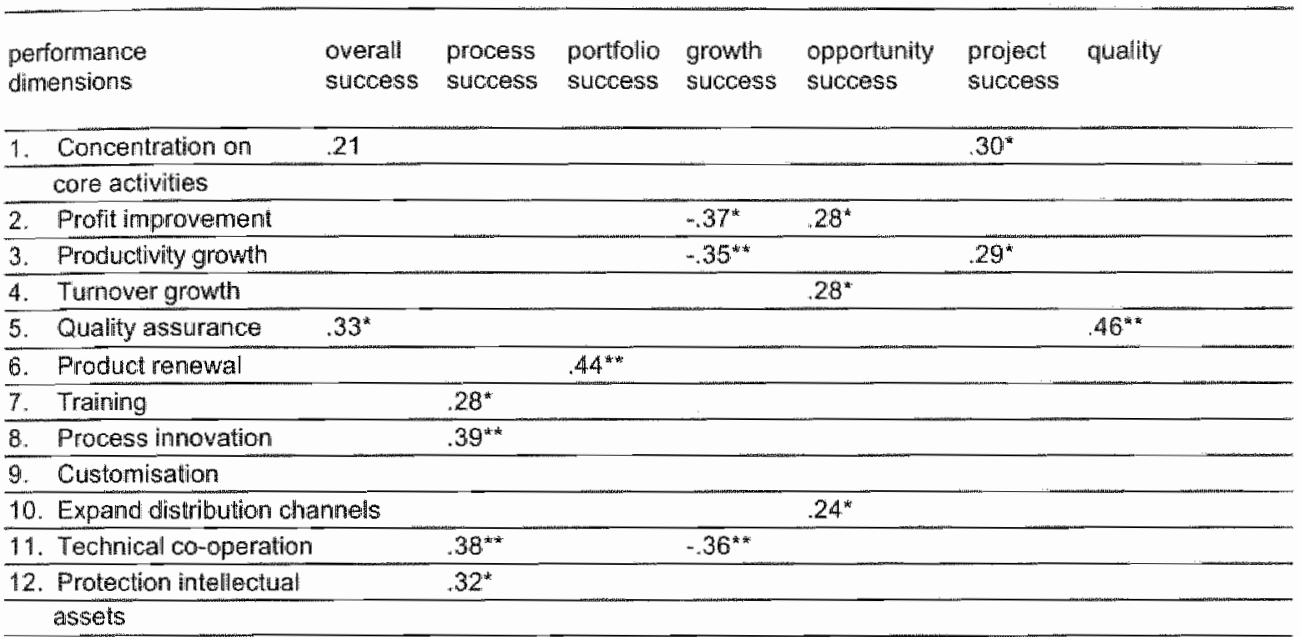

Strategic variables for the period 1992-1996 are listed in order of decreasing awerage prionity (* denotes significance at the .05 level and denotes significance at the .01 levelj. Significant correlation coefficients in the range $0.3-0.4$ are showin and remarkable correlation resulls

The results of the correlation analysis must be interpreted tentatively as most coefficients are in the range of 0.3 to 0.4 . The correlation analysis indicates that:

- the overall success factor and the quality measure significantly correlate to the quallity assurance variable;

- the process success factor is typified by differentiating factors such as training, process innovation, technical co-operation and protection of intellectual assets;

- the growth success is negatively correlated to differentiating factors such as profit improvement, productivity increase and technical co-operation;

- The opportunity success is positively correlated to differentiating factors such as profit improvement, turnover growth and expansion of distribution channels;

\section{Strategic prionities in retrospect: $1988-1992$}

To provide an indication of the changes in strategic priorities over a longer period of time, the same configuration of variables have been measured on the time axis, covering the years 1988 until 1992. When presenting these retrospective variables to the respondents, we explicilly 
asked managers to look back in time to prioritise policy items. The retrospective data set can provide insight into how managers perceived changes in strategic priorities. To some extent it allso provides, in retrospect, a kind of pattern in the strategic priorities and the priority setting of ICT firms, based on managers' perceptions (cf. Van de Ven \& Poole, 1990).

On the basis of the correlation analysis we are able to make a number of observations. First, the strategic priorities for the 1988-1992 period differ from those for the period 1992-1996. Table 7.2 gives the correlation results. Second, the overall success measure negatively correlates with productivity growth. Furthermore, a bigh prioritisation by companies for product renewal between 1988 till 1992 also correlates, but not significantly, with overall performance (.22) and process success $(.24)$. The process success criteria ind icates that they are be driven by:

- cost reduction,

- protection of intellectual assets.

\section{Table 7.2: Correlation coefficients between strategic priorities (period 1988-1992) and performance}

\begin{tabular}{|c|c|c|c|c|c|c|c|}
\hline $\begin{array}{l}\text { performance } \\
\text { dimensions }\end{array}$ & $\begin{array}{l}\text { overall } \\
\text { success }\end{array}$ & $\begin{array}{l}\text { process } \\
\text { succenss }\end{array}$ & $\begin{array}{l}\text { portfolio } \\
\text { situcess }\end{array}$ & $\begin{array}{l}\text { growthi } \\
\text { success }\end{array}$ & $\begin{array}{l}\text { opportunity } \\
\text { success }\end{array}$ & $\begin{array}{l}\text { project } \\
\text { siuccess }\end{array}$ & quality \\
\hline 1. Produci remenal & .22 & .24 & $.29^{*}$ & & & & \\
\hline 2. Personnel recruitment & & $29^{4}$ & & & & & \\
\hline 3. Cost reduction & & $.43^{\text {ink }}$ & & & & & \\
\hline 4. Productivity growth & $-.28 *$ & & & & & & \\
\hline 5. Process innovation & & & & & & & $-.32^{*}$ \\
\hline 6. Training & & $.28^{*}$ & & & & $-.34 *$ & \\
\hline \multicolumn{8}{|l|}{ 7. Protection intellectual } \\
\hline assets & & $37^{* * *}$ & & & & & \\
\hline 8. Technical co-operation & & & & $-.39^{* * *}$ & & & \\
\hline 9. Acquilstion of the firm & $.31^{*}$ & & & & $.30^{1 *}$ & & \\
\hline
\end{tabular}

Strateglc wariables for the period $1988-9992$ are listed in order of decreasing average priorty "denotes significance at the .05 level and denotes significance at the 01 lewell).

Significant correlation coefficients in the range 0.3-0.4 are shown and remarkabte correlation results.

\subsection{Discussion: Strategic Priorities}

At the beginning of this chapter we implied that there is a difference between what is said and what is actually true about strategy in ICT firms. In this section, we will see that many firms acknowledge the strategic relevance of quality and core competencies and at the same time that firms differ in their timing of strategic priorities.

\section{Quality assurance}

As shown in box 7.3, quality assurance is significantly associated with the overall imnovation success dimension. Quality assurance has become a dominant and structural item in the business operations of $\mathrm{ICT}$ companies. The argument for this high priority setting may lie in the belief that companies view quality as a differentiating lactor. Equally relevant is the fact that the ICT sector has for many years suffered from an image of projects that went over budget and time deadlines. In order to improve their Image and operations, a lot of ICT firms 
have started to articulate the quality of the product and service offerings. The attention for quality matters can be found in their increased dedication to service level agreements as a means of ensuring the delivery of services as promised. In various instances, case material indicated that quality assurance is a spearhead and integral part of the strategic plan and policy of the company (see also box 7.3). Their focus on quality was a returning and explicitly stated element in their striving for highly qualified people and high-quality products and services.

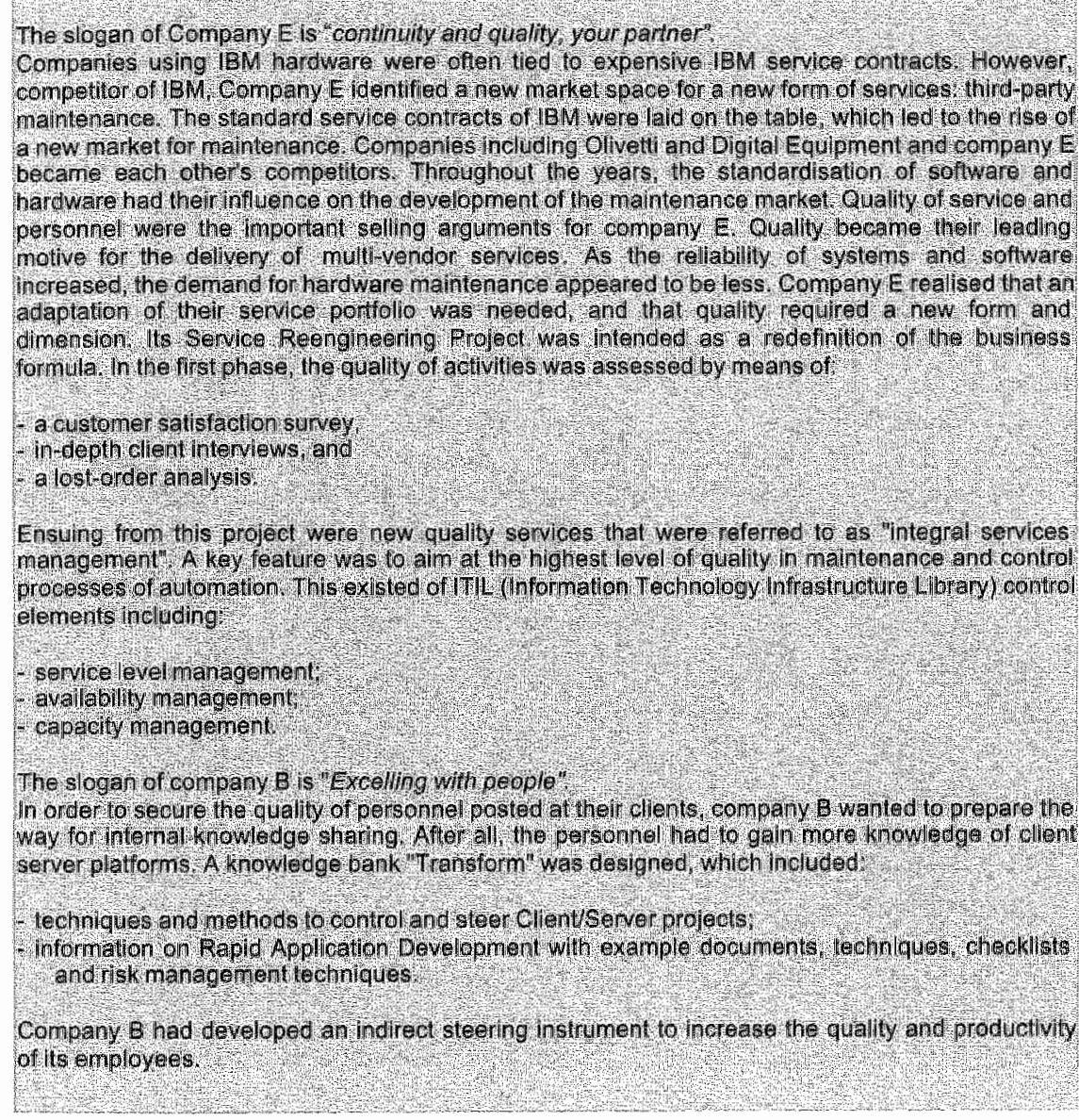

\section{Box 7.3: Focus on quality in ICT firms}

\section{Concentration on core activities}

Table 7.1 also shows that the variable 'concentration on core activities' is moderately correlated with overall success $(r=21)$. This variable is significantly correlated with project success $\left(r=30^{*}\right)$. Concentration on core activilies is a differentiating factor. This topic attracted a lot of attention in companies in the late $1980 \mathrm{~s}$ and $1990 \mathrm{~s}$. In line with concepss like 'business process reengineering' (Hammer \& Champy, 1993), 'lean and mean' and streamining (Cobbenhagen, 1999; Den Hertog \& Huizenga, 1997), the emphasis is on 'doing the right things" and 'doing the right things right'. 
Streamlining was also an important policy issue for frontrunners in the preceding study (Cobbenhagen, 1999), whereas pack members devoted less attention to this issue. The ICT study confirms that companies pay attention to streamlining and focus on the core activities.

On the basis of the correlation outcome, one might argue that ICT companies that have concentrated their business activities are also more successful:

- at selecting potentially profitable new product ideas, and

- at tuming innovation projects into commercial vilable products and services.

This might indicate that a firm restricting itself to its core business activities also involves the careful selection of new product ideas, that is, selects ideas that fall within the range of core business activities. This means that firms developed products and services that did not take the firm into new and unfamiliar markets, nor required technology that was totally new for the firm.

A next set of key success factors relates to priority for tumover growth, profit improvement and expansion of distribution channels. Firms that prioritise these matters are particularly successful in generating profit and turnover from entering new markets (opportunity success). The process success dimension is most significantly related to technical co-operation and management attention for process imnovation. This means that companies that have directed most attention to improvement of operational processes and invested in strengthening technical partnerships excel in process success (box 7.4). Managers that deliberately prioritise process innovation high in their company, also excel on this performance aspect.

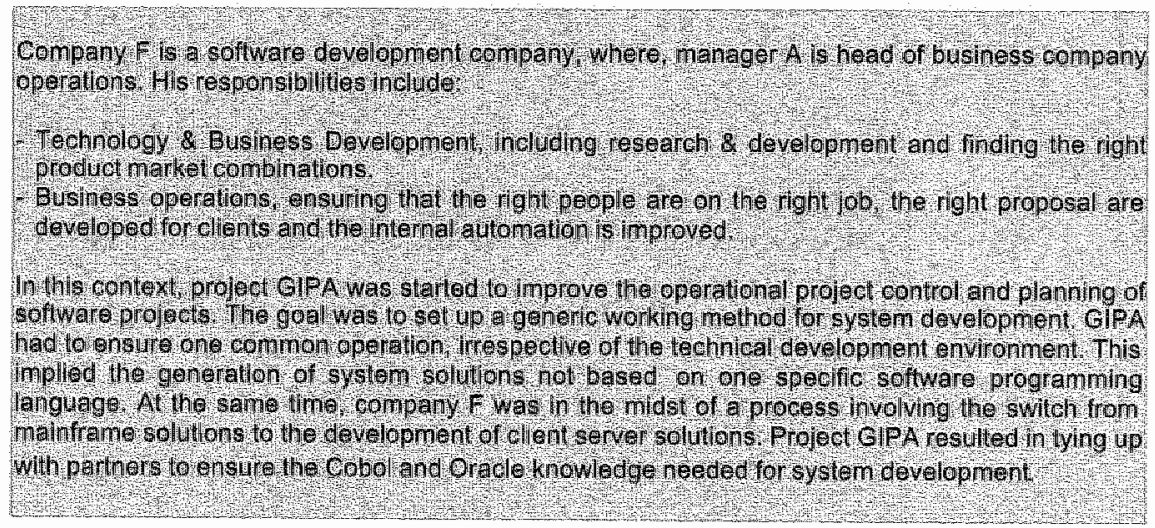

\section{Box 7.4:" Improvement of operational processes}

\section{Strategic priorifies in retrospect}

When we look at the results of table 7.2 , it is remarkable that early timing can contribute to success. The ICT companies that viewed the recruitment and retention of professionals as a high priority belong to the more successful innovators. This topic differentiates frontrunners from pack members. The argument is particularly relevant, given the fact that ICT personnel are a scarce resource.

Another interesting outcome is concerned with firm acquisitions. Acquisition of the firm is significantly related to overall success (.31). The companies gave high priority to take-over by 
another firm in the period 1988-1992. This might suggest that firms explore new market territory, obtain access to new areas of technology, or expand their business by taking over another company.

\section{Differences in timing of company policy}

The timing of policy items is important to innovation success. This is in line with the MERIT study (Cobbenhagen 1999). Firms that address strategic issues at an early stage in their management agenda and sooner compared to other firms will be more successful. With respect to timing we found the following:

- Successful innovators address more policy items and take these into account earlier than less success firms. To give an example, cost reduction is strongly significant to process success. ICT firms that have addressed this issue sooner have a better chance of being a successful innovator. The same applies to the recruitment of personnel and training. The sooner ICT firms attend to these strategic issues, the better they score on the process success factor.

- Success requires long-term commitment and devotion to key policy items. To give an example, long-term devotion to product renewal is beneficial to the portfolio success factor. This item is significantly correlated in both periods. The same holds true of longterm devotion to training and process.

- Successful innovators differentiate by addressing the following issues sooner: less emphasis on productivity growth, cost reduction, protection of intellectual assets and acquisition.

This suggestion of timing differences in company policy was also considered in the preceding MERIT innovation study (Cobbenhagen, 1999). Cobbenhagen supported the hypothesis that frontrumers differ from pack members as to the timing of company policy concerning the development of their competencies. In particular, the latter study concluded that frontrunners address policy items earlier and pay attention to a broader range of policy items. Indications were found that attention for organisational policy items (e.g. reorganisation, quality assurance, training and acquisition of personnel) in the past decade is of importance to explain current innovative success.

Also, support for this timing argument was found in a mattched pairs study in the Netherlands on differential performance of firms operating in the bears market (Schreuder et al., 1991). This study suggested that successful firms differed in their pro-active behaviour and vigour when anticipating declining market demands. Successful bear-fighting firms take more measures and take them earlier than less successful firms.

Looking at the difference between success and less success, several observations can be made:

- frontrunners encountered certain organisational issues earlier and hence had to address the policy implications early, or

- frontrunners are more action-oriented and pro-active than less successful firms and are better at foreseeing policy issues by picking up wealk signals from the environment and the organisation, or

- frontrunners have a more integral perspective of strategy and innovation and therefore address issues broader and sooner, or

- by the very nature of the company culture, frontrunners know when to change and get rid of built-in organisational routines and therefore concentrate on change issues earlier. 
Each of these arguments might be true for ICT firms. Further analysis might provide more insight into this point.

In summary, the ICT study confirms the aspect of timing found in other studies. Frontrunners devote attention to policy items earlier.

\title{
7.6 Innovation Strategy Style
}

The presentation of strategic priorities in the previous section indicates some of the strategic beacons and objectives of companies in the ICT sector. What about the strategic discussions on innovation? Do managers discuss the innovation strategy as much as they discuss their business strategy (see also box 7.2)? This section will present a further analysis to identify the strategic directions of ICT companies. In doing so, this study attempts to characterise how thoroughly a firm's strategy adheres to innovation in terms of the strategic focus on new products, markets and technologies (see box 7.5).

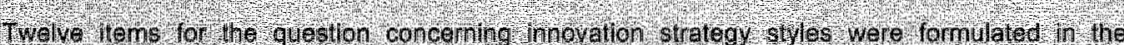

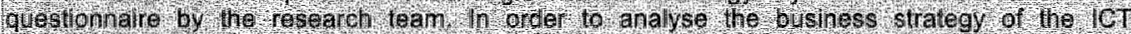

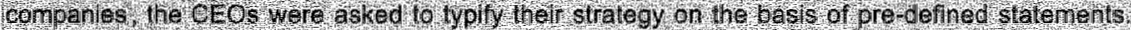

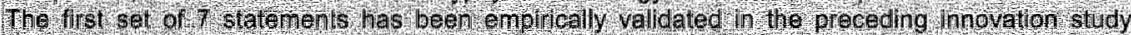

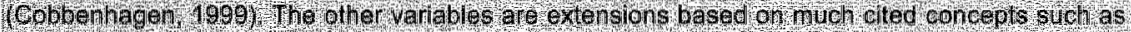

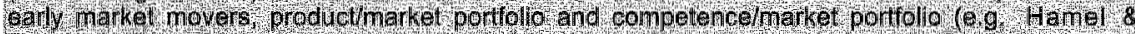

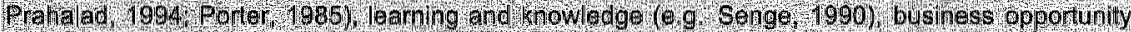

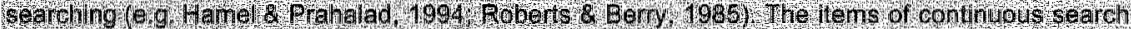

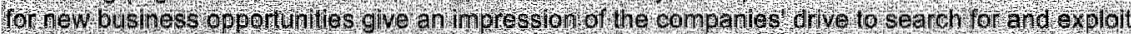

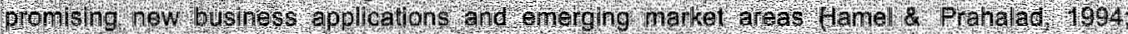
Robaris of Barry 2085 )

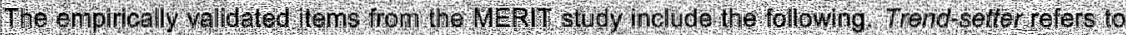

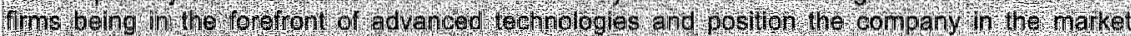

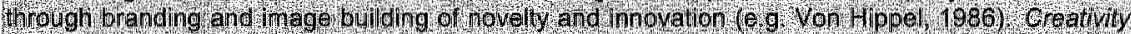

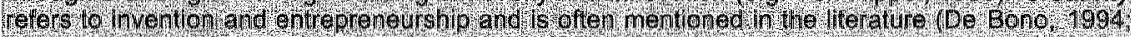

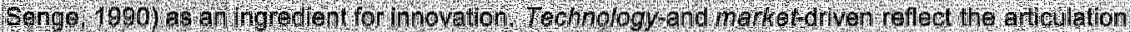

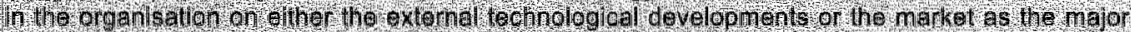

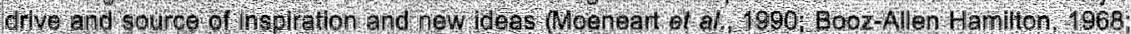

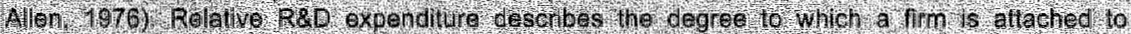

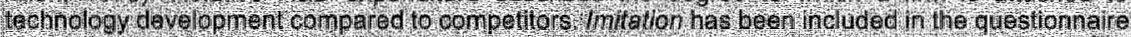

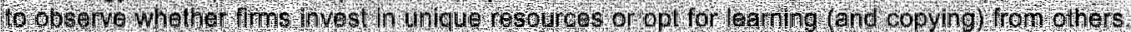

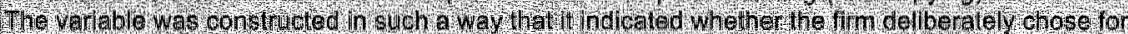

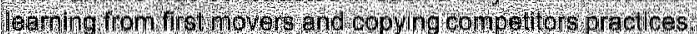

\section{Box 7.5: Definitions for innovation strategy style}

Figure 7.2 presents the descriptive statistics. The average score is depicted next to the score of the most successful innovator and the least performing company in this study. The lines show the biggest difference between the average score, the score of the laggard and the score of the frontrunner with regard to:

- the investment in $\mathrm{R} \& \mathrm{D}$,

- the attention given to the existing product/market/customer portfolio,

- creativity and trend-setting, and

- learning from other market entrants. 
A correlation analysis on these items has produced the following table (table 7.3). This table shows that five ratings are significantly correlated to overall innovation success. Although the outcomes should be considered carefully as the correlation ratings are not high, we can derive three interesting categories of outcomes.

\section{Figure 7.2: Innovation strategy style}

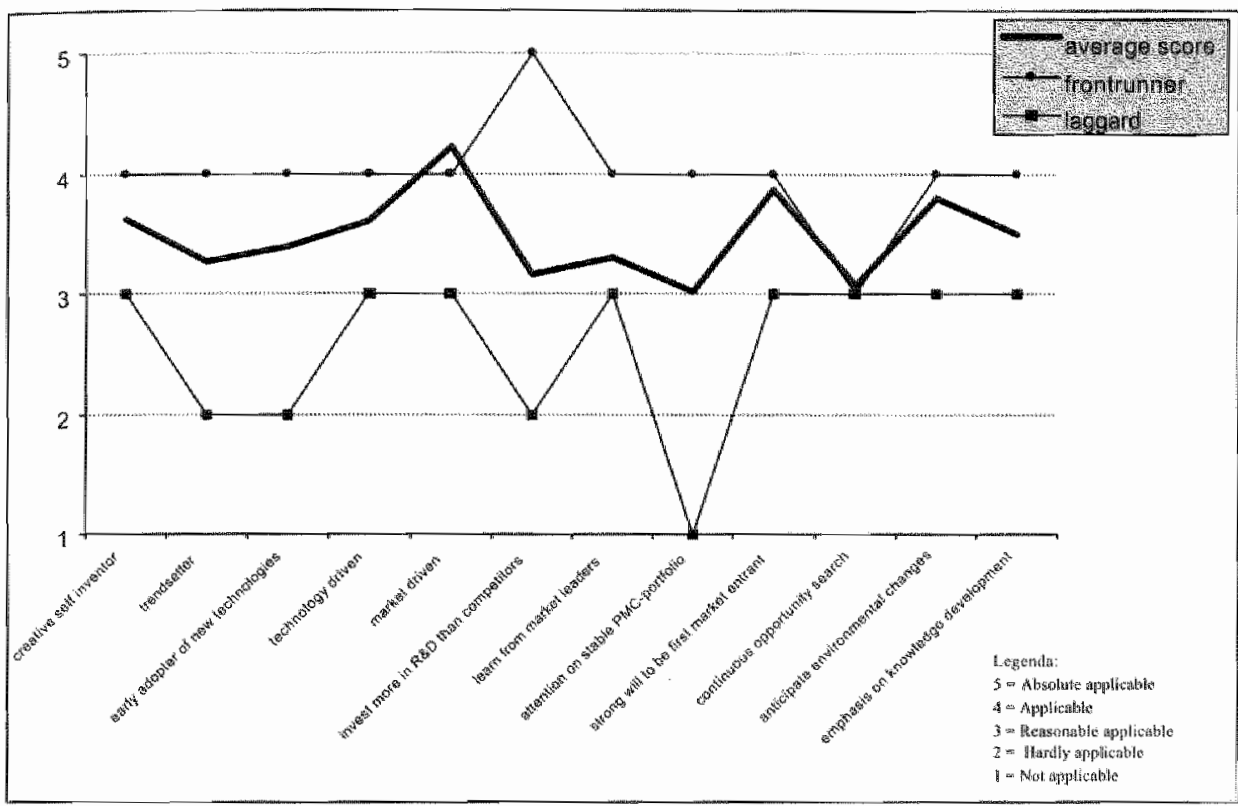

Category 1: variables with significant convelation to overall stuccess

- trend-setter,

- relative R\&D investment,

- desire to be first market entrant

- business opportunity searching.

Category 2: variables with significant correlation with stuccess criteria

The impact on the process success criteria can be exemplified by the four following variables: early technology adoption, technology-driven strategy, anticipation of environmental changes, and emphasis on knowledge development.

The impact on the growth success criteria is typitied by the four following variables: creative self-development, desire to be first market entrant, business opportunity searching and anticipation of external change.

\section{Category 3: variables with no correlation result}

The ratings of the variables "market-driven" and "attention for stable product-market ponfolio" do not correlate with any of the success factors. 
Table 7.3: Correlation results of strategic characteristics and performance

\begin{tabular}{|c|c|c|c|c|c|c|c|}
\hline $\begin{array}{l}\text { performarice } \\
\text { dimensions }\end{array}$ & $\begin{array}{l}\text { overall } \\
\text { success }\end{array}$ & $\begin{array}{l}\text { process } \\
\text { success }\end{array}$ & $\begin{array}{l}\text { portiolio } \\
\text { success }\end{array}$ & $\begin{array}{l}\text { growth } \\
\text { suctess }\end{array}$ & $\begin{array}{l}\text { opportunity } \\
\text { success }\end{array}$ & $\begin{array}{l}\text { project } \\
\text { success }\end{array}$ & quality \\
\hline \multicolumn{8}{|l|}{ Innowation strategy: } \\
\hline 1. Trend-setier & $.37^{\text {** }}$ & & & & & & \\
\hline \multicolumn{8}{|l|}{ 2. Early adopler of } \\
\hline new technologies & $\times 31 *$ & & & & $-.32^{*}$ & & \\
\hline 3. Teathollagy-driven & & $344^{*}$ & & & & & \\
\hline \multicolumn{8}{|l|}{ 4. Market-driwen } \\
\hline 5. Invest more in $R \& D$ & $24^{*}$ & & & & $.34^{* *}$ & & \\
\hline \multicolumn{8}{|l|}{ than competitors } \\
\hline 6. Croative selfi-developer & & & & $.30^{\prime \prime}$ & & $-.25^{*}$ & \\
\hline 7. Strong desire to be first & $.35^{* k}$ & & $39^{m+x}$ & $.31^{k}$ & & & \\
\hline \multicolumn{8}{|l|}{ market entrant } \\
\hline 8. Learning from markel leaders & & 22 & & & & & \\
\hline 9. Continuously searching & $.30^{*}$ & & $.25^{\circ}$ & $.31 *$ & & & \\
\hline \multicolumn{8}{|l|}{ new business opportunities } \\
\hline \multicolumn{8}{|l|}{ 10. Altention for stable product- } \\
\hline \multicolumn{8}{|l|}{ market-customer portfolio } \\
\hline 11. Anticipate ervirommenlas & & $.24^{*}$ & $.24^{\mathrm{k}}$ & & $27 \%$ & & \\
\hline \multicolumn{8}{|l|}{ changes } \\
\hline 12. Emphasis on knowledge & & $.38^{* *}$ & & & & $.24^{*}$ & \\
\hline dewelopment & & & & & & & \\
\hline
\end{tabular}

\subsection{Discussion: Innovation Strategy Style}

First mover and trend-sether

As illustrated in table 7.3 , successful imnovating firms differentiate by having the desire to be a 'mover" and "trend-setter' in the market. Both variables reveal moderately significant correlation coefficients with the overall success factor $\left(r=0.37^{* *}\right.$ and $r=0.35 * *$ respectively). The subject of first-mover advantages has gained attention in the literature. Being a first mover reflects the drive and capability to be the first in launching new products or services. Porter (1992) argued that it illustrates the firm's objective to constantly broaden and upgrade the internal strengths in order to sustain and extend its competitive advantage. For the ICT sector, first mover indicates the firm's willingness to be at the edge of new technological applications (see box 7.6). A first-mover company tries to reap the econonic benefits (first-mover advantage) from entering a new business area, for example the ecommerce market. Being there first may result in colossal turnover or profit growth or a sustainable advantage. Hamel \& Prahalad (1994) associate such company behaviour with companies that are willing to deal with risk taking, with new market creation and with "expeditionary marketing". Companies stretch their strategy. Zander \& Kogut (1995) refer in this context to first movers as companies that have the strategic intent to develop unique and differentiating competencies that are hard to imitate or transfer. 


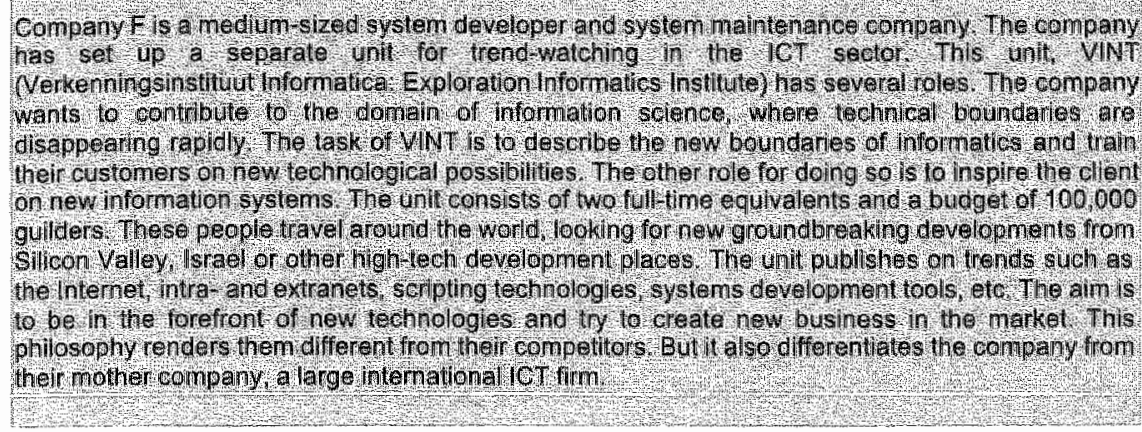

\title{
Box 7.6: Trend-setter
}

\section{Technology-driven}

The analysis reveals that technology-driven firms that adopt technologies early excel in their innovation process. Software producers that devote attention to leveraging in-house technology might explain this. Large ERP-software producers possibly did so in a more proficient manner than their competitors. Several studies have advocated that teclnologically driven firms possess high levels of techmical know-how and skills (Moeneart et al, 1990; Booz Allen Hamilton, 1968; Allen, 1976). This study confirms that "technology-driven" can contribute to innovation success, in particular process success (see also box 7.4 and 7.6).

\section{Market-driven}

The absence of a correllation of the variable marketwdriven is remarkable. Market-driven reflects the quality of performing activities, such as preliminary market assessment, market studies and customer tests. Empirical studies have recorded this to be positively affecting innovation success Kleinschmidt \& Cooper, 1991). It might be argued that this is not a differentiating factor between the ICT firms. All firms claim to be close to the market and interact with their customer. The interviews with the respondents have confirmed this observation, as the majority of the respondents emphasised their market focus (see box 7.7). ICT services providers pointed out that renewal of their services is not driven by technology. but by customer demands.

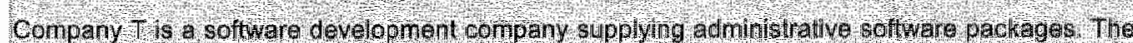

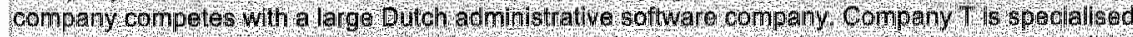

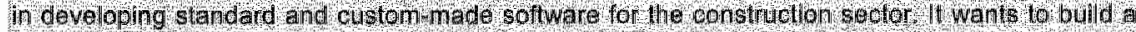

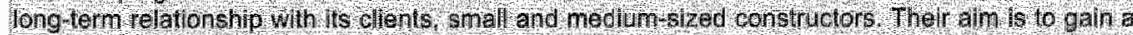

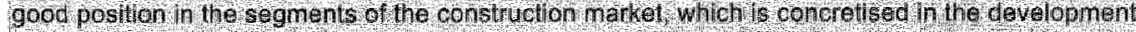
and mplementation of soltware, for inslance, subject natter experts conduct woftware training lor

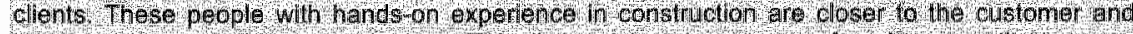

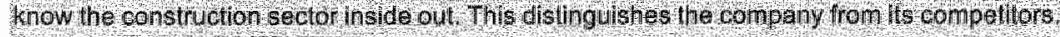

\section{Box 7.7: A market-driven software company}

This outcome is particularly interesting in that it does not support the outcome of the MERIT innovation study (Cobbenhagen, 1999). In the latter study, the degree to which the firm sees itself as being market-driven was a factor influencing a firm's innovative success at a statistically significant level. Here it is indicated that being market-driven is not a 
differentiating characteristic for ICT firms. It is not a factor that is separating the better innovating firms from the less performing companies.

\section{Creative self-developer}

Burns and Stalker (1961) already argued that a lower formalisation degree in an organisation contributes to a more open, receptive organisation, which is more creative and inventive. The origin of creativity can lie in different sources, such as a strong emphasis on searching new technology or markets in daily work practice, or from allowing slack resources in $R \& D$. It can also be associated with the organisation culture of creative destruction, informal communication and dialogue (Abernathy \& Clark, 1985). The creativity item in this study is significantly correlated with the growth success criteria. This might indicate that creativity is a rewarding attribute for companies in the ICT sector. In an organisation, creativity may substantially contribute to the uniqueness of new product designs and the innovative features (De Bono, 1994).

\section{Focus on productimarket portfolio}

A company might choose to manage a portfolio of products and markets as Porter (1985) advocated. The rationale of such portfolio thinking is that firms can compete on market segments, based on identifiable sets of products, customers and market segments. In the theory of strategy, within each of these segments, the enterprise can take up rivalry by positioning their product against competitot products, eventually leading to a competitive advantage. The actual ICT practice shows that firms' intentions do not seem to differ in terms of this strategic behaviour. Managers are well-informed about their positioning and strategic manoeuvring and how to gain competitive advantage. The statistical analysis also shows that there is no actual relation with portfolio thinking and any of the success criteria. On the other hand, this portfolio issue is subject to debate in the strategic literature. The resource-based perspectives argue that competitive advantage from product-market positioning is only temporary (Rumelt, 1991). Product market combinations are perishable and can be copied by competitors. Competencies and tacit resources are unique and hence an invaluable source of competitive advantage. In the next section we will go into a number of resource-based figures in the ICT sector.

In conclusion, the analysis points to the idea that successful innovators seem eager to be dominant market players and show trend-setting behaviour. Successful firms are furthermore characterised by a constant search for new business opportunities and the perception of comparatively high $\mathbb{R} \& D$ spending.

\subsection{Results: Resource Capacity}

To determine the degree of resources devoted to innovation, we looked at several types of resources included in the MERIT questionnaire (see also Barney, 1989; Grant, 1991; Cooper \& Kleinschmidt, 1995). The following resource measures were used:

- R\&D resources: $R \& D$ intensity, $R \& D$ allocation, $R \& D$ personnel;

- Human resources: education and training expenditures; and

- Technical resources: technological position, portfolio of technologies.

A traditional resource variable in the literature is the investment of $R \& D$ resources, measured as a percentage of tumover (Cooper \& Kleinschmid, 1995). This R\&D intensity figure 
reflects the level of $R \& D$ investments made by a company. In the literature a debate is being conducted as to whether higher values of R\&D intensity are related to innovation success (Rothwell, 1992, 1994; Freeman, 1988). The descriptive data on R\&D intensity of the ICT companies reveal no consistent patterns between $R \& D$, growth or firm size (see figure 7.3), with the exception that sofware firms show relatively higher R\&D percentages. Yet this difference is not statistically significant.

\section{R\&D resources}

A correlation analysis on the R\&D intensity variable, for successive time periods, reveals the following. The correlation coefficients in table 7.4 show no significant results between the wariable R\&D intensity and the overall innovation success criteria. Moreover, the variable R\&D intensity is only positive and significantly correlated with the portfolio success factor. A significant correlation between R\&D intensity and portfolio success was found for three successive periods (for $1993 r=0.42$, for $1994 x=0.5$ and for $1995 r=0.55$ ).

\section{Figure 7.3: R\&D-firm size}

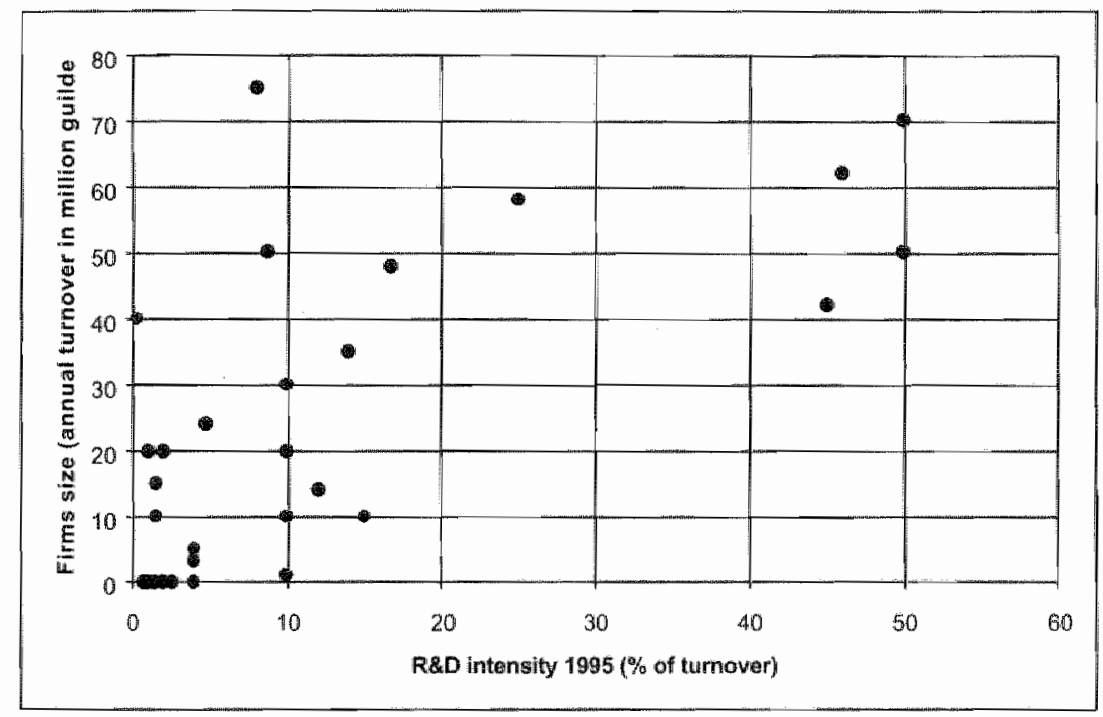

\section{R\&D allocation}

The relative amount of $R \& D$ investments only partly explains whether fims are successful at innovation. The allocation of $R \& D$ resources also mafters. To what kind of innovation activities are R\&D resources allocated, and are there differences in expenditure pattems? In order to identify possible differences in R\&D spending, respondents were asked to breakdown their invested $R \& D$ resources into a predefined set of $R \& D$ activities. Descriptive figures in table 7.4 show that $60 \%$ of R\&D went into product innovation and $35 \%$ into process imnovation. This means that more than half of the R\&D investments is focused on improving and renewing products and services. This finding might indicate that ICT companies are more inclined to invest in innovation through new products and services and less inclined to innovate through new or improved processes. 
Table 7.4: Allocation of R\&D efforts

Percentage of R\&D inwestments allocated to the following activities $(N=30)$ :

R\&D focused on product \& service innovation

Total

$100 \%$

Table 7.5 presents the correlation coefficients for the variable that measures R\&D resource allocation. This variable measured the percentage of $R \& D$ allocated either to product (including service) innowation or process innovation.

The correlation analysis results indicate that the variable ${ }^{R} \& D$ resources allocated to product innovation' significantly correlates with both overall success $\left(r=.47^{*}\right)$ and with project success $\left(r=.64^{* *}\right)$.

\section{R\&D personnel}

Another resource variable is concerned with the number of $R \& D$ employees (measured in full-time equivalents). This variable can indicate a possible association between the absolute number of people working on R\&D and innovation success. In this study a split is made between:

- the internal R\&D personnel, and

- the R\&D personnel, external to the company.

The latter can entail outsourcing of R\&D activities, joint R\&D projects or the hiring of external R\&D professionals. When we take a look at the figures presented in table 7.5 , the total amount of R\&D efforts might indicate low but significant correlation coefficients ( $r=0.39^{*}$ ) with two imnovation success factors: portfolio success and growth success.

A breakdown of the total number of R\&D human resources shows a slight difference:

- internal R\&D: the number of internal R\&D employees is positively significantly associated with growth $(r=.39 *)$

- external R\&D: the correlation analysis reveals that the number of external R\&D employees is supportive to portfolio renewal $(r=39 *)$.

\section{Human resources}

Another question in the context of resource-based approach to innovation is how the success factors rellate to companies' expenditures on personnel education and training. Especially the services part of the ICT sector is a knowledge- and people-intensive business. Investments in employees, through training and education, can be regarded, particularly for service providers, as an indication of the investments in innovation. Descriptive figures for education and training show that average expenditures have risen. Company data indicate that firms have substantially increased their education expenditures from $2.8 \%$ in $1993-1994$ to $3.5 \%$ in 1995 1996. 


\section{Table 7.5: Correllation of $R \& D$ resources and performance}

\begin{tabular}{|c|c|c|c|c|c|c|c|}
\hline $\begin{array}{l}\text { perfomance } \\
\text { dimensions }\end{array}$ & $\begin{array}{l}\text { overall } \\
\text { success }\end{array}$ & $\begin{array}{l}\text { process } \\
\text { success }\end{array}$ & $\begin{array}{l}\text { portiolio } \\
\text { success }\end{array}$ & $\begin{array}{l}\text { growth } \\
\text { success }\end{array}$ & $\begin{array}{l}\text { oppoitumity' } \\
\text { 'success }\end{array}$ & $\begin{array}{l}\text { phoject } \\
\text { sucoess }\end{array}$ & qualiy \\
\hline \multicolumn{8}{|l|}{ R\&D resources: } \\
\hline R\&D intensily $1993-94$ & & & $42^{*}$ & & & & \\
\hline R\&D intensity $1994-95$ & & & $.50^{\text {* क }}$ & & & & \\
\hline R\&D intensity 1995.96 & & & $.55^{* \alpha}$ & & & & \\
\hline
\end{tabular}

\begin{tabular}{lll} 
R\&D allocation: & \\
product innovation & $47^{*}$ & $64^{\text {m* }}$ \\
\hline
\end{tabular}

process innovation:

\section{R\&D personnel}

Tolal number of R\&D rescurces

\begin{tabular}{lll}
\hline in full time equivalents & $.39^{*}$ & $.35^{*}$ \\
\hline internal R\&D (in fle) & $.39^{*}$ \\
\hline external R\&D (in fte) & $.39^{*}$ & \\
\hline
\end{tabular}

\begin{tabular}{l}
\hline Education \& training expendifures: \\
\begin{tabular}{ll}
\hline for $1993-1994$ & $42^{*}$ \\
\hline for $1994-1995$ & $38^{*}$ \\
\hline
\end{tabular}
\end{tabular}

\begin{tabular}{llll}
\hline Technological resaurces: & & & \\
\hline technological pasition & $.31^{*}$ & $.40^{* *}$ & $.37^{* *}$ \\
\hline portfolio technologies & $.31^{*}$ & $.47^{* *}$ & $.39^{* *}$ \\
\hline
\end{tabular}

("denotes significance at the .05 level and " denotes significance at the .01 leveli, resulls $>0.3$ are shown)

When we look at the correlation results in table 7.5 , the figures show no clear relation between the HR expenditures and the overall success factor. Remarkably, the HR variable is only correlated with the growth success factor for both time periods. One would expect the market to reward investments in human resources, especially if the labour market shows severe signs of labour supply shortage. One would expect fims that take good care of their employees by training and educating them to be more successful.. Yet the figures indicate no sign of reward other than growth of the firm, implying that company growil and increased personnel recruitment are closely related.

\section{Technological resources}

The above-mentioned resources were measured in quantitative terms. The survey also included a qualitative measure for resources. The technology managers were asked to state:

- the technological position relative to their competitors, and

- the technological portfolio relative to their competitors.

For example, technologies for such software programming as Java, Oracle, Cttit as well as technologies for object-oriented programming. Table 7.6 shows the correlation coefficients of the techmological resources. The proficiency of technologies mastered by the firms correlates positively to overall innovation performance. In particular, it bears astrongly significant correlation with portfolio success (40) and opportunity success ( $r=37$ ), albeit at low levels. Similar figures apply to the variable measuring the portfolio of technologies internalised by the company. 


\subsection{Discussion: Resource Capacity}

At the beginning of this chapter we stated that strategy and competencies were well-discussed subjects in the ICT sector. In actual practice, however, the implementation and operationalisation of strategy were less clearly defined by managers. This 'strategy in action' would mean that firms make different choices about resource investments. Is this really the case? Before starting this discussion, it should be observed that the outcomes of this section should be interpreted carefully. The correlation figures are based on a small sample.

\section{R\&D intensity}

Interestingly, R\&D intensity only correlates with portfolio success, and not with any of the other success measures. The figures show a wide range of percentages spent on R\&D (see box 7.8). Furthermore, this correlation is repetitive as it accounts for three success time periods. It is interesting to observe the meaning of this correlation. Going back to the definition of the criteria (see chapter 5), the portfolio success criteria measures the contribution to tumover and profit, by constantly developing new products and services. The correlation result might indicate that firms investing in R\&D are continuously successful at developing profit- and revenue-generating new products and services.

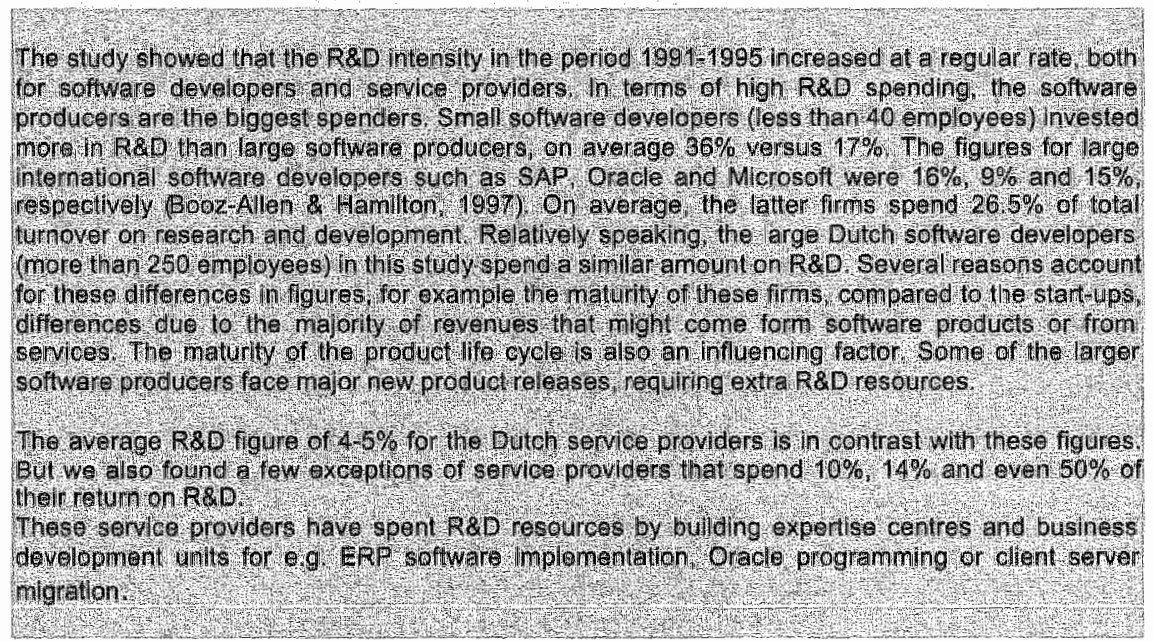

\section{Box 7.8: Differences in R\&D figures}

\section{R\&D allocation}

The allocation of $\mathrm{R} \& \mathrm{D}$ to product innovation is a key success factor. It is also related to project success. As stated in chapter 5 the project success measure consists of two variables, it.e., one measuring 'the percentage of new product "deas', and the other measuring 'the percentage of innovation projects actually launched into the market'. The results suggest, first, that ICT firms spending more R\&D on product innovation have a higher percentage of successful new product ideas. Second, ICT firms allocating more R\&D to product innovation have a higher percentage of products and services actually being launched in the market.

RdD personnel

We observed a correlation between intemal R\&D personnel and the growth success factor $\left(r=39^{*}\right)$. This positive figure might suggest that an increase in internal R\&D is beneficial in terms of growth. Next to internally conducted research and development, a company can also 
decide to (partially) outsource research and development activities to externall parties like research \& development centres, networks or technology laboratories. In this study we refer to such activities as extemal R\&D. The correlation analysis reveals that conducting extemal R\&D activities support the renewal of the product portfolio. This finding implies a contribution to turnover and profit resulting from new products developed by external researchers and developers.

\section{Human resounces}

A remarkable finding is the absence of a correlation between training expenditures and overall innovation success. The ICT sector is perceived as a sector with a scarce supply of ICT personnel, while companies invest fairly large amounts in education and training. A detailed analysis of the education and training expenditures reveals the existence of large differences between firms. Expenditure rates differ from 0.5 percent of total tumover for some companies to over $10 \%$ of total turnover in education and training for others. Differences in companies can be based on differences in opinion of holding on to employees to ensure a low percentage of personnel turnover. Additionally, companies seem to differ in opinion on employee training to ensure the value of an employee to the company. Why do conpanies spend over $10 \%$ on training? First, some companies with high expenditures do so to upgrade the skills of their employees, either because clients require up-to-date skills or because new technologies. make existing skills obsolete rather quickly. These companies invest heavily in personnel to develop new skills, for example object orientation, client server maintenance skills, Java script skills (see also box 7.9). Second, some companies show high scores on their education and training expenditures to strengthen their recruitment efforts. These firms try to differentiate in the labour market, e.g. through weekly recruitment campaigns and brand building in newspapers, or special recruitment actions like flying with polential senior colleagues.

The data of the regression analysis show that training expenditures were correlated with one specific performance dimension, i.e., growth success (e.g. turnover and employee growth). The training expenditures wariable was positively significantly correlated for successive periods, namely for the 1993-1994 period with $r=0.42$, and for 1994-1995 with $r=0.38$. Similar to the results on the internal R\&D employee figures (see above), this association might suggest two things. First, that firms heavily invest in high education and training and realise high growth rates by quickly training new employees and posting them at clients. Or, second, it might suggest that firms achieve high growth rates because they work with highly qualified and trained employees. Both lines of reasoning might be true for the ICT sector (see box 7.9). ICT companies can grow due to well-trained and professional personnel and/or to extra investing in newly acquired personnel. At the time the ICT market was and still is a supply-dominated market. 


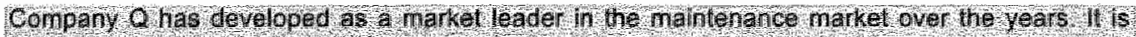
known wor is contulbution to develowng the I n nintenanee market based on ML standards. Fom

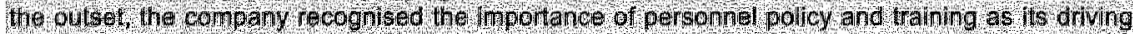

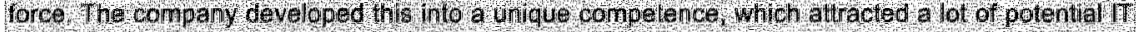

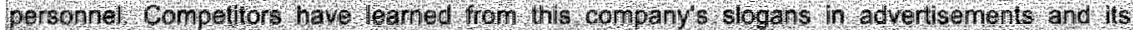

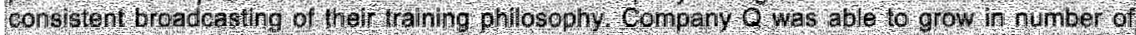

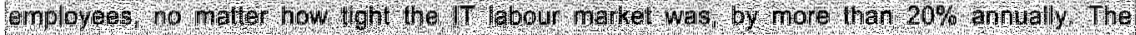

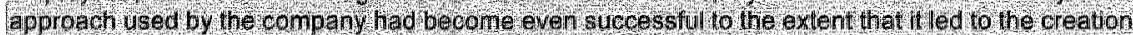

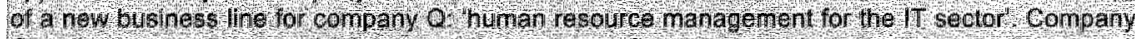

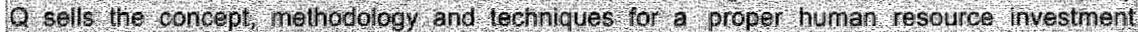

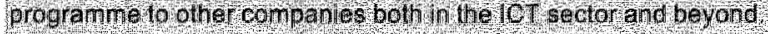

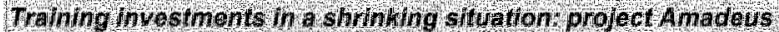

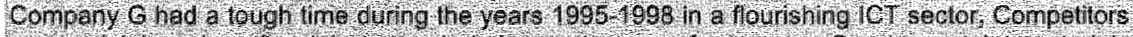

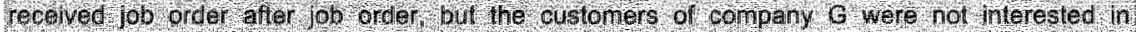

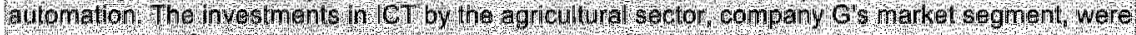

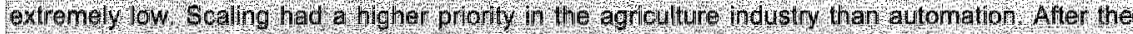
Wave of take overs ox hra attention was given to new automation but not until early in $1998 \mathrm{~h}$ the context or tris markat development the guostien was whal he company woud do in the mean ime.

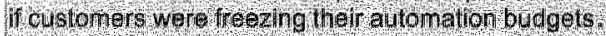

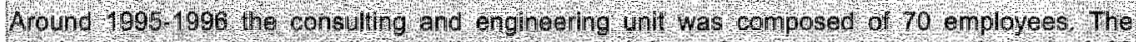

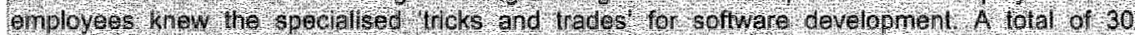

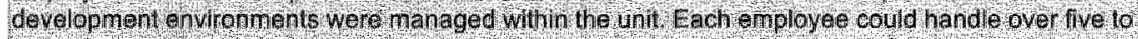

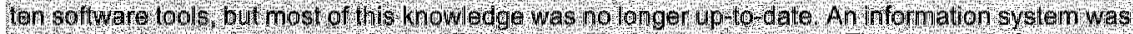

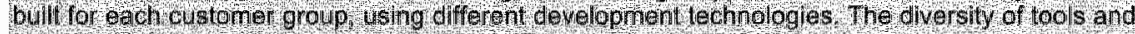

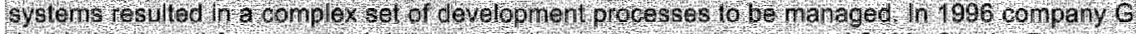

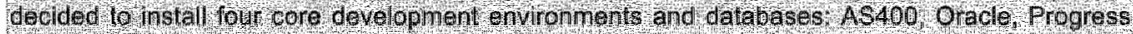

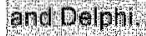

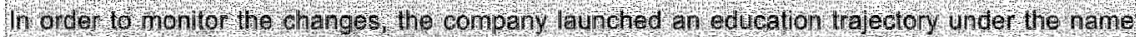

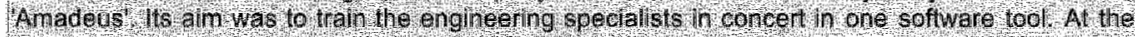

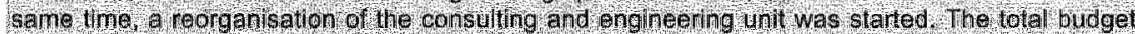

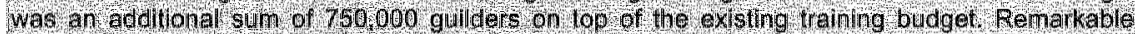

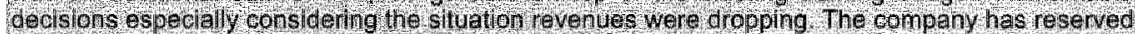

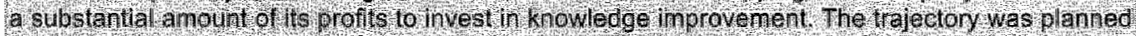

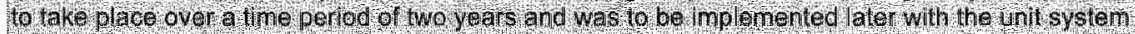
contiol

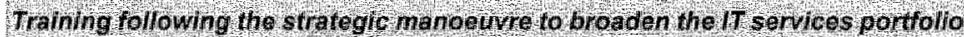

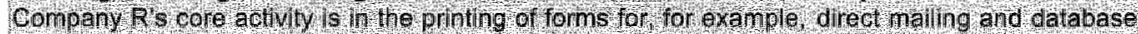

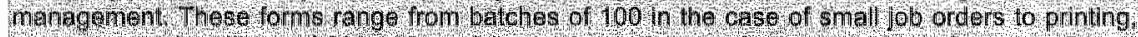

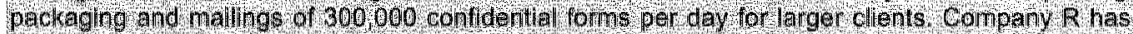

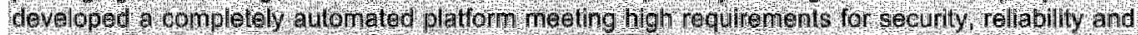

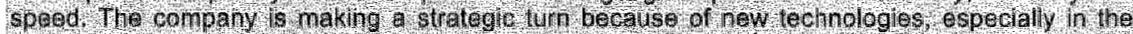
digutsation af the brodugtion brocess and the acrompanying torondion flows. The form fows are

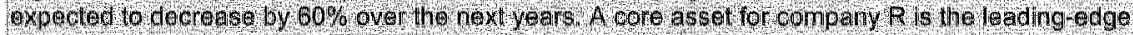

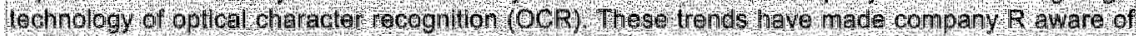
the nosd to broten and hirenify Its senices oflerings.

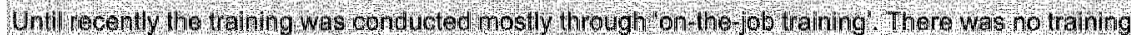

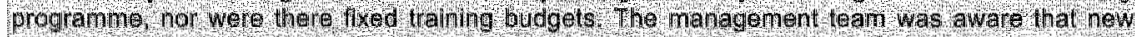

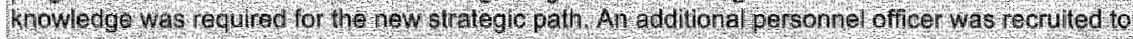

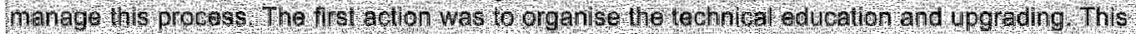

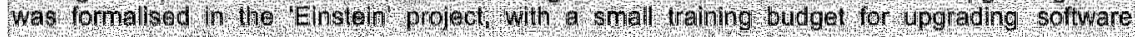
Drogrannings:suls

\section{Box 7.9: Strategic goals for human resource management}

The paradoxical outcome of this study lies in the high priority and attention given by firms to human resources. Yet in itself it is not a success factor. The cases illustrated in box 7.9 show the deeper and complex situations of human resource management in ICT firms. The motives for human resounce investments differ between firms, considering creative solutions such as 
subsidised training in company $\mathrm{P}$, marketing HRM as core asset in company $\mathrm{Q}$, or even taking decisions as in company $G$ to reserve a substantial amount of the profits for knowledge investment. By taking a closer look at the core of the complex reality we find new answers, which provide a deeper understanding of the actual practice. This research approach has taught us that a large(r) survey may not reveal the actual business rules behind management topics. Rather, the supportive combination of qualitative and quantitative methods gives a more complete insight into the way things work. In fact, this is one of the learning experiences of the present research project.

\section{Technological position}

Both the technological position and the portfolio of technologies are key success factors for ICT firms. They tell us something about the absorptive capacity of ICT firms. Absorptive capacity refers, for example, to the extent to which new technologies are identified and used to reduce software development costs or the transter of technological knowledge from outside the company. The MERIT study found contradicting evidence on the technological position and portfolio of technologies. Using a similar operationalisation of the variable, this study failed to find conclusive support for the idea that technological sophistication can be regarded as a discriminating factor. Nor was there evidence that the breadth of technologies and innovativeness were significanily correlated. "This contradicting evidence might be due to the scope of the previous study, e.g. a wide range of industries and service sectors. The ICT study found evidence that the ICT firm's technological absorptive capacity influences a firm's innovative success, in particular the extent to which the ICT firms are prompt to detect and adopt technological developments (see box 7.10).

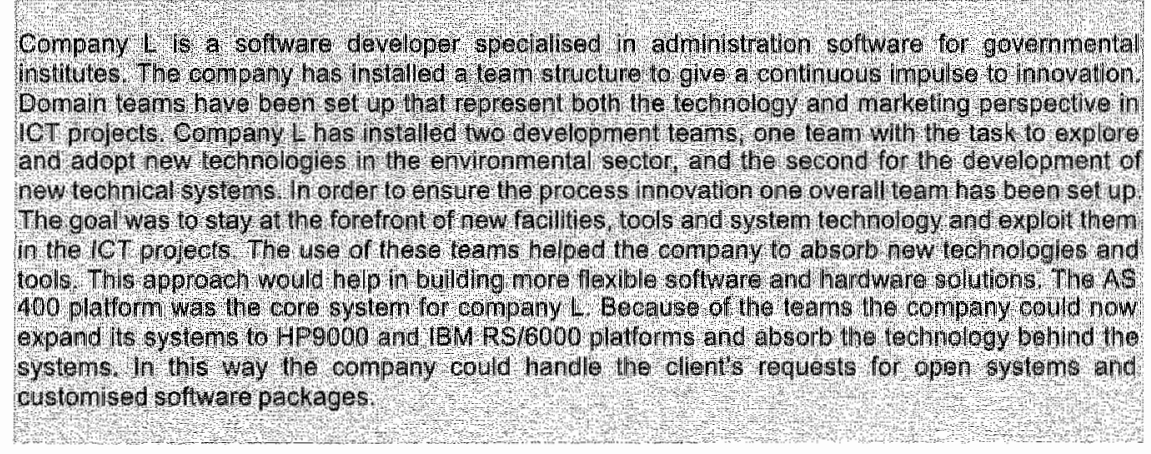

\section{Box 7.10: Technology-driven software developer}

\section{Summary}

In this chapter we addressed the management priorities of ICT companies, their innovation strategy style and the resources committed to innovation. We raised the expectation that these topies would provide interesting outcomes, primarily because strategy is a hot discussion topic in the ICT companies. The management agenda of ICT companies has drastically changed over time. The subjects that were high on the agenda some years ago have been replaced by such new topics as core business and quality. The subjects that were given little attention in the period 1988-1992: training, new internal information systems and market cooperation, acquired reasonable to high priority in the more recent period (1992-1996). The most urgent topies attracting management attention were quality assurance profit improvement, recruitment of personnel and concentration on core activities. The policy agenda of software producers and service providers differed in these aspects. With respect to 
quality assurance this seemed one of the key success factors. The data show that "concentration on core activities" is moderately correlated with overall success. The timing of policy items is important to innovation success. This finding is in line with the MERIT study. With regard to the innovation strategy style we observed that being a trend-setter, spending relatively more on $R \& D$ than competitors, being the first market entrant, and business opportunity searching are key success factors. Remarkably, the ratings on "market-driven" and 'attention for stable product-market portfolio' do not seem to matter for success. With regard to the resource capacity for innovation, the R\&D intensity did not point to any relation with growth or firm size of the companies. R\&D intensity is not a key success factor in this study. Nevertheless, the way R\&D is allocated to product and process innovation is of interest. R\&D allocated to product innovation is a key success factor. Another remarkable finding is the absence of a relation between training expenditures and overall innovation success. As a result of the need to constantly upgrade skills and quality of personnel this item does not seem to be a discriminating factor. Finally, the technological position and the portifolio of technologies such as Java and $\mathrm{C}+$ exploited by a firm are key success factors. A further comparison of these outcomes will be made in Chapter 9 , where we will discuss the findings with other innovation studies. In the next chapter we will further detail the subject of the organisation of innovation. 


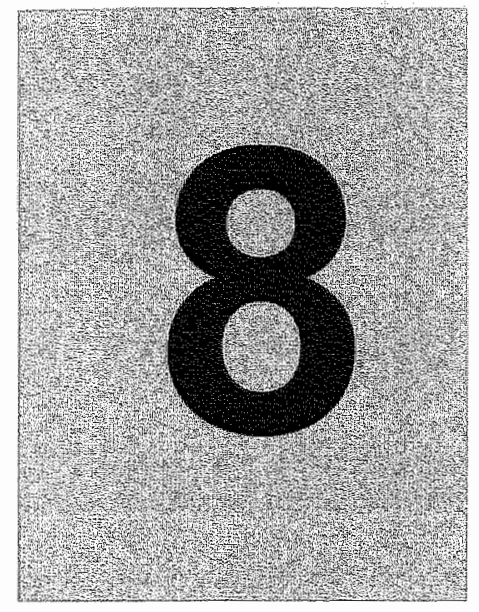

\section{Organisation, \\ Process and}

Innovation Performance 


\subsection{Quality Management}

In the literature (D'Aveni, 1994; Den Hertog \& Huizenga, 2000; Lemmink, 1991; Porter, 1985 it is argued that a client and quality focus have become essential entry conditions for operating in the current competitive markets. The Dutch economy prospered in an economic boom in the late 1980s. Companies achieved high turnover and profit growth and started to pay attention to quality. The issue of quality management showed up on the management agenda through the development of quality assurance systems, certification and strict product quality controls. In the same period, the ICT suppliers grew rapidly due to the high demand for ICT products and services. Yet ICT firms seldom addressed the subject of quality and the quality levels that they offered their clients. During the economic recession in the early $1990 \mathrm{~s}$, the Dutch companies, e.g. the banking, insurance and chemical industry and public sector, primarily devoted attention to the reduction of costs. In addition to the efrorts made to downsize operational costs, the companies started to wonder if they received enough value for their ICT expenditures from their suppliers. The firms had become aware of the high risks of ICT dependency. At that time, reliability was a matter of great concern due to the increased dependency on and performance of information systems for data transactions and information handling processes (as illustrated by the software developer in the government sector in box 8.1). ICT became integrated into the primary processes of banks, traders, logistics companies, and other organisations. System reliability could mean the difference between profit and loss.

As a consequence, the ICT suppliers were facing two strict market conditions: delivering better quality and lower demand for ICT products and services. Chients of ICT firms had numerous complaints about the quality of ICT products and services as well as the large number of ICT projects that exceeded deadlines and budgets (see box 8.1). The image of ICT companies was damaged. Clients had the feeling they had lost control over their ICT activities and partly blamed their suppliers. They demanded betier and high-quality services. Some Dutch companies even sued their suppliers, for example HCS and Multihouse, for delivering bad performance.

ICT suppliers reacted to the upheaval about their quality and performance and came up with service level agreements on time, money and performance requirements. Ever since, ICT companies have adopted a far mone critical attitude towards quality to better control ICT projects. Other examples of the attention for quality include the use of client surveys and the emphasis in brochures and websites on delivering quality. ICT companies also started investing in the quality of products and services by recruiting and training quality personnel. In the second half of the 1990s the economy had recovered and started to grow, which led to a strong growth phase for ICT services.

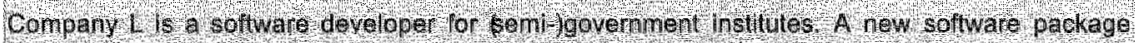
(2asows) hoorporaung how leglitation and regulations in ah miportant policy area had lo bes

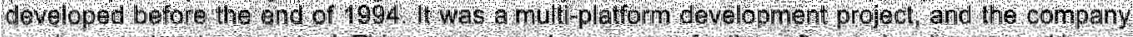

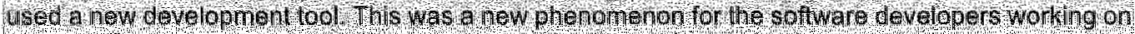

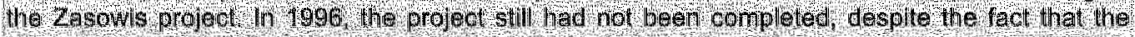

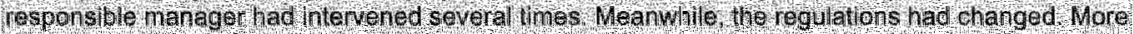

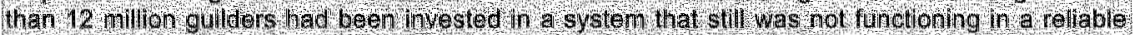

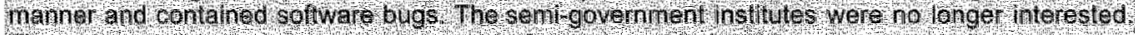

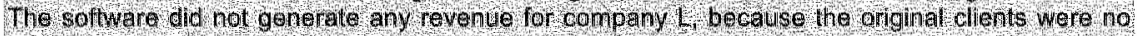
longer orepared 16 bovit,

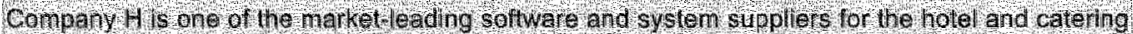

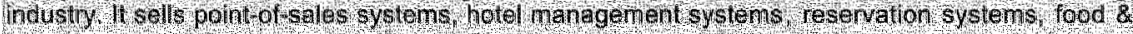

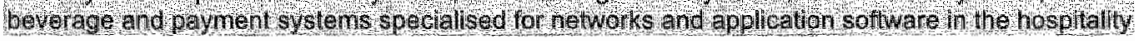




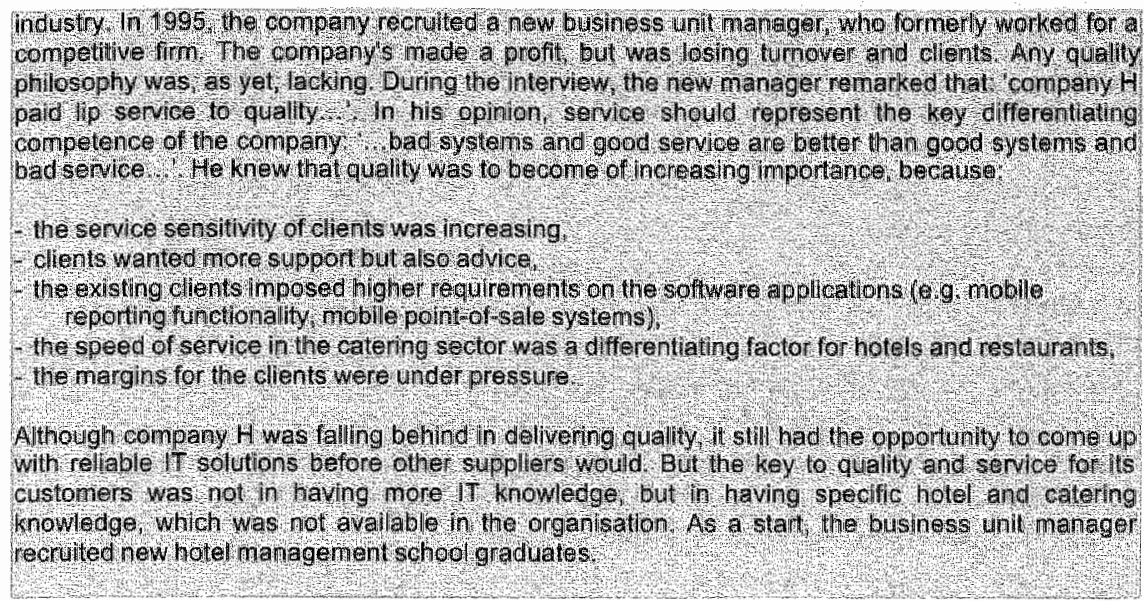

\section{Box 8.1: The risks of ICT and the meed for quality}

In the questionnaire the respondents were asked to provide data on three areas: a) the presence of a formal quality assurance system and quality procedures; b) the presence of a quality certification (e.g., ISO), and c) the perceived benefits of a quality assurance system.

The third variable was included to obtain an indication of the benefits for an organisation of implementing certain quality procedures and standards. In doing $s 0$, respondents were asked to point out the benefits they perceived, using a list of statements (see Appendix for the relevant question). Descriptive statistics revealed the following figures:

- a total of $50 \%$ of the companies reported to have a quality assurance system,

- a total of $40 \%$ of the companies reported to be ISO-certified.

Correlation anallysis revealed that the variable 'quality assurance system' is modestly but significantly correlated with overall success measure $\left(r=29^{*}\right)$. With respect to the variable "perceived benefits", no significant findings were found between this variable and one of the success factors, with the exception of one. There was a significant negative association ( $\mathrm{F}=$ 40) between the variable "an increase of flexibility of processes' and the overall success measure.

\section{Discussion}

The first correlation finding might imply that the presence of a quality system is beneficial to innovation. The earlier finding (section 7.2) is in line with the finding that better performing firms attach a higher priority to the policy issue of quality. The latter correlation is remarkable, especially for a service-oriented $\mathbb{I C T}$ sector. It might indicate that a quality system also has negative side effects, which might hamper the flexibillity of the innovation processes.

\subsection{Project management}

In chapter 2 we have discussed the role of project management. Tight planning and control of an innovation project can be conducive to innovation success. In order to explore the relevance of project management in the ICT sector we have tried to measure the presence and 
quality of project managenent and its impact on innovation success. In doing so, we have mainly focused on the following dimensions, which are based on the MERIT questionnaire (Cobbenhagen, 1999) and previous innovation studies (e.g. Cooper \& Kleinschmidt, 1995):

- project planning dimensions, as a measure for the degree of detailed plaming of an innovation project, and

- project responsibility dimensions, as a measure for the degree of responsibility and accountability of the project leader and the project team.

Both dimensions are an attempt to capture the extent to which companies have emphasised the role of up-front development work and detailed market and technical assessment. Figure 8.1 provides the average figures for project planning. The figures show that companies' plans start from financial targets (profit and turnover) and go/no go decision points. Less emphasis is placed on planning costs and time schedules.

Figure 8.1. Project planning
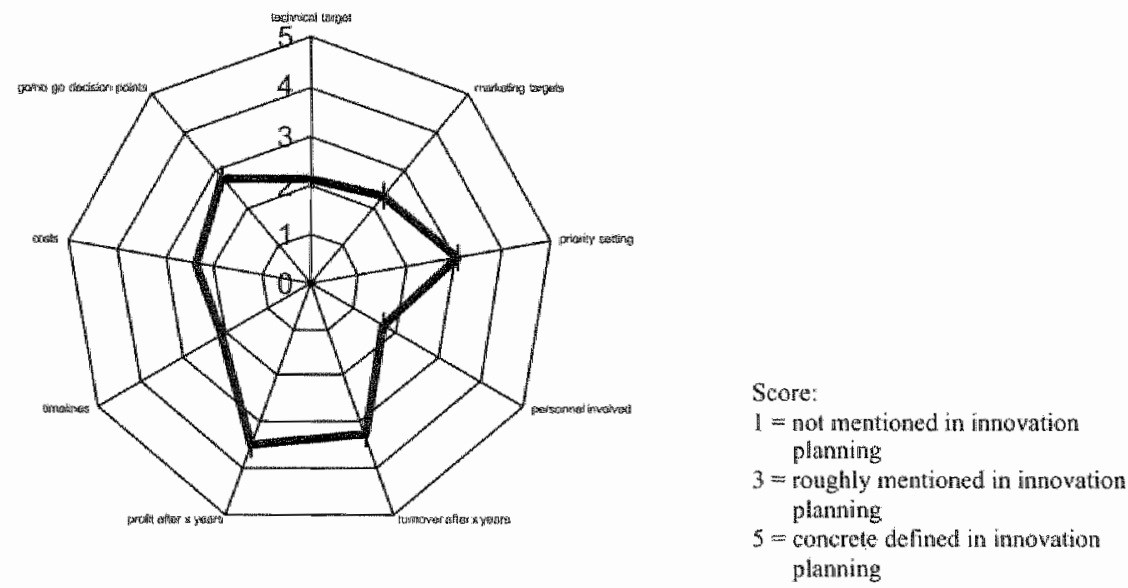

\section{Results}

The correlation analysis has led to the following findings. Significant results and overall success correlations atre shown. Concerning the planning variables, especially the priority setting wariable is significantly conelated with both the overall success factor $\left(r=26^{*}\right)$ and opportunity success factor $\left(r=36^{* *}\right)$. Stating the profit goals is also beneficial to opportunity success factor ( $=39^{*}$ ). Incorporating marketing targets into the project plan is beneficial to the quality success factor $(r=52 *)$. As regards project responsibility, no variable is significantly correlated with overall imnovation success. A remarkable finding is that the responsibility for technical design is beneficial to growth success $\left(r-40^{* *}\right.$ ). Furthermore, the responsibility for the project leader for project costs and team composition but not for test running, is beneticial to opportunity success $\left(r=31^{*}\right.$ and $r=39^{*}$ ). Finally, the variable cost price of a project deliverable seems to be significantly correlated with project success $\left(r=28^{*}\right)$. 
Table 8.1: Correlation results between project management variables and performance

$\begin{array}{ll}\text { performance } & \text { overal } \\ \text { dimensions } & \text { success success portfolio growth opportunity project quality }\end{array}$

project planning of innovation project

\begin{tabular}{|c|c|c|c|c|}
\hline priority setting & $.26^{1 \cdot 2}$ & $.26^{*}$ & $.36^{* t *}$ & \\
\hline marketing targets & .07 & & & $.52^{k}$ \\
\hline tectunicall target & .24 & & & \\
\hline personnel involved & .05 & & $.39^{*}$ & \\
\hline costs & -.13 & $29^{*}$ & & \\
\hline prolit after $x$ years & .13 & & $26^{*}$ & \\
\hline tumover after $x$ years & -.02 & & & \\
\hline go/no go decision poin & .07 & & & $.29^{*}$ \\
\hline
\end{tabular}

performance

overall process portfolio growth oppoirtunity project quality dimensions success success success success stuccess success

project responsibilities for project leader

\begin{tabular}{|c|c|c|c|c|}
\hline project aligrnment & 17 & $.32^{*}$ & & \\
\hline technical design & .19 & & $.40^{1 \times 1}$ & \\
\hline project costs & .13 & & & $.311^{*}$ \\
\hline team composition & .24 & & & $.39^{*}$ \\
\hline cost pirice & .15 & & & $.28^{*}$ \\
\hline test run & .02 & & & $-.32^{*}$ \\
\hline market introduction & .19 & & & \\
\hline
\end{tabular}

(c) denotes significance at the .05 level and ** denotes significance at the .01 level).

\section{Discussion}

In accordance with other studies (e.g. Cooper \& Kleinschmidt, 1995) variables such as making the profit and tumover goals explicit up-front, having clear decision milestones (go/no go) and priorities, contribute to innovation success. In this study these variables correlate, although at low levels, with one of the success measures (see table 8.1). In line with the literature is the finding that go/no go decision points add to the quality success factor, particularly for a service delivery environment, whereas most key success factors studies are concerned with the industry. This supports work on the stage-gate model of innovation (Cooper, 1994; Ancona \& Caldwell, 1992, Eisenhardt \& Tabrizi, 1995), which emplhasises the explicit use of go/no go decision points.

The overall question is whether project leaders should attain broader and deeper responsibilities, or companies should use cross-functional teams. We have observed that responsibility for the technical design, project alignment, project cost and team composition each correlate with a success measure. This is not surprising given the empirical findings from the literature (chapter 2). Moreover, companies that make project leaders responsible for cost control and team composition better seize new business opportunities. This responsibility contributes to the realisation of profit growth and the opening of new markets. This is a new finding seldom tested in the empirical Jiterature. We have also observed that companies spend 
time to professionalise their project management, while at the same time supporting the use of teams. In addition to the statistics, what do the case studies tell us about this?

About half the companies reported that they invest in new project workflow methods and supportive information systems, all of them aimed at speeding up and tightening the predevelopment work and the design of innovation (as supported by the case illustrated in box 8.2). We have come across a large number of projects using Rapid Application Development (RA.D) in the companies visited in the context of this study. This suggest that the professionalisation of IT project management was a serious issue at the time of the visits. A number of remarkable statements made by the managers interviewed (see also box 8.2), are concerned with the project working methods. This finding is supported by similar research on passing cross-functional borders in the industry (Den Hertog \& Haizenga, 2000, Roussel, Saad \& Erickson, 1991), where programming of development work will be effective only if the organisation has streamlined its development process. In particular, it includes the introduction of formal control systems such as PERT (Project Evaluation and Review Technique) and. CPM (Critical Path Method) in up-front work. It is suggested that task allocation, work standardisation and formalisation are not the opposite of steering innovation by means of teams. In this process of streamining the development activities are decentralised to the smallest unit, for example the team. Programming along the process flow appeared to be a crucial point in the chemical industry (Den Hertog \& Huizenga, 2000).

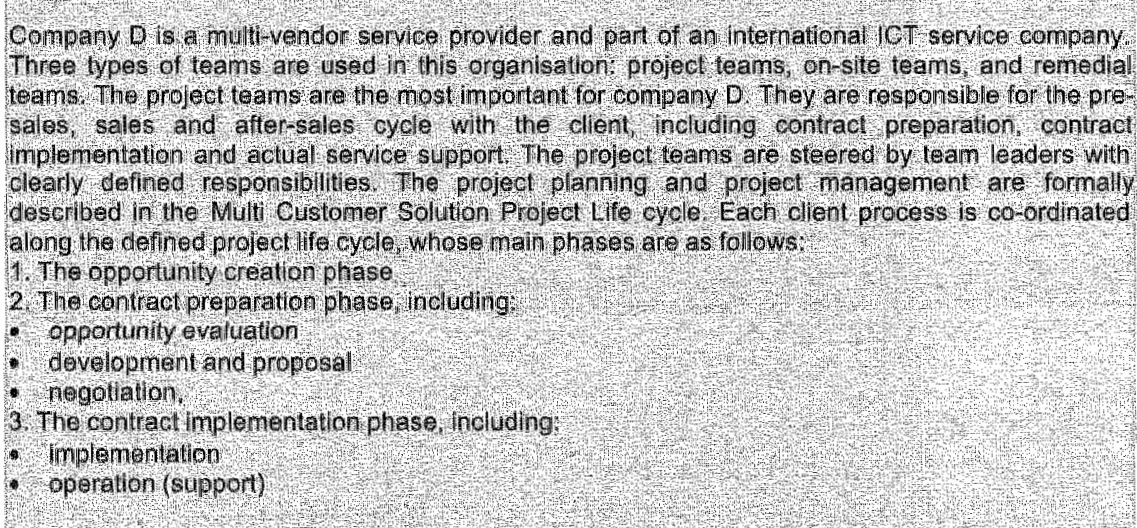

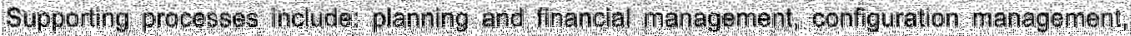

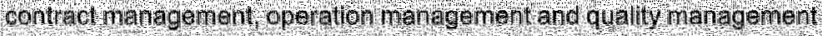

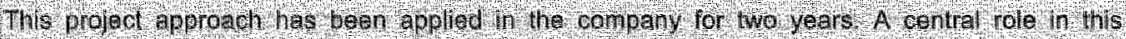

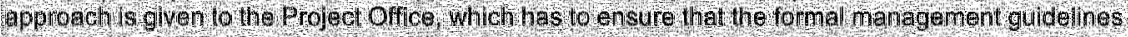

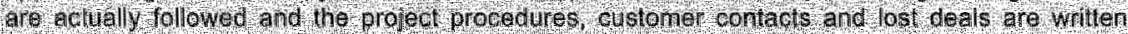

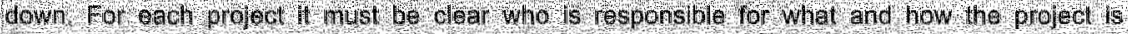

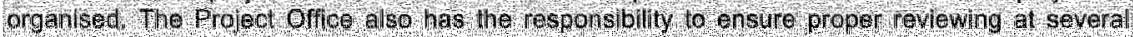

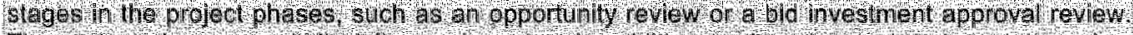

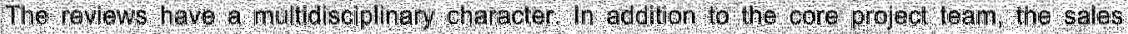

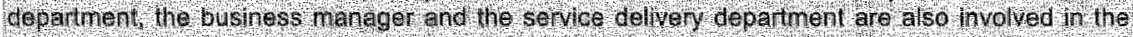
revews

\section{Box 8.2: Advanced project management methods}




\subsection{Organisation Structure and Teams}

The MERIT study identified the use of teams as a key success factor. Supporting evidence has been found for this in the literature (see Chapter 2). This raises the idea that the team organisation is prevailing in the ICT sector. In order to look at the relevance of teams in the ICT sector, the respondents were asked to typify the organisation structure of innovation processes. Based on a vallidated typology of five basic organisational structures, we were able to classify the companies" organisation structures (Cobbenhagen, 1999; Larsson \& Gobeli, 1988; Galbraith, 1971). Table 8.2 describes the respective organisational characteristics and reports on the ICT firm responses. This typology of structures ranges from the pure functional organisation reflecting a functional specialisation of innovation to the project tean-based organisation structure.

\section{Table 8.2: Organisation of innovation process}

\section{Functionall organisation}

Art inmovation project is divided into segments and assigned to relevant functional (sub)departments. Departments conduct project tasks successively. The project is coordinated by the functional managers and higher management echelons.

\section{Functional matrix}

A project leader with limited authority is appointed to coordinate the project across the respective functionat (sub)departments. The functional managers have responsibility for and authority over their specific segment of the profiect.

\section{Matrix organisation}

A project leader is assigmed to oversee the project and shares responsibilities and authorities with respect to the completion of the project with the functional managers. Decisions are made jointly by the functional managers and the project leader.

\section{Project matrix}

A project leader is assigned to supervise the project and has the primary responsibility and authority for its complietion. The functional managers provide human resources and the necessary functional knowledge and capabilities.

\section{Project team organisation}

A project leader is put in charge of a project team composed of a core group of people from all relevant functional disciplines. They are allocated to the project on fullime basis. Functional managers do not have any formal involvement.

Total percentage

\begin{tabular}{|c|c|c|}
\hline $\begin{array}{l}\% \text { of LCT } \\
\text { firm } \\
(n=32)\end{array}$ & $\begin{array}{l}\% \text { of } \\
\text { frontrumners } \\
\left.(n=3)^{*}\right)\end{array}$ & $\begin{array}{l}\% \text { of } \\
\text { members of } \\
\text { the parto } \\
\left(n=31^{\text {in }}\right)\end{array}$ \\
\hline 12 & 3 & 36 \\
\hline
\end{tabular}
preceding research (Cobbenhagen, 1999) 
A second aspect of a horizontal flow-oriented organisation structure is the introduction of multidisciplinary teams (or cross-functional teams). The organisation literature argues strongly in favour of the use of such teams to innovate (e.g. Takeuchi \& Nonaka, 1986). Multidisciplinary teams organise around the integral development task itself, rather than focusing on the single contributions to the overall product outcome.

\section{Results correlation analysis}

Correlation analysis was conducted to test if both the organisation structure variable and the multidisciplinary team variable affect innovation success. In line with earlier empirical findings Nonaka, 1990; Cobbenhagen, 1999; Larsson \& Gobelli, 1988) the organisation structure was found to be a statistically significant key success factor in the ICT study $\left(r=32^{*}\right)$. The multidisciplinary team variable was not significantly cortelated with any of the success factors. Statistics might indicate that the composition of multidisciplinary teams does not affect overall success $(r=05)$. We also tested for team composition. Three types of teams were incorporated into the questionnaire: 1) a full-time dedicated project team, 2) a core team composed of temporary team members for different project phases, and 3) different teams for different project stages. This variable did not correlate with any of the success factors. Overall, multidisciplinary teams do not seem to be a differentiating factor for ICT firms.

\section{Table 8.3: Correlation results of organisation variables and performance}

\begin{tabular}{|c|c|c|c|c|c|c|c|}
\hline $\begin{array}{l}\text { perfomance } \\
\text { dimensions }\end{array}$ & $\begin{array}{l}\text { overall } \\
\text { success }\end{array}$ & $\begin{array}{l}\text { process } \\
\text { stucess }\end{array}$ & $\begin{array}{l}\text { portfolio } \\
\text { Successs }\end{array}$ & $\begin{array}{l}\text { growth } \\
\text { sticcess }\end{array}$ & $\begin{array}{l}\text { opportunty } \\
\text { suctcess }\end{array}$ & $\begin{array}{l}\text { project } \\
\text { sucreess }\end{array}$ & qualiey \\
\hline Organisation structure & $32^{*}$ & $.25^{*}$ & & & & & \\
\hline Multidisciplinary teams & 17 & .44 & & & & & \\
\hline Team assembling & .05 & & & & & & \\
\hline
\end{tabular}

\section{Discussion of arganisation structure}

The results of the MERTT study indicated that innovative frontrunners specifically organised innovation through project-dominated structures, whereas pack members opted for more functionally dominated structures. The figures in tables 8.2 and 8.3 demonstrate that the ICT sector has adopted a more project-oriented approach to innovation than the firms studied in the preceding study. This shows that we deal with a sector-specific factor. The ICT firm responses indicate that firms with a functional orientation are in the minority. Around 75\% of the ICT firms have organised innovation through a matrix, project matrix or project team structure. One third $(32 \%)$ of the ICT firms have opted for the project team structure compared to $18 \%$ of the frontrunners in the preceding study. The question in the present study is whether the extent to which the firm's imnovation processes are organised horizontally (project-wise) differentiates the successful companies from less successful companies.

\section{Discussion of teams}

ICT firms that organise their innovation projects with multidisciplinary project teams do not appear to be more successful innovators than firms using a linear functionally oriented approach. The correlation analysis results do not confirm earlier findings on the importance of a flow-oriented and multidisciplinary method of organising innovation (Cobbenhagen, 1999; Cooper 1994; Nonaka \& Takeuchi, 1986). Up to 80\% of all ICT companies work with a core 
team that is facilitated in each of the sequential project phases by temporary team members. The data on variations in multidisciplinary team composition show no correlation. No wonder then that we did not find a correlation. For the majority of the sector it is common practice, so it cannot be a differentiating factor. This might indicate that working with multidisciplinary teams is neither a key nor a differentiating success factor in the ICT sector. The use of such teams has become a standard for ICT companies. This finding contrasts with the MERIT innovation study, which suggested that multidisciplinary teams differentiate frontrunners from pack members.

Managers advocate (e.g. Barczak 1995; Stopford \& Baden-Fuller, 1994) a team approach and argue that the "entrepreneurship" conditions allow for a more effective application of scarce resources within shorter time schedules. In the ICT sector the interviewed managers stressed the importance that without teamwork it is impossible to secure the cross-functional interfaces, which are essential to the business services sector. Cooper et al. (1995) are among the numerous authors (e.g. Galbraith, 1994; Den Hertog \&. Huizenga, 1997, 2000) who argue that multidisciplinary teams can help improve decision making and implementation of new services. Especially in cases where barriers have to be taken the proper working of crossfunctional interfaces are essential. Box 8.3 gives an illustrating example. It is a form of teamwork, which can be called "skunk work'. In 'A Passion for Excellence', Tom Peters (1988) defined skunk works as highly innovative, fast-moving, and slightly eccentric activities operating at the edges of the corporate work. The origins of "skunk works" go back to a development team at Lockhead's Design and Development Centre that developed radical new product concepts by using fully independent heavyweight project teams. In sum, teams are an effective means for cross-functional co-operation and working across traditional organisational borders (Kanter, 1983).

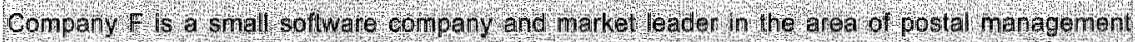
sofiware. The canpany eniloys 30 people. Thee vears ago a new developmenl prejed was

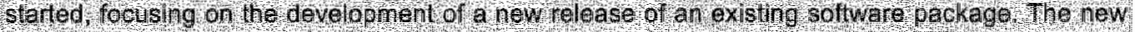

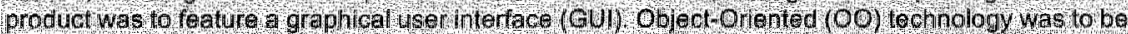

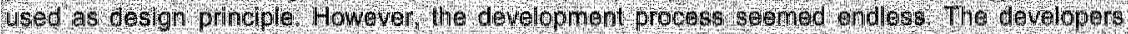

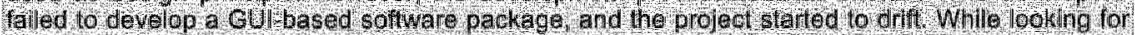

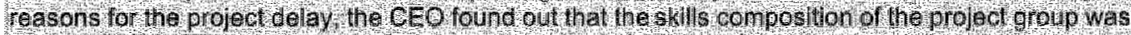
not sultable for the profed geal. The group nembers we re programmers thet used second and

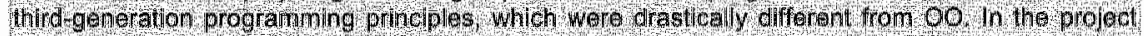

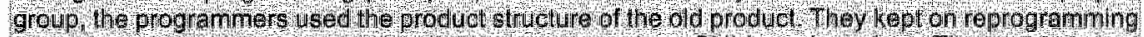

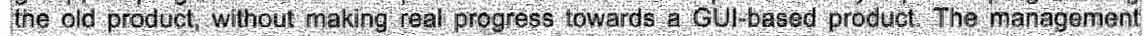

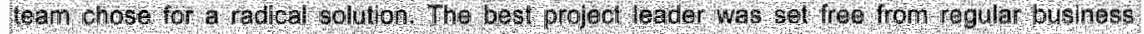

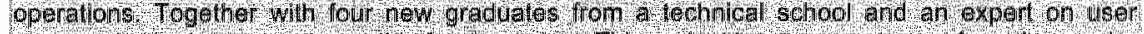
ergonomies he bie came rosponsible lon ho projed. This projed te m was set apant from the regular

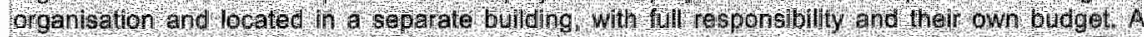

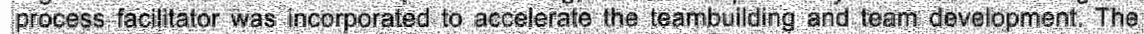

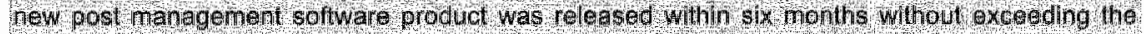

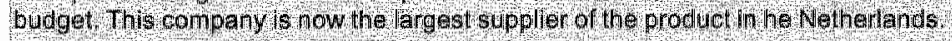

\title{
Box 8.3: A separate team for innovation
}




\subsection{Organisation Culture}

A thriving positive climate for innovation is not determined by structure and project management systems only, but also by the values and norms prevailing in the organisation. These "soft" organisation aspects are referred to in this study as the culture of the organisation. Culture is often addressed as a key success factor (Moss Kanter, 1983, Johne \& Snelson, 1988). The question we asked in the study was whether non-bureaucratic structure elements are also expressed in the perception of the organisation, for example the culture. We explored a number of cultural values and norms without explicitly conducting an in-depth culture survey.

In order to explore the culture dimension of innovation we have conceptualised the organisational culture through a configuration of 10 variables. The variables have been constructed on the basis of the earlier empirical study Cobbenhagen, 1999). Respondents (marketing managers and technology managers separately) were asked how they perceived the company culture, which was defined as "the way things are going around here' (e.g., Senge, 1991).

Table 8.4: Correlation coefficients of culture dimensions and innovation performance

\begin{tabular}{|c|c|c|c|c|c|c|c|}
\hline $\begin{array}{l}\text { performance } \\
\text { dimensions }\end{array}$ & $\begin{array}{l}\text { overall } \\
\text { success }\end{array}$ & $\begin{array}{l}\text { process } \\
\text { success }\end{array}$ & $\begin{array}{l}\text { portiollo } \\
\text { success }\end{array}$ & $\begin{array}{l}\text { growth } \\
\text { success }\end{array}$ & $\begin{array}{l}\text { opportunity } \\
\text { success }\end{array}$ & $\begin{array}{l}\text { project } \\
\text { success }\end{array}$ & quality \\
\hline \multicolumn{8}{|l|}{ uniformity } \\
\hline hieranchical & $-.27^{*}$ & & & $-28^{* 1}$ & & & \\
\hline conservative & $-.33^{4}$ & & & $-25^{6}$ & & & \\
\hline competitive & $.24 *$ & & & & & & \\
\hline structured & & & $-.26^{*}$ & & & & \\
\hline uncertainty-awoiding & & & & & $-30^{*}$ & & \\
\hline \multicolumn{8}{|l|}{ result-oriented } \\
\hline \multicolumn{8}{|l|}{ formal } \\
\hline process-ariented & & & -.25 & & & & \\
\hline
\end{tabular}

Table 8.4 presents the correlation coefficients which on average range around 0.3 . Although it does not reveal high correlation coefficients, the appearance of different correlation signs is remarkable. 'The 'hierarchy' and 'conservatism' variables are negatively and statistically significantly correlated with overall innovation performance. The "competitive culture" variable is positively and significantly correlated with overall success $\left(r=24^{*}\right)$. Both the 'hierarchy" $\left(r=-.28^{*}\right)$ and "conservatism" $\left(r=-25^{*}\right)$ variables are negatively correlated with the growth success factor. The portfolio success factor is negatively correlated with a culture that is characterised by "structured" and "process-oriented". Furthermore a company culture that can be described by 'uncertainty avoidance' is significantly negatively correlated with the ability to grasp opportunities. On the subject of the organisation culture, we might conclude that no surprising results have appeared. 


\section{Discussion}

It seens to be apparent from this analysis that hierarchy and conservatism are cultural values that characterise the less successful innovators. These values also seem to be in conflict with team functioning. The successfully innovating companies seem to be characterised by an internal competitive culture. Structuralism, uncertainty avoidance and process focus are cultural values that partially differentiate the laggards from the frontrunners. In the MERIT innovation study (Cobbenhagen, 1999) the culture dimensions revealed that innovative frontrumers distinguished themselves by a culture characterised as creative, non-bureaucratic and progressive. This finding is in line with other non-bureaucratic features of the organisation. Stopford \& Baden-Fuller (1994) already argued that most organisation scholars: ...regard bureaucracy as the antithesis of entreprenewrship [and innovation]...".

Both sets of findings support Vos' (1985) and other's (e.g. Quinn, 1985; Damanpour, 1991) empirical outcome of a risk-taking climate being beneficial in development projects in the software industry. Based on an in-depth case study of Microsoft, Cusumano \& Selby (1995), indicated that improvement and imovation were present through continuous self-critiquing, feedback and sharing: :...the open culture of Microsoft is still not too far away from the loosely organised world of hacker programmers. Its people abhor political 'nuy battes' as well as bureaucratic mules and procedures, whecessary documents, or overly formalised modes of communication. As a result, individuals and teams act quickly on issues they feel are important... (p. 416)'. The cultural values that seem to matter in the ICT include hierarchy and conservatism. Both factors lead to lower imnovation success, whereas internal competitiveness in a company is found to be a key success factor.

\subsection{Knowledge Development: Internal and External Co-operation}

Our research has focused both on company-internal and company-external issues. In the preceding sections, support was found for matrix structures being the most preferred structures to allow for cross-lateral work. The subject of cross-lateral relations can be extended beyond the enterprise. Below we will address the external relations that $1 \mathrm{CT}$ firms have established and their relevance to innovation. In three sections we will examme:

- knowledge development resulting from external and intemal co-operation,

- the degree of extemal co-operation with external partners, and

- the types of co-operation in the innovation process.

We will both address the relationships with (potential) customers and the supplier relationships.

There are several reasons for firms to co-operate with other companies on innovation (subjects). Among such reasons are the joint application of expertise in development areass and the sharing of research and/or development costs (illustrated in box 8.4). Other examples include co-operating with research centres to exchange software engineering knowledge or co-operating with customers in testing new software packages.

Company S is a sof ware developer of ERP systems, The conpany faced a lack of howowlodge of

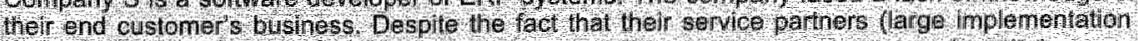
specialists were inplementing sofwere, the conparty noticed that this customer knowledge Was crucial 10 the develooment of now sof waire. Based on the knowledge hey needed ond the markets Mey wanted to senve company 5 theretore devetoped the Enterprise Modeller They asked heir service partiers la jontly develop a reference nodel tor each narket the ain of the Enterprise 


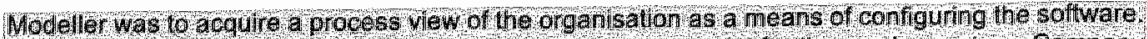

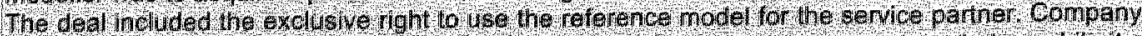
8 was to loe he owner of the nocel and to passess the necessan custonier kriowedge, while its

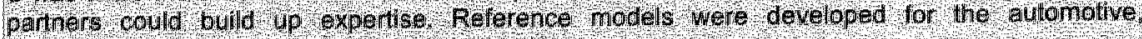

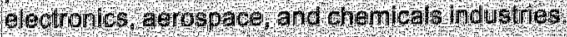

\section{Box 8.4: Co-operation between software developers and service providers}

The questionmaire asked respondents to provide data on the total efforts they had made in knowledge development. To obtain some indication, we used a somewhat unusual procedure As an experiment, we supposed that it was possible to weigh knowledge in terms of relative amounts (e.g., money, full-time equivalents). For example, 100,000 guilders of knowledge development activities might be linked to internal sources. With this assumptions we might be able to recover the wellsprings of knowledge (Leonard Barton, 1995). The procedure showed a number of interesting outcomes.

The question was stated as follows: "If the total knowledge development efforts of your company are set equal to $100 \%$, how would you allocate the company's total efforts in knowledge development originating from internal and external sources?" The figures (table 8.5) show that on average $59 \%$ of all knowledge development efforts are based on external sources. Internal knowledge development efforts account for $40 \%$ of total efforts. When subdividing external knowledge development, the figures indicate that around one third of the knowledge created is derived from co-operation with customers. Suppliers account for $16 \%$ of external knowledge creation. Knowledge institutions, in particular universities and related research institutes, account for $5 \%$ of external knowledge development. Knowledge development through direct acquisitions only matters for a small set of firms, and is responsible on average for $3 \%$.

Table 8.5: Distribution of knowledge development activities

\begin{tabular}{|c|c|c|}
\hline & $\begin{array}{l}\text { Total \% of } \\
\text { knowledge } \\
\text { development }\end{array}$ & $\begin{array}{l}\text { Standard } \\
\text { deviation }\end{array}$ \\
\hline Internally developed knowledge & $41 \%$ & $(22,1)$ \\
\hline \multicolumn{3}{|l|}{ Extemally developed knowledge } \\
\hline \multicolumn{3}{|l|}{ Knowledge acquired through: } \\
\hline $\begin{array}{l}\text { - Comoperation with customers } \\
\text { - Co-operation with suppliers } \\
\text { - Acculsition } \\
\text { - Other sources }\end{array}$ & $\left.\begin{array}{l}(28 \%) \\
(16 \%) \\
(5 \%) \\
(3 \%) \\
(7 \%)\end{array}\right\} 59 \%$ & $\begin{array}{l}(17,1) \\
(15) \\
(4) \\
(6) \\
(11,4)\end{array}$ \\
\hline Total knowledge development efforts & $100 \%$ & \\
\hline
\end{tabular}




\section{Results}

A correlation analysis was performed in order to see if differences in the above experiment on knowledge development influence the innovation success. The following outcomes were found:

- In this knowledge-intensive sector, firms seldom co-operate with universities. Yet we have observed that those few firms that acquire knowledge developed in co-operation with universities score highly on overall innovation success. The variable correlates positively significantly $\left(r=45^{*}\right)$ with overall success.

- Firms that develop knowledge through co-operation with customers score highly in terms of growth. The variable correlates $\left(r=39^{*}\right)$ positively significantly with growth success.

- A few firms gained new knowledge through external acquisitions. These firms have a high success score due to their ability of better seizing new opportunities and realising new profitable products. The corresponding variable correlates $(r=38 *)$ positively significantly with opportunity success.

\section{Discussion}

A first glance at the statistics shows that external sources are more often used to develop new knowledge, and that in particular customers and suppliers are the major external sources of knowledge development.

Although the correlation coefficients are not high, the correlation ontcomes provide a number of indications. First, no significant correlation was found between any of the success factors and the variable representing the intemal knowledge development practices. This might imply that this variable does not discriminate successful firms from less successful firms. Alternatively, it might imply that external knowledge development contributes more to innovation success than internal practices. Cohen and Levinthal (1993) and Szulanski (1986) already argued that the 'absorptive capacity' of an organisation is of importance to innovate (see box 8.5). The correlation results confirm their argument that exploring and exploiting external information and knowledge sources is conducive to innovation.

Secondly, the correlation result on customer involvement for knowledge development might indicate that this is beneficial only to growth. A customer focus has been emphasised as a common practice by all the companies in the survey. In this respect it is interesting to observe that the frontrunners in this study differentiate from the less performing companies because of: the knowledge development initiatives in scanning trends for their customers (box 8.5). Firms that do so score highly on growth success.

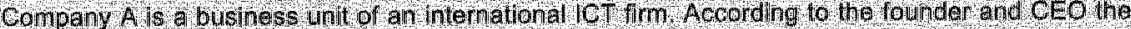
Butch company is the malor hrovator of the European affices. 1 spends $50 \%$ of is turnover on RRD Wost R\&D aclivies are diected al scaning new technologies and'polentlal markets and applicatton areas, with the aim of picking up now technologles, such as datawarehousing and

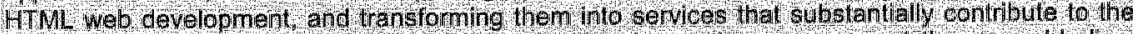

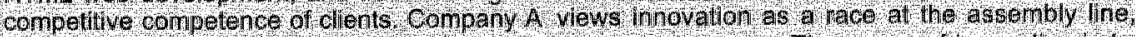

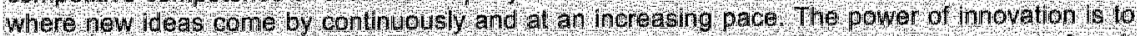

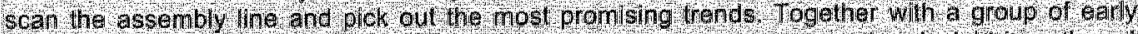

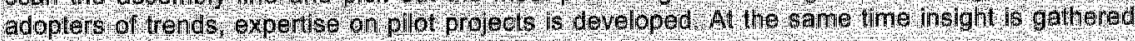
Whto the miarket potentlal of the product ar service.
}

\section{Box 8.5: Innovation at the assembly line}


Thirdly, another form of developing new knowledge is through instant acquisition. For example, knowledge of market conditions, competitors and customers is gained through acquiring ventures, niche players or firms with established brand names. In the $\mathbb{C T}$ research study, these types of acquisition are associated with opportunity success. This might indicate that frontrumners differentiate through take-overs to buy market share or absorb knowledge on niche markets through buying the niche market players. An earlier statistical finding (section 7.2) supports this outcome. The priority paid to the policy item of acquisitions was regarded as a key success factor.

Fourthly, the correlation coefficient of the 'university' variable and overall imnovation success is a remarkable finding, as only a few firms reported efforts to gain new knowledge from university sources. This is a surprising observation for a knowledge-intensive sector of which we would expect more co-operation, especially because a large number of ICT start-ups originate from universities and polytechnic schools. Only a few firms differentiate by develloping knowledge through contacts with universities and academic research institutes. Interview data revealed that such co-operation could take different forms, such as joint research and development on ICT issues, as well as graduate programmes with universities to recruit new employees. ICI companies might regard the university as a supplier of new knowledge by means of potential employees.

A last observation is concerned with the role of suppliers. Suppliers as a source of knowledge do not affect the innovation success measures. An explanation might be the use of proven technologies by ICT firms. All of the companies use the same technology standards for software development or ITIL standards for infrastructure maintenance. These standards are predominately set by US companies. Also, at the time of the study the ICT firms were not involved in technological co-operation agreements with US ICT firms.

\subsection{Co-operation with Customers and Suppliers}

The study has demonstrated that the market is a source of inspiration for imnovation. Ideas may originate from new supplier products, a direct "equest from a custoner, or an expenience of an unsatisfied customer (box 8.6). This is not different from other organisation studies (Cobbenhagen, 1999; Cooper, 1996). The question we raised in the survey was whether close co-operation with customer and/or suppliers is actually beneficial to innovation.

\section{Results}

The figures in table 8.6 indicate the presence of co-operation efforts by ICT firms. The correlation analysis reveals that:

- co-operation with universities is statistically signinficantly correlated with overall success $\left(1=.42^{*}\right)$,

- co-operation with universities is significantly correlated with process success $\left(r-47^{*}\right.$ and $.46^{*}$ respectively),

- weak customer and supplier co-operation is correlated with portfolio success $\left(r=-.55^{*}\right.$ *an and $-.45^{*}$ respectively) 
Table 8.6: Correlation results of external co-operation

\begin{tabular}{|c|c|c|c|c|c|c|c|}
\hline $\begin{array}{l}\text { performance } \\
\text { dimensions }\end{array}$ & $\begin{array}{l}\text { overali } \\
\text { Succeess }\end{array}$ & $\begin{array}{l}\text { process } \\
\text { success }\end{array}$ & $\begin{array}{l}\text { portiolio } \\
\text { success }\end{array}$ & $\begin{array}{l}\text { growth } \\
\text { success }\end{array}$ & $\begin{array}{l}\text { opportunity } \\
\text { success }\end{array}$ & $\begin{array}{l}\text { project } \\
\text { success }\end{array}$ & quality \\
\hline \multicolumn{8}{|c|}{ co-operation with: } \\
\hline universities & $.42^{\star \prime}$ & $.46^{\star 4}$ & & & & & \\
\hline customers & & & $-.55^{* *}$ & & & & \\
\hline suppliers & & & $-45^{.1}$ & & & & \\
\hline
\end{tabular}

$(\mathbb{N}=30)$

( denotes significance at the .05 lewel and " denotes significance at the 01 level)

\section{Discussion}

The figures are based on a small sample and a few illustrative cases, but they indicate interesting outcomes on co-operation with customer and suppliers.

- First, the intensity of university co-operation is significantly correlated with overall success and process success. This result supports the previous finding that for those few firms that do co-operate with universities the knowledge development with universities is conducive to innovation success.

- Secondly, the "customer co-operation" and "supplier co-operation" variables are negatively correlated with portfollio success. What is the implication of these correlation figures? There may be two differentiating factors here. A very high degree of co-operation with customers and suppliers seems not to be beneficial to innovation success, in particular portfolio success.

The first results indicate that too much involvement of these external parties is not beneficial to success. The empirical literature (e.g. 'lead users' by Von Hippel, 1986; Cooper \& Kleinschmidt, 1995) has revealed the importance of close co-operation with customers. The managers interviewed in the ICT study also enphasised the importance of this subject. However, the correlation figures seem to be in contrast to these expectations. This result had been found in the MERIT study as well Cobbenhagen, 1999). In that context it is less interesting to know the 'what' question and key success factor, but to understand the 'how" and "why" question of this co-operation. Can the qualitative data help us here to explain these findings?

One reason for this remarkable finding might be that the customer interaction is much more complex in reality. Customer interaction might then be difficult to express with one single key success factor. The illustrative case material (see box 8.6) shows us that other factors also play a role in the customer interaction and that renewal in the ICT services sector is almost by definition in a paradox. A more fundamental paradox for ICT companies, which we can formulate as: "The ICT company must do what the customer tells" versus "The ICT company must tell the customer what he should do". The case example of company $\mathrm{Q}$ shows how the role of the customer was used as an argument for internal politics to carry on as before. In company A we observe the opposite. The customers expect the JCT service provider to be ahead of them in terms of supplying new market and technology knowledge. The firms in box 8.6 seem to be tightly linked to their customers and depend on them for new product development. We might speak of a 'path-dependent' relationship between the company and its customers. 
This kind of customer interaction in the service sector is less investigated in the innovation literature. The examples reveal a mutual interaction, which seems to be rooted in a complex customer knowledge development process, where ICT companies should provide new knowledge to their customers, e.g., about the opportunities of selling through the Internet. At the same time, they should depend upon them to build up customer and product knowledge. Various arguments (Cobbenhagen, 1999) can be given why frontrunners seem to better handle this interaction, for example:

- market pull does not seem to dominate in frontrunner companies but is balanced by a technology push;

- frontunners set strict limits on the customisation of services and soffware;

- frontrunners limit the degree of modification of new products;

- or frontrunners let customers pay for special orders, extra software functionality and unique services specifications.

More research to investigate the need for tight upstream and downstream relations in the innovation process would contribute to the innovation management discipline, particularly in areas of fast-moving teclinology and/or market fields.

\begin{abstract}
A consonathe custonger croup

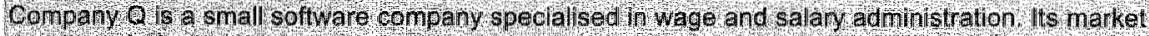

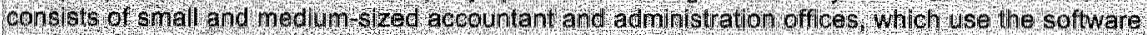

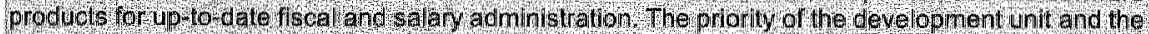

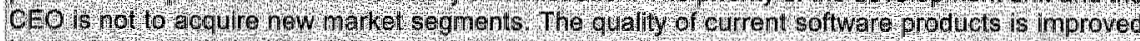
10 med now techícal standards, aod to a lesser extent, to cusitomer requirements. buing we

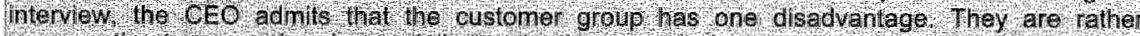

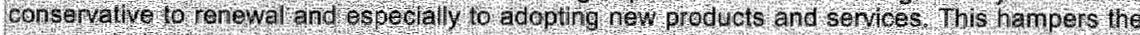

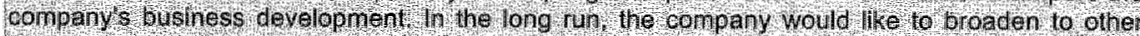

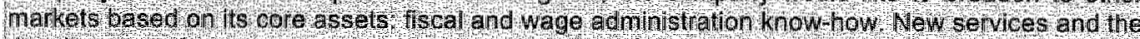

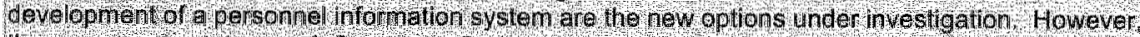

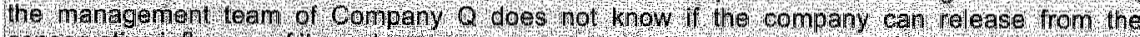
conservive ntuence or is cusloners

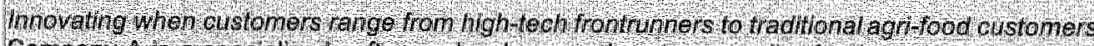

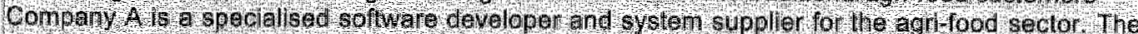

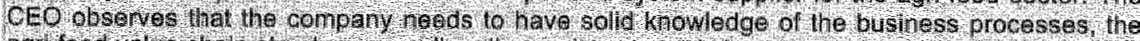

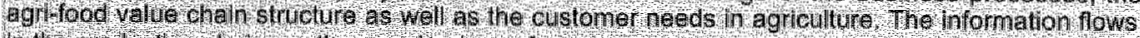

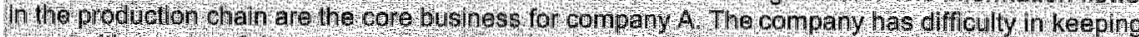

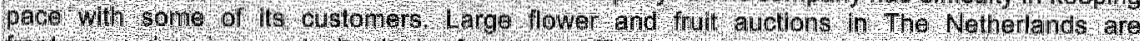

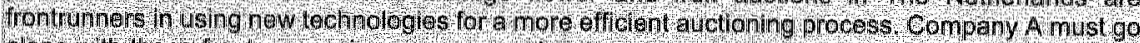

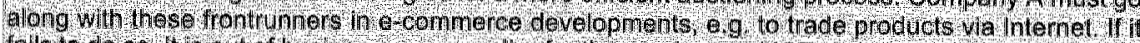

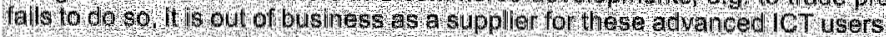

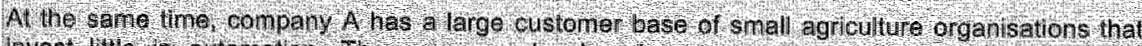

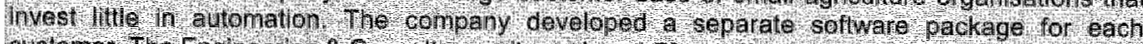

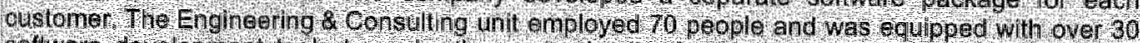

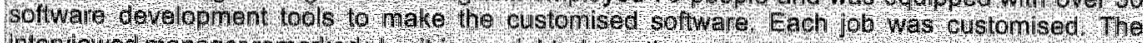

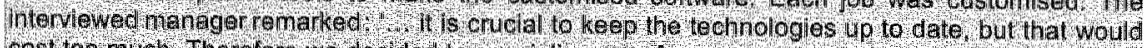

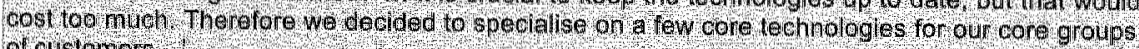
0. costomers:

Abollshing ho solware wser rivou

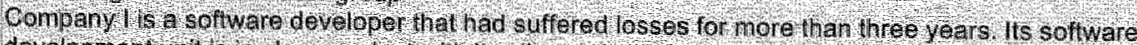

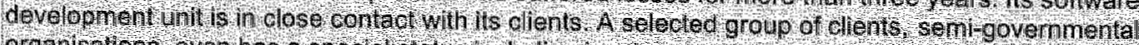

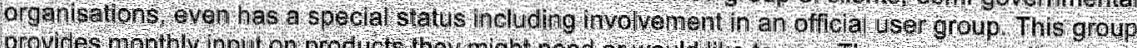
prowles nonthy input on products thay night need or would like lo use. The wser group discusses

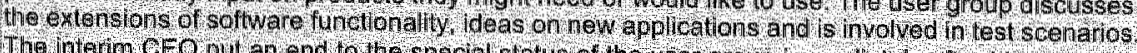

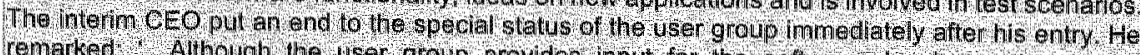
remarkes 1 Allbough the user group provides input for the software development unit the mentbers of the group are 10 obliged 10 biy any or the new products product extensions or 


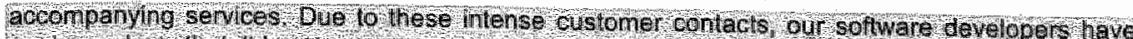

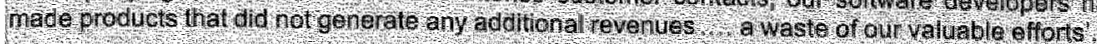

\title{
Box 8.6: Does customer involvement always pay off?
}

We have also observed that the co-operation with suppliers is relatively highly and negatively correlated with the growth success factor $(r=-45)$. The supplier interaction seems to have a negative effect on the contribution to tumover and profits by new products and services. The case material in box 8.7 illustrates this finding. This might indicate that frequent and intensive comoperation with suppliers is not conducive to success for ICT Companies.

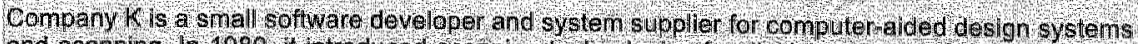

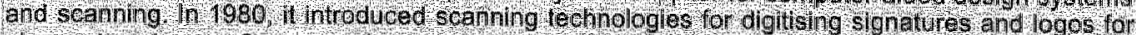

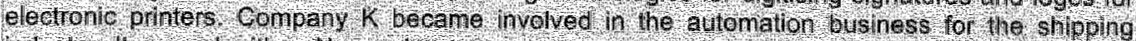

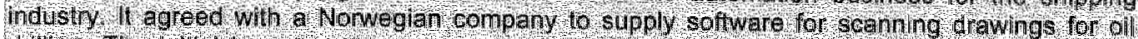

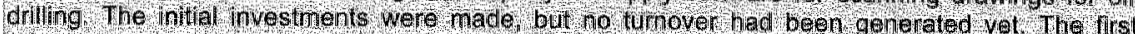

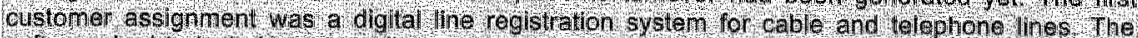

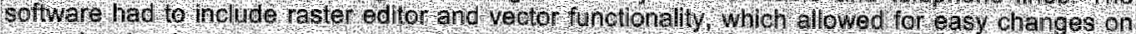

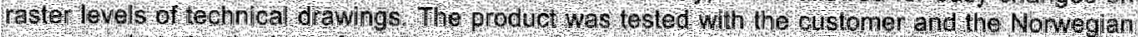

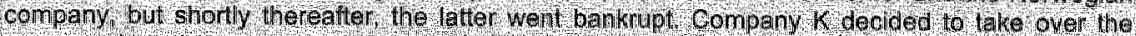

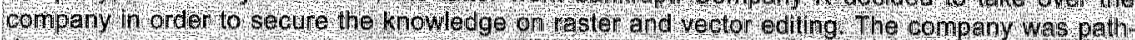

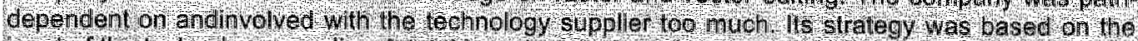

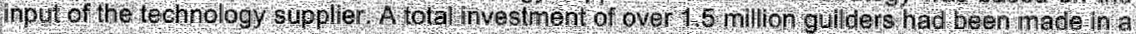

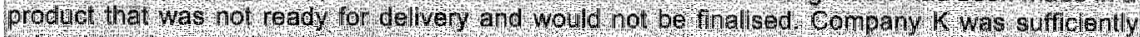

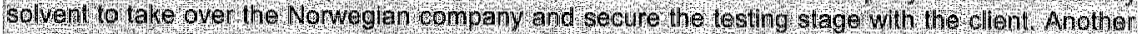

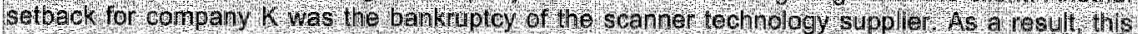

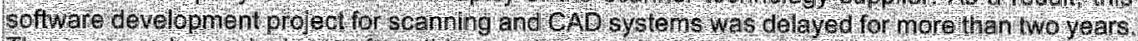

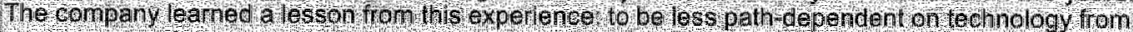
exteral supplers hingovation.
\end{abstract}

Box 8.7: Co-operation with technology suppliers

\subsection{Co-operation during Stages of Innovation}

The implication of the preceding argument as to whether close customer co-operation is conducive was further investigated. The questionnaire addressed the company perspective on external involvement at different stages of the innovation process. At what stage in the innovation process, the generation of ideas, implementation, or testing, is it beneficial to work in close conjunction with external partners?

\section{Results}

\section{Customers}

Table 8.7 presents the correlation coefficients between external co-operation and success factors. None of the variables correlates significantly with overall innovation criteria. A remarkable finding is the close relation between the variables and the qualify success factor. Customer involwement is significantly correlated with quality in the four following stages: new product idea generation ( $\left.r=0.27^{*}\right)$, in the ideas for process improvement $(r=0.39 *)$ and in the stages of implementation of process improvement $(r=0.43 *)$, and product testing $(r=28 *)$. In particular, customer involvement in process improvements seems to be a differentiating factor. Customer involvement in the generaion of ideas, both for new products and processes, and involvement in testing also correlate with process success. 


\section{Suppliers:}

A similar set of questions conceming external supplier involvement was included in the survey questionnaire. The correlation coefficients vary and should be tentatively interpreted. However, the close relation between the variables and the quality success factor is noteworthy. There is a positive and significant correlation between the quality success factor and the variables of 'supplier involvement in ideas for process improvement" $\left(r=.43^{* *}\right)$ and 'supplier involvement in new product idea generation' $(r=28 *)$.

\section{Table 8.7: Correlation results of external co-operation variables and performance}

\begin{tabular}{lllll}
\hline performance & overall process portfolio growth opportunity project quality \\
climensions & success success success success success success
\end{tabular}

\begin{tabular}{|c|c|c|c|}
\hline Customer inwolvement in: & & & \\
\hline ideas for process improwement & $40^{*}$ & & $.39^{* * *}$ \\
\hline implementation of process improvements & & & $.43^{* * *}$ \\
\hline product dea generation & $.32^{\text {由 }}$ & & $.27^{*}$ \\
\hline product testing & $.31^{*}$ & $-.29^{\mathrm{k}}$ & $.28^{*}$ \\
\hline \multicolumn{4}{|l|}{ supplier involvement in: } \\
\hline ideas for process improvementsi & & $.31^{*}$ & $.43^{* *}$ \\
\hline product idea generation & & & $.28^{*}$ \\
\hline product testing & & & $-.31 *$ \\
\hline
\end{tabular}

(" denotes significance at the .05 level and ${ }^{* *}$ denotes significance at the 01 level)

\section{Discussion}

As an overall observation, none of the variables are linked to the overall success factor, but all of them correlate with quality. Both customer and supplier involvement differentiate frontrunners from pack members and laggards.

- Customer: customer involvement in new process improvements and new product ideas and product testing correlate with process success. This implies that customers can help streamlining processes and generate new products ideas. This finding suggests that frontrunners differentiate by involving customers in these particular areas. When we move on to the qualitative stories, we will come across more insights on this issue (box 8.8).

- Customer: Another finding is concerned with the correlation of the customer involvement in product testing. This hampers the growth of the company, based on the negative correlation with the success factor growth $\left(r=-29^{*}\right)$.

- Supplier: Remarkably, we found that there is a negative relation/correlation between product testing and quality success $\left(r=-31^{\text {* }}\right.$ ). This coefficient implies a negative influence on the quality rate if suppliers are involved in the product testing stage of innovation (box 8.8). 


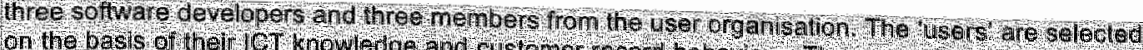

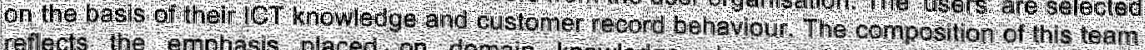

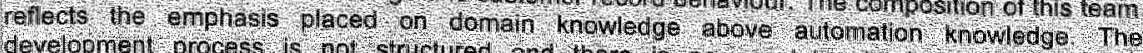

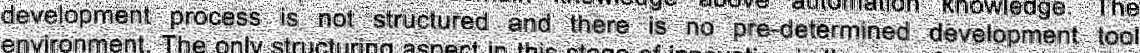

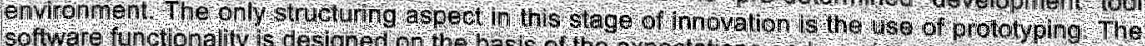
sorno

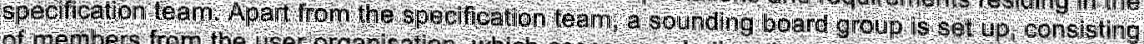

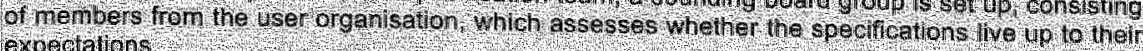
expectalons:

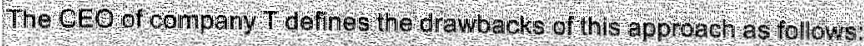

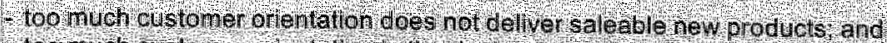

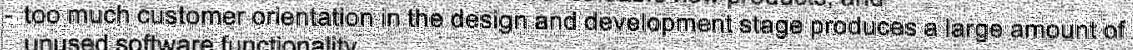
unused sotware Wnetionaity

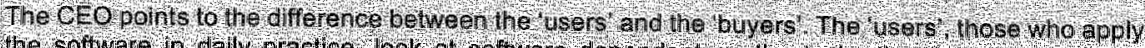

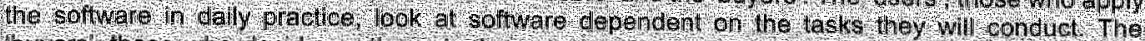

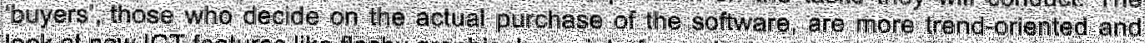

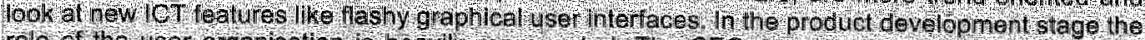

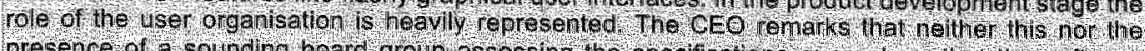

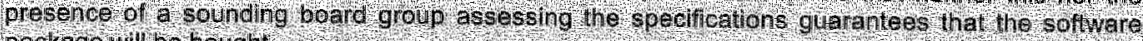
package Wirbo bought

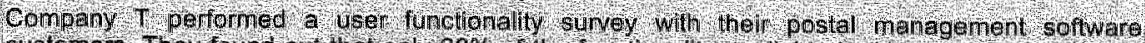

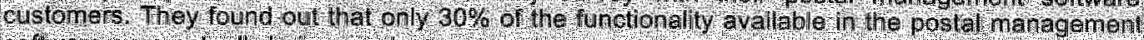
sofware were achally being insed

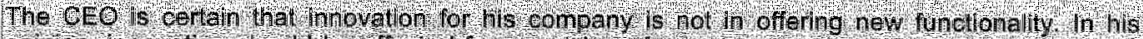

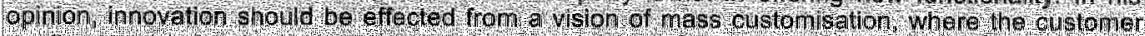

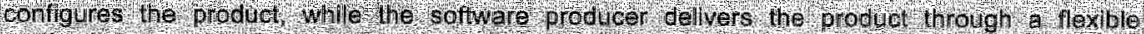

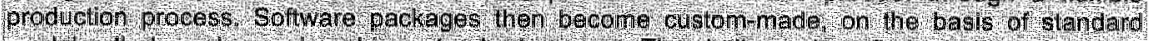

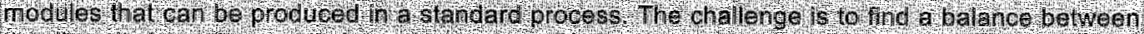

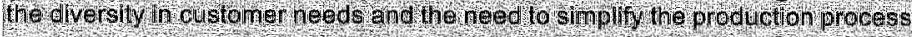

\section{Box 8.8: Involving customers in software development}

The motto of customer involvement seems to be contradicting. On the one hand, ICT companies cllaim that they are market-driven and customer-driven, and that it is important to listen to what customers have to say and need. ICT companies preach a client-oriented innovation process and are aware of the value of marketing as a source for new product developments. In reality, however, customer orientation is no longer a factor that discriminates the frontrunners from the ICT companies lagging behind. But is this actually true? We have observed that interfaces are important, but at the same time that key success factors do not tell us much about aligning customers to service innovations. The figures seem to indicate similarities in leaming from the customer. Yet companies differ in the extent to which customers are recognised and used as a booster for innovation. The qualitative datat give us some clues (box 8.8). Although this does not provide evidence based on statistical correlation, it gives new insight into the question on the role of lead users.

There are several explanations for this "customer leaming paradox". There is a difference in learning from "(potential) customer surveys" or "getting feedback from actual users'. But also the paradox inherent in the thin line between 'nice-fo-have' customer needs and actual "customer requirements" might lead to excess functionality. Furthemore, there appears to be a difference between management perception and action. Similar to Argyris and Schön (1978), who distinguish between espoused theories and theories in action, there might be a difference between wivat people think (espousing) and how they act (acting). Espoused theories represent the official strategy, the innovation strategy style, while the theory in action represents how 
they are used in the real world. Similarly, we got the impression that the managers think they listen to the customer and are driven by the market and the customer, but in reality act differently in terms of involving the customer. Frontrunners play a greater role in guiding customer involwement in innovation.

The most obvious finding is that the involvement of customers and suppliers in the innovation stages is perceived to be conducive to the quality of the innovation outcome. Yet, this correlation does not hold true for supplier involvement in product testing and customer involvement in the implementation of new processes. Interaction with third parties in the value chain is more complex. This section reweals subtle differences in customer involvement due to the use of multiple output success measures. But above all by the qualitative cases, which indicate the role of path dependency. In conclusion, the issue of customer involvement seems to be far more complex than we thought and knew of from the literature. Innovation in the service sectors is an important area for research to focus on.

\subsection{Human Resource Management}

The previous chapter presented figures on the strategic priority for personnel matters and human resource development. The training and education expenditures revealed that these may contribute to positive innovation performance (see also Becker \& Gerhardt, 1996; Schuler \& Jackson, 1996; Van Sluijs et al., 1991). In section 7.8 we already touched upon the relation between company growth and education and training expenditures. This issue may play a role in the analysis in this section. Two lines of reasoning were suggested. First, firms invest in training because they achieve high growth rates and training ensures the up-to-date availability of knowledge and skilled people. Second, firms realise high growt rates because they invest in highly educated and trained employees. Both lines of reasoning might be true for the ICT sector. The validity of both suggestions can be analysed when the ICT sector will have passed the years dominated by the ICT practices regarding the Euro conversion and Millennium.

\section{HRM \& education}

This section presents additional analysis on the practices of human resource management (HRM). It is remarkable that in a "people business" like the ICT sector no interesting outcomes were observed. The majority of the $\mathrm{ICT}$ companies reported to conduct relevant activities on each of the HRM subjects. Several items were included in the survey to see whether differences in HRM practices influence innovation performance. In this section we will examine the value of HRM practices for innovation performance, focusing on the differences and the direction of the correlation. In order to measure the organisation's HRM practices, the questionnaire addressed four dimensions of personnel policy, namely:

1. the presence of a formal education plan for employees

Over $80 \%$ of the firms reported to have a formal education plan for their employees. No correlation was found between one of the success factors and the variable education plan'. This is not surprising, since for the majority of the companies in the ICT sector it is common practice. This might suggest that an education plan does not differentiate successful from less successful firms.

2. the planning horizon of an education plan for individual employees 
The average planning horizon of an education plan averaged between two and three years. No significant variance was found between firms. Again, for the majority of the companies in the ICT sector it is common practice.

3. the planning of career paths

The respondents in the survey reported the same planning horizon with respect to career planning, i.e., two to three years.

4. the nature of individual perfornance appraisal

The survey results indicate that $90 \%$ of the firms conduct formal appraisal interviews with employees once a year. About $70 \%$ of the firms state that they conduct a formal career development interview once a year, so it is not surprising that the figures show no correlation. However, the question is whether these outcomes are correct, shouldn't we investigate other possible differentiating factors that play a role? The illustrative cases (box 8.9) seem to support this. The company cases indicate to have a different history and are path-dependent with respect to their HRM practices. These case figures show the actual differences in the 'people business' such as the ICT sector. The cases might suggest that regular appraisal and career interviews are common practice of the HRM policy in ICT companies. But the figures also confirm the difference in training and personnel recruitment between companies.

\footnotetext{
Traning of enployes ro reallso growh

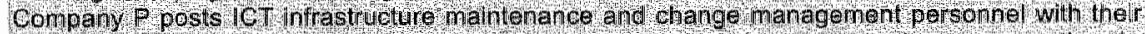

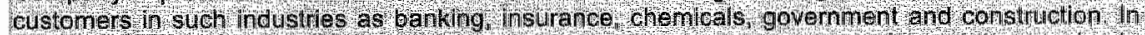

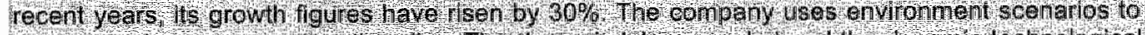

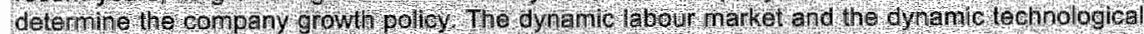

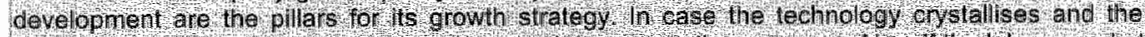

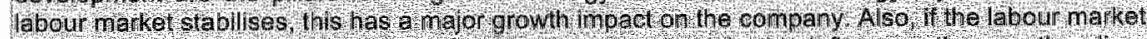

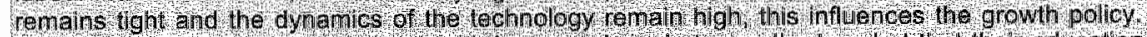

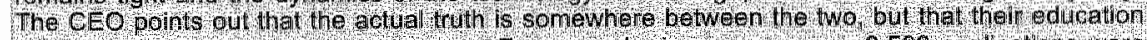
polley should incorporate these impacts. For example, in ono year aver 3,500 applications were

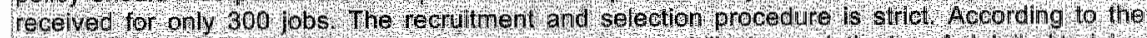
phiosophy or the company, en ployees nus t have the capabilith lo reach he top. A detalled training programme by which now employes are posled with ditiereni gubtomers, epmplemenited with

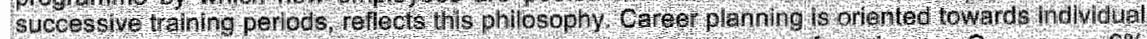

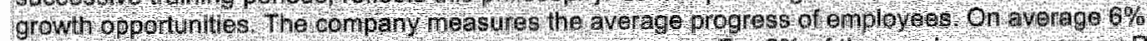

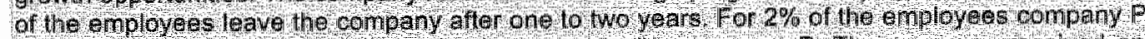
agreed that the career perspect ves were better outs de company $\mathrm{P}$ The compeny recolved ath

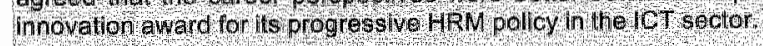

\section{Training of employees as a means to genorate revenues}

Company $\mathrm{H}$ is a company posthg ICT personnel. The C EO has baen with Ihe conpany tor wo

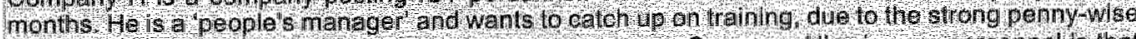

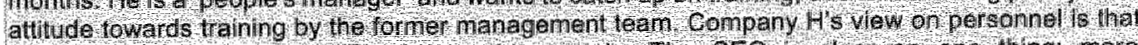

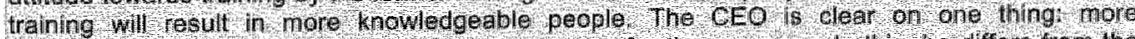

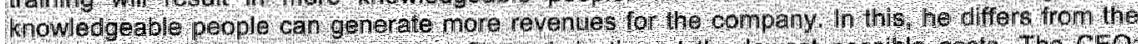
pervious managers, who aimed at proft maximisaton al tho lowest possible costs. HWe CEO

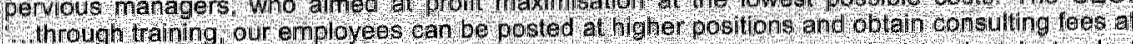
thie customer side, 5 o they Wil be pmogram managors and sofiwane project leaders instead of

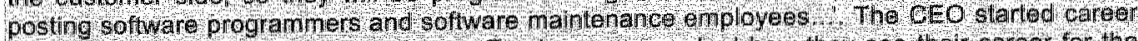
planning ntentews with the employees. Employees are as ked how they see their career for the pext five roars. The CEO found ad soon that the best beople had already left he orcanisat on and the remaining emplovers were less notyated
}

\section{Box 8.9: The importance of training: Different perspectives on "people business"}




\section{HRM \& Cross functional career paterns}

In addition to the above figures, a further examination of HRM practices focused on crossfunctional personnel transfer. Companies were asked to indicate "if' and 'in which direction" personnel was transferred between departments (see appendix $B$ for the questionnaire). The HR policy of ICT firms was explored with respect to competence development. Two proxy measures were used to assess the development of competencies, i.e. career patterns and individual performance appraisal.

\section{Resulis}

Table 8.8 shows the correlation coefficients of these variables. Again, no surprising results were found. Overall, there are only a select number of indicators for HRM that possibly show a clear relation with the success criteria. The correlation figures, which range between 0.3 and 0.4 , correlate significantly only on a few success criteria. In particular personnel transfers from production to $R \& D$ departments $(r=35)$, and vice versa from $R \& D$ to production $(r=32)$ correlate positively significantly with overall innovation success.

For a more detailed analysis of performance appraisal, the survey listed appraisal criteria and the relation with innovation success, taking into consideration both the number of appraisal interviews conducted and the individual performance appraisal criteria. In order to do $\mathrm{SO}_{3}$ a pre-specified list of appraisal criteria was presented to the company respondents (appendix B). Athough the correlation analysis revealed the following differentiating factors, no remarkable results were observed:

- The regularity of individual appraisals by a company is conducive to a company's success. The corresponding variable is positively significantly correlated with the growth success factor.

- Employees that have specialist knowledge contribute to the delivery of high-quality work. They are the key to developing new products. This variable correlates $\left(r=35^{*}\right)$ with the portfolio success criteria, although at low levels.

- Those companies where the manager explicitly evaluates and pays attention to the quality of work of their employees score high on the quality success criteria $\left(r=.30^{*}\right)$.

- The degree to which employees achieve deadlines in their (project dominated) activities is conducive to the companies' innovation success. The variable is positively correlated with the quality success factor $(r=32$ *). This significant but relatively low correlation coefficient might imply a direct relation between achievement of deadlines and the quality of innovation.

- The individual contributions to the team functioning can be beneficial to the firm's innovation success. The correlation of the variable and the growth success factor is relatively significant $\left(r=44^{*}\right)$. 


\section{Table 8.9: Correlation results of human resource management wariables and innovation performance}

\begin{tabular}{|c|c|c|c|c|c|c|c|}
\hline $\begin{array}{l}\text { performance } \\
\text { dimemsions }\end{array}$ & $\begin{array}{l}\text { overall } \\
\text { success }\end{array}$ & $\begin{array}{l}\text { process } \\
\text { success }\end{array}$ & $\begin{array}{l}\text { portiolio } \\
\text { success }\end{array}$ & $\begin{array}{l}\text { growtin } \\
\text { success }\end{array}$ & $\begin{array}{l}\text { opportunity } \\
\text { success }\end{array}$ & $\begin{array}{l}\text { piroject } \\
\text { success }\end{array}$ & quality \\
\hline \multicolumn{8}{|l|}{ crossufunctional careers } \\
\hline Irom R\&D to production & $32^{*}$ & & & & & & \\
\hline from production to $R \& D$ & $.35^{i}$ & & & & & & \\
\hline \multicolumn{8}{|c|}{ performance appraisal criteria: } \\
\hline regularity of appraisals & & & & .39 & & & \\
\hline specialist knowledge & & & $.35^{\mathrm{k}}$ & & & & \\
\hline achiewe deadlines & & & & & & & $.32^{*}$ \\
\hline quality of work & & & $.34^{*}$ & & & & $30^{*}$ \\
\hline contribution to team functioning & & & & $.44^{\text {* }}$ & & & \\
\hline
\end{tabular}

(" denotes significance at the .05 level and ** denotes significance at the 01 level).

\section{Discussion}

Figures on the transfer of personnel between functional departments provide an indication of the cross-functional career patterns of personnel. It is argued in the literature (Clark \& Wheelwright, 1993) that such movements are conducive to innovation. Cross-functional personnel movements are one way of enhancing a multidisciplinary attitude in developing new products and processes. This can help to survey the impact of decision and activities upstream for the future activities taking place downstream in the trajectory.

The outcome on R\&D $\rightarrow$ Production transfer suggests that the transfer of employees between the operational work environment (production of software, systems and service) and research and development is associated with innovation success. R\&D $\rightarrow$ Production transfer is a key success factor. Frontrumners practise this transfer more often than members of the pack.

The ICT sector is it "people business". The people represent the invaluable knowledge needed to deliver services and make products work. Taking care of these people is the distinguished task of ICT companies. The results of the study on employee evaluation and appraisal criteria seem to have no direct effect on innovation success, with the exception of the positive contribution of employee appraisals on the growth of the company. The high-growth firms conduct a significantly higher number of individual performance appraisal discussions, on average more than four times annually. Remarkably, team functioning aspects are taken into account in appraisal interviews mone often by frontrumners, especially in a service delivery environment. This differs significantly between high-growth and low-growth companies. It should be noted this is in keeping with the earlier finding that more than $50 \%$ of the companies indicated that they conduct innovation with project-based structures.

\section{Conchusions}

We can conclude that a large number of sector-specific factors play a role in this study. One reason why key success factors might be expected to appear but did appear. Especially customer interaction and human resource management have not shown surprising results despite the fact that the ICT sector is knowledge-intensive and a "people business". No differentiating factors were observed. 
However, we learned from the case studies that path dependency seems to explain some of the contrary expectations and actually shows differences in innowation practices. Interactions with customers and suppliers are more complex than, for example, the assumptions in the imnovation literature that strong customer interaction is conducive to innovation success. The case studies have shown a paradox in services innovation, where companies need to balance between 'the ICT company must do what the customer tells' versus and 'the ICT company must tell the customer what he should do'. This area of customer interaction and knowledge development is a valuable area for future research. 


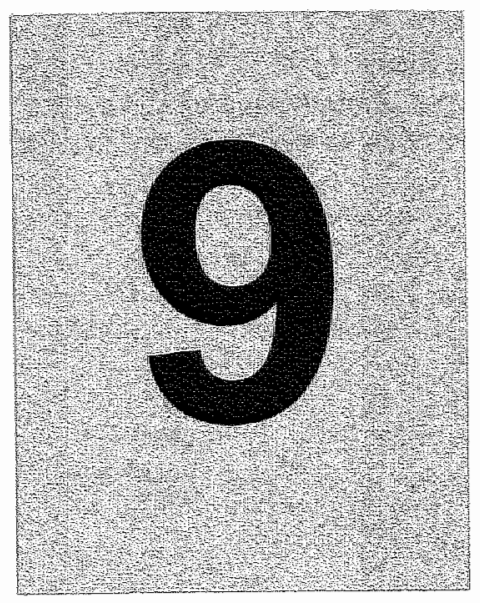

Key Success Factors Differentiating the Frontrunners from Pack Members: A Discussion 
In the prewous chapters we examined the success factors and the trends in today's ICT business. As a result, we have gained a better understanding and to some extent are better prepared to deal with the isste of effective innovation management in ICT companies. The next sections may be useful in even better understanding the analysis of strategy, organisation and process by comparing the patterns of this study with other innovation studies. The discussions in this chapter focus on the identification of a number of remarkable results, similarities and differences.

\subsection{Overview and Comparison}

The analysis of $321 \mathrm{CT}$ firms and their practices and performance has yielded a large set of success factors. Some of them had been expected, based on the previous MERTT study. A number of outcomes that are considered to be crucial in the literature are noticeable for their absence in this study. Other outcomes are more provocative in that they reveal new areas of management attention for ICT companies. In order to assess the relative importance of the findings of the survey, this chapter will compare the empirical findings with the results of preceding innovation studies. We will start with the observations that are consistent with the MERIT innovation study and the empirical literature, followed by findings that are inconsistent with the MERIT study and/or literature.

In addition, this study has shown a wide range of success factors that support or are inconclusive with regard to earlier assumptions. Subsequently, we will go into: a) the remarkable outcomes that differentiate between success, and b) the inconclusive outcomes that had been expected in advance but were not found to be relevant in the current ICT sector study.

\section{Sitwming up}

In the ICT study we found the following set of key success factors:

- quality assurance as a strategic priority for the period 1992-1996

- acquisition of the firm as a strategic priority for the period 1988-1992

- productivity growth as a strategic priority for the period 1988-1992

- innovation strategy style characteristics: being a trend-setter

- innovation strategy style characteristics: investing more in R\&D than competitors

- innovation strategy style characteristics: strong will to be first matket entrant

- innovation strategy style characteristics: continuous search for business opportunities

- innovation strategy style characteristics: anticipating environmental change

- the allocation of R\&D resources to product innovation

- the technological position and portfolio of technologies relative to competitors

- priority setting as part of the project planning of innovation projects

- the organisation of innovation by means of project team structure

- the culfural values: competitive, hierarchical and conservative (negative correlation)

- cross-functional careers between R\&D and production 


\section{The timing of strategic issues}

What is the importance of the past in explaining current differences in innovative success? What is the role of timing in this respect? These questions relate to the differences in timing of policy issues in the recent past. In chapter 7 we observed that the attention devoted by $1 \mathrm{CT}$ firms to certain issues in the past can predict their strengths today. Differentiating factors in innovation success were found both in the present and in the past.

Firms that address strategic issues at an early stage can be successfull compared to firms timing certain issues at a later stage. With respect to timing, the images of this study are in line with findings in the literature. The following findings have been observed:

- There are indications that successful innovators pay attention to more policy subjects at a time. But we also observed that frontrunners draw attention to policy subjects and put them on the priority agenda at an earlier stage than less successful firms do. ICT firms that addressed the subject of cost reductions sooner on the management agenda are more likely to be a successful innovator. The same applies to the recruitment of personnel and training. The earlier ICT firms addressed these strategic issues, the better they score on the process success factor.

- There are indications that frontrunners keep certain issues constantly at a high-priority level. Success requires long-term commitment and devotion to key policy issues. The long-term and continuous devotion to product renewal is beneficial to ICT firms. Firms that practice this are successful in developing high-revenue and profit-generating products and services. This policy issue is significantly correlated both in the past and at present (see box 9.1)

- Successful innovators differentiate by addressing the following issues sooner. the emphasis on productivity growth, protection of intellectual assets and the acquisition of firms.

Cobbenhagen (1999) also considered this impact of timing differences in company policy. The results of his study suggested that a proactive policy contributes to success. Frontrunners began to recruit skilled people early and set up training programmes. The main thing is to do things ahead of competitors by concentrating on activities that are unique and hard to copy.

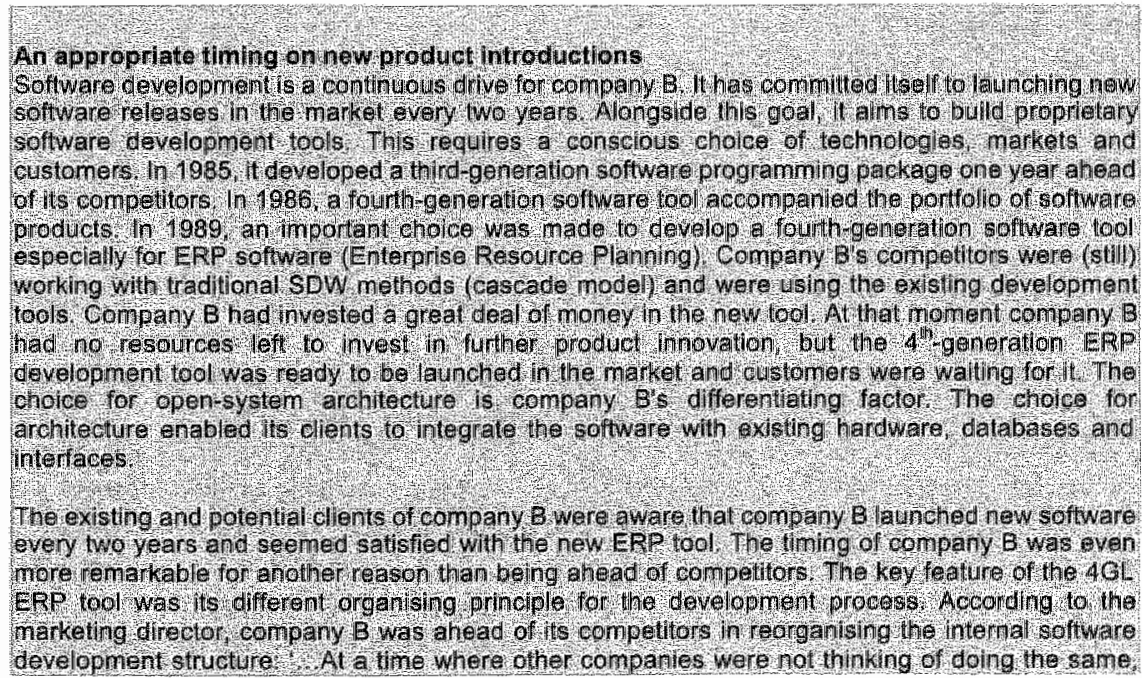




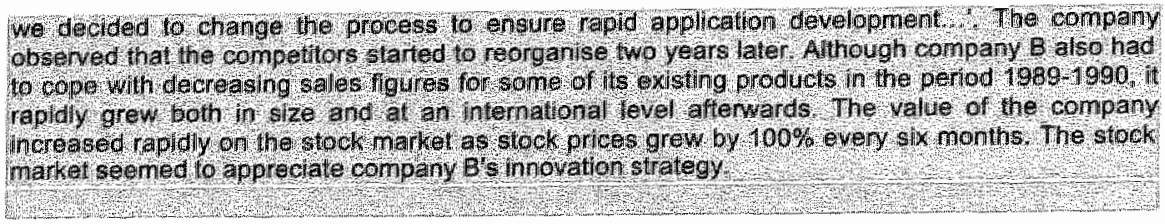

\section{Box 9.1: Timing of new product releases}

\section{Imovation project management}

Pre-development, design and implementation represent the major phases in the innovation trajectory. They require project management in order to ensure a good fit between the phases. The results of the ICT study appear to be consistent with preceding studies on new product development. The outcomes stress the importance of pre-development work (e.g. Cooper, 1995). Empirical findings suggest that the proficient execution of tasks prior to the start of an innovation project can result in a faster development process and/or a more successful product launch. The relevance and quality of the pre-development activities for ICT companies seem to be confirmed (see box 9.1). More particularly, project planning and project responsibilities seem to matter. The study revealed the following key factors:

- Sharply defined project planning with respect to:

- priority setting,

- project cost.

- go/no go decision points,

- the estimation of profit after $x$ years, and

- the definition of clear marketing targets.

- Responsibilities of a project leader for:

- project aligument,

- technical design,

- control or project cost, and

- team composition.

\section{Organisation}

Other explanations for success revealed by this study relate to the nature and structure of the organisation. Apparently, integrating interdepartmental views through team-based structures was found to foster innovation success. Among the main organisation-related key success factors are:

- Project team-based structures;

- Cultural factors dominated by the absence of hicrarchy and conservatism, and the presence of internal competitiveness;

- Regular meetings between marketing and production and strong internal communication links between R\&D, production and maintenance; and

- Cross-functional career patterns between production and R\&D.

Organisational aspects seem to have received more attention by frontrunners than pack members and laggards, indicating that the attention devoted to organisational aspects in recent years is important in explaining differences in success. This is important, because it is consistent with the preceding study. The MERIT study argued that a project-wise and multidisciplinary approach is conducive to innovation success. Contrary to our expectations, the results indicate that multidisciplinary teams do not discriminate between ICT firms. The 
resence of multidisciplinary teams is not a key success factor. Contrary to many sectorpecific and non-sector-specific studies, we were unable to prove that frontrunners differ from ack members in their multidisciplinary approach. This finding might be explained by the resence of multidisciplinary teams in the ongoing operations of ICT firms. Both frontrunners ad pack members are acquainted with multidisciplinary teams.

he multidisciplinary team approach is specially used to conduct complex ICT projects, and articularly more innovative ICT projects. Above all, the nature of complex ICT projects :quires a different type of organisation. Projects have short timeframes, tight schedules and mplex technology integration. Companies are forced to complete projects on time and ithin the budget, particularly ICT infrastructure and software development projects. These rms typically encounter the difficulty of rapid application where the right technological loices and business choices must be made. At this crossroads of choices, a team approach alps to reduce the co-ordination problems. We learned from ICT firms that the organisation ust be capable of structuring itself laterally at the project level, because:

ICT firms are predominantly task-oriented,

Tasks have by definition a business and technology impact and are therefore multidisciplinary, and

Tasks require specialist input in various stages of IT concept development, design and building and testing. This calls for involvement of several disciplines (designers, testers, maintenance) in various parallel stages of innovation.

owever, the use of the multidisciplinary approach does not discriminate success from ilure. More research might reveal the influence of ICT project complexity and the typical ctor approach to realising innovation projects.

astomers: King or business partner?

istomer focus is an important competitive characteristic for companies. However, to what tent is it a differentiating characteristic in actual practice? Qualitative data have indicated at customer focus is relevant to almost every ICT company. What then is of interest in stomer interaction in this study? Many innovation studies fully support the idea that a mpany should be concentrating on its clients and involve them in new product velopment. Managers practise this outside-in thinking. In contrast with the mainstream rovation argument, Cobbenthagen (1999) argued that too much customer involvement ring the various phases of the innovation process could harm innovation success. The ERIT study observed that frontrumners use a different customer approach. Based on case Idy material the study revealed typical frontrunner approaches:

Frontrumners have a highly critical attitude towards new client expectations and needs, Frontrunners are aware of the danger inherent in serving conservative customers that feel no need to innovate,

Frontrunners build mutual trust in client relationships but let customers pay for extra services.

is ICT study outcome seems to confirm these ideas of restrictive co-operation and olvement with customers in various innovation stages such as idea generation and concept velopment. 


\subsection{The Context behind the Research Findings}

To put the results into perspective, the possible influences of the sector have to be identified.

\section{The particular $1 C T$ market environment}

The market environment of the ICT companies is of influence in this study. We abserved the typical market conditions of the ICT sector:

\section{Market demand}

Several demand factors contribute to a high demand for ICT products and services. Among them are:

- The increased dependency by information- and service-intensive companies on automation of the core business processes of information processing;

- The increased need for reliable systems, software and services;

- The replacement of depreciated computer systems which results in the investment in migration from mainframes to client server architectures;

- The investments in new software for better process integration, e.g., enterprise resource planning;

- The adaptation work for hardware and software in transaction and payment systems due to the introduction of the EURO;

- The repair work of computer hardware and software for preventing possible system failures due to the new Millennium.

\section{Market supply}

The services market represents $30 \%$ of the Dutch ICT market. The market is scattered with a few large multi-service providers and a great number of small-specialised service producers. The sofwware market includes a small number of large international players for administrative software and software programming tools. Yet medium-sized and small players typically represent the supply side of the software market.

- Labour market conditions: The absence of a market condition of an equal labour supply and demand seems to interfere with the growth paths

- Environmental conditions:

- Technological conditions: the ICT firms participating in this study emphasised their choice to work with "proven techology" towards their clients, i.e., the use of technologies that have been thoroughly tested and have a reliable track record.

Competitive conditions: due to the high demand for ICT services and products and the scarce capacity of ICT personnel, there is room for a large number of market players. This implies fierce competition in terms of aggressive price strategies or hostile takeovers to ensure a large market share. However, the market concentration, measuring the market share of the four largest market players, is rather low. The four largest suppliers of ICT services grasp a market share somewhere around $20 \%$, whereas the index for the software market is around $5 \%$

The innowation focus

Results have also indicated that the service providers interpret the development of new services in particular as early absorption of new technological knowledge. The software developers place more emphasis on product development. Yet there seems to be no market
condition that rewards service providers for investing in new technology. 
These environmental circumstances have an impact on such issues as the quality of services and products, the role of $R \& D$, and scarce resources. The market circumstance might be favourable to almost all firms operating in the ICT sector. This suggests that there are only few firms that do not benefit from the growth of the sector. An actual selection mechanism and market conditions that differentiate the high performers from the low performers might be absent (as illustrated in box 9.2 for dispatching ICT personnel). Currently, ICT firms can grow in the short term due to a high ICT demand and short labour supply. There seems no need to commit to innovation. This study argued that quality was important to the ICT sector. This devotion to quality was observed in discussions with the managers and also revealed by the strategic priorities of ICT finms. Yet we found some exceptions of firms that were not fully committed to quality, but can still realise growth and profits in the short term. Due to the lack of a market selection mechanisms, these firms are not competed out of the market (see box 9.2).

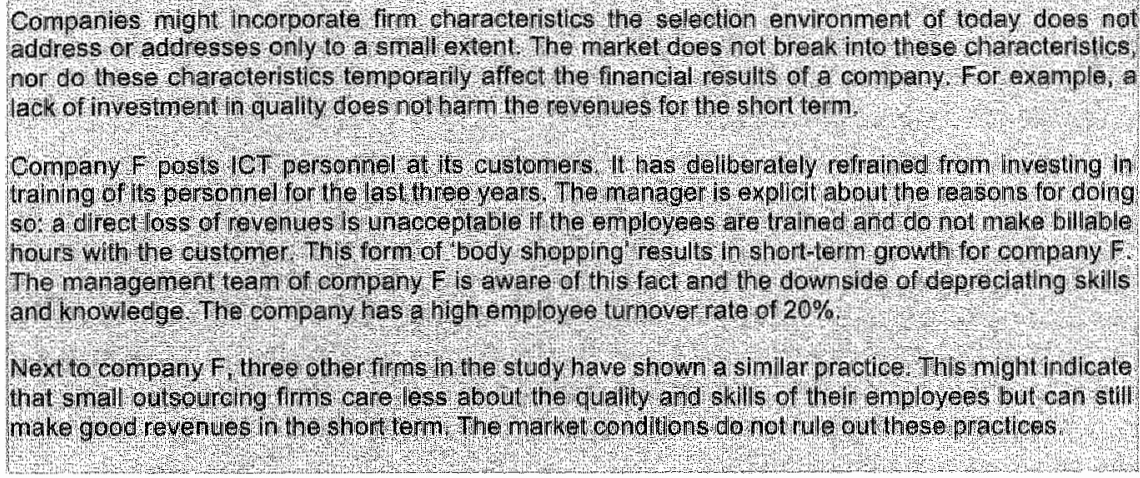

\section{Box 9.2: The selection environment allows for "bodyshopping"}

\section{Measuring success: Multiple roads for being successful}

We have repeatedly noticed that the results have to be interpreted cautiously due to low correlation levels and a small survey sample. It is interesting to see that the use of multiple success measures has revealed detailed correlation patterns, whereas the drawback of using one single success measure is that one can only reveal certain "high-levell' outcomes. The use of multiple success indicators has the advantage of finding detailed patterns of correlation coefficients that provide new insight into the issues behind success or lailure.

Firms have to predetemine and manage a set of business goals, e.g. maximising profit, revenues or growth. Additional goals include new product or process development and delivering quality. The strategy formulation process has to determine the order of the main goals and the sub-goals. This strategy implementation leads to a certain hierarchy of company goals, which differ per company. Ultimately, however, for each firm profit is essential to survive in the market. The use of multiple success criteria has provided insights into this hierarchy of goals. We learned from this study that different mixtures of main goals and subgoals might be equally effective. There is no one company having a "secret recipe' for success, which consists of particular strategic priorities and certain choices in the organisation and process of innovation. Given the context of the ICT sector and the lack of a strict selection environment, there appear to be several ways that lead to a successfull enterprise. Why? 
1. We learned more from the multiple success criteria about how to describe these ways, what they look like and what they essentially consist of. The key success and differentiating factor results obtained might probably not have been observed if this study had used one single success measure.

2. Firms can achieve high scores on a small set of success factors. In a sense, different routes lead to Rome. This is congruent with our earlier idea that innovation and innovation success are a multidimensional phenomenon.

3. On the other hand, innovative success is not the result of a number of separate routines but of the configuration of these routines (Cobbenhagen, 1999). Insight into this configuration can start with a comprehensive set of key success factors and differentiating factors. Yet, the continued replication of dominant factors may not provide us with more insight into such substantial configuration questions. Conducting more configuration and contingency-oriented research implies more than merely listing and testing success factors.

Another learning experience from the study is that there is space for gaining more knowledge and a broader view of the interrelation between strategy and innovation, particularly in the service sector, of which less is known. Furthermore, it is increasingly common for the ICI businesses to recognise, even in the most traditional parts of the sector like hardware, that the nature of the offering to the customers increasingly involves service properties. Service dimensions enter into all ICT products and at all business levels. This poses new challenges to researchers to investigate the innowation in a dynamic competitive environment, which becomes more complex as a result of the rise of the 'service intensity'. In fact we can also say that the innovation management field has to deal with the strategic implications of the increased need for innovation in 'service functions' itself. This calls for a more intense dialogue between the strategy and innovation literature and more research in knowledgeintensive and complex service sectors.

The results of this ICT study reveal the presence of some supportive outcomes of previous innovation studies. An overview of the key success drivers of innovation success has been presented. A number of findings, however, are counterintuitive and contradictory to results reported in the literature and the previous MERIT study. We will present these factors in the following section, and provide some arguments as to why these findings differ.

\subsection{Findings Inconsistent with the Previous MERIT Study}

We call items inconsistent if they differentiate the frontrunners in the ICT sector, but were not observed in the MERIT study (Cobbenhagen, 1999). Inconsistencies were found in particular
in the following areas:

- Both studies revealed a high rellevance of team structures, because many firms have adopted project team structures. However, the presence of multidisciplinary teams is not a

A culture representing strong inten in the ICT sector.

companies, but was not found to be rempetitiveness is a key success factor for ICT contrary to the MERIT study, the culural valu in the MERIT study. Besides this, and working are not differentiating success criteria in like openness and an informal way of

- ICT fims revealled a high priority setting in the ICT study. personnel in contrast to the findings in the prefor firm acquisitions and the training of 
- The presence of career patterns between R\&D and production in the current ICT study differs from the MERIT study.

- The low impact of R\&D resources on success, and the allocation of R\&D resources to product development activities identified as a $\mathrm{KSF}$ in the ICT study were not observed in the MERIT study.

- We observed that universities are a source of innovation in the high-tech ICT sector for a small number of firms. This finding has not been noted in the MERIT study.

- Remarkably, the ICT study revealed the impact of the teclnnological position and technologicall portfolio on the overall innovation success, whereas the previous study did not identify a significant distinction between frontrunners and pack members in this area.

\section{Assumptions \& outcomes}

The following table shows a comparison between the two studies as well as the literature, where different signs are attached to the outcomes. The signs indicate:

- whether strong and significant support was found $(++)$;

- whether some support was found $(+)$;

- whether outcomes were inconclusive $(+i-)$;

- whether outcomes are not conflicting nor differentiating (0)

- whether the outcomes indicated a reverse relation of the one assumed (-); or

- whether it was impossible to test the variable's effect on innovation success or the variable's effect was not tested $(x)$.

\section{Table 9.1: Indications of support for innovation key success factors}

\begin{tabular}{|c|c|c|c|}
\hline $\begin{array}{l}\text { Key success factors that differentiate frontrunners } \\
\text { from pack members and laggards }\end{array}$ & $\begin{array}{l}\text { (1) } \\
\text { factor relevant in } \\
\text { MERIT } \\
\text { innovation stitudy* }\end{array}$ & $\begin{array}{l}\text { (2) } \\
\text { factor relavant } \\
\text { in ICT } \\
\text { innowation } \\
\text { study }\end{array}$ & $\begin{array}{l}\text { Comparative } \\
\text { outcome of }(1) \\
\text { and (2) }\end{array}$ \\
\hline Ojganiation & & & (3) \\
\hline $\begin{array}{l}\text { The rextent to which the firm's innovation piocess } \\
\text { is organised project-byse (horizontally) }\end{array}$ & ++ & 0 & Consistent \\
\hline $\begin{array}{l}\text { The extent to which the firm's innovalion process } \\
\text { is conducted with multidisciplinary teams }\end{array}$ & ++ & $4 \%$ & Inconclusive \\
\hline $\begin{array}{l}\text { The extent to which a company's culture is } \\
\text { characterised as non-hierarchical, non- } \\
\text { conservative and competitive }\end{array}$ & 4 & ++ & Consistent \\
\hline $\begin{array}{l}\text { The extenit to which a company's cullure is } \\
\text { characterised as creative, non-bureaucratic and } \\
\text { progressive }\end{array}$ & $+\%$ & $x$ & No compatison \\
\hline Strong intemal team communication & $+/ /-$ & $+/ / \infty$ & Consistent \\
\hline
\end{tabular}




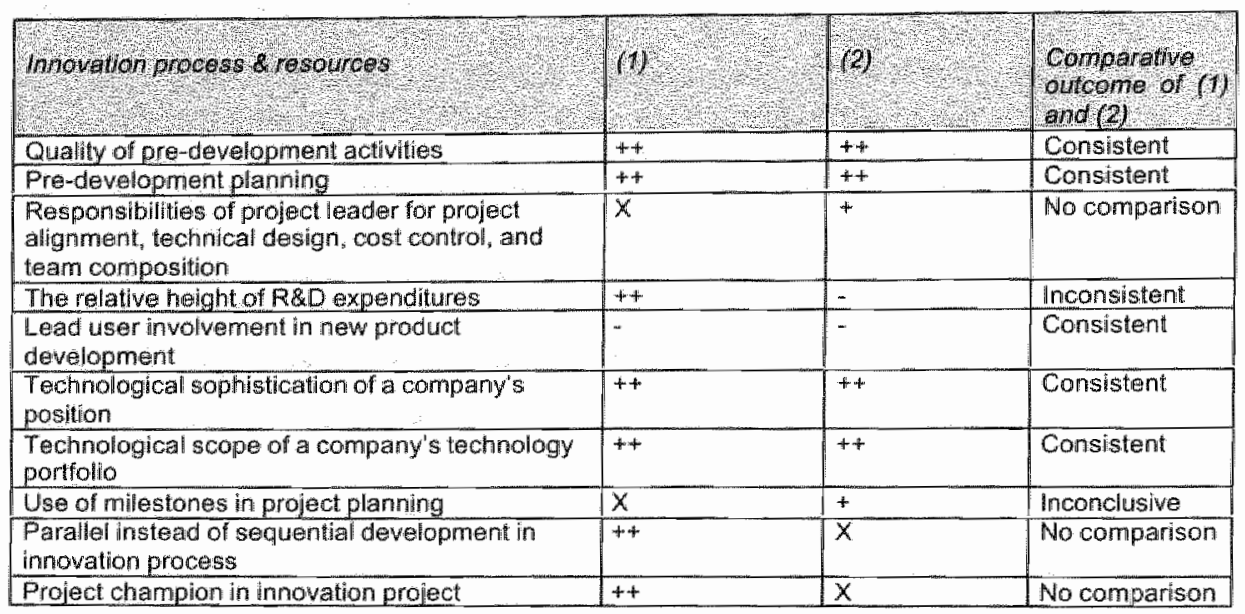

\begin{tabular}{|c|c|c|c|}
\hline 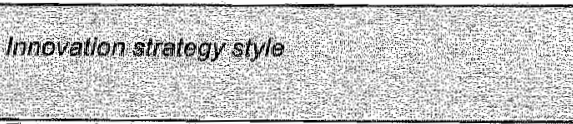 & (1) & (2) & $\begin{array}{l}\text { Comparat } \\
\text { oumpros } \\
\text { and }(2)\end{array}$ \\
\hline External orientation mentality & +4 & + & Consistent \\
\hline First-mover innovators & + & ++ & Consistent \\
\hline The extent to which a company is market-driven & +4 & $\infty$ & inconsigtent \\
\hline Quality assurance as a high-priorily policy matter & 0 & + & No comparison \\
\hline Timing of company policy matters & ++ & +4 & Canisistent \\
\hline External co-operation with universities & $x$ & ++ & Inconclusive \\
\hline Top management commitmient & $\bar{x}$ & $\mathrm{x}$ & No comparison \\
\hline
\end{tabular}

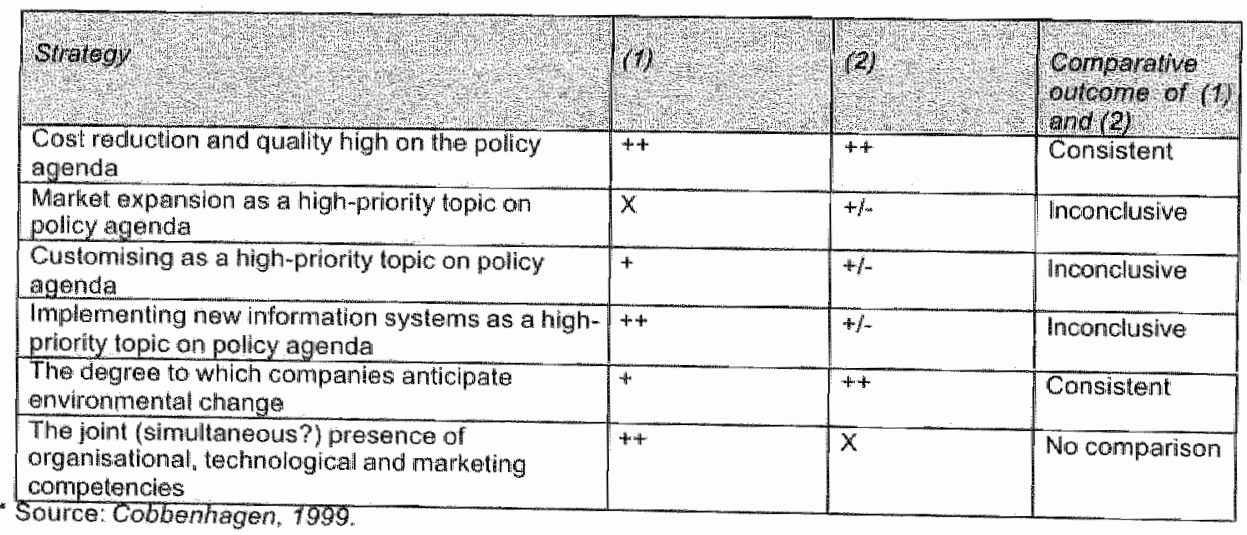

We will go into further detail of some of these outcomes below. 
Streamlining: Multidisciplinary teams

Previously, we have observed that the adoption of non-authoritative, team-oriented approaches to innovation management is beneficial to success. Therefore, firms striving for project-dominated organisation designs, similar to Burns \& Stalker's (1961) organic structures, are supposed to be the frontrunners in intnovation.

However, contrary to this expectation, a more detailed analysis has indicated that this is inconsistent with other studies. In section 9.1 we pointed out that ICT companies need a strong horizontal organisation. Most companies that we visited described their organisation in terms of competence centres and skills units and adhered to cross-functional teams, e.g. for implementation of enterprise resource planning (ERP). This emphasises the integration of several disciplines into teams. Moreover, this finding is inconsistent with the MERIT study, which found multidisciplinary teams with core team members to be typical of frontrunners only.

This might indicate that the organisation design of innovation is different in character in the ICT sector. Another explanation might be that, given the time lag between both studies ( 1994 - 1997), multidisciplinary team practices have been adopted by companies in recent years. The rapid changes in technology and the inter-disciplinary nature of the primary business (development of software, implementation and maintenance of systems) require close organisational integration. Traditional management approaches may not be satisfactory in such a complex environment prone to change. ICT companies are aware of this and have adopted new forms of development, e.g. rapid application development (RAD), joint application development (IAD) and object-oriented workflow. The research outcome deserves more extensive research attention, as ICT companies" organisation structures show characteristic signs of an organic nature.

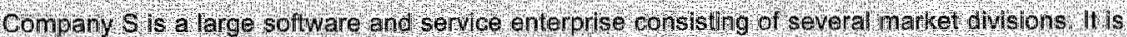
orgarised along a divisional stricture and has a separate innovation unit, the (ehief Innovation

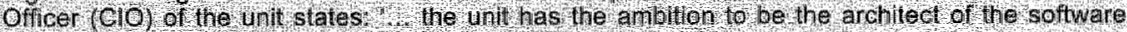
Gacton. W We are developing a vision of streamining the gofware process similar lo a production

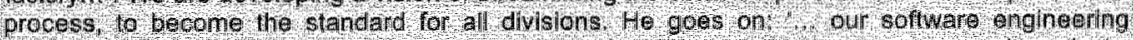
philosob hy has to leavo the ploneering phase. . Wost so fware projects are gus lon made piojerls.

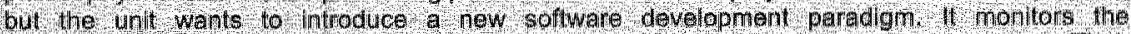

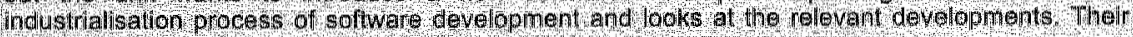
ambitionis based on ther knowledge or:

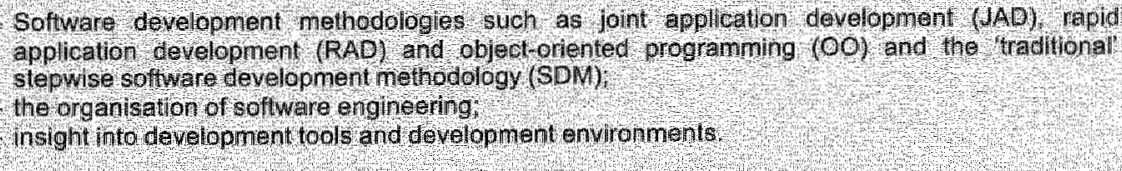

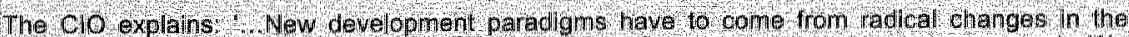
current way of working. Our divisons eannot rely on al evolullonary development approaidh Wa heed to introduce a paradign silitt n he sofware production propess, otherwise it will nol have arty effect Paradigms lke 00 rule biased engñes and cormponent thinking al an tall adtrerent context.

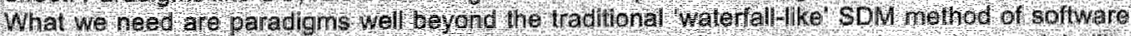

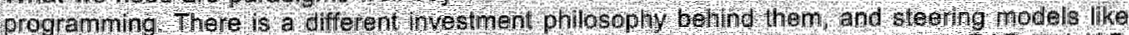

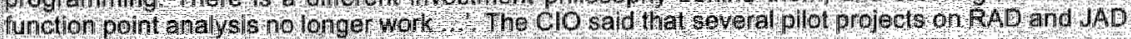
were to be started in the dlvisions within s l months.

Box 9.3: Visions beyond streamlining of the software process 
Another remarkable finding is concerned with the strategic priorities that firms attach to subjects:

\section{Differences in priorities}

Another inconsistency with prewions findings was found in the area of strategic priorities. According to the MERIT study, product renewal was one of the top five priorities for companies. In that study, innovative frontrunners allocated much strategic attention to product renewal and process innovation, and firms also reported to address these issues earlier in their strategic policy making than pack members. In the ICT study the companies rated the subject of product renewal and process innovation lowly. We observed a low priority for innovation on numerous occasions. In particular service providers attached low priority to innovation compared to product developers. Also, the timing of strategic priorities for innovation made a difference between frontrunners and pack members in the ICT sector.

What might be the elements contributing to the inconsistencies in the research results? We will try to answer this question below.

\section{A sector-specific study}

The participating companies belong to the ICT sector. Secondly, the environmental conditions for companies constantly change over time, at a rapid rate in a high-tech sector. These and at number of other factors might explain the above-described inconsistent results, e.g. the 'people business' and knowledge-intensive sector. Probably the differences in innovation success and consistencies would be greater in a larger combined sample of quantitative and qualitative data. However, the combination of quantitative and qualitative data has revealed possible explanations for particular findings.

\section{Secondly: the selection enviromment}

The nature of the ICT sector explains why some factors do not contribute to success. We can image that the market circumstances in the ICT sector are such that investments in innovation are hardly rewarded. This might result from the absence of a selection environment (Hannah \& Freeman, 1979). For example, new technology knowledge is not rewarded in a market characterised by firms making money based on outdated technological knowledge like Cobol and PLI. The high-tech nature would suggest that product innovativeness is an important dimension for ICT companies. We observed that all market players, including their clients, wanted proven technology. Bat also service providers that hardly invest in product renewal and process improvement still perform well in terms of financial success and growth. Why? Because they still gain from selling their existing products, services and people. There barely seems an urge to invest in the future. Especially the latter is a delicate matter in view of the Millennium and EURO circumstances. People with outdated skills may return to the business as experts on old technologies, for instance to repair and maintain mainframe systems.

\section{Thirdly: a swapshot picture}

The ICT study was conducted in a relatively short research span (1996-1998), providing no more than a snapshot picture of the companies and their market positions. It is not a longitudinal perspective where firms are followed for a longer period of time. Such a research setting would enable researchers to observe and measure how companies move and which paths they choose (Van der Ven, 1986) and to identify the moves that frontrumers, pack members and laggands would make in the complete leagne. It is difficult to detect differences in time. We have included retrospective company variables to see if past differences have an effect on today"s innovation position. Timing differences in company policy indicate that the 
explanation for differences in success can be traced back to the past to a significant extent. The previous MERIT study is characterised by a heterogeneous set of companies.

\section{Fourthly, the time dimensions: Perishable key success factors}

Key success factors are subject to time erosion. Factors that accounted for success in earlier studies may no longer be valid in current market circumstances. This might be because market circumstances have changed. On the other hand, managers might have learned from key success factors and adopted policies and practices that have operationalised such key success factors. As a result, the unique differentiating character of key vartables might then disappear. Frontrunners are no longer unique in this characteristic in the market. Innovation characteristics seem to be subject to a life cycle, e.g. multidisciplinary teans or the issue of employee training. Investing in training was a unique altribute for a number of years. However, because of the shortage of labour supply, firms started to attract new personnel (and hold on to employees) by offering broad training facilities as part of the work conditions. As more and more companies have become aware that this was a means to attract people, it will become standard practice in the sector.

\section{Af fift argument: sampling out the laggards}

The variance differences between successful innovators and pack members are larger than in the previous MERIT study. This study incorporates frontrumers, pack members and laggards. The previous study focused on the first two groups. The large differences can be attributed partially to the sample selection. In this study, a normal distributed sample approach was used, whereas in the preceding study a bipolar distribution approach was used. The MERIT study incorporated an expert-based pair-wise selection method to acquire the data sample (we refer to an extensive explanation in the methodological sections).

\subsection{Future Research Agenda}

In this final section we speculate on the implications of the analysis for a broader and deeper understanding of the current role of innovation in the ICT sector. In this thesis we discussed a number of issues arising from the state of innovation affuirs in the ICT sector. In ordar to contribute to the knowledge development on innovation management we essentially propose the following.

\section{Innovarion isswes that need more attention}

The contribution of the ICT study is particularly in investigating and identifying a broad spectrum of sector-specific factors that explain innovation success. The KSF method has appeared to be transferable and applicable to the ICT sector. The study delivered the identification of a core set of key factors conducive to innovation success. We also succeded to identify differentiating success factors and confirm certain key success factors valid in other research studies, e.g. proficient pre-development work. The retrospective and replication nature of this study has strengthened the validity. We also conclude that some items are sector-specific and have appeared not as a KSF in the ICT sector, e.g. multidisciplinary teams, and human resource management practices.

In the recent past the attention of ICT imnovation has focused on technological advancements, which were incorporated into novel hardware and software products. Service innovations were incremental and merely required to complement these technological innovations. More recently, the ICT sector has moved into an era in which knowledge and service-intensive 
organisations play a much more powerful role than previously, particularly due to the need of grasping and exploring the customer needs. What can we conclude from this development? We observed that certain subjects are different from previous innovation studies, and that especially the observed complex role of customer interaction needs more research attention. Customer interaction is difficult to express with a single key success factor. The illustrative case material has shown that other factors play a role in customer interaction.

Whether we focus on the outputs of the service sectors or on the renewal of service functions, the growth of the service components of ICT activity is one of the great trends. More research is advocated on service innovations and the appearance of an innovation paradox ("do what the customer tells" versus "tell the customer what to do' and also 'customisation' versus "inspiration"). Here the interactions with customers and suppliers are more complex than presumed in the literature. We learned that path dependency could explain some of the contrary expectations. These items are among the major challenges for the innovation and strategy sciences. More insight is needed into the qualities and competencies that control and steer these innovation processes.

The proactive timing of strategic priorities and the innovation strategy style are another subject that deserves greater research attention. We have seen that many firms acknowledge the strategic relevance of quality and core competencies but at the same time that ICT firms differ in their timing of strategic priorities. Firms that concentrated their business activities on selecting profitable new product ideas, and turning innovation projects into conmercial viable products and services were more successful. Research on the innovation strategy style might test assumptions as to whether frontrunners are more action-oriented, address priorities sooner and better foresee policy issues by picking up weak signals from the environment. Or investigate why frontruners seem to have a more integral perspective of strategy and innovation. Paying more attention to all these ideas contributes to new knowledge development on innovation in the ICT sector.

\section{Next research phase: towards configuration research}

The outcomes of the ICT study convey the idea that the point of orchestration of the imnovation process has shifted beyond multidisciplinary teams. But this movement is actually hard to address with a single key success factor. Next steps need to be taken. Varianceoriented perspectives, typologies and factors are no longer satisfactory to understand the "why and how question of innovation". Statistical constraints often force us to use KSF notions to map imnovation in a sector. However, we have to recognise that the understanding of innovation processes and consequences calls for combined variance- and process-oriented research. No comparison can be made without variance research and no insight can be gained without process research. This will not be easy but the synergy in perspectives and methodologies has proved to be valuable in this study. The combination of context and process information complements the variance research to build a more complete image of innovation.

This call for new contributions can start with more configuration-theoretical research to concentrate on the explanation of success factors rather than identification by applied research. So far, the innovation research field has not constituted a theoretical base and deeper understanding on each of the key success factors and their interrelations. The new knowledge does not cone from observing extra key success factors, but is derived from investigating the configurations, the collective set of factors, from studying a limited number of categories based on many interrelated success features. In other words, study why organisations perform 
well by combining strategic and structural attributes in a synergistic way. Such configuration research involves both incorporating the theoretical and empirical findings in the strategy field. This proposes a new line in the strategy-structure debate to start investigating configurations of structure and strategy. But it also involves grasping new developments around resource-based and competence-based approaches to organisation, strategy and innovation.

\section{Methods and vision of innovation management research}

It is clear that innovation should be seen in a new perspective in which the environment changes constantly and the criteria for success alter. Innovation processes become the vital primary processes due to the rise of the knowledge- and service-intensive economy. Separate research methods do not help us any further here. As pointed out previously, the KSF studies are characterised by their empirical nature and variety of methodologies. New concepts of and approaches to innovation management have often emerged out of management practice, without a need for theoretical foundations. They are less suitable to get a grip on the dynamic nature. But at the same time we still need the KSF method to quickly grasp what matters to managing new product and process development, and map the difference between frontrumers and pack members.

We actually need new research combinations; a transition to and combination with a process approach. Combinations of variance- and process-oriented research have proved valuable to interpret outcomes or provide alternative explanations. One of the most obvious and now remarkable research features, for example, is the customer interaction and the role of path dependency. While, established measurement procedures may be missing out on important elements of innovation, the new combinations bring a new perspective to the research of innovation management. Finally, understanding 'product, service and process innovation' is therefore quite liable to both deepen and widen the future research directions of innovation management. 


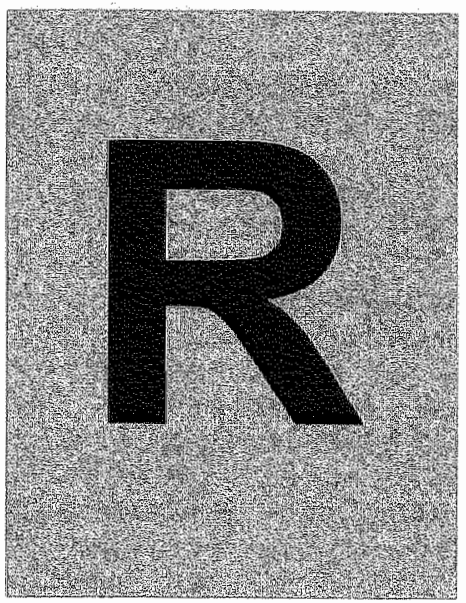

\section{References}

Abernathy, W.J. \& Utterback, J., (1978), Patterns of Industrial innovation, Technology review, June, July, 40-47.

Abernathy, W.J. \& Clark, K.B., (1985), Innovation: Mapping the Winds of Creative Destruction, Research Policy, 14, 3-22.

Adler, P., (1989), CAD/CAM: Managerial Challenges and Research Issues, IEEE Transactions on Engineering Management, 36, 3, 202-215.

Allen, T.J., (1978), Managing the Flow of Technology, MIT Press, Camebridge, MA.

Allen, T.J. \& Cohen, S., (1969), Information flow in R\&D laboratories, Administrative Science. Quarterly, 14, 19-24.

Allen, T.J. \& Katz, R., (1986), The dual ladder: Motivational solution or managerial delusion? Research \& Development Management, 16, 2, 185-197.

Amburgey, T.L. \& T. Dacin, (1994), As the Left Foot Follows the Right? The Dynamics of Strategic and Structural Change, Academy of Management Journal,37, nr.6, p. 1427-1452.

Amit, R. \& Schoemaker, P.J.H., (1993), Strategic assets and organizational rent, Strategic Management Joumal, 14, 33-46.

Ancona, D.G. \& D.F. Caldwell, (1992), Demography and design: Predictors of new product team performance, Organization Science, 3(3), p. 321-341.

Andrews, K.R., (1971), The Concept of Corporate Strategy, Irwin, Homewood, IL.

Ansoff, 1., (1965), Corporate Strategy, McGraw Hill, New York.

Argyris, C. \& Schön, D.A., (1978), Organisational Learning: A Theory of Action Perspective, Addison-Wesley, Reading, MA. 
Astley, W.G., (1984), Toward an Appreciation of Collective Strategy, Academy of Management Review, 9, 3, p. 526-535.

D*Aveni, R., (1996), Hyper-competition: Managing the Dynamics of Strategic Maneuvering, The Academy of Management review, 21, n. I p.291-293.

Bain, J., (1959), Barriers to New Competition, Camebridge, MA, Harward University Press.

Bamberger, P. A Fiegenbaum, (1996), The Role of Strategic Reference Points in Explaining the Nature and Consequences of Human Resource Strategy, The Academy of Management review: vol. 21, nr. 4, p. $926-958$.

Barclay, I., (1992), The new product development process: Part 1. Past evidence and future practical application, $R$ \& D management, vol.22, nr.3, p.255-263.

Barclay, 1., (1992), The new product development process: Part 2. Improving the process of new product development, $\mathbb{R} \&$ D management, vol.22, nr.4 p.307-318.

Barczak, G., (1995), New Product Strategy, Structure, Process, and Performance in the Telecommunications Industry, Journal of Product Innowation management, 12, 224-234.

Barney, J.B., (1995), Looking inside for competitive advantage, Academy of Management Executive, November, p. 49-61.

Barney, J., (1991), Firm resources and sustained competitive advantage, Journal of Management, 17, $99-120$.

Barney, J., (1986), Strategic factor markets: Expectation. Luck and business strategy, Management Science, 32, 10, 1231-1241.

Barney, J., (1991), Firm resources and sustained competitive advantage, fournalof Management, 17, p. $99-120$.

Bart, C.K., (1986), Product Strategy and Formal Structure, Strategic Management Journal, 7, 4, 293312.

Becker, B. \& Gerhard, B., (1996), The impact of human resource management on organizational performance. Progress and prospects, American Management Journol, 39, 4, 779-802.

Bertsch, H.B. \& Stam, J.A., (1990), Naar een nieuwe stijl van productontwikkeling. In: J.F. den Hertog \& F.M. van Eijenatten (eds.), Managenent wan technologische vernieuwing, Van Gorcum, Maastrichtid Assen.

Biemans, W.G., (1992), Managing Imnovation within Networks, Routledge, London.

Bolwijn \& Kumpe, (1992) About facts, fiction and forces in Human Resource Management, Human systems managentent voll.15 (1996) nr.3 p.161-172.

Bono, de E., (1994) Seriaus Creativity: Using the Power of Lateral Thinking to Create New Ideas, Harper Collins Lonton.

Booz, Allen \& Hamilton, (1968), Management of New Products, New York: Booz Allen \& Hamilton Inc.

Booz-Alen \& Hamilton, (1997), Enabling the Imformation Society. Supporting Market-Lead Developments, Den Haag.

Bourgecis, L.J. III \& K. M. Eisenhardt, (1988), Strategic decision processes in high velocity environments: four cases in the microcomputer industry, management Science, vol. 34, p. 816 835.

Bowar, J.L., (1970), Managing the resonme allocation process, Boston, MA, Harvard University.

Brown, S.L. \& Eisenhardi, K.M., (1995), Product Development: past, present and future directions, Acodeny of Managenent Review, 20,2,343-378.

Brownel, P. \& A. Dunk (1991). Task uncertainty and its interaction with budgetary participation and budget emphasis: some methodological issues and empirical investigation, Accounting. Organizations and Society, vol. 16, nu.8 p.693.

Bruce, M. et aL. (1995), Success factors for collaborative product development: A study of suppliers of information and communication technology, $R \& D$ Managemen, vol.25, nr. 1 p.33-44.

Burgelman, R., (1983), Corporate entrepreneurship and strategic management: Insights from a process study, Management Sicience, 29, p. 1349-1363.

Burgelman, R.. (1983). A Model of the Interaction of Strategic Behaviour, Corporate context, and the Concept of Strategy. Acadeny of Management Review, 1, 61-70.

Burns, T. \& Stalker, G.M., (1961), The Management of Imowation, Tavistock, London. 
Calantone, R.I. \& Di Benedetto, C.A. \& Divine, R., (1993), Organisational, technical and market antecedents for successful new product development, R\&D Management, 23, 4, 337-351.

Cameron, K., (1980), Critical questions in assessing organizational effectiveness, Organizational Dynamics, $9,66-80$.

Carter, C. \& B. Willians, (1957), Industry and iechnical Progress, Oxford University Press.

Chaffee, E.E. (1985), Three Models of Strategy, Academy of Management Review, 10, 1, p. 89-98.

Chandler, A. D., (1962), Strategy and structure: Chapters in the History of the Industrial Enterprise, Cambridge, MA, MTT Press.

Chen, M. et al., (1993), An exploration of the expertness of outside informants, Academy of Management Joumal, 36, 6, p. 1614-1632.

Child, J., (1984), Organisation: A guide to problems and pracrice, London: Harper \& Row.

Child, J., (1972), Organizational structure, environment and pertormance: The role of strategic choice, Sociology, 6, p. 1-22.

Christensen, C.R. et al., (1978), Business Policy: Text and Cases, 6 ed. Homewoord, Irwin.

Clark, K. \& Wheelwright, S., (1993), Managing New Product and Process Development, The Free Press, New York.

Clark, K. \& Fujimoto, T., (1991), Product Dewelopment Performance: Strategy, Organization and Managenent in the Auto Industry, Harvard Business Press, Boston, MA.

Cobbenhagen, J., (1999), Managing Innowation at the Company level: a sfudy of non-sector specific success factors, Datawysed niversitaire Pers Maastricht, Maastricht.

Cobbenhagen, J., J. F. den Hertog \& J.M. Pennings, (1995), Succesvol Veranderen: Kerncompeteneries en Bedriffsverniewwing, Kluwer Bedriffs Wetenschappen, Deventer.

Cockburn, I. \& R. Henderson, (1998), Absorptive Capacity, Coauthoring Behavior, and the Organization of Research in Drug Discovery, The Joumal of Industrial Economics, vol.46 (1998) nr.2 p.157-182.

Cohen, W.M. \& Levinthal, D.A., (1990), Absorptive Capacity: A New Perspective on Learning and Innovation Administrative Science Quaterly, 35, 2, 128-152.

Collis, $\mathrm{D}_{n}$ (1995), Understanding sustanable competitive advantage: The role of positioning, resources and organisational capabilities, Working paper. Harvard Business School, Division of Research.

Collis, D \& C. Montgomery, (1995), Competing on Resources: Strategy in the 1999s, Harvard business review, vol. 73 , nr.4 p.118-129.

Collis, D.J., (1.991), A Resource-Based analysis of global competition. the case of the bearings industry, Strategic Management yournal, 12,49-68.

Cool, K \& D. Schendel, (1988), Performance Differences Among Strategic Group Members, Strategic Management Jotinal, 9, p. 207-223.

Cooper, R., (1979), Identifying Industroal New Product Success: project NewProd, industrial Marketing Managemeni, 8, May.

Cooper, R., (1983), The new product process: an empirically based classification scheme, $R$ \& $D$ Management, 13, 1- $\$ 3$.

Cooper, R.G., (1986), New product performance and product innovation strategies, Research management, May-June, 17-25.

Cooper, R.G., (1994), Third generation new product processes, Journal of Prodtuct Innowation Mamagement, 11, 1, 3-15.

Cooper, R.G., (1996), Wiming at New Products: Accelerating the Process from Idea to Launch, Addison-Wesley, reading, MA.

Cooper, R. \& E.I. Klemschmidt, (1987), What makes a new product a winner: Success factors at the project level, R\&D Management, 17,3, p. 175-189.

Cooper, R. \& E.J Kleinschmidt, (1993), Screening New Products for Potential Winners, Long Range Planning, vol.26 nr.6 p.74.

Cooper, R \& EJ. Kleinschmidt, (1993), New-Product Success in the Chemical Industry, Industrial marketing management, vol.22 (1993) nr.2 p.85.

Cooper, R.G. \& E.J. Kleinschmidt, (1995), Benchmarking Firm's New Product Performance \& Practices, Engineering Management Review, 23, 3, 112-120. 
Cooper, RG. \& E.J. Kleinschmidt, (1995), Benchmarking Firm's Critical Success Factors in New Product Development, Journal of New Product Development, 12(5), pp. 374m391.

Cooper, R. \& EJ. Kleinschmidt, (1995), The relative importance of new product success determinants - Perception versus reality, $R$ \& $D$ Management, vol. $25, \mathrm{nr} .3$ p.281-298.

Cooper, R.G. E. E. , Kleinschmidt, (1996), Winning Businesses in Product Development: The Critical Success Factors, Research-Technology Mamagement, vol.39, nr.4 p.18-29.

Cooper, RG. \& R.A. Moore, (1979), Modular risk management: an applied example, R\&D Mamagement, vol. 9, n. 2, p. 93-99.

Cusumano, M. \& Selby, R., (1995), Microsoft Secrets: How the world's most powerful software company creates technology, shapes markets and manages people, HarperCollins Business, London.

Daft, R. \& A. Lewin, (1993), Where are the Theories of the "New" Organisation Forms? An Editorial Essay, Organisation Science, 4, 4 p. i-iv.

Daft, R.L., (1983), Learning the craft of organizational research, Academy of Management Review, vol. 8,4, p. $539-546$.

Damanpour, F., (1991), Organizational Innovation: A Meta-analysis of Effects of Determinants and Moderators, Academy of Management Joumal, vol.34, nr.3 p.555.

Davis, S. \& P.R. Lawrence, (1977), The Matrix Organization - Who Needs It?, in: Davis, S. \& P.R. Lawrence, Matrix. Addison Wesley, Reading: MA.

Delery, J, \& D. Doty, (1.996), Modes of Theorizing in Strategic Human Resource Management: Tesis of Universalistic, Contingency, and Configurational Performance Predictions, Academy of Management journal, wol. 39 , nr. 4 p. $802-835$.

Dierckx, 1. \& K., Cool, (1989), Asset Stock Accumulation and Competitive Advantage, Management Science, 12, 1504-1511.

Donaldson, $L$., (1995), American anti-management theories of organization: A critique of paradigm proliferation, Camebridge University Press, Camebridge.

Dougherty, D., (1990), Understanding new markets for new products, Strategic Management Joumal, 11, p. 179-202.

Dougherty, D., (1992), A Practice-Centered Model of Organizational Renewal through Product Innovation, Strategic management Jounal, vol.13, p.77.

Dougherty, D., (1992), Interpretive barriers to successful product innovation in large firms, Organization Science, 3, p. 179-202.

Dougherty, D., (1993), Managing your core incompetencies for product innovation, McGill University, Montreal.

Dougherry, D. \& S.M. Corse, (1995), When it comes to product innovation, what is so "bad" about "bureaucracy"?, Joumal of High Techwology Management.

Dougherty, D. \& Hardy, C., (1996), Sustained Product Innovation in Large, Mature Organizations: Overcoming Innovation-to- Organization Problems, Academy of Management Journal, 39, 5, $1120-1153$.

Downs, G. \& L. Molr, (1976), Conceptual Issues in the Study of Innovation, Adwinistrative Science quarterty, 21,700-714.

Doty, Glick, \& Huber, (1993), Fit, Equifinality, and Organizational Effectiveness: A Test of Two Configurational Theories, Academy of Mamagement Jowmal, wol.36, nr.6 p.1196.

Drucker, P., (1993), Posi Capitalist Society, Harper Business, New York.

Duysters, G. \& J. Hagendoom, (1995). Strategic Groups and Inter-firm Networks in International High-tech Industries, Joumal of Management Studies, vol.32, nr.3 p.359-382.

Dwyer, L. et all., (1991), Organizational environment, New product process activities, and project outcomes, Joumal of Product Innowation Management, 8, p. 39-48

Dyer \& Wilkins, (1991), Better stories, not better constructs to generate better theory: A rejoinder to Eisenhardt, Academy of Management Review, 16(3), pp. 613-619.

Eisenhardt, K.M., (1989), Building theories from case study research, Academy of Management Review, vol. 14,4, p. 532.550 .

Eisenhardt, K. \& B. Tabrizi ((1995), Accelerating Adaptive Processes: Product Innovation in the Global Computer Industry, Administrotive Science Quarterb, vol.40, nr.1 p.84-110.

EIrO, (1999), European hnformation Technology Obsenvatory, Frankfurt am Main. 
Ethie, J.E, W. Bridges \& R.D. O'Keefe, (1984), Organization Strategy and Structural Differences for Radical versus Incremental Innovation, management science, 30, 6, p. 682-695,

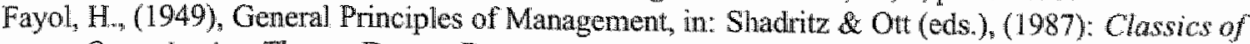
Organization Theory, Dorsey Press.

Foster, R., (1986), Innovation: The attacker's advantage, Summit, New York.

Fowler, F.., (1988), Survey research methods (revised edition), Newbury Park: Sage.

Frederickson, J.W., (1986), The Strategic Decision Process and Organizational Struciure, Acadenry of Management Review, 11, 2, p. 280-297.

Freeman, C., (1988), The Ecanomics of Industrial hmonation, 2nd edition, London: Frances Pinter.

Freeman, I. \& W. Boeker, (1984), The Ecological. Analysis of Business Strategy, California Management Review, 26, 3, p. 73-86.

Gailbraith, J.R., (1973) Designing Complex Orgamizations, Addison Wesley, Reading, MA.

Gailbraith, J.R., (1994), Competing with Flexibie Lateral Organizations, 2nd edition, Addison Wesley, Reading, MA.

Galbraith, J.R. \& D.A. Nathanson, (1979), Strategy Implementation: The Role of Structure and Process, St. Paul: West.

Galunic \& Rodan, (1998), Resource Recombination in the Firm: Knowledge Structures and the Potential for Schumpeterian Innovation, Strategic Management Journal, vol.19, nr.12 p. 1193.

Gaspersz, J. \& Ott, M., (1996), Management wan employabitity. Niewwe kansen in arbeidsrelaties, Vasn Gorcum, Assen.

Gersick, C., (1994), Pacing Strategic Change: The Case of a New Venture, Academy of Management Jousnal, vol.37, nr.1 p.9.

Giddens, A., (1979), Central Problems in Social theory, MaxMillan, London.

Glaser, B. \& A. Strauss, (1967), The Discovery of Grounded theory: Strategies of qualitative Research, London: Wiedenfeld \& Nicholson.

Giobeli, D. \& D. Brown, (1988), Analyzing product innowations, Research Managemeni, July-August, p. $25-31$.

Gobeli, D, \& D. Brown, (1993), Improwing the Process of Product Innovation:, Research-Technolagy Management, vol.36, nr.2 p.38-44.

Gomez-Mejia, L. \& D. Balkin, (1989), Effectiveness of individual and aggregate compensation strategies, Industrial Relations, vol. 28, p. 431-445.

Grant, R.M., (1991), The Resource-Based Theory of Competitive Advantage: Implications for Strategy Formulation, California Management Review, 114-135, Spring.

Grant, (1996), Prospering in Dynamically-competitive Environments: Organizational Capability as Knowledge Integration, Organization Science, vol.7, nr.4 p.375-387.

Griftin, A. \& Page, (1996), PDMA success measurement project: recommended measures for product development success and failure., The Journal of Product Immovation Management wol. 13, mir.6 p. 478 .

Griffin, A. \& J. Hauser (1996), Integrating R\&D and marketing : a review and analysis of the literature, The Journal of Product Innovation Mamagement, voll113, nr.3 p.191.

Haanes, K.; Fjeldstad, (2000), Linking intangible resources and competition, European Managenem Journal, vol. 18, nr.1 (February) p. $52-62$.

Hall , D. \& M. Saias, (1980), Strategy follows structure, Strategic Management Joumal, 1, 149-163.

Hamel, G. \& A. Heene, (1994), Competence based Comperition, John-Willey, Chichester.

Hamel, G. \& C.K. Prahalad, (1991), Strategic Intent, Harvard Businesw review, May-June, p. 63-76.

Hamel, G. \& C.K. Prahalad, (1994), Competing for the Future, Harvard Business School Press, Boston, MA.

Hammer, M. \& Champy J., (1993) Reengineering the Corparation: A Manifesro for Businesss Revolution, Harper Business, New York.

Hammersley, M. \& P. Atkinson, 1983, Ethnography: Principles in Practice, London: Tavistock.

Hannah, M.T. \& Freeman, J.H., (1989), Organizational Ecology, Harvard University Press, Camebridge.

Hansen, G. \& B. Wernerfelt, (1989), Determinants of firm performance: The relative importance of economic and organisational factor, Strategic Management Jownal, vol. 10, p. 399-411. 
Harrigan, K., (1983), Research methodologies for contingency approaches to business strategy, Academy of Managenent Review, vol. 8., p. 398-405.

Hedlund, G. \& D. Rolander, (1987), The strategy-strucrure paradigm in international business research and practice. Research paper 87/4, Institute of International Business at the Stockholm School of Economics, Stockhoim.

Heene, A. \& Sanchez, R., (1997), Competence-based Strategic Managemen, John Wiley \& Sons, Chichester.

Henderson, R. \& K. Clark, (1990), Arehitectural Innovation: the reconfiguration of existing product technologies and the failure of established firms, Administrative Science Quarterly, 35, 9-30.

Henderson, R. \& I. Cockbum, (1996), Scale, Scope, and Spillovers: The Determinants of Research Productivity in Drug Discovery, The Rand Journal of Economics, vol.27, nr.1 p.32-59.

Hertog I.F., den et al. (1991), Innovatie en personeelsbeleid: de beheersing van de kennishuishouding, Bedrifskunde, wol.63, nir.2 p.158.

Hertog, J.F. den \& Van Sluijs E., (1995), Managing knowledge flows: a key role for personnel management, in: Europe's Next Step: Organizational Innovition, Competition and" Employment, Eds. Andreasen, L.E, Coriat B. den Hertog, J.F. and Kaplinsky, R. Frank Cass, rlford.

Hertog, J.F. den \& van Sluijs E., (1995), Onderzoek in organisaties. Een methodologische reisgids, Van Gorcum, Assen.

Hertog J.F. den \& E.I. Huizenga, (1997), Het Innowatieve Softwarebedrijf: Strategie, Organisatie en Personeelsbeleid, Kluwer Bedriffswetenschappen, Deventer.

Hertog, J.F. den \& E.I. Huizenga, (1997), De Kennisfactor: Concurreren als kennisondememing, Kluwer Bedrijfsinformatie, Deventer.

Hertog, J.F. den \& E.I. Huizenga, (2000), The Knowledge Enterprise: Implementation of Intelligent Business Sirategies, Imperial College Press, London.

Hertog, J.F., den \& J. Cabbenhagen, E. Huizenga, W. Bodewijs, (2000), Blending words and numbers: strategies for combining qualitative and quartitative methods for organizational research, MERTT, Universiteit Maastricht.

Hippel, E. von, (1986), Lead users: A source of novel product concepts, Management Science, 32, 7.

Hitt, M., R. Ireland (1985), Corporate Distinctive Competence, Strategy, Industry and Performance, Srategic Management Joumal, 6, p. 273-293.

Hoesel, P. van, (1985), Het programmeren wan beleidsonderzoek: analyse en receptuar, Leiden: Lisbon.

Huselid, M. elt al., (1997), Technical and Strategic Human Resource Management Effectiveness as Determinants of Firm Performance, Academy of Managenent Jourmal, vol.40, nr.1 p.171-188.

Huselid, M. \& B. Becker, (1996), Methodological Issues in Cross-Sectional and Panel Estimates of the Human Resource-Firm Performance Link, Inditstrial Relations, vol.35, nr.3 p.400-422.

Iansiti, M., (1993), Real-wonld R\&D Jumping the Product Generation Gap, Harward Business Review, vol. 71, inr. 3 p. 138

lansiti, M. \& K. Clark, (1994), Integration and Dynamic Capability: Evidence form Product Development in Automobiles and Mainframe Computers, Industrial and Corporate Change, vol.3, ni.3 p.557-606.

lansiti, M. \& T. Khanna, (1995), Technological Evolution, system Architecture and the Obsolescence of Firm capabilities, Industrial and Corporate Change, vol.4, ar.2 p.333-362.

Imai, K., Nonaka, I. \& H., Takeuchi, (1985), Managing the new product development process: How Japanese companics learn and unlearn, in: K. Chark et al. (ads.), The Uneasy Alliance, Boston Marvard Business School Press.

Itami, H., (1987), Mobilizing Invisible Assets, Boston: Harvard University Press.

Jensen, M. \& W. Meckling, (1976), Theory of the Firm Managerial behavior, agency costs and ownership structure, in: Werin, L. H. Wijkander (eds.), Contract Economic, Blackwell, Oxford, p. $251-274$.

Johne \& Snelson, (1988), Success factors in product innovation: a selected review of the literature, Jownal of Product Innowation Mandgenent, vol. 5, 2, p. 100-110.

Karlsson, C. \& P. Ahlstrom, 1996), The difficult path to lean product development, The Joumal of Product Innovation Management, vol. $13, \mathrm{nr} .4$ p.283. 
Katz, R. \& T. Allen (1985), Project performance and the locus of influence th the R\&D matrix, Academy of Management Journal, vol. 28, 1, p. 67-87.

Katz, Ralph; Tushman, Michael; Allen, Thomas, (1995), The Influence of Supervisory Promotion and Network Location on Subordinate Careers in a Dual Ladder, Joumal of Mamagement Science, vol. 41, nr. 5 p. $848-863$.

Keller, R.T., (1986), Predictors of the performance of project groups in R\&D organisations, Academy of Management Joumal, vol. 29, 4, p. 715-726.

Ketchen D. et al., (1997), Organizational Configurations and Performance: A Meta-Analysis, Academy of Management Journal, vol.40, nr.1. p.222-240.

Kets de Vries, M., (1991), Whatever Happened to the Philosopher-King? The Leader's Addiction to Power, Journal of Management Studies, vol.28, nr.4, p.339.

Khandwalla P., (1973), The Design of Organizations, Harcourt, Brace, Jowanovich, New York.

Klimstra, P.D. \& Pots, J., (1988), What we've learned about managing R\&D projects, Research de Technology Managemen, May-June, $42-58$.

Kline, S.J., (1985), Imnovation is not in linear process, Research Management, July-August, p. 36-45

Kogut, B. and Zander, U., (1992). Knowledge of the firm, combinative capabilities, and the replication of technology, Organization Sicience, 3 (3), 383-397.

Larson, E.W. \& Gobeli, D.H., (1985), Project Managenent Structures: Is there a common language? Project Management Jownal, vol. 16, 2, p. 4044.

Larson, E.W. \& Gobeli, D.H., (1988), Organizing for Product Development Projects, Jounal of Product Innowation Management, 5, 180-190.

Larsson, R., (1993), Case survey methodology. Qualitative analysis of patterns across case studies, Academy of Management Joumal, 36, 6, 1515-1546.

Lawrence, P.R \& Lorsch, J.W, (1967), Organization and Enviromment: Managing Differemtiation and Integration, Irwin, Homewood.

Lemmink J., (1991), Kwaliteitsconcurrentie tussen ondenemingen. Profschrift, Maastricht: Rijksuniversiteit Limburg.

Leonard-Barton, D., (1990), A Dual Methodology for Case Studies: Synergist Use of a Longitudinal Single Site wit h Replicated Multiple Sites, Organization Science, $1 \quad(3), 248-66$.

Leonard Barton, D., (1995), Wellsprings of Knowledge, Harvard Business School Press, New York.

Lewis, L. et al, (1993), Innovation Modification During Intraorganizational Adoption, Academy of Management Review, vol.18, nr.2 p.322.

Likert, R. (1932), A technique for the measurement of attitudes, Archives of Psychology, 140.

Lowendahl, B.\& K. Haanes, (1996), The unit of activity: A new way to understand competence building and leveraging. In: R. Sanchez \& A. Heene eds., Strategic Learring and Knowledge Management, John Wiley \& Sons, Chichester.

MacDuffie, J., (1995), Human Resource Bundles and Manufacturing Performance: Organizational Logic and Flexible Production Systems in the World Auto Lndustry, Industrial \& Labor Relations Review, vol.48, nr.2 p.197-221.

Mahoney, J. \& J. Pandian, (1992), The Resource-based View Within the Conversation of Strategic Management, Strategic Management Journal, vol. 13, m:5 p.363.

Maidique, M.A. \& Zirger, B.J., (1985), The new product learning cycle, Research Policy, 14, 299-313.

March, J.G., (1991), Exploitation and exploration in organizational learning, Orgarization science, 2, 1, p. $71-87$

McCann \& J. Galbraith, in: Cobbenhagen, J., (1999), Managing Inmovation ar the Company level: a study of non-sector specific stuccess factors, Datawyse/Universitaire Pers Maastricht, Maastricht.

McGrawth, R. G. \& I. MacMillan, S. Venkatraman, (1995), Defining and developing connetence: a strategic process paradigm, Strategic Management Joumal, 16, pp. 251-275.

McGrawth, R. G., (1995), Creating and Transforming Core Business: A Competence Oriented Analysis, paper Academy of Management Anmual Meeting 1995.

McGrawth, (1997), A Real Options Logic for Initiating Technology Positioning Investments, The Academy of Management review, vol.22, nr.4, p.974-996.

Meyer, A., Tsuil, A.S., \& C.R. Hinnings, (1993), Configurational A.pproaches to Organizational. Analysis, Academy of Management Jownal, vol. $36,6, \mathrm{p} .1175-1195$. 
Miles, R.E. \& C.C. Snow, (1978), Organizational Strategy, Struckure and Process, McCraw-Hill, New York.

Milier, D., (1986) Configurations of Strategy and Structure: Towards a Synthesis, Sirategic Managenent Journal, 7, 233-249.

Mil.Jer, D. \& P. Friesen, (1980), Archetypes of Organisational Transition, Administrative Science Qucretly, 15, 2, 268-300.

Mintzberg, H, (1979), An emerging theory for direct research, Administrative Science Quarterly, 24, pp. $582-589$.

Mintzberg, H., (1990), Strategy Formation: Schools of Thought, in: Frederickson, J.W, Perspectives on Stralegic Management, New York, 105-235.

Mintzberg, H., (1979). The Structuring of Organisations, Prentice Hall, Englewood Cliffs, New York. Miyazaki, H. et al. (1995) On the Level Probabilities for Useful Partially Ordered Alternatives in the Analysis of Variance, Communications in Statistics, vol.24, nr.8, p.2059-2072.

Moeneart, R. et al., (1990), R\&D Marketing Integration Mechanisns, Communication Flows and Imnovation Success, Jourmal of Product Innovation Management, II, p. $31-45$.

Mohr, L.B., (1982), Explaining Organizational Behaviour: The Limits and Possibilities of Theary and Research, San Fransisco: Jossey-Bass.

Mohrman, S. et al, (1992), Human resource strategies for lateral integration in high technology settings, in: Human resource Strafegy in High Technology, Gomez-Mejia L.R. \& Lawless, M.W., JAI Press, Greenwich.

Montoya-Weiss, M.M. \& Calantone, R., (1994), Determinants of new product performance: A review and meta-analysis, Journal of Product Innovation Monagement, 11, 397-417.

Moss Kanter, R.M., (1983), The Change Masters: Innovation for Productivity in the American Corporation, Simon and Schuster, New York.

Muijen, J. van et al (1996), Focus op organisatiecultuur. Het concurrerende-waarden model en het meten en veramderen van organisatiecultuur.

Myers, S. \& D. Marquis, (1969), Successful Industrial Innowation, Washington D.C., National Science Foundation.

Nelson, R. \& S. Winter, (1982), An Evolutionary Theory of Economic Change, Cambridge, Harvard University Press.

Nonaka, I., (1990), Redundant, Overlapping Organization: a Japanese Approach to Managing the Innovation Process, Califomia Management Review, vol. 32, 3, p. 27-38.

Nonaka, 1., (1991), A dynamic theory of organizational knowledge creation, Orgamizarion Science, 5, 1.p. 14-37.

Nonaka, I. \& Takeuchi, H., (1996), The Knowledge Cheating Company, Oxford University Press.

Nunally, J.C. \& J.C. Bernstein, (1978), Psychometric Theory, third edition, New York: McGraw-Hill.

Nystrom, P.C.\& W.H. Starbuck, (1981), Handbook of Organizational Design: volume 2 Remodeling Organizations and their Environments, Oxford University Press.

OECD, (1994), Frascati Manual: The measurenent of scientific and technological activities: proposed standowd practice for surveys of research and experimental development, Paris.

O'Reilly, C. et al., (1991), People and Organizational Culture: A Profile Comparison Approach to Assessing Person-Organization Fit, Academy of Management Joumal, vol.34, nr.3 p.487.

Pavitt, K., (1991), Key Characteristics of the Large Innowating Firm, British Jowrnal of Management, vol. 2, p. $41-50$.

Pennings, J.M. \& F. Harianto, (1992), The Diffusion of Technological Innovation in the Commercial Banking Industry, Strategic Management Joumal, vol.13 (1992) nr.1 p.29.

Pennings, J.M., (1993), De strategische rol van tijdige innovatie, Holland Management Review, nr.37 p. 104.

Penrose, E, (1959), The Theory of the Growth of the Furm, Oxford: Basil Blackwell.

Peteraf, M., (1993), The Comerstones of Competitive Advantage: A Resource-based View, Strategic Management Joumal, vol. 14, ar 3, p.179

Peters, T. \& N. Austin, (1985), A Passion for Excellence, Harper-Collins, New York.

Peters Shadritz \& Ott, T, (1988), The mythology of innovation, or a skunkwork tale, Part II, in: M.L. Tushman \& W.L. Moore, Readings in the Management of Innovation, Harper Business, 138 148. 
Pettigrew, A., (1985), The Management of Sirategic Change, Oxford, Basil Blackwell.

Pettigrew, A.M., (1990), Longitudinal field research on change: Theory and practice, Organization Science, vol. 1, n. 3, p. 267-292.

Pfeffer, J., (1981), Power in Organisations, Marshfield, MA, Pitman.

Pfeffer J., (1994), Competitive Advantage through People, Harvard Business Press, Boston.

Pfeffer, J. \& G.R. Salancick, (1978), The extemal control of organizations: A resource dependence perspecrive, New York: Harper \& Row.

Pierce, J.L. \& A.L. Delbecq, (1977), Organization structure, individual attitudes, and innovation, Academy of Management Review, p. 27-37.

Pisano, G. P. \& S.C. Wheelwright, (1995), The Logic of High-tech R\&D, Havard Business Review, vol. 73 , nr.5, p. 93-1.07.

Polanyi, M., (1966), The Tacit Dimension, Anchor Books, New York.

Porter, M., (1980), Competitive Strategy: Techniques for Analyzing Industries and Competitors, The Free Press, New York.

Porter, M., (1985), Competitive Advantage: Creating and Sustaining Superior Perfomance, The Free Press, New York.

Prahalad, C.K. \& Hamel, G., (1990), The core competence of the organisation, Harvard Business Review, 68, 3, 79-91.

Prahalad, C.K. \& G. Hamel, (1994), Strategy as a field of study: Why search for a new paradigm? Strategic Management Joumal, vol. 15, p. 5-16.

Pugh, D., Hickson, D., Hinnings, C. \& C. Turner, (1969), Dimensions of Organisation structure, Administrative Science Quarterly, vol. 13, p. 65-105.

Quélin, B., (1996), Approbriability and the creation of new capabilities through strategic alliances. In: R. Sanchez \& A. Heene eds., Strategic Learning and Knowledge Management, Jolnn Willey \& Sons, Chichester.

Quinn, J.B., (1985), Managing Innovation: Controlled Chaos, Harvard Business Review, May-June, p. $73-84$.

Quinn, J.B., (1993), Managing the Intelligent Enterprise: Knowledge \& Service-based Strategies, Planning Review, vol. 21, 5, p. 123-137.

Reeken, A.J. van \& J. Trienekens, (1991), Het praktisch belang van methoden en CASE-tools. Resultaten van empirisch onderzoek, Informatie, vol.33, nr.7-8, p.494.

Roberts, E.B. \& B. Berry, (1984), Managing the internal corporate venturing process, Sloan Management Review, 33-48, Winter.

Robinson, W. \& C. Fornell, M. Sullivan, (1992), Are Market Pioneers intrinsically Stronger than Later Entrants?, Strategic Management Joumal, vol. 13, ar. 8, p.609.

Rothwell, R., (1972), Factors for Success in Industrial Annovation. Project SAPPHO: A comparative study of success and failure in industrial innovation, Brighton, Sussex, SPRU.

Rothwell, R., (1974), SAPPHO-Updated-Project SAPPHO Phase Il, Research Policy, 3. p. $30-38$.

Rothwell, R., (1992), Successful Industrial innovation: Critical factors in the 1990s, R\&D Management, 22, 3.

Rothwell, R., (1994), Industrial Innovation, Success, Strategy, Trends, in: M. Dodgeson \& $\mathbb{R}$. Rothwell, The Handbook of Imnovation Managemen, Edward Elgar, Aldershot.

Roussel, Ph. A. et al., (1991), The Third R\&D Generation, Managing the Link to Corporate Sirategy, Harward Business School Press, Boston.

Rumelt, R.P, (1991), How Much Does Industry Matter?, Strategic Management Journat, vol. 12, mr.3 p. 167.

Rumelt, R.P, (1984), Towards a Strategic Theory of the Firm, in: Lamb, R.B. ed., Comperitive Strategic Management, Englewood-Cliffs, NJ: Prentrice Hall.

Rumelt, R. \& D. Schendel, D. Teece, (1996), Fundamental Issues in Strategy: A Research Agenda, Administrative Science Quarterly, vol.41, nr. 1, p.196-198.

Sanchez, R. \& A. Heene, H. Thomas, (1996), Dynamics of competence-based comperition: theory and practice in the new strategic management, Pergamon, Oxford.

Sanchez R. \& A. Heene, (1997), Reinventing Strategic Management: New Theory and Practice for Competence-based Competition, European Management Journal, vol. 15, ni. 3 (June), p. 303317. 
Sarren, M., (1984), A Classification and review of models of the intra-innovation process, R\&D Managemem, 14,1, p. 11-24.

Schein $_{,}$E.H., (1985), Organizational culture and leadership, San Francisco: Jossey-Bass.

Schein, E.H., (1989), Corporate culture is the key to Creativity, Business, May, p. 73-75.

Schmalensee, R., (1985), Do markets differ much?, The American Economic Review, vol. 75, p. 341 350.

Schoemaker, P.J.n (1992), How to Link Strategic Vision to Core Capabilities, Sloan Management Review, Fall, p. 67-81.

Schumpeter, J.A., (1942), Capitalism, socialism and dewocracy, Harper and Row, New York.

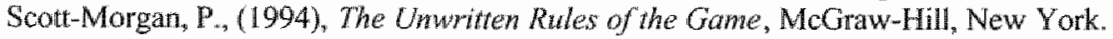

Schreuder, H. et al., (1991), Successful Bear-Fighing Strategies, Sitrategic Management Journal, vol. 12, nr. 7, p. 523.

Schuler, R.S. \& Jackson, S.E., (1996), Human resource managewent Positioning for the 21st century (6th ed.) West Publishing Company, Minneapolis.

Senge, P.M., (1990), The Fiffh Discipline: The Art and Practice of the Leaning Organization, Century Business, London.

Senker, J., (1995), Tacit Knowlledge and Models of Innovation, Industrial and Corporate Change, vol.4, nu. 2, p.425-448.

Shortell, S.M. \& E.J. Zajac, (1990), Perceptual and Archival Measurement of Miles and Snow Strategic Types: a comprehensive assessment of reliability and validity, Academy of Management Journal, vol. 33, 4, p. 817-832.

Shrivastava, P. \& W.E. Souder, (1987), The strategic management of technological innovations: a review and model, Joumat of management Studies, vol. 24, n. 1., January.

Snow, C. \& L. Hrebiniak, (1980), Strategy, Distinctive Competence, and Organizational Performance, Administrative Science Quarterly, 25, p.317-335.

Snow, C. \& D. Hambrick, (1980), Measuring organizational strategies: some theoretical and methodological problems, Academy of Management Review, vol. 5, p. $527-538$.

Song, X. \& M. Parry, (1993), How the Japanese Manage the R\&D-Marketing Interface, ResearchTechnology Management, vol.36, nr.4 p.32-38.

Song, X. \& M. Parry, (1996), What separates Japanese new product winners from losers, The Journal of Product Innovation Management, vol.13, nr.5, p.422.

Song, X. \& M. Parry, (1999), Challenges of managing the development of breakthrough products in Japan, Joumal of Operations Management, wol.17, nr.6 (November), p.665-688.

Souder, W.E., (1987), Mamaging New Product Innowations, Lexington Books, New York.

Staccy, R., (1993), Sirategic Management and Organisational Dynamics, Pitman, London.

Stacey, R. (1996), Strategic Management de Organisational Dymamics, 2nd edition, Pitman, London.

Stalk. N.I., (1988), Time, the next source of competitive adwantage, Harvard Business Review, July-
August.

Starbuck, W.H. (1965), Organizational Growth and Development, in: Handboak of Organizations, edited by J.G. March, Chigaco: Rand-McNally, p. 45॥-533. Stopford, I. C. Baden-Fuller, (1994), Creating Corporate Entrepreneurship, Strategic Management
Journal, vol.15, nr. 7, p.521-536. Strauss, A d. Corbin, (1990), Basics of Qualitative Research: Grounded Theory, Procedures and
Techmiques, Newbury Park: Sage.

Szulanski, G., (1996), Exploring Internal Stickiness: Impediments to the Transfer of Best Practice Within the Fim, Sirategic Managemen Journal, vol. 17, p.27-44.

Takeuchi, H. en Nonaka I., (1986), The new product development gane: stop ruming the relay race

and take up rugby, Harvard Business Review, 64 (1), Jan./Febr., p. $137-146$.
Taylor, F.W.. (1911), The Principles of Scientific Management, in: Shadritz \& Ott (eds.), (1987)
Classics of Organization Theory, Dorsey Press. Classics of Organization Theory, Dorsey Press. Teece, D. \& Pisano, G. (1994), The Dynamic Capabilities of Firms: An Introduction, Industrial and
Corporate change, 3, 3, p. 537-556.

Teece, D. G. Pisano \& A. Shuen, (1994), Dynannic Capabilities and Strategic Management, CCC
Working paper, n. 94-09. 
Teece, D., G. Pisano \& A. Shuen, (1997), Dynamic Capabilities and Strategic Management, Strategic Management Journal, 18(7), p. 509-533.

Thomas, H. \& N. Venkatraman, (1988), Research on Strategic Groups: Progress and Prognosis, Joumal of Management Studies, vol. 25, 6, p. 537-555.

Thomson, J.D., (1967), Organizations in Action: Social Science Basis of Admaimistrative Theory (McGraw Hill, New York, 1967).

Tushman, M. \& P. Anderson, (1986), Technological Discontinuities and Organisational Environments, Administrative Science Quarterly, wol. 31, p. 439-465.

Tushman \& W.L. Moore, (1992), Readings in the Management of hmovation, Harper Business, New York.

Twiss, B., (1980), Managing Technological Imnowation, 4th edition, London, Pitman.

Ven, A. van de, (1986), Central problems in the management of innovation, Mandgement Science, $32(5)$, p. $590-607$

Ven, A. van de \& G. Huber, (1990), Longitudinal field research methods for studying processes of organizational change, Organization Science, vol. 1, n. 3, p. 213-219.

Ven, A. van de \& S. Poole, (1989), Research on the management of innovation: The Minnesora Studies, New York, Harper Row.

Vasconcellos, J. \& D. Hambrick, (1989), Key success factors: Test of a general framework in the mature industrial product sector, Strategic Management Joumal, 10, p. 367-382.

Vaus, D.A. de (1991), Surveys in Social Research, 3rd Edition, London, LCL Press/Allen \& Uniwin.

Volberda, H.W., (1990), Een flexibele organisatie als voorwaarde voor innovatie, M\&O, vol. 44, 3, p. 215-242.

Von Hippel, E, (1978), A customer active paradigm for industrial product idea generation, Research Policy, p. 240-266.

Von Hippel, E, (1986), Lead users: A source of novel product concepts, Management Science, vol 32, p. 7 .

Von Hippel, E., (1988), The Sources of Innovation, Oxford University Press.

Voss, A.C., (1988), Implementation: A key issue in manufacturing technology: The need for a field for study, Research Policy, 17, p. 55-63.

Walker, A. \& J. Lorsch, (1968), Organizational Choice: Product Versus Function, Harnard Business Review, Now-Dec.

Wallace, W.L., (1971), The Logic of Science in Sociology, Aldine, Chicago.

Weber, M., (1949), The theory of Social and Economic Organization, in in: Shadritz \& Ott (eds.), (1987): Classics of Organization Theory, Dorsey Press.

Weick, $K_{n},(1979)$, The Social Psychology of Orgamizing, Berkley: University of Califormia Press

Wemerfelt, B., (1984), A resource-based view of the firm, Strategic Managenent Jownal, 5(2), pp. $171-180$.

Whittington, R. et al., (1993), What is Strategy - And Does it Matter?, Organization shadies, vol. IS nre.6, p.931-933.

Willianson, O., (1975), Markets \& hierarchies, New York, Free Press.

Williamson, $0 .,(1991)$, Comparative econonic organization: the analysis of discrete structural alternatives, Administrative Science Quarterly, vol.36, nr.2, p.269

Winter, S. et al., (1992), The nature of the Firm: Origins, Evolution and Development, Ecomomic Journal, vol. 102 , nr. 414, p. 1292.

Winter, S., (1995), Four Rs of Profitability: Rents, Resources, Routines, and Replication, in: C. Montgomery, Resource-Based and Evolutionary Theories of the Firm: Towards a Synthesis, Kluwer, Hingham, MA, p. 147-177.

Woodward, J., (1965), Industrial organization : theory and practice, London [etc.] : Oxford University Press.

Womack, J., D. Jones \& D. Roos, (1990), The Machine that Changed the World, Rawson Associates, Maxwell Macmillan, New York.

Wright, P. \& G. McMahan, B. McCormick, W. Sherman, (1998), Strategy, Core Competence, and HR Involvement as Determinants of HR Effectiveness and Refinery Performatnce, Humon Resource Management, vol.37, nr. 1, p. $17-30$. 
Xenikou, A. A. Fumbam, (1996), A Correlational and Factor Analytic Study of Four Questionnaine Measures of Organizational Culture, Human Relations, vol.49, nr.3, p.349-372.

Yap, C. \&W. Souder, (1994), Factors influencing new product success and failure in small entrepreneurial high-technology electronics firms, Journal of Product Innovation Management, 11, p. $418-432$.

Yin, R. K., (1989), Case study restearch, design and methods, Sage, Beverly Hills.

Zairi, M., (1996), Benchmarking far Best Practice. Continuons Learning throngh Sustainable Innovation, Butterworth-Heinemann, Oxford.

Zirger, B. \& M. Maidique, (1990), A model of new product development: An Empirical Test, Management Science, 36, 7, p. 867-883.

Zmud, R.W. (1982), Diffusion of modern software practices: Influence of centralization and formalization, Management Science, vol. 28, p. 1421-1431. 


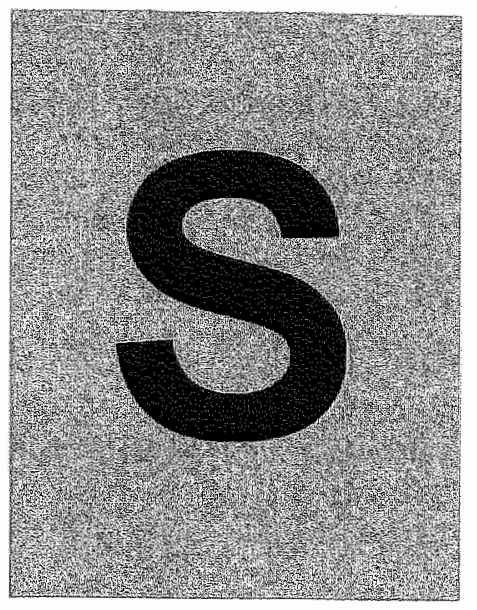

\section{Samenvatting}

Innovatie vormt een belangrijk onderwerp in de hedendaagse, kennisintensieve markten en draagt bij aan een verbetering van de concurrentiepositie van een ondermeming, ook in de Informatie- en Communicatie Technologie (ICT) sector. Het internet en electronic commerce zijn dergelijke belangrijke innovaties. Startende internetbedrijven en gevestigde dotcom bedrijven verschijnen geregeld in het nieuws. Internet Service Providers, onlline retailers en financiële dienstverleners starten een beursgang in de Verenigde Staten en Europa. De NASDAQ is de meest wispelturige high-tech index op de Amerikaanse beurs. Zijn dit signalen dat de ICT sector groeit door innovatie en ondememerschap?

In dit proefschrift bediscussieer ik de stand van zaken van innovatie en innovatief success bij ondernemingen in de Nederlandse ICT sector met alls doel een onderzoeksbijdrage te leveren aan de ontwikkeling, van onze kennis over innovatic van producten en diensten. De studie vond plaats in de periode 1996-2000, bij 32 ICT ondernemingen, zoals software ontwikkelaars, systeembouwers en systeembeheerders. Ik mak hierbij gebruik van de recente wetenschappelike inzichten uit de strategisch management en de organisatieliteratuur. Het onderzoek richt zich op het innovatiesucces in ondernemingen in een kennis- en serviceintensieve sector. In dit proefschrift wordt gebruik gemaakt van de metafoor uit het wielrennen waarbij de koplopers zich als onderneming onderscheiden van de pelotonleden en de achterblijvers. In het onderzoek wordt daarbij met name gekeken naar de kritieke success factoren die de koplopers onderscheiden.

Dit onderzoek makkt deel uit van het MERIT-onderzoeksprogramma warbij een research strategie is opgezet om management en wetenschappellike doelstellingen te realiseren. De ICT innovatie studie richt zich in het bijzonder op de volgende onderwerpen. 
- De inventarisatic of "de Kritieke Succes Factor (KSF) methode" toepasbaar is voor het meten van innovatieprestaties in de ICT sector. Kritieke succes factoren onderscheiden de succesvolle van de minder succesvolle imovaties.

- De identificatie en verklaring van factoren die discrimineren tussen succesvolle ondernemingen en minder succesvolle ondernemingen.

- De vergelijking van de kritieke succes factoren in de ICT sector met empirische onderzoeken, inclusief een reeds eerder uitgevoerd MERIT innovatie onderzoek.

- Het onderzoeken wan de verschillen tussen sectorspecifieke en niet-sectorspecifieke factoren. We onderzoeken of succes items typisch voorkomen in de ICT sector, maar ook warom bepaalde verwachte KSF unt de empirische literatuur niet als resultaten zijn aangetroffen in de ICT sector.

- Het ontwikkelen en toepassen van een geschikte onderzoeksmethode. We maken gebruik van een duale research methodologie, waarbij kwantitatief onderzoek (middels een benchmark enquete) en kwalitatief onderzoek (middels case studies) worden gecombineerd in een zogenaamde "case survey".

In de zoektocht naar de factoren achter innovatiesuccess start ik met een overzicht van de ICT industrie en service sector. De marktomvang en marktstructum, de marktontwikkelingen in de hardware, software en service sector passeren de revue. De nieuwe technologie-, marktontwikkelingen en groeisectoren komen daarbij aan bod.

In hoofdstuk 2 verduidelijk ik het concept en de definitie van innovatie waarbij ik duid op de rol die kritieke succes factor onderzoek heeft voor de innovatie management discipline. Veel van de nieuwe concepten en aanpakken zijn met name ontwikkeld en getest in de managenent praktijk om antwoonden te vinden op nieuwe management vraagstukken in de kennis-intensieve economie. Dit heeft de laatste 15 jaar geresulteerd in en zich snel ontwikkelend multidisciplinair veld wan organisatie wetenschappen. In een schematisch overzicht worden de belangrijkste studies wit het KSF onderzoek besproken. De verschillende stuclies bieden meer inzicht in de succescriteria voor product-, dienstenontwikkeling en procesontwikkeling. Vervolgens kijk ik vanuit een wetenschappelijk perspectief naar twee research stronen, namelijk "variantie-georiênteend en proces.georienteerd onderzock. De studies hebben een kemset wan succes factoren opgeleverd omtrent strategie, organisatie, het ontwikkelingsproces en human resources management. Ik concludeer dat er nog weinig empirisch bewijs beschikbaar is over de factoren die bijdragen aan het succes van innovatie in de ICT sector. Boyendien lijkt or nog en aantal methodologische en theoretische tekortkoningen te zijn in de huidige KSF onderzoeken. Met de ICT-studie wil ik bijdragen an een versterking van het $\mathrm{KSF}$ onderzoek.

In hoofdstuk 3 en $4 \mathrm{kijk}$ ik vanuit een theoretisch oogpunt naar innovatie. In hoofdstuk $3 \mathrm{ga} \mathrm{ik}$ met de lezer op strategie safari. Een safari waarin ik duid op de veranderingen in het strategisch denken over innovatie. In de literatum beschrijung over strategisch managenent wordt ingegaan op de verschillende denkscholen. Het belang van vernieuwing voor de strategische planning school, de positionering school en de nieuwe resource en competentiegebaseerde schollen kont aan bod. Dergelijke nieuwe inzichten benadrukken het belang van innovatie en competentic ontwikkeling. Ik beargumenteer dat de kennisontwikkeling in de competentiegebaseerde literatuur echter nog van een theoretische en een normatieve aard is. In de innovatic management literatuur is nog weinig bekend over het concept van strategie en het effect op innovatie succes. Met deze ICT-studie will ik bijdragen aan een verdere empirische ontwikkeling. 
Vanuit het strategisch management wordt de stap gemsakt naar de organisatie theorie in hoofdstuk 4. In de theoretische discussies lijken de wetenschappers het er over eens te zijn dat de organisatiestructur een onontbeerlijke bouwsteen is voor innovatiesucces. Bovendien tonen empirische onderzoeken dat de organisatie aspeeten tot de succesfactoren behoren. Echter, de organisatie theorie staat bekend om zijn rijkheid en variëteit aan perspectieven en theorieèn. In hoofdstuk 4 neem ik een normatief standpunt in bij het beschouwen van de reeks wan procesaanpakken die zich in de afgelopen jaren hebben ontwikkeld. Daarna worden vanuit een structuurgeoriënteerd standpunt de organisatie structuur opties beschouwd. Daarbij duid ik op de relevantie van de contingentie- en configuratie theorie voor innovatie management, de ideaal type configuraties van de organische en mechanische organisatie, en het strategie-structuur debat. Tot slot wordt ingegaan op de verschillende organisatiestructuren voor innovatie, zoals de functionele organisatie, de matrix organisatie en team-gebaseerde organisatie. De voor- en nadelen van de structuren komen aan bod. In het empirische deel van het onderzoek wordt uitgebreid ingegaan op de verschillende organisatiestructuren bij ICT ondernemingen.

In hoofdstuk 5 en 6 beschrijf ik het onderzoeksontwerp en de onderzoeksmethodologie. In hoofdstuk 5 wordt ingegaan op de succesmeetcriteria voor innovatieprestaties voor koplopers, pelotonleden en achterblijvers. Ik beargumenteer dat er in de empirische onderzoeken nauwelijks een uniforme set van succes criteria is gebruikt. Om de drijfveren achter innovatieprestaties in de ICT sector te meten is een multidimensionaal score criterium ontwikkeld. Ik beschrijf de meetmethode en het gebruik van verschillende indicatoren, waaronder de combinatic van management beoordelingen, objectieve financiële prestaties en overall ratings. In hoofdstuk 6 beschrijf ik het gebruik van een dualle onderzoeksmethodologie en de research strategie van een "case survey". De methodologie combineert de kracht van kwantitatief en kwalitatief onderzoek door gebruik te maken van de sterktes van case studie onderzoek en survey-onderzoek. De voordelen, nadelen en eisen voor het ontwerpen van case-survey komen aan bod. Voorts worden in dit hoofdstuk de keuzes ontrent de steekproef, de selectiecriteria en -procedure, het ontwerp van het benchmark-instrument en de datacollectie besproken.

In het laatste deel van dit proefschrift presenteer ik de empirische resultaten. De kritieke succesfactoren worden besproken en beargumenteerd, in combinatie met illustratieve cases. De statistische analyse laat relatief lage correlaties zilen. We moeten daarom woorzichtig zijn met het interpreteren van de resultaten. Het is echter interessant om te zien dat een gebruik van een meervoudig succes meetinstrument en de 'case survey' verrassende uitkomsten biedt. Ik concludeer dat de kritieke succes factoren voor het strategisch beleid met mame liggen bij de timing van prioriteiten. Koplopers besteden meer aandacht aan kwaliteitsmanagement, bedrijfsovername, en productiviteitgroei in verschillende tijdperiodes. Aandacht voor kemcompetenties is bijvoorbeeld geen onderscheidende factor ussen koplopers en pelotonleden. De koplopers zetten prioriteiten zoals productiviteitsgroei, aandacht voor intellectueel eigendom en acquisities eerder op de management agenda. Tevens zijn dit onderwerpen die bij de koplopers een hoge prioriteit blijven behouden.

Bij het bestuderen van de strategie van ICT ondernemingen is gebleken dat de invulling van de innovatiestrategie (de stij) een kritieke stucces factor is. Koplopers identificeren zich als een trendsetter met een sterke wil om de eerste op de markt te zijin. Andere kritieke succes factoren voor de strategiestijl zijn: het continu zoeken naar nieuwe marktkansen en het anticiperen op omgevingsveranderingen. De investeringen in inmovatie zijn ook een kritieke 
succes factor. In het bijzonder gat het on de toewiyzing van $\mathbb{R} \& D$ investeringen in productontwikkeling, de technologische positie en het technologie portfolio. Met betrekking tot projectmanagement blijkt de prioriteitstelling bij project planning van belang. Op het terrein van organisatie is de project team organisatie een kritieke succes factor. Het is opmerkelijk dat de aanwezigheid van multidisciplinaire teams geen onderscheid maakt tussen koplopers en pelotonleden. Een mogelijke verklaring is de gewoonte binnen de ICT sector om te werken met multidisciplaire teams. Voor de organisatiecultuur blikt de interne competitie een kritieke succes factor te zijn.

Ik concludeer dat enkele items, zoals multidisciplinaire teams en human resource management, geen onderscheidende kenmerken zijn in de ICT sector voor innovatie succes. Dit verschilt van niet-sector specifieke studies waar deze onderwerpen wel een onderscheid maken. Concepten als "path dependency" en de belang van de 'selectieomgeving" helpen bij het verklaren van de tegengestelde verwachtingen. Zo laten de resultaten zien dat de complexe rol van klantinteractie meer onderzoeksaandacht vergt. De illustratieve case studies geven hier meer inzicht in. Koplopers hebben een kritische houling richting klantverwachtingen en klantbehoeften. Koplopers zijn zich bewust van het gevaar van een conservatieve klantgroep, wat immers een rem op het inteme innovatievermogen kan betekenen.

Tot slot wordt in hoofdstuk 9 een discussie gevoerd over de uitkomsten die consistent en nietconsistent zijn met eerdere innovatie KSF onderzoeken. Tevens wordt aangegeven welke succesfactoren sectorspecifiek zijn. We speculeren over het innovatievermogen van de ICT sector op basis van de studieresultaten en wijzen op het belang van zaken als klantinteractie, service imnovatie en de strategie stijl van ondernemingen. 


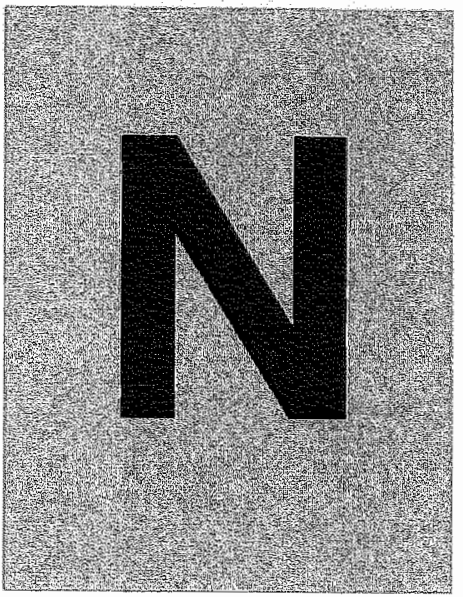

\section{Nawoord}

We waren als onderzoeksteam meer dan nieuwsgierig hoe een snel groeiende, kennisintensieve en vooral jonge sector als de ICT sector de rol van innovatie beleefde. Met een potlood en een blocnote en later met laptops, e-mail communicatie en video conferencing voerden we dit onderzoek uit in de periode 1996-2000. Met veel plezier denk ik aan de samenwerking met mijn onderzoekscollega's die hun kennis en inspiratie met mij deelden: Jan Cobbenhagen, Wynand Bodewijs en Hans Pennings. Daar ben ik jullie dankbaar woor. Maar vooral dank ik ook de managers die bereid waren tijd vrij to maken om hun verhaal te vertellen. Zij verschaften de achtergronden bij het innovatievermogen van hun bedrijwen en de aspiraties die er waren voor de Nederlandse replic ¿an 'de Silicon Valley idealen'. FENIT, in het bijzonder Sylvia Roelofs, en het Ministerie van Economische Zaken, dank ik voor hun financiële steun en het openen van deuren die anders gesloten bleven.

Daama begon natuurlijk pas de werkelijke klus: het schrijven wan de dingen die ik wist, die ik heb meegemaakt, die ik over wilde brengen. Schrijven is niet alleen een kunst maar ook een kunde. Friso, bedankt dat ik bij je in de leer nnocht. We hebben samen heel wat uren doorgebracht op het scherp stellen van betogen, de argumentatie en het reviewen.

Natuurlijk heb ik me vaak genoeg afgevraagd of ik op de goede weg zat, of ik deze weg wel wilde bewandelen en hoeveel bochten en heuvels er nog voor me lagen. Langs die weg vond ik natuurlijk de wegwijzers, de meterpaaltjes en de veilige parkeerhavens. Ik noem er een paar in het bijzonder. Corien Gijsbers, je hielp me om het proefschrift tot een vlotte wetenschappelijke publicatie te maken. Wilma Coenegrachts, dank voor het regelen wan al die financiële zaken die erbij komen. Minouk den Hertog, voor je hulp bij de interviews en 
uitvoering van de analyses. Berry Veldhoen en Wilfred Achthoven, voor de nieuwe parkeerhaven die jullie me boden bij Altuition. We hebben elkaar leren kennen tijdens dit onderzoek, we deelden ervaringen over nieuwe business development en veranderende tijden. Dat daar de onderneming Altuition uit ontstond blijft een apart gevoel. De promotiecommissie, Prof. dr. J. Lemmink, Prof. dr. W. Buitelaar. Prof. dr. ir. K. Boon, die met waardevolle adviezen en suggesties aangaven dat de bestemming (bijna) bereikt was.

Naast de serieuze bezigheden waren er de collega's van het MERIT, die me tijdens mijn onderzoekstijd het idee gaven van een verlengd studentenleven. Niet te vergeten het Altuiltion team: een bonte familie van inspirators, ontwikkelaars en whizzkids, die me langs de kant van de weg aantnoedigden. Jongens bedankt.

Mijn familie, Yvonne, Istvàn, Robert, Hub, Maria, Marcel en Rieke. Ik dank jullie voor je medeleven, geduld, de steun, de interesse, de rust en wrijgevigheid, ook in minder goede tijden. Jullie betekenen veel voor me. Het proefschrift heeft een groot stempel gedrukt op de afgelopen jaren. Het lukt dan niet altijd om te relativeren en de belangrijke dingen voorop te zetten. Carme, I love you. Dit boek drag ik aan jou op.

Dank jullie allemaal.

De finish is behaald.

\section{Edward}

Breda, 15 November 2000 


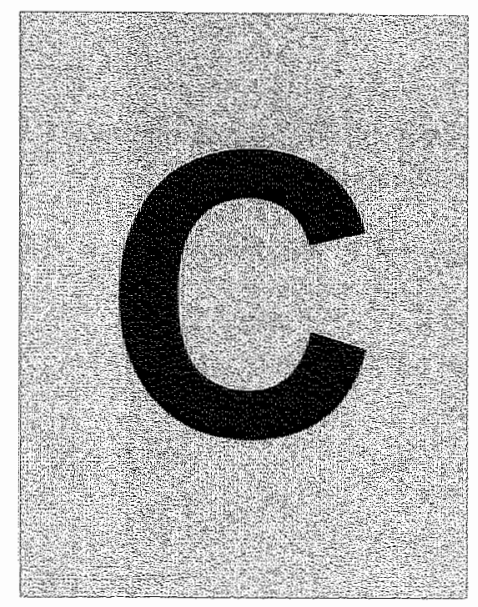

\section{Curriculum Vitae}

1970

geboren op 11 februari te Rheden

1982-1988 Atheneum (VWO), Thomas á Kempiscollege, Arnhem

1988-1994 Doctoraal Economie, Faculteit der Economische Wetenschappen \& Bedrijfskunde, Universiteit Maastricht, Specialisatie: Internationale Economische Betrekkingen

1992-1993 Doctoraal Bedrijfseconomic, Universidad de Zaragoza, Spanje

1994-1997 Onderzoeker in Opleiding, Nederlandse Organisatie voor Wetenschappelijk Onderzoek \& Maastricht Economic Research Institute (MERIT), Maastricht.

1997- nu New business architect \& management auteur, Altuition bv, 's-Hertogenbosch

Altuittion is een onafhankelijk management adviesbureau gespecialiseerd in de generatie en realisatie van business innovatie op het grensvlak van business, marketing en ICT strategie. Altuition ondersteunt klanten bij strategievorming, concept- en procesontwikkeling en realisatiebegeleiding in business development processen. Altuition werkt onder meer voor: ABN AMRO Bank, Bruna, Centraal Beheer, Ericsson, GeoDelft, Nationale Nederlanden, Planet Media Group, Postkantoren BV, en Syntens. 


\section{Publications:}

\section{Books}

2000 The Knowledge Enterprise: Implementation of Intelligent Business Strategies, F. den Hertog \& E. Huizenga, Imperial College Press, London.

1997 De Kennisfactor: Concurreren als Kenmisonderneming, F. den Hertog \& E. Huizenga, Kluwer Bedrijfslnformatie.

1997 Het Innovatieve Soffwarebedriff: Strategie, Organisatie en Personeelsbeleid, F. den Hertog \& E. Huizenga, Kluwer Bedrijfsinformatie

\section{Articles.}

1997 F. den Hertog \& E. Huizenga, De Klant in de Kennisonderneming: van Koning tot Businesspartner. In: Leenen, H. e.a. Concurreren op Deskundigheid, Samson.

1997 F. den Hettog \& E. Huizenga. Kennismanagement bij Pink Elephant In: Boekhofr, T. (ed), Management van Kennis, Kluwer.

1997 The Knowledge Factor: Competitive advantage through knowledge management, conference paper and presentation, Annual Conference, Strategüc Management Society, IESE Business School, Barcelona.

1995 Core Competences and Organisational Renewal, conference paper and presentation, Annual Meeting, Academy of Management, Technology and Imnovation Management Division, Vancouver.

1994 European competitiveness in some key global markets, chapter in: European report on science and technology indicators 1994, European Commission, DG XIII, Telecommunication, Information Markets and exploitation of Research. 